
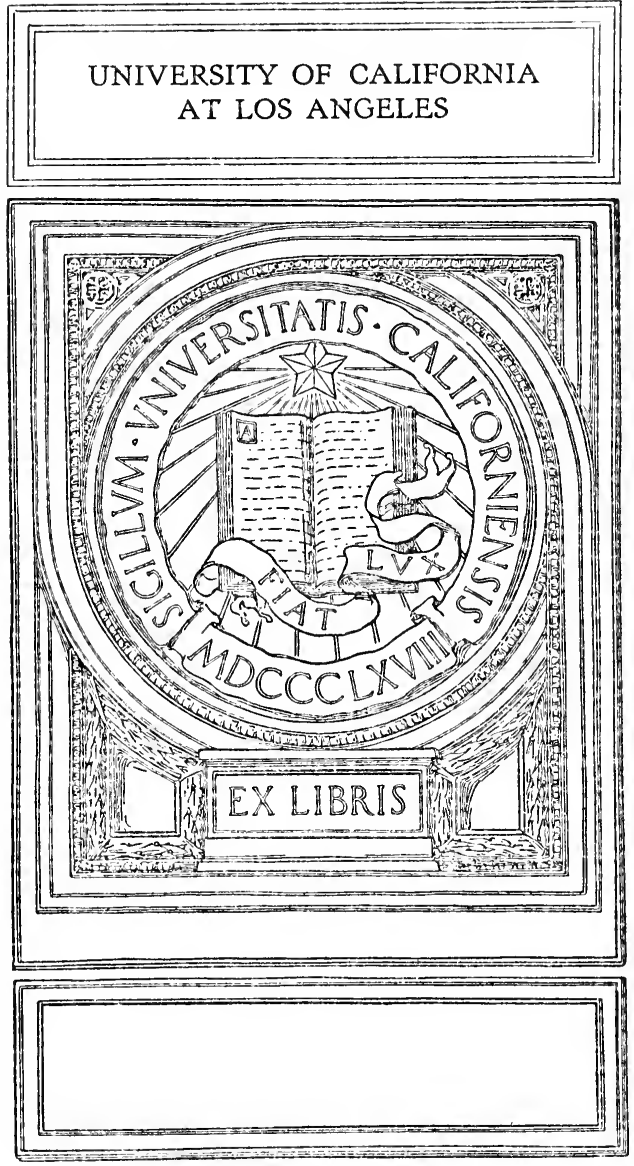






\title{
CONTRIBUTIONS
}

\section{MENTAL PATHOLOGY.}

\author{
BY I. RAY, M.D.. \\ ACTHOR OF "MEDICAL JURISPRCDENCE OF INSANITY," \\ AND "MENTAL HYGIENE."
}

\section{B O S T O :}

LITTLE, BROWN, AND COMPANY.

1873.

794363311 
Entered according to Act of Congress, in the year 1873, by I. RAY,

In the Office of the Librarian of Congress, at Washington.

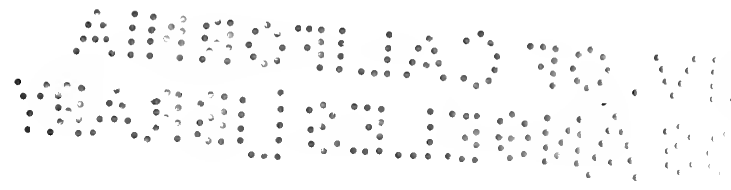

CAMBRIDGE:

PRESS OF JOHN WILSON AND SOX. 


\section{PREFACE.}

THe contents of this volume, with two exceptions, have already appeared in print. I am induced to put them into a more accessible shape, for the reasons that, since their first appearance, the subjects they discuss have lost none of their original interest; that many of the questions they present are far from being settled: and that the public are seeking for information respect. ing a disease that has most important relations to private happiness and social order. In making this selection from a much larger number of contributions to the literature of insanity, I have chosen such only as present the disease in those aspects which have become peculiarly interesting, either from a signal advance in knowledge, or some particular circumstance of the time, or some remarkable social, legal, or . asthetic relation. Though written on different occasions, the reader will find them, I trust, not entirely deficient in that unity of doctrine and purpose which is expected in a systematic treatise. They are given now with scarcely any other alteration than an occasional change 
of phraseology, and the omission of personal and local allusions which have lost their original interest. From the scope of this remark, I must except the paper on George the Third, the most of which has been rewritten, in order to avail myself of the new materials since presented in the various Memoirs and Diaries of persons ' who had access to the court, or had other opportunities of learning about its concerns.

Though the lawyer and physician will meet with much in the book strictly within the line of their professional studies, yet the general reader will find in it nothing unworthy the attention of any thoughtful mind.

I. R.

Philadelphia,

January 1, 1873. 


\section{CONTENTS.}

Adpress on the OCCAsion of LAYING the Corner-Stone of the State Hospital for the Ixsaxe, at Danville, Penn., August 26, 1869 . . . . . . . . . . . 1

Causes of Ixsanity.

Reports of Butler Hospital, 1863, 1864 . . . . . . 25

Statistics of Ixsaxity.

American Journal of Insanity, July, $18+9$. . . . . 66

Objections to Moral Ixsanity Considered.

American Journal of Insanity, October, 1861 . . . . 97

Doubtful Recoveries.

American Journal of Insanity, July, 1836 • . . . . 121

Delusions axd Hallucixations.

American Journal of Medical Sciences, July, 1868 . . 142

Confinement of the INsaxe.

American Law Review, January, 1869 . . . . . . 168

The Law of Ixsaxity ix Criminal Cases . . . . . . 203 
The Trial of Rogers.

Law Reporter, February, 1845 . . . . . . . . 210

The Trial of Baier.

American Journal of Insanity, July, 1846 . . . . . 229

The Trial of C. A.

American Journal of Insanity, January, 1856 . • . . 239

Tile Trial of Canglex.

American Journal of Insanity, July, 1865 . . . . . 252

The Trial of Winvemore.

American Journal of Ins:mity, October, 1867 . . . . 264

Insanity of Seduceid or Deserted Women.

American Journal of Insanity, October, 1866 . . . . 282

The Hinchinan Case.

Law Reporter, August, 1849 . . . . . . . . . . 294

The Parish, Will Case.

Medical Opinions in the Parish Will Case . . . . 315

The Avgell Will Case.

American Journal of Insanity, October, 1863 . . . . 345

Management of Hospitals for time Insane.

Report of Butler Hospital, 1863 . . . . . . . . . 391

Medical Experts.

Read to the American Social Science Association, at Philadelphia, October, 1870. . . . . . . 409 
Insanity of King George the Third.

American Journal of Insanity, July, 185̃ . . . . . 433

Shakespeare's Illustrations of Insanity.

American Journal of Insanity, April, 1847 . . . . . 482

Illustrations of Insanity by Distinguished Exglish WRITERS.

American Journal of Insanity, October, 1847 . . . . 53- 



\section{A D D R E S S}

DELIVERED ON THE OCCASION OF

LAYING THE CORNER-STONE OF THE STATE HOSPITAL FOR THE INSANE, AT DANVILLE, PENN.

Acgest 26, 1869.

We have come together, my friends, to lay the foundation of an Institution very unlike the most of those that give rise to occasions like this. The structure whose massive walls are to rest on this spot is to commemorate no victory of war, no triumph of a cause achieved by sacrifices of life and property. It is designed to minister to the advancement and glory of no sect or party, however worthy its ends. It is designed to be not even a storehouse of the treasures of science and art for the promotion of knowledge and the refinement of taste. No, my friends, it is nothing of the kind. I am not here for the purpose of kindling anew the fires of patriotism, or of inspiring you with fresh zeal in some popular association of the day, or of awakening your admiration of the works of nature and the products of genius. The institution which we now inaugurate with solemn ceremonies has in it no element of the heroic or romantic. It makes no appeal to the fancy; it can excite no enthusiasm; it demands no personal sacrifice. On the contrary, it springs from those common instincts and virtues of our nature which have received from the 
civilizing and christianizing influences of our time a scope and direction unknown to the polished nations of antiquity. To relieve suffering both of body and mind; to rescue helpless men and women from practices discreditable even to a barbarous age; to lead back the wandering mind out of the darkness and mazes of disease into the unclouded light of reason; to remove from many a home some stricken one whom all the arts of affection only serve to embitter rather than to console and heal; to lighten the burden of those who have exhausted their strength and their means in caring for some cherished member of the family circle; to improve this ministry to the disordered mind by the intelligent application of medical science, - such are the ends which it belongs to enterprises like this to fulfil. Is it not worthy of our warmest sympathy, our deepest respect, our strongest help? Is it not fitting that it should be inaugurated with the solemnities we have witnessed; that the Chief Magistrate of the Commonwealth should lend the dignity of his character and his office to the imposing ceremonial; that the ministers of our holy religion should invoke upon it the blessing of Almighty God; that the people of this community should come together to testify their interest in the work?

What, then, is the evil we seek to relieve? What part does it bear in the economy of this our modern life? To say that insanity is the loss of reason - the great prerogative of man - conveys to the dullest understanding the fact of a great calamity to the sufferer himself; but no one without a professional acquaintance with the subject can have any thing like an adequate idea of the extent and variety of the misery inflicted by this plague of our race. From one thus qualified we may obtain a more particular and definite conception of what 
is meant by this word-insanity. It means a measure of distress that no bodily ill can produce. It may mean a painful struggle between the convictions of reason and the suggestions of disease, while the mind is tortured with the dread of the approaching calamity. It may mean the absorption of the whole soul in one single, horrible idea, none the less horrible because it is false as regarded by others. It may mean that depression of spirit in which the whole universe, material and moral, seems to be enveloped in a funeral pall; or, as the poet of all time has described it with inimitable fidelity and beauty, when man delighteth not, nor woman neither, and this goodly frame, the earth, seems a sterile promontory; this most excellent canopy, the air, this brave, overhanging firmament, this majestical roof fretted with golden fire, appears no other thing than a foul and pestilent congregation of vapors. It may mean a state of jealousy and suspicion in which every creature, even the nearest and dearest, seems to be an enemy ready for any conceivable mischief or annoyance. It may mean a paroxysm of fury or an overpowering delusion, ending in a scene of blood and carnage, the dearest and most cherished being the victims. It may mean a complete change of character and habits, - a course of idleness and neglect of duty in place of industry and a scrupulous discharge of all the requirements of life; indifference, perhaps hostility, towards the objects of the tenderest affection; hurry and restlessness without measure or motive, in place of an habitually calm and judicious movement; extravagant expenditure and a reckless, lawless habit of living, in place of rigid exactness and an exemplary demeanor. It may also mean a perpetual sense of anxiety and apprehension, for months or years together, pervading a family circle once the 
abode of peace and love and mutual confidence; and extreme destitution where once were prosperity and plenty.

Such are the things which are meant by insanity, but a far more deplorable feature remains to be mentioned. This fearful malady, not content with its ravages on the individual, re-appears in his children and his children's children, vitiating the very principle of life which he has transmitted.

Is it strange, then, that peculiar interest attaches to this disease, and that special and costly arrangements should be provided even by the State for the purpose of mitigating its evils? And yet such arrangements, with a few trifling exceptions, are of comparatively recent origin. Even among the most civilized nations, the lot of the insane, bad as it is at best, was made still more wretched by the manner in which they were treated. In cases where the recuperative powers speedily effected a recovery, little harm was done. But if the disease became seated and all hope of recovery had fled, the disposal of the patient was determined solely by regard to the safety or convenience of society. In this country, if he were considered, as most of them were, to be dangerous to persons or destructive to property, he was thrust into a cell in the county jail, or a cage in the poorhouse, or a strong, dark room on his own premises, his limbs, probably, loaded with restraints, and his wants supplied very much like those of the brutes whose quarters he may have shared. And it could not well be otherwise. Sooner or later, in most cases, the patient becomes intractable, acknowledging no guide nor law but his own disordered will. His ways and his views are incompatible with the peace and safety of a wellregulated household. Every day witnesses some scene 
of discord, strife, and terror. Excited and restless, he roams about without end or object, alarming the timid, wasting his substance, and adding fresh fuel to the fire that is consuming his senses. The family means, never large, perhaps, are finally exhausted. The utmost efforts of the other members can scarcely keep the wolf from the door, and they are driven to the last resort, - close confinement. Thenceforth, the places that knew him will know him no more. His seat at the fireside is vacant. The face of nature, the sun, moon, and stars, the smiling fields, the ripening crops, will no more gladden his eye; the breezes of heaven, the hum of industry, the prattle of children, will no more greet his ear. Though not entirely dead to all the sweet influences of life, yet they will visit him no more. When, from time to time, as the tumult of his disease subsides, some throb of his old affections, some touch of his kindlier nature, some glimpse of the high estate from which he has fallen, reveals a spark of the Divinity that stirs within us, no wise and friendly ministry will be near to cherish the sacred fire, and canse it to illumine, though never so feebly, the dreary pathway before lim.

Such is a picture of the insane that was frequently exhibited up to a very recent period, and many an'original may yet be seen at this moment, within the limits of our own State. The time came at last when the public feeling called for a change; and it is a matter of pleasing reflection, peculiarly fit to be remembered on an occasion like this, that the Prorince of Pennsylvania was the first of all those communities which, in the fulness of time, grew up into this glorious Union, to recognize its duties to the insane, and to proceed to perform them in a liberal, generous spirit, without precedent either in the New or the old World. In 1752 some benevolent 
persons in Philadelphia joined in a petition to the House of Representatives, in which they say that "with the numbers of people the numbers of lunatics, or persons distempered in mind, and deprived of their rational faculties, hath greatly increased in this province; that some of them going at large are a terror to their neighbors, who are daily apprehensive of the violences they may commit, and others are continually wasting their substance, to the great injury of themselves and families, ill-disposed persons wickedly taking advantage of their unhappy condition, and drawing them into unreasonable bargains; that few of them are so sensible of -their condition as to submit voluntarily to the treatment their respective cases require, and therefore continue in the same deplorable state during their lives." For the purpose of affording those and other sick persons suitable care and treatment, they solicit the aid of the House, in establishing a "small, provincial hospital," which, they declare, "will be a good work, acceptable to God, and to all the good people they represent." Their prayer was granted. An act of incorporation was passed, two thousand pounds were promised, on condition that an equal sum should be raised from private sources, the hospital, extemporized out of a dwelling-house, was opened, Feb. 11, 1752; and it is a noteworthy fact bearing upon the original design, that of the first four patients admitted three were insane. Thus originated the Pennsylvania Hospital, and no benevolent institution in our country has pursued a nobler or a wider career. Nor should it be forgotten, as another claim on our gratitude, that it furnished Dr. Rush with the materials for his work on "Diseases of the Mind," - the first of the kind in the English tongue, displaying thorough observation and original thought. 
I have said deliberately that this example was without precedent. Bethlehem, the only hospital at that time in the mother country exclusively for the insane, sprung from an old religious House, and was supported chiefly by its charitable endowments. In Catholic countries, the insane were then kept in old monasteries, at the expense of the State or the Church, but with a deprivation of comfort and with positive hardships, which one can hardly read of without a shudder. In one sense they were public establishments, but the public felt no interest in their work; and by the government they were regarded as a means of police for the custody of dangerous subjects, rather than as institutions for the relief of suffering, or the promotion of recovery.

The example of the Pennsylvania Hospital was, apparently, not without its legitimate influence. In 177.3, the State of Virginia opened at Williamsburg a hospital exclusively for the insane, and to that State belongs the credit of having been the first to provide such an establishment at the public expense. Many years elapsed, I am sorry to say, before this worthy example was followed; nor was the great want supplied by associations like that which founded the Pennsylvania Hospital, nor by individuals, as in the private asylums of England. The latter class of enterprises was almost unknown in this country until the beginning of the present century, for they required a knowledge of insanity not easily obtained by our physicians, an outlay of capital which few of them possessed, and a rate of prices greatly beyond the means of our people. In process of time, they made their appearance, few and far between, but their benefits were confined to the affluent classes.

The most noticeable event in the history of the cause we are now considering was the establishment of a hos- 
pital in York, England, by the Society of Friends, in 1796. True to their characteristic principles of peace, quiet, and goodwill to men, the movers in this enterprise conceived that the insane could be more successfully managed by mild and gentle methods than by the harsh and coercive practices that then prevailed both in public and private asylums. We of this generation have been familiar with such different ways that we find it difficult to believe what we are told on unquestionable authority respecting the treatment pursued in those days. I do not refer to chains, or close confinement, though they were common enough, but rather to the principle which underlaid this treatment. It was supposed to be the fundamental step in the management of the insane, to make them feel that they were in the hands of a keeper who required implicit obedience, and whose look must be sufficient to put down the slightest show of resistance. In one word, their will was to be broken, and they were to know no other will but that of their keeper. Of course such an end could not be obtained without some severe discipline. And there was no concealment nor disguise in the matter. It was understood by all parties concerned to be the way, and the only way, whereby the insane could be successfully managed. Against the whole of it, however, the Friends entered their most emphatic protest, and the experiment at York showed conclusively that their work was as good as their faith. For the first time in the world, there was witnessed a considerable collection of insane persons enjoying a measure of comfort, never before supposed to be within their capacity, without a blow, or a chain, or a harsh word.

Impressed by this noble work, the Friends in this State took measures to obtain a similar institution here, and 
the result was the asylum in Frankfort, opened in 1817. Improving upon the course of the English Friends, they chose a place in the country somewhat remote from the village, having plenty of land, and furnishing abundant opportunity for walking, driving, and working. No single advance on prevalent ideas has been followed by greater good to the insane than this. A considerable tract of land, amounting to hundreds of acres, is now considered as indispensable an appendage to a public hospital for the insane, as arrangements for bathing, or warming and ventilation.

Thus far, it will be observed, no State, with the exception of Virginia, had provided hospital accommodation for its insane, and such continued to be the case until the year 1832, when the State of Massachusetts established one in Worcester, erected and furnished at its sole ex. pense. True, the bounty of a State had been bestowed in a few cases in aid of enterprises undertaken by benevolent persons for the benefit of the insane, but the end could be effectually reached only by taking a new and higher ground. This kind of aid had been granted as an act of grace, to be giren or withheld, according as it might suit the conveniences or caprice of the State; thenceforth it was to be considered a matter of obligation, with all the force if not the authority of a legal enactment. The late Horace Mann, standing in his place in the Legislature of Massachusetts, uttered that memorable declaration that the pauper insane are the wards of the State. It was an instance of that quick discernment of a great moral truth which comes like a flash of inspiration. It taught the people, once and forever, the exact nature of their relations to this class of their fellow-creatures. They were to be regarded not merely as paupers reduced to the lowest grade of the 
social scale, perhaps by vicious indulgence, and entitled only to that lowest measure of care and sustenance compatible with the preservation of life; nor as criminals, and therefore proper subjects of penal discipline. They were to be regarded as wards of the State, and under that relation entitled to a degree of consideration to be measured only by an active, intelligent, liberal humanity. There were a few who regarded the idea as quixotic, the utterance of a man of ardent feelings and benevolent instincts, whose zeal had quite outrun his judgment. Looking at the subject, however, from the higher standpoint at which we have now arrived, we do not hesitate to pronounce it to be the offspring of a broad and lofty view of human responsibility and a belief in the great brotherhood of man as a ground of social obligation.

The example of Massachusetts, executed as well as conceived in a most generous manner, was followed by other States, one after another, so that now, in all except one or two of the newest, there exists more or less public provision for the insane. Why a beneficent enterprise, so much needed and so long deferred, should so suddenly have risen into popular favor, is a matter of instructive inquiry, and so germane to the purposes of this occasion that I venture to give it a moment's attention.

First and foremost, unquestionably, among the incidents that gave rise to this movement, was the example of the corporate hospitals. Few as they were, and cramped in their means, the work they were doing was sufficiently striking to excite reflection in every thoughtful observer. The spectacle they presented was a practical denial and disproof of the prevalent notions respecting the management of the insane. Here was a scene of quiet, good order, and no small amount of com- 
fort, if not enjoyment, where all traditionary belief would have led one to expect only noise, turbulence, and unmitigated wretchedness. Here it was demonstrated beyond question, that, with an occasional exception, strength and force were not only unnecessary elements in the management of the insane, but were positively detrimental. In view of such results, it was impossible to suppress some uncomfortable reflections respecting the condition of those who had been consigned for safe keeping to the jails and poor-houses, where brute force was the ready substitute for skill and kindness. Such a flagrant discrepancy would seem to be an imputation on the justice and intelligence of the community, that could be removed only by admitting all the insane to an equal share in all the privileges that the science and philanthropy of the age had provided. Private beneficence was' obviously inadequate to meet the requirements of the case. No power less than that of the State could cope with the tremendous necessity.

Most fortunately, too, as if to confirm a farorite belief, - that when a great exigency arises, the right man or woman will be found ready to meet it, a young woman in Massachusetts, about this time, became deeply interested in the condition of the insane, and thenceforth devoted her time to the noble purpose of effecting its improvement. With this end in view she visited the jails, prisons, and poor-houses in her native State, and subsequently in other States, that she might see for herself precisely what that condition was. No place was so distant, no circumstances so repulsive, no lack of welcome so obvious, as to deter her from the thorough performance of her mission. Neither the storms of winter nor the heats of summer could diminish the ardor of her zeal, and no kind of discouragement could prevent her 
from gauging exactly the dimensions of this particular form of human misery. Favored by that exquisite tact and happy address peculiar to her sex, she overcame obstacles that would have defied the ruder efforts of the other sex, and thus brought to light a mass of suffering that seemed more like an extravagant fiction than real, unexaggerated truth. Thus prepared, she went before the Legislatures of the several States in which her inquiries were pursued, and in the name of humanity implored them to put an end to practices that would shock even a barbarous people. This appeal was enforced, not by vague sentimentalisms about the softening influences of kindness, or the debasement produced by such harsh and heartless treatment, but by a multitude of cases given in all their appalling details. It is creditable to our people that this appeal was seldom made in vain, but was usually followed by an act establishing a State hospital for the insane.

But probably these things would not have had their legitimate effect without the aid of those influences, none the less potent because less obtrusive, designated generally as the "spirit of the age." In a careful review of the events of the present century, one cannot help being struck with the fact that, about the period in question, there began a remarkable moral and intellectual uprising, that reached every department of thought and action. It was witnessed in a clearer and wider outlook over the whole field of human requirement, in a livelier faith in the possibility of human endeavor, in a keener sense of social obligation. My limits will not allow me to dwell on this point. Suffice it to say that, at a period when slavery was abolished in the British West Indies, and many a soul was longing and praying for the same blessed consummation here, 
in some constitutional way; when the cry for a larger measure of liberty began to arise from every people in Europe; when steamships and telegraphs were shortening the distance between nations, and thereby making them better acquainted with one another's wants, sympathies, and aspirations; when education was casting off the last of its medireval vestments, and science had started on a new career of discovery, - it is not strange that men should have been startled by the wrongs of the insane, thus exposed in all their terrible details, and should have resolved on assuming their rightful office of care and guardianship.

In justice to the hospitals, let me say in this connection that, in their turn, they have repaid their debt to society, by diffusing benefits besides those immediately connected with the care of the insane. We have been so impressed by the immediate effects of this benevolent enterprise, that the good which has come from it indirectly has been in danger of being wholly overlooked. To have restored the light of reason to thousands and made comparatively comfortable tens of thousands is, certainly, a noble work; but let us not be insensible to the light it has thrown upon the dark places of mental philosophy, and of civil and criminal jurisprudence; upon the temperament and habits of men, and the course of human conduct. It will hardly be disputed that, without a correct philosophy of the mind, we shall strive in vain to master the great questions of moral and political science that deeply involve the happiness of men. Neither will it be disputed by many, I apprehend, that the actual, available knowledge contained in the writings of all the metaphysicians, from Plato down to Dugald Stewart, is marvellously small, when compared with the mass of words in which 
it is conveyed. To the student familiar with the exacter methods of modern investigation, the reason is obvious. The properties of organic matter, the nature of its functions, and the laws which regulate its action, cannot be thoroughly understood without observing it when under the influence of disease. This separates and analyzes what seemed to be inseparable, and associates by a common bond things supposed to have no necessary connection. It shows us, as nothing else can, the true limits and distinctions between one power and another, and gives us the clew to the secret of their harmonious action. The brain, though not itself the mind, is the organ of the mind, the material instrument whereby its operations are conducted; and it is only by the study of its organic conditions, both in health and disease, that we can expect to obtain any insight into the processes that result from the mysterious union of mind and body. To learn how we think and how we feel; to understand, in any degree, the wondrous mechanism by which the mental manifestations are accomplished, we must study its morbid aberrations from the line of healthy action, as exhibited in the wards of the hospital. There, in the ravings of the excited maniac, in the gross delusions of the monomaniac, in the mischief and malice of the morally insane, in the gloom and despair of the melancholic, in the dual life of the subject of circular insanity, we have the materials, in part, wherewith to construct a true psychology. Any mental philosophy in which this source of information is ignored must needs be imperfect; but this fact could not be perceived by the metaphysicians, with whom it was a cardinal principle that, for the successful study of the mental phenomena, one has all the necessary materials within himself. Better views on this point 
are beginning to prevail. "He who raises moral pathology to a science," says one of the prominent thinkers of our day, "expanding, systematizing, and applying many fragmentary observations that have been already made, will probably take a place among the master intel. lects of mankind." 1 No one who has carefully followed the course of psychological inquiry during the last twenty or thirty years can have failed to observe abundant ground for this opinion. In the writings of Spencer, Bain, Morell, Lewes, and others, hardly excepting Comte, we may easily trace the influence exerted by that study of morbid psychology, which has been stimulated by the abundant opportunities of obserration afforded by the numerous hospitals for the insane. Is it too much to say that if those writers liave struck upon the true path to successful inquiry, and inspired the world with new faith in metaphysics, it must be attributed in some degree to that influence?

That the laws involving questions of insanity, and especially the common law, have reflected the same influence, is admitted by all who are conversant with the subject. It is little more than fifty years ago, when the law regarded no one as really insane who was not raving. Or, if the disease was recognized in its less obtrusive forms, it was considered as merely a disturbing influence which the patient was bound to control by means of the sanity that yet remained. Insane persons were made to suffer the extreme penalty of the law, if they knew the criminal act was wrong or illegal, or displayed design and contrivance; and especially was the idea of insanity scouted, if the act seemed to be the result of provocation, or any other rational motive. Within our time, persons have been executed who pro-

${ }^{1}$ Lecky, W. E. K., History of European Morals, i. 167. 
claimed from the gibbet delusions as monstrous as any that may be heard within the walls of any hospital in the land ; and others have been discharged from confinement, by due course of law, simply because they could utter a few coherent sentences, and maintain for a few minutes a calm and rational demeanor. Such things are seldom seen now, thanks to the better knowledge and better influences diffused by hospitals for the insane; and if they are to disappear entirely, it will be owing in great part, no doubt, to the same agency.

Let me also say that the moral pathology to be learned in these establishments will have an important bearing on some of the prominent questions of moral and social science. If we are ever to obtain a correct theory of human conduct; to discover, in any degree, the secret springs of action, or to penetrate into the mysteries of human delinquency, it must be by the study of morbid psychology in that broad and liberal manner which is possible only amid large collections of the insane. No one who declines to receive his opinions on trust can help being embarrassed by the problems presented by many an historical name, or those revelations of character so often found on the records of our courts. We seek in vain for any light on the questions thus raised, and are obliged to rest helplessly in the conviction that there are more things in heaven and earth than are dreamt of in our philosophies. Indeed these difficulties cannot be overcome by any theories of human conduct which suppose the mind to be in a perfectly normal condition. They point to imperfection, or deficiency, or obliquity, - the result of organic influences, - and they can be cleared up in no degree except by the profound study of organic conditions in connection with abnormal mental phenomena. From this kind of study 
we may justly expect that a light will be thrown on the field of history and biography, by which many of their pages will be read with sentiments very different from those which they now inspire. It would show us, probably, that much of what the world calls genius is the result of a morbid organic activity; that many a saint, or hero, or martyr, became such, more by virtue of a peculiar temperament than of a profound sense of moral or religious obligation; that the horrible crimes which have imparted an infamous distinction to the Tiberiuses and Caligulas of history proceeded rather from cerebral disorder than a native thirst for blood. But we must leave these speculations, and resume our record of events.

The benevolent movement already alluded to was not long in reaching Pennsylvania. In 1838, the project was agitated of establishing a State hospital for the insane; but though an act for this purpose passed the General Assembly, yet, owing to the financial embarrassments of the time, it was never carried into effect. In $18 \pm 5$, another attempt was made, fortified by one of Miss Dix's characteristic memorials respecting the lamentable condition of the insane in the various jails and poor-houses of the State. The attempt succeeded; and again the requisite act was passed, which, after slumbering awhile on the statute book, was revived, the building was erected at Harrisburg, and in 1851 was opened for the reception of patients.

In the mean time, some benevolent persons, strongly impressed by the wants of the western part of the State, undertook to establish a hospital for diseases, both bodily and mental. In this effort they were eminently successful; and after a few years, with liberal aid 
from the State, they established a hospital exclusively for the insane, at Dixmont.

To one not particularly acquainted with the subject, it might have seemed that ample provision had thus been made for the insane of the State. But, in truth, there has never been a time when the provision was commensurate with their number, and with every succeeding year the deficiency has been steadily increasing. To contend that the public duty was fully discharged, when a certain number of buildings had been raised, and a certain amount of money expended, is simply to ignore the principle on which that duty is founded. If the helpless insane are the wards of the State, then each and all of them are equally entitled to its care and protection. To extend them to one, and refuse them to another; to render it almost impossible for the distant counties to avail themselves of the benefits of the hos. pital, is to act the part of an unnatural guardian. And yet that is precisely what has been done. At this moment, there are hundreds suffering every variety of hardship, who are as clearly entitled to the privileges of a hospital as any of those who have been actually received within their walls. But the utmost capacity of these institutions has long since been reached, or, more truly speaking, stretched to a point quite incompatible with the highest measure of success. It is so common to crowd hospitals beyond their proper capacity, that the public is not aware, I fear, what this fact implies. When a hospital intended for two hundred patients is made to receive three hundred, they excite and disturb one another; dangerous, even murderous, collisions, fearful to think of, become unavoidable; the means of ventilation are deficient, and consequently the air of the house is loaded with effluvia calculated to pro- 
duce disease; the officers, who need the utmost strength and serenity of mind in performing their allotted work, are constantly filled with apprehension; and the result of it all is that the hospital fails to accomplish that degree of comfort and restoration which it otherwise would. Let it be distinctly understood, therefore, that to place a patient in a hospital already full is to inflict a positive injury on many, for the doubtful chance of benefiting one.

What, then, is the extent of our hospital capacity, and what relation does it bear to the amount of insanity among us? An answer to these questions will show how far we have discharged our duty to the insane.

The statistics of insanity as usually presented are deplorably deficient in that scientific accuracy which alone can make them of much worth, and those which profess to give the actual number of the insane in the community are especially unreliable. One memorable exception to this last statement was made in 1855 by the State of Massachusetts, which, for the purpose of obtaining various kinds of information respecting the insane within her own borders, appointed a commission, of which the working member was Dr. Jarvis. Probably no statistics on this subject were ever collected, so free from error or inaccuracy as these; and, for the first time in the world, the actual number of the insane was given with a very near approach to the exact truth. It appeared that in that Commonwealth the insane, not including born idiots or imbeciles, amounted to one in four hundred and twenty-seven of the whole population. There is no reason to suppose that the proportion is much if any less, in this State; but, to prevent all risk of overstatement, let us estimate it at one in six hundred. Supposing the population to be $3,500,000$, the 
number of the insane will be 5,833. One-third of these may not need, or may be supposed not to need, hospital treatment. Deducting these, we have 3,889 for whom some hospital provision is required, either for purpose of custody or cure. At this present moment, the number of patients in all our special hospitals and asylums is about 1,700 , so that there still remain 2,189 who are without the only suitable care and treatment.

The need of more hospitals has been strongly felt for years, but the Legislature was too well satisfied with what it had done in this direction, to be very anxious to do more. At length the "Medical Society of the State of Pennsylvania," at its annual meeting in 1867, appointed a committee to prepare a Memorial to the General Assembly on this subject, as they did at its next session in 1868. In this document they set forth the fact, as already stated, that the number of the insane is greatly in excess of the capacity of our hospitals; that a large proportion of these persons are kept under conditions shocking to the dullest sense of propriety, or even of common humanity, suffering from cold or heat, from bad air, and indecent exposure, chained to the floor, perhaps, deprived of every means of recreation or employment, and dying by that process of decay which physicians call dementia; that the state is annually burdened with the life-long support of persons, who, if subjected to early hospital treatment, might have been restored to society; and that, in the long run, the expense of such treatment would be far less than that of supporting the chronic insane as they now are supported. The Memorial concluded by urging the establishment, without delay, of a hospital for the district composed of the counties of Wayne, Susquehanna, IVyoming, Luzerne, Columbia, Montour, Sullivan, Bradford, 
Lycoming, Tioga, Clinton, Centre, Clearfield, Elk, Cameron, M'Kean, Potter, and Forest ; and also, if the finances of the State will justify it, one for the district composed of the counties of Berks, Bucks, Carbon, Lehigh, Monroe, Montgomery, Northampton, Pike, and Schuylkill.

To the credit of the General Assembly of 1868, the appeal was heeded, and an act was passed providing for a hospital for the insane within the district specified by the Committee of the State Medical Society. The act also provided for a committee, composed of Dr. Curwen, Superintendent of the State hospital at Harrisburg, Dr. Reed, Superintendent of the Western Hospital for the Insane, and Dr. Traill Green, Professor of Chemistry in Lafayette College, to obtain a location, and proceed to the erection of the building. This committee, aided by the advice of several other persons who accompanied them, inspected various places, and decided upon this as the most eligible of all those brought to their notice. Here, then, is to stand the new structure to be devoted to the care of a helpless class of our fellow-men. On this spot, in the midst of a beautiful landscape, with its clumps of noble trees, and its fair meadows stretching by gentle slopes to the waters of the Susquehanna, within sight of the dwellings and workshops and churches of a busy population, will be our Bethesda pool, whose healing virtues shall be felt by thousands yet unborn.

In conclusion, allow me to address you, in all frankness and sincerity, touching your own duties towards the new institution about to be established among you. What these duties are, you will readily perceive by understanding the relations that necessarily arise between you and it. Its immediate benefits will be ex- 
perienced by the people of this particular region, and they, therefore, are deeply concerned in the results of its operations. From the sad disorder which is to be treated within these walls, no one has any privilege of exemption. No accident of fortune or birth, no measure of strength, no exercise of prudence, may be able to save you from the fate of others once as little likely to meet it as you. Or, if you escape personally, the stroke may fall on child, parent, or neighbor, with far more sorrow than if it fell on yourself. You, therefore, are deeply interested in having it perform its allotted service successfully, and are bound, as far as in you lies, to promote this end. The Executive will appoint its trustees, who will have the general direction of its affairs; and their names, I doubt not, will always be a sufficient guaranty for the faithful performance of their trust. The officers, who are to direct the remedial measures, and superintend its daily working, will be equally worthy, I trust, of their charge. But the comfort of the inmates, the place it is to hold in the regards of the community, may be determined in no small degree by you. Within your respective spheres of duty and of influence, many of you may materially aid the work which is here to be performed. While the State will provide the necessary means of living, there are many things capable of promoting the comfort and gratification of the inmates, for which it must be indebted to private benevolence. To take from it, as much as possible, the prison-like aspect inseparable from such structures, and give it the amenities of a private residence, it will need objects pleasing to the eye, and calculated to draw the mind from depressing reflections. The time is coming, I hope, when the State will regard these things as no less legitimate appliances in accomplishing the end 
in view, than those strictly material ones of food and lodging. Until it comes, howerer, the institution will have to depend, for aids like those, on private bounty. Many of you may be able, without inconvenience, to give it occasionally, a book, or a picture, or a plant, or something else equally calculated to diffuse a little sunshine through halls that will need all that they can obtain. I know no other way of accomplishing so much good at such little cost, for it must be considered that the benefit of such things is not transient and confined to a few, but will continue, year after year, to soothe and cheer hundreds of successire comers.

In another way you may afford it material aid. Like every other human enterprise, it will encounter trials and difficulties. Accidents may disturb the even tenor of its way, servants may prove unfaithful, unforeseen circumstances may defeat its wisest plans. In all such shortcomings, many people are swift to censure, and not unwilling to rouse the prejudices of the ignorant and ill-natured. Let it be your duty to examine before you decide; and, to do that properly, qualify yourselves, as you easily may, to distinguish between the accidental and unavoidable, on the one hand, and carelessness or intentional wrong, on the other. In this way you will often ascertain that what is put forth as unquestionable abuse, or indicative of culpable remissness, is merely the result of that imperfection which attends every thing human, and that many a tale of wrong-doing; when stripped of all exaggeration and false coloring, will be reduced to rery harmless proportions. The institution asks for fair, dispassionate, intelligent judgment, and this it has a right to expect, at all times, and under all circumstances. Firmly relying on your candor and intelligence, on the wishes and prayers of every friend 
of the cause, and on the smiles of an ever-gracious Providence, I have the faith to believe that the enterprise inaugurated here this day will ever prove a matter of just pride to this community, an honor to the Commonwealth, and an incalculable blessing to hu. manity. 


\section{THE CAUSES OF INSANITY.}

[Is the following observations on the Causes of Insanity, it was my object to show, not only that the prevailing notions respecting the production of the disease are exceedingly narrow and imperfect, but that they entirely ignore the most potent agencies concerned in the process. As long as such notions constitute our whole philosophy of the subject, attention will be fixed on accidental and subordinate points, while essential and indispensable conditions will be little understood or cared for. Why one person becomes insane, and another does not, both being exposed to the action of the same cause which was thought to be disastrous to one of them, would seem to be one of the first questions for the inquirer to answer, especially as it is suggested by all the analogies of bodily disease. It is not supposed that high living will produce gout in everybody who freely indulges his appetite; that cold will give rise to rheumatism in all who expose themselves to its rigors; or that every full-blooded, short-necked individual will inevitably die of apoplexy. It is hard to conceive how the absurdity of attributing an attack of insanity to incidents perfectly innocuous to almost everybody else, or of believing that a host of agencies as diverse in their nature and mode of operation as can well be conceived of should agree in accomplishing the same result, should have so completely escaped notice. It shows how superficial our study of insanity has been, notwithstanding it meets us in so many relations of the highest importance both to the parties immediately concerned and to society at large. Inasmuch as it is, of all discases, that in regard to which the right of private judgment is claimed with the strongest confidence, it ought to be, preëminently, the best known and understood by all who have any knowledge at all. It must be adıitted, however, that until very recently the vulgar conceptions of 
insanity could not be corrected by any worthier knowlerge on the part of those who professed to be especially acquainted with its phenomena. They were more disposed to speculate than to observe, and were not entirely devoid of prejudice and error.

Of late years the predominant error in the current views respecting insanity has eonsisted in the negleet of some important organie qualities of the brain. That its action could be deranged by those lesions designated as inflammation, congestion, softening, œdena, extravasation, and the like, was a fact always well understood, but any other conditions competent to induce a deviation from the line of sound, healthy activity, were scarcely suspected. In contemplating any instrument or machine of human invention, our attention is fixed not only by the nice adaptation of one part to another, and the admirable result thus obtained, but also by the flexibility of the materials used in the construction, their fitness for resisting noxious influences, and their power of endurance. And we are well aware that, generally speaking, it is on one or all of these qualities that the practical value of the machine will depend. No matter how ingenious the contrivance, or how perfectly the work is performed, if it is defective in any of these essential requisites, - if it is corroded by the very things it deals with, or speedily breaks down by means of its own friction, - then it is a failure. For ages the structure of the brain has received extraordinary attention, and its operations as the minister of the mind have been studied more profoundly than those of any other organ; and yet it never was supposed that its value as a working apparatus depends, in any measure, on the quality of the materials used in its construction. While men recognized the influence of disease and other deteriorating agencies in depriving other parts of their normal vigor and eapacity, this, the most delicate of them all, engaged in the most subtle and complicated processes, was practically considered as beyond their reach. It was supposed to be as sound, as vigorous, as well fitted for its work, in one generation as another, unscathed by any of those noxious agencies that have ever been checking the normal development of the human faculties. Inherited tuberele, from its chosen seat in the lungs, night at any moment spring into fatal activity; scrofula miglit so vitiate the humors as to spread debility over the whole system; gont and rheumatism might render the muscles and fibrous tissues of father and child, in long succession, sources of exquisite pain; but the brain alone continted, generation after generation, to retain its pristine vigor under the vices and errors of civilization. 
The researches of Gall and Spurzheim first led to more philosophical views respecting the constitution of the brain; for although their system has failed to obtain any considerable belief, yet their particular proposition, marking a long stride in the progress of knowlerlge. that size is a measure of power, - will scarcely be disputed now. The next step, of little less importance, was made by their followers. in explaining the apparent exceptions to the rule, by supposing a diversity of quality in the materials of which the brain is composed. At a later period, the deteriorating influences of vicious or unhealthy habits and usages were made the subject of an admirable work by Morel, while the effect of nervous disorders on the cerebral organism was investigated by Moreau de Tours with remarkable acuteness. The result of these and other kindred inquiries was to establish beyond a reasonable doubt the principle, that the brain comes into the world with the same imperfections and deficiencies, the same irresistible tendencies to disease or perversity of action, which have long been observed in regard to other organs. Thus was opened a new realm of inquiry, of unprecerlented interest to the student of pathological psychology, and of immense importance in many practical relations of life. We have as yet but a faint idea of its full significance, but it needs no great faith to believe that it is destined to modify very much our present theories of human action, and throw new light on many a dark problem of human conduct.

While physicians and philosophers have always admitted, in general terms, the damaging effect of corebral lesions on the mental powers, they have been far from being agreed as to its nature and extent. The only particular on which they have manifested something like an approach to unanimity of opinion is that of reducing the impairment of moral liberty thus produced to its narrowest limits. Governed merely by casual appearances, and strongly impressed by that show of reasoning power very common with the insane, they shrink from a truth which is the result of special investigation, but none the less certain and worthy of acceptation because completely beyond their range. Within a few years better notions have made their appearance among them; but the recent investigations, fruitful as they were, have added new difficulties to a subject already resarded with much diversity of opinion. If overt disease, manifested by appreciable symptoms during life and various lesions after death, can annul responsibility, the question inevitably follows, whether that cerebral condition, - neither of health nor of disease, as those terms are usually understood, - which is produced by tendencies to disease 
or ancestral vices, may not impair it, in some degree, under some circumstances? This is the question of questions presented to the psychologists of our times, and destined, undoubtedly, to raise sharper conflicts than any other in the whole range of medical jurisprudence. It is involved in obscurity, it is met by the bitter prejudices of those who lead popular opinion, and extensive investigations and various knowledge are neeled for its solution. Townley's case is but one of an immense class, and well illustrates what we are to expect hereafter. The following pages will give the reader some idea of the general course of inquiry, and the character of the particular questions involved.]

Nothing connected with insanity excites more popular interest than its causes; partly owing, perhaps, to the idea that to learn the cause is the first step towards its cure, but chiefly, no doubt, to an instinctive curiosity to know the why and wherefore of a strange and momentous event. With equal zeal, if not more discretion, the philosopher and the physician have speculated on the subject; and if an imposing array of figures and adverse incidents, embracing almost every human ill, from a blow on the head to a disappointment in love, were always equivalent to true knowledge, we might fancy that we have little to learn respecting the causes of insanity. When we ponder, however, the meaning of certain current words and phrases, and consider the vague and indefinite ideas which they convey, we shall be inclined to suspect, even without any profound acquaintance with the mental movements connected with disease, that we have been mistaking words for ideas, - grasping at a substance and finding only a shadow. The practical importance of the subject requires that it should be rightly understood, and this induces me to enter upon a discussion which might seem, at first sight, more appropriate in a professional treatise. 
Our first mistake consists of a vulgar misconception respecting the relations of cause and effect, which is not confined to the ignorant and unthinking. We see it in the common fallacy which supposes that a specific, prominent, well-defined event must necessarily be preceded by some other event equally specific and prominent. This error is the more easily committed, because the imagination is always pleased by discovering an agency whose properties seem to render it abundantly sufficient for the purpose. The mind rests upon it with a certain satisfaction, as if it had arrived at a sure and reliable result. I scarcely need to say how little support is afforded for this notion by the plainest rules of philosophical inquiry. Very often, an event that strongly appeals to the senses, and violently disturbs the present relations of things, may have been prepared by a series of agencies so slight and obscure as to be discovered only by the most keen and penetrating research. They seem to be slight, simply because, with our limited vision, we are unable to discern the whole field of their operations, or measure the results of their mutual dependence. Indeed, there can be no surer way of mistaking the real cause of a signal event than to suppose that it lies upon the surface, ready to be discovered without skilful and laborious research.

We see the same misconception in the common disposition to consider the relation of cause and effect to be determined by proximity of occurrence, or some other casual circumstance, ignoring all distinctions between the necessary and the accidental; and thus we are ever in danger of repeating the process of the untutored mind, by mistaking, in our way, Tenterden steeple for the cause of Goodwin sands. Indeed, it can hardly be denied, that, on this subject, such mistakes 
have been the rule rather than the exception, both with the wise and the simple. When an attack of insanity takes place, and we look among the occurrences of the past life for the cause of so singular a phenomenon, we seize on the most prominent or peculiar, and easily persuade ourselves that we have found the object of our search. It may be a singular, a remarkable, an extraordinary event, and yet the proof of necessary connection be utterly wanting. That proof seldom can be obtained without an exhanstive investigation of that and many other occurrences in the life of the patient, - the inner as well as the outer life, - and not always, by any means, then. No partial or superficial investigation can lead to a reliable conclusion. So long as a single incident remains untouched, we have no right to pronounce on the sufficiency of any other. But who is willing to take the necessary pains? Who is adequate to such a nice and complicated inquiry? How are its materials to be obtained?

Admitting that the antecedents are thoroughly un. derstood, if that were possible, it would be quite beyond our power to measure the amount of agency exerted by one and another in the production of the disease. The great misfortune, the terrible affliction, the stunning blow, may have had less to do with the final result, than some trouble concealed from the common gaze, deep in the inmost recesses of the inner life. On conversing with those who have recovered from an attack, respecting the incidents which led to it, I have found, oftener than otherwise, that they laid far less stress on the prominent event which had been fixed upon by others as the source of the evil, than on something so slight, apparently, as to have escaped the notice of the most intimate friend. In my observation of insanity, nothing 
has surprised me more than such revelations of mental experience, completely upsetting, as they did, our own elaborate conclusions respecting the canse of the disease. Not that the revelations of those who have been insane are always reliable, even if they have perfectly recovered, for the rery disturbance of mind must necessarily prevent them from reasoning about or even remembering correctly their mental impressions while under the influence of disease; yet, after all due allowance is made, their conclusions may not be more liable to error than those of outside observers. But, well as we may understand these incidents which are obvious to the senses, we can seldom, if ever, be sure that the morbific agency has been exerted by them rather than by those mysterious conditions of the cerebral organism which are indicative of imperfection or tendency to disease, and derived, in the process of generation, from imperfections in the parent or ancestor.

There is another consideration which has been too much disregarded, in this search for the causes of insanity. Even they who are not so dull as to suppose that the relation between the effect and the alleged cause is merely one of sequence, often fail to see the lack of any relation between the character of the supposed cause and the constitution of the brain, - the properties of its tissues, and the laws of morbid activity. It is not strange that, in the infancy of medical science, the mumbling of some cabalistic words over a wound was supposed to make it heal speedily; or that, in cases of injury, the remedy was sometimes applied to the instrument by which it was effected. It is strange, however, that, in an age which has laid down the strictest rules of philosophizing, few are disturbed by seeing events placed together in the relation of cause and effect, hav- 
ing as little mutual adaptation as the remedy and the ill here mentioned. We recognize at last the folly of believing, as our ancestors did, that the insane are possessed by the devil, that submersion to the very point of drowning is a sovereign cure, or that the moon has any influence on the movements of mental disease, simply for lack of this relation; but we fail to apply the same test to other alleged agencies in the production of insanity. Although it may not always be incumbent on us to demonstrate, beyond a doubt, this kind of adaptedness between the alleged cause and the cerebral constitution, yet, at the very least, we should be cautious how we offer as a cause of insanity an incident which all actual fact and all analogies forbid us to believe can, in the nature of things, have any influence upon the vital properties of the brain. Considered in this light, many of those incidents which figure among the causes of insanity must be regarded as of little consequence, if not entirely impotent. Taking up the first hospital report within reach, and turning to the table of causes, I find in it hard work, fear of poverty, and jealousy, to mention no others. The habit of repeating, one after another, certain words and phrases, is apt to render us insensible to the errors they represent. But dropping, if possible, all former impressions, and looking upon the matter afresh, by the light of sure and unquestionable knowledge, we shall scarcely find any warrant, I think, for believing that the incidents here named can, in the nature of things, exert a morbific effect on the brain. A poor man can have no apprehension of poverty, while, in the rich, it must be a morbid feeling, of course, part and parcel of the disease of which it is alleged to be the cause. Jealousy, in process of time, gradually increasing, way become a form of mental disease; but 
to call it the cause of insanity is very like saying that it is the cause of itself. Hard work may produce that exhaustion of the vital energies which faror's the development of insanity, but directly it cannot injure the brain. The occasion forbids me to multiply instances of this kind, but these are enough to illustrate $m y$ meaning.

Again occurs a difficulty no less serious than the last. In the series of antecedents which precede an attack of insanity, many of which may seem to be connected by a bond of mutual dependence, by what rule of selection are we led to pronounce this or that the efficient cause, - the causa causans? Within what period have we a right to look for the noxious agency? Are we to be confined to the last ferw weeks? or montlss? or years? We do not get rid of the difficulty by claiming for our purpose, without regard to time or any other circumstance, the incident or event which seems to the mind of a spectator to bave had the deepest appreciable effect. We rather substitute for it one still greater. To select any one incident, and leave out of the account entirely the rest, is merely to express an opinion, not to establish a fact. Such a proceeding is worthless, of course, as a matter of science. It can satisfy those only who are dazzled by a show of knowledge.

If driven by force of proof to admit that a multiplicity of incidents are usually concerned, each in its particular way, in producing the ultimate result, we are thus more philosophical in our investigation, more faithful to the truth; but what then becomes of our TABLEs? Even if, by any device of columns and figures, we could still preserve the tabular form, their statistical charac. ter would be utterly gone. To enumerate all the events 
which precede the attack is to give a history of the case, not to assign its cause.

One source, and perhaps the principal, of the prevalent error, is the habit of regarding insanity as a sharply defined phenomenon, easily separated from all accompanying incidents, like an earthquake or a chemical action, instead of a condition arising from obscure beginnings, culminating more or less rapidly, and declining by imperceptible steps as the darkness of night is succeeded by the light of common day. Any occur. rence which can be properly regarded as its cause must necessarily precede the morbid process. But the difficulty is to ascertain that point in the line of sequences which marks the beginning of the diseased action, so that we shall be in no danger of assigning, as a cause, some incident of the morbid process. Of course, the difficulty is all the greater, the longer the duration of the initiatory stage, and the less demonstrative its manifestations. It often happens, in fact, that the first prominent event having, apparently, any connection with the disease, is, clearly, not the cause, but an incident of it; while all before it is too vague, too obscure, too little known, to furnish any light as to the really efficient agency for which we are in search. To avoid mistake on this point requires a knowledge of the patient's history - to mention no other requirement - too minute and thorough to be often obtained. They who have been immediately around him are seldom capable of observing his mental movements correctly, for to do that implies the highesst kind of culture, and they may have only the lowest; and yet it is from their reports, chiefly, that the physician is obliged to draw his conclusions respecting the cause. How little reliance can be placed on this source of information daily experience teaches 
us, even when we have to deal with persons considera. bly above the lowest grades of mental culture. A single leaf from that experience will show the nature of the mistake in question, and the ease with which it may be made.

Prominent among the antecedents of a case is drunk. enness, for instance; and an incautious observer would straightway pronounce it the cause of the attack. That insanity may sometimes be fairly attributed to drunkenness, cannot be doubted; but, considering the nature of maniacal impulses, and the abundant opportunities for gratifying the desire for drink, there is reason to suspect that the vice may be an effect rather than a cause; and farther inquiry often confirms the suspicion. Again, a person is found to have aroided society, to have shut himself up in his own home, and thus for years dwelt only with himself, - eating his own heart, as old Burton has it, - and when, at last, he becomes unequivocally insane, his misfortune is attributed to love of solitude. Another, while correctly performing all the duties of his lot, fears that he will eventually come to want, though with enough at present, and with prospects that forbid any reasonable anxiety. $\mathrm{He}$ is frugal to meanness, denies himself and family the comforts suitable to their station, and acts as if the poorhouse were ever looming up in the future. After years of such mental experience, every incident becoming gradually intensified, he is pronounced insane, and his case is duly chronicled as produced by fear of poverty. Now, in cases like these, - and they might be multiplied ad infinitum, - it often needs only a thorough knowledge of the mental history of the individual, to find conclusive proof that the drinking, the love of solitude, the fear of poverty, \&c., merely mask less obvious steps 
in the progress of that morbid process which finally ends in overt insanity.

When the prominent events are many and nearly contemporary, the difficulty is scarcely less. By one friend the attack is attributed, for instance, to the trials of an arduous and highly responsible business. Another attributes it to the loss of a dearly beloved associate; while still another, better acquainted with the patient's private history, is quite sure that he owes his misfortune to fast living. According as we consult one or another of these friends, we shall set down as the cause of the disease application to business, or death of a companion, or intemperance. And yet any one of these incidents, calculated though they all are to derange the health of the mind, might have been completely harmless in the present instance. The business, though arduons and perplexing, might not have been beyond an easy stretch of the mental powers. The emotion caused by the deep affliction might have subsided under the influence of time or the pressure of duties; and the manner of life, though not conducive to longevity or good health, might have been borne by the help of a strong constitution. It is all a matter of conjecture, and conjecture is no foundation for a scientific conclusion. So that, at last, witl all the information within reach, the question to be settled is, not which of these events was the cause of the disease, but whether any one of them was concerned in its production.

To ignore all these difficulties, or decry them as of little moment, for the very reason that, if duly considered, they would effectually debar us from arriving at any fixed results, will not help us to obtain the truth. In all philosophy, there is no error more obstinate, or more fatal to true progress, than that so often witnessed, - 
of believing that any conclusion, however defective, is better than none. To the unwary reader, the TABLEs which are made up with such an elaborate show of statistical accuracy, representing so many cases as caused by domestic affliction, so many by religious excitement, so many by this, that, and the other, are the embodiment of so much genuine knowledge. True, he may be told that they are put forth only as approximations to the truth; full of errors, indeed, but through these very errors leading the inquirer to unquestionable truth. Nerertheless, the cantion thus implied will scarcely weaken the force of the popular adage, that figures will not lie. Nothing better indicates the true value of such statistical results than the fact that the proportion of cases attributed, in our hospital reports, to "Causes unknown," has been steadily rising from zero to half or more of the whole number. This is not an expression of positive ignorance merely. Rightly interpreted, it means, I apprehend, the conviction that the develorment of insanity generally requires a concurrence of several adverse incidents, and that the instances which can be attributed exclusirely to any one special erent, however prominent or serious, are exceedingly few. Such, indeed, is the lesson of experience. True, it disturbs the complacency naturally arising from the supposed discovery of something clear, well-defined, almo: $t$ tangible, which meets the question, and seems to answer the conditions of the case. It destroys, at a blow, a great deal of fancied knowledge, and leaves us to wander about, seeking anew for the solution of the problem. Here, as everywhere else, truth can be found only after' long and patient inquiry, and we may be assured the rule will not be relaxed in the case of one of the most difficult questions in morbid psychology. 
Occasionally, no doubt, the disease may be attributed to some particular occurrence, the circumstances excluding apparently every other agency. Even then we fall short of the object of our search, for the question comes back, why such an occurrence, which has happened times without number to the children of men, without any harm, should have proved so mischievous in this particular case? To say that its potency for ill was caused by some previous adverse incident, and that, perhaps, by some other, does not relieve the difficulty. Such philosophy is no better than that of the Indian who thought the earth rested on an elephant, the elephant on a tortoise, and the tortoise on a serpent.

We are thus led to the inquiry, whether there is not something behind all these alleged causes, which imparts to them all their potency; whether there is not something in the original constitution of the brain and nervous system of the patients which, with more or less aid from favoring circumstances, determines the development of insanity. Most persons preserve their mental integrity, even through a life of trial; while a few, with no trials at all, or only the smallest, break down utterly and come to naught. It would seem to be an inevitable conclusion, that this difference must depend on the different degrees of vigor and soundness possessed by the material organ by which these trials are sustained. Time out of mind, the popular belief, sanctioned by the wise and learned, has been that, in some degree, insanity is a matter of blood - something transmitted from parent to child. Such is the belief of the simple and the wise now precisely so - without variation or improvement. In how large a proportion of cases is this the efficient element? what are the laws that regulate its transmission? what are the conditions of its existence and 
development? - these are questions of which, till re. cently, we knew about as little as our ancestors. Their belief, vague, shallow, and partial, seemed sufficient for us.

The knowledge we have gained respecting the laws of hereditary transmission, as witnessed in the brutes and plants, might justly have been expected to shape our views on this subject; but, curiously enough, it seems, in a great degree, to be theoretically and practically ignored, in regard to man. That it should be disregarded in the actual practice of life is not very strange, because the fact only exemplifies the usual carelessness of consequences, when one is controlled by interest or passion ; but it is strange that observing and thinking men can see, in such transmission, nothing but an infelicitous play of accidents. And many, even, of those who believe in hereditary transmission, have but very imperfect conceptions of its operations and conditions, as compared with the exact and abundant information of the breeder and the florist. The prevalent mistake is that of regarding no disease as hereditary that does not descend fully formed directly from parent to child. Now this we know to be contrary to all the analogies of the animal and vegetable kingdom, where a desirable quality is obtained and fixed at last by being repeated and intensified through successive generations. Permanent traits of size, shape, color, speed, endurance, are the results of a gradual work, and nobody contends that they are, in no sense, hereditary, because they did not exist in the same measure in the parent as in the offspring. The fact seems now to be well established, that many hereditary diseases other than nervous oftentimes do not pass through their successive stages of development in a single generation. The tubercle that suppurates, and destroys the patient in the maturity 
of his years, may have originated in the parent, or grandparent, in whom it gave no appreciable trace of its existence. It would be regarded as no mark of wisdom to ignore altogether this relation; and yet many are reluctant to believe that insanity is often the result of abnormal organic movements that have proceeded from one generation to another, gaining, steadily or fitfully, in intensity. This narrow conception of the great law in question must be exchanged for broader views, before the physical conditions of insanity will be studied as their importance requires. Until we recognize and rightfully appreciate this law of progressive development, - whether as manifested in improving some desirable quality, or moulding some feature into a more graceful form, or strengthening the foundations and enlarging the range of some morbid movement, - we shall fail to get more than a school-boy's notion of the relation of cause and effect in the production of mental disease. Facts illustrative of the true doctrine are abundant, and we have only to consider them carefully to learn their full significance.

Starting, then, from this settled principle, that disease is an ultimate product elaborated from simpler elements during a period that may embrace more than one genertion, - that its essential element, considered in any stage of its progress, is imperfection, defect, abnormal depreciation, to be manifested, under the process of hereditary transmission, in every variety of form, - we shall be led to a correct theory of the production of insanity. Under the adverse influences of a highly cirilized condition, the cerebral system suffers in common with the others; while the signs of such suffering will generally be found only in the mental manifestations, varying all the way from some slight peculiarity 
or anomaly of character, to the gravest moral or intellectual impropriety. The defect, under the predominant influences of a different blood, may not be witnessed in any succeeding generation. More frequently, however, even in spite of this conservative influence when present, it does make its appearance again, in one or more of the descendants, in forms more or less severe than the original. One's daily experience scarcely fails to furnish illustrations of our doctrine.

This person manifests a certain peculiarity in his manners, in his turn of thought, in the expression of his feelings, in the character of his discourse. This signally lacks the power of adaptation to circumstances: he lives and moves as if in a world to which he does not really belong, and is always above or below the requirements of the occasion. This goes through life with the constant idea that his deserts are unjustly withheld from him, and without reason and against reason is jealous of every one enjoying blessings beyond his reach. This neglects the common duties of life, and ignores the common sentiments of humanity, while dwelling in the realms of imagination, and charming the world, perhaps, with the beanty of his thoughts. Now all these persons go through the ordinary routine of life very well, for the most part, and no one thinks of attributing to them any mental defect. Nevertheless, there is in them a departure, be it never so little, from the line of normal activities, indicative of a permanent cerebral condition, to be transmitted, probably, to the next generation, and manifested in some form or other of mental irregularity. One child passes through the various phases of hysteria, catalepsy, and other nervous affections, a burden to herself and to others. Another delights in the mysteries of spiritualism, and finds the extraragances of the 
times more congenial to his mental temperament than the practical realities of life. Another is merely con. ceited beyond all reasonable limits, aiming at much, sure of every thing, and achieving nothing. Another has seasons of deep depression, when a dark cloud that has no silver lining settles down upon his soul; and this may be succeeded by a period of exaltation, when his whole horizon is bright and joyous. Another, in spite of the holiest infuences, becomes, in early life, the slave of criminal impulses, and ends his days in a hospital or prison, perhaps on the gibbet. Another becomes unequivocally insane. Thus the abnormal condition of the parent is represented in the clildren, - not always in the same way precisely, but in any possible form of nervous disorder. The next generation will probably show us the morbid element equally diversified, and exhibiting, it may be to a greater extent, its ultimate results. It is immaterial what may be the character of the primordial germ. It may assume any of the forms here mentioned, as well as countless others, in passing from one generation to another.

It is another of the organic laws on this subject, that morbid as well as healthy traits may disappear in the second generation, and re-appear with fresh energy in the third. A degree of eccentricity, for instance, which renders a man a by-word in the community, affects not at all the mental integrity of his children, but among those children's children may be observed every form of mental and nervous disorder. And even when the morbid element manifests its presence in each succes. sive generation, it may not pass down in the direct line of descent. The uncle or the aunt, rather than the parent, may present the connecting link between the grandparent and the grandchild. Such facts are neither 
extraordinary nor anomalous. The suppression of a trait, entirely, for one or two generations, its transmission by collateral descent, its infinite variety of modifications, are facts familiar to those who have studied this subject in the animal and vegetable kingdom. Disease and tendencies to disease, implying as they do a certain organic condition, must necessarily be governed by the same laws of transmission. If these were better understood, we should not be obliged to meet the objec. tion sometimes made by men of liberal culture, that the mental disease or defect so often dies out with the individual in whom it originated, that its occasional appearance in successive generations may be fairly regarded as accidental. No one can help seeing, on a little reflection, that all the peculiarities of feature, temperament, and mind, in both parents, cannot, of necessity, be transmitted to any single child. By some mysterious law of selection, the forehead of one and the eye of the other parent, the nose of one and the mouth of the other, the vigor of one and the fragility of the other, the stature of one and the complexion of the other, go to make up the form and constitution of the individual child. A feature of the most decided character may thus fail of transmission, even to a single one of a numerous progeny. The same law governs the transmission of imperfections and all abnormal traits. No more are they transmitted to each and every child alike. The myopia, or the hare-lip, the tendency to gout or consumption, in one of the parents, may be witnessed in a part only of the children. It could not be otherwise with insanity.

This occasional disappearance of hereditary disease marks the operation of the great universal law of hereditary transmission. While Nature indulges in such a vast variety of forms that no two individuals in all this 
immense creation can be found exactly alike, she permits no considerable deviation from the normal condition to become permanent. Her tendency ever is to abolish all gross anomalies of form, feature, complexion, - not excepting disease, - and to reëstablish, in all their integrity, the original characters of the species. Supernumerary fingers or toes, extraordinary conformations of the limbs, defective or excessive development, - all these may occur in a few generations, but having no place in the normal constitution of the species they sooner or later disappear. Breeders tell us of the great difficulty of maintaining any desirable feature which marks a considerable deviation from the normal type. They succeed only by a persevering system of breeding in and in, and that finally produces a deterioration of the general qualities of the stock; and it is obvious that without this restraining influence these deviations would become established, and the distinctive characters of the species be utterly lost.

The same law also restrains the indefinite transmission of disease and defect, which would lead to the same result. While some of the children inherit the defects of one parent, the rest inherit the excellences of the other; and even when both parents are defective, their sound points, by being firmly fixed in the blood, may maintain their place to the exclusion of the others, and the offspring thus escape the blight. It must be considered, too, that the germs of the disease, when actually transmitted to the child, may, under favoring circumstances, remain latent, and for lack of any activity fail to be transmitted any farther. In common phrase, they die out. Thus it appears that the invariable transmission of any quality or condition is contrary to the ordinances of nature; and that the absolute, uncon- 
ditional transmission to each and every child of every trait and quality possessed by the parents is simply an absurdity. Amid all the ways and works of the Creator, it would not be easy to find a more wise and beneficent arrangement, which preserves the characters of the species, while, by penalties severe, but not inexorable, it prevents the deterioration of the race. Let not the kindness and mercy which preëminently distinguish this provision, become inducements for disregarding its requirements and defying its penalties.

The course of our inquiry, then, leads us to this conclusion, - that in the production of insanity there is generally the concurrence of two classes of agencies, one consisting in some congenital imperfection of the brain, and the other in accidental, outward events. I do not say that mental disease is never produced by the latter class of agencies exclusively. The present limited state of our knowledge forbids so sweeping a conclusion. Cases sometimes occur where the closest investigation discloses, apparently, no cause of cerebral disorder within the patient himself. There is good reason to believe that the number of such cases would be lessened by a deeper insight into the inner life, and a minuter knowledge of those organic movements which lead to disease. We know that even in those cases in which, to all appearance, the casual incident was most competent of itself to produce the disease, the constitutional infirmity may be often discovered. Drunkenness, epilepsy, blows on the head, sun-stroke, would seem capable, if any thing outward could, of producing insanity; but, as a matter of fact, we find not unfrequently, behind these casual events, firmly seated in the inmost constitution of the brain, the hereditary infirmity. Can we believe that it took no part in the morbid process? 
The almost universal conjunction of these two classes of agencies being admitted, it becomes us to thoroughly understand and profit by the fact; for this, like most facts on the subject of insanity, may be turned to practical account. It might seem, at first sight, that the presence and predominance of the constitutional defect implied a kind of fatality in the course of things, which it would be useless to attempt to resist. That there may be, occasionally, some ground for this idea, it would be wrong to deny; but, in a large proportion of cases, the morbid element is not so potent as to be entirely beyond control. The peril being understood, it may be kept in abeyance by avoiding all those incidents and influences which are calculated to bring it into active operation, and by faithfully complying with the proper rules of living. And if the particular doctrine here taught would seem to lead to a scrutiny of one's mental constitution, more likely to produce the saddest apprehensions and forebodings than any salutary effect, it must be considered, on the other hand, that entire ignorance of the subject must, necessarily, often lead to evil. An exact knowledge of the truth may, occasionally, excite unpleasant reflections; but, in the long run, it will do more good than harm. The various ways in which it may be made practically useful it is not my purpose to describe; but there is one view of the subject so little understood, though of paramount importance, that it may be worth our while to dwell upon it for a moment.

To say that a man's character and conduct are determined, in a great degree, by the original constitution of his brain and nervous system, is to utter a truth that can hardly be called new. Few, however, are disposed to make any proper account of those cerebral qualities 
which imply a deviation, of some kind or other, from the line of healthy action. It is not in accordance with the philosophy of our times to see in them an explanation of those strange and curious traits which are utterly inexplicable on the principles that govern the conduct of ordinary men. How, then, could they expect the popular approbation, who find in them a clew to some of the mysteries of human delinquency? But the teachings of science, the stern facts of observation, cannot be disregarded. Whether we ignore them or not, sooner or later their full significance will be triumphantly acknowledged.

In the popular apprehension, even downright insanity is regarded as of little practical account, unless it courts observation by the force and variety of its manifestations. Only its more demonstrative forms are supposed to be capable of affecting the legal responsibility of men. The world is reluctant to believe that a person who, in most respects, is rational and observant of the ordinary proprieties of life, can be so completely under the influence of disease as to be irresponsible for any of his acts. If the world is reluctant to allow to this description of persons the immunities of insanity, it could hardly be expected to treat, with any degree of favor, those traits or conditions of mind which imply, not disease, perhaps, but abnormal imperfection of the brain. And yet it cannot be denied that the course of thought, the sense of moral distinctions, the actual conduct, may be greatly affected by the influence of such imperfection. Are we not bound, then, by a sense of justice and the claims of science, to make some account of it in forming our estimates of character, and fixing the limits of responsibility? Can we do otherwise without the grossest inconsistency? Knowing that an individual 
is descended from a line of progenitors abounding in every form of nervous disorder, shall we think it strange that some vestige thereof should have come to him? And knowing that the quality of the brain is necessarily affected by such disorder, shall we not seek, in this fact, for an explanation of what would be inexplicable upon any ordinary principles of human conduct?

The doctrine of transmission here adopted warrants us in assuming that, if fairly considered by the light which the facts of physiology, pathology, and natural history throw upon it, it will furnish a clew to the true philosophy of those minor or obscure derangements of mind, which are much misunderstood, if not entirely ignored. It was once the common belief that no disease could be considered as hereditary whose exact prototype had not existed in a previous generation. But nobody now believes that hereditary disease is transmitted only as disease. Every day's observation shows us that, in this mysterious operation, it is not the disease itself - not the host of morbid movements implied in that term - which is transmitted, but what, for want of a better term, we call the tendency to disease. It shows us that gout, apoplexy, or epilepsy never passes, fully formed, from parent to child, but only such a constitution of the inmost principles of the vital organism, as, under favoring circumstances may, in the course of time, be converted into one of those diseases. The ,thing actually transmitted is hidden from the senses, and beyond the reach of the scalpel or microscope. But it is none the less actual, nowe the less a power in the organism to be manifested by the most serious effects. Now, insanity is subject to the same law of transmission as other diseases, little as we might be led so to suppose by the prevalent notions respecting it; and the law is 
as devoid of mystery, as sure, as explicit, as beneficent as any other in nature.

Considering, then, that tendency to disease, not discase itself, may be the only thing actually transmitted, it is not strange that orert insanity in the parent is not always followed by the same condition in the child; nor that overt insanity in the child has not always been preceded by the same condition in the parent. Beyond the mere tendency to disease, all the rest is, to our apprehension, - very often, certainly, - a matter of accident. Not the necessities of the constitution, but circumstances, determine whether the tendency remains in abeyance, or is converted into overt disease. Hence it is that insanity may be properly called hereditary, even when undiscovered as such in any progenitor of the patient.

The tendency once established in any particular brain, the next step of the inquiry is, to know what becomes of it. To this question, the results of observation furnish a satisfactory reply. In the first place, like all accidental characters, it may die out with the individual himself, and leave no trace of its existence in his offspring. Secondly, it may be transmitted to his immediate offspring, in whom it may assume any possible form of nervous derangement or defect. Thirdly, it may remain in abeyance in the next succeeding generation, and be developed in the third with even more than its original gravity. The eccentric old man, whose conduct and discourse make him a by-word among people, perpetuates his name in half a score of children who manifest no mental obliquity or defect, while among their offspring may be found a great variety of each, from the "simplest peculiarity to furious mania. It may appear in early youth, in the form of chorea, epilepsy, 
catalepsy, proclivity to mischief, or fits of passion; in maturer years, in the form of alternate excitement and depression, of irresistible propensity to drink, of striking peculiarities of behavior, of some strange, unexpected, and inexplicable act, of raving mania; in advanced age, in the form of premature decay, or complete dementia. The incident which preceded all the subsequent evils may have been a slight eccentricity, hardly perceptible to the world, chronic neuralgia of the head, habitual intemperance, excessive study, or protracted vigils; a defective development of the brain while young, produced by bad physical influences, such as impure water and air, lack of ventilation, crowded and uncleanly dwellings, hardship, and hunger. Looking either to the canse or the effect, we see the utmost possible variety; and the fact should teach us to be cautious how we undertake to circumscribe the range of nature's operations in the broad domain of cerebral disease. But the ailment, whatever it may be, - whether it come in some familiar form of mental disorder, or one of those obscure conditions which perplex both the wise and the simple, - whether it break out suddenly, or go throngh a long course of derelopment, - is the last of a series of morbid or abnormal movements whose beginning was in a previous generation. The more extensive and accurate our observations, the more strongly is this fact confirmed; and it must be thoroughly understood and appreciated, if we would avoid a very common error on the subject.

When unequivocal insanity in the parent is followed by the same affection in the child, nobody is unwilling to recognize in the fact the relation of cause and effect. But when some obscure phase of mental obliquity, or even overt insanity, is followed by some form or degree 
of mental disturbance not distinguished, by any positive characters, from normal peculiarities or conditions of mind, the idea of any such connection is apt to be considered rather as an ingenious speculation than a strictly philosophical deduction.

This, then, is the general conclusion to which we are led, by wide and careful observation; viz., that the hereditary taint of insanity appears, in various stages of progress, from the lowest to the highest grade of intensity, and under a variety of forms and aspects. This being so, it follows that these various forms and stages of the disease are as worthy of investigation as that of the fully formed, fully developed, unmistakable attack. Their effect on the mental capacity and vigor, and on the complexion of the moral sentiments and determinations; their connection with the habitual feelings and transitory impulses, with the power of resisting evil and pursuing good, - are points on which we need to be enlightened, in forming our estimates of character, especially in reference to moral and legal responsibility. They are agencies no less effective than education, social influences, or mental endowments; and these, surely, are not regarded as unworthy of attention in this relation. To admit the general fact, but deny that it has any practical value, is a sort of philosophy more indicative of prejudice and presumption than of sound, scientific reasoning. That disease may exist in any organ, without appreciably disturbing its operations, is, undoubtedly, true. Such a thing sometimes happens; but it is an exception to a general rule, - and, consequently, only proves the rule, - which is, that disease, infirmity, or defect of an organ, necessarily, in one way or another, affects its functions. That it is often difficult to estimate very precisely the extent of this deteri- 
oration, I grant; but cases sometimes arise where the fact is so ubvious, that, without any elaborate reasoning, almost instinctively, as it were, we recognize its potency. Let a man whose family abounds with cases of mental disease be arraigned for some unexpected crime, and the word goes round at once, that the trouble is in the bluod.

$\checkmark$ The next step in our inquiry is, to ascertain how we may be able to recognize the presence of the hereditary taint. By what signs or manifestations have we a right to infer that it exists in any given case?

In the first place, we must bear in mind that it would not be inconsistent with any thing we know respecting the laws of disease if it remained in a latent condition, unobserved by the person's most intimate acquaintance. A good physical education may have prevented the development of diseased tendencies, a sound mental disci. pline may have so strengthened the powers of the mind as to furnish them the least possible play in the habitual mental movement, or no fitting conjunction of circumstances afforded an opportunity for their exhibition. Even when actually manifested, they may have appeared so little like the traits of disease as not to be recognized as such by the casual observer. Precisely so with one who has inherited a tendency to bodily disease, - consumption, for instance. A judicious physical training may have so strengthened his constitution as to render the local defect powerless; a broad chest and florid countenance may negative any suspicion of pulmonary weakness; easy circumstances and a genial climate may keep the noxious germ where it began, to the latest hour of life, or allow merely that slight development which is cognizable only to the inspection of the expert. And the same sort of analogy might be furnished by the 
course of other diseases. Now, in these cases, there may exist no doubt as to the inherited tendency: and we do not expect of the person that amount of endurance under exposure, or the power of succeeding in special efforts, which we do - other things being equal - of those who are born with no such tendencies. Neither, when, in spite of all appearances to the contrary, the disease does break out, are we astonished at the fact, or inclined to ignore its existence.

Disease in any organ is manifested - if manifested at all - in a disturbance either of its own functions or of those having close nervous connections with it. In one or the other of these two ways only, can disease of the brain be made apparent to the outward observer. It is, therefore, a fair inference, that any considerable deviation from the ordinary course of its functions indicates the existence of disease, in some one or other of its phases; and one of its functions, I take it for granted, is to make manifest the operations of the mind. A notion, ostensibly founded in fact, but really without any such foundation; an irresistible impulse to do or say a thing abhorrent to one's own ideas of fitness or moral propriety; a loss of self-control, if not consciousness, under extraordinary trial; the occasional ascendency of appetite or passion over all the restraints of education, habit, and conscience; an act of violence, unprovoked by any adequate cause, and at variance with the character and disposition, coming like thunder from a cloudless sky, such traits as these warrant us in believing that the disease, or tendency to disease, which existed in the progenitor, has been transmitted to the offspring, strengthened and quickened, perhaps, in its passage through one or two generations. We have also a right to recognize the hereditary taint in those extraordinary phases and 
incidents which, unexpected and unaccountable as they are, always amaze and perplex the superficial observer. If manifested at all, these are its legitimate effects, and they ought not to surprise us. Indeed, it should surprise us more if it always remained in abeyance, and gave no token of its presence.

Of course it cannot be denied, that manifestations very like these attributed to the hereditary fault may and do occur in a normal condition of the cerebral system; and the peculiar difficulty of the present question is to distinguish the one from the other. Cough, pain, fever, are unmistakable signs of disease, which we are in no danger of regarding as compatible with a state of perfect health. On the other hand, an act of mischief or folly, which in one man would be the offspring of insanity, would in another be justly attributed to moral deprav. ity. Now, it is a fair question to ask, - and it is entitled to a satisfactory answer, because one of great practical importance, - can we distinguish, in every case, between these two orders of facts, with any reasonable degree of certainty? With no disposition to make light of the difficulty, I still believe that it requires no extraordinary skill or discernment to save us from mistake beyond what is incident to all human judgment. The occasion hardly admits a thorough discussion of this point, and therefore I will only briefly indicate some of the rules which should govern our inquiries.

Every act, every course of conduct, must have an adequate cause; and, in order to ascertain this cause, we may need the largest knowledge of men, and a profound discernment of the springs of action, and of the effect of social, moral, and religious influences. The question whether a certain act is or is not the offspring of insanity, must often be decided, not by the intrinsic qual- 
ities of the act, but by the circumstances of the case. A person of doubtful mental condition must not be considered as responsible for an act of violence, merely because a Fejee islander or a professional bravo might do the same thing as a matter of business or pleasure. And the converse of the proposition, I admit, is equally true. An act of violence must not be attributed to insanity merely because, to a person of high culture and correct morals, it seems inexplicable on the ordinary principles of human conduct. In one community, some forms of murder would very properly raise a suspicion of insanity, while in another they might unquestionably arise from passion or calculation, and be viewed with indifference, if not complacency. Let the person, therefore, whose mental condition is in doubt, be compared, not with somebody else, but with himself, in connection with the circumstances in which he is placed. In cases of this description, a man's habitual character furnishes the best clew to the nature of his acts. If these are apparently inexplicable, it is because we overlook the only key that will unlock the mystery. However strange and unexpected they may be, a thorough inquiry will show that they are consistent with the laws of psychology, as displayed in the operations of the mind, in health and disease. For instance, a person commits a flagrant crime, though nothing in his previous history would have led one to begin to anticipate such an event. His record is fair, and not even the closest scrutiny of friend or foe can detect in it a single flaw. No sudden provocation, no ulterior object, no overmastering passion, can be discerned. He comes of a stock, however, whose nervous constitution has been vitiated by some defect or ailment calculated to impair its efficiency and derange its operations. In some shape or 
other, it may have been transmitted to him, and, on the doctrine of chances alone, the fact is more or less probable. Here, then, are the only two possible solutions of the difficulty, - depravity or infirmity; and we have no right to choose the former, merely because the latter cannot be proved by the grosser tests. Indeed, a superficial examination finds the one as unsatisfactory as the other. If the act in question is the only indication of disordered mind, in the whole life of the individual, the difficulty of reaching a satisfactory result would be increased, no doubt; but, taking it even in this shape, we are warranted in saying that a single act of insanity, intruded into the midst of a correct and even life, is not more strange than a single act of depravity apparently foreign to the character and disposition. In most cases, however, - might I not say, in all? - a thorough inspection of the mental manifestations, as displayed in the conduct and discourse, would bring to light certain peculiarities which, though not strictly incompatible with soundness of mind, furnish, at least, fair ground for suspecting the presence of hereditary taint. Excitement and depression, moody, difficult temper, extraordinary proneness to jealousy and suspicion, a habit of saying or doing proper things under improper circumstances, an unreasonable disregard of ordinary ways, customs, and observances, an habitual extravagance of thought and feeling, an inability to appreciate very nicely moral distinctions, gusts of passion, reckless indulgence of appetite, - such are the traits, some or all of which will be generally found in connection with transmitted mental infirmity.

It may be replied, that these are mental defects signifying, not mental unsoundness, but merely that sort of imperfection that necessarily belongs to human nature. 
That any one of them, singly and alone, is invariably an indication of cerebral infirmity, I do not contend; but I think we are warranted in saying, that, under certain circumstances, each one of them may be an unmistakable sign of such a condition, and that in actual practice there can be but little difficulty in making the distinction. Let it be observed, however, that I do not present them as indications of insanity, but rather of a cerebral condition which, under certain circumstances, may become insanity. And this is the point that deserves especial attention. When a person, hitherto regular and rational in his ways, commits an appalling crime, the world is very reluctant to believe that it could have sprung from any other source than some hidden foun. tain of depravity, deep down in the recesses of the moral being. If, however, a faithful examination of the individual shows any of the abore-mentioned traits, have we not a right to suppose that some bodily ailment or some moral shock, sudden and severe, may have quickened the morbid element into overpowering activity? There is nothing in the nature of mental disease that forbids the supposition, - nothing in its rise and progress, according to the present state of our knowledge, incompatible with such an event. Change of phases, slow or sudden, rapid development, frequent fluctuations, are eminently characteristic of mental disease. Admitting the morbid element to be present, we can scarcely limit the modes of its operation, nor be surprised at any turn it may take.

Let it be observed, too, that this sudden and rapid development of mental disease which has been lying in embryo is strictly in accordance with the laws of morbid action, as witnessed in the rise and progress of other diseases. Tubercles which have existed in the lungs 
for years, giving no signs of their presence, are suddenly aroused into fatal activity by a severe cold. The germs of inherited gout lie unsuspected in the system, until some impairment of the vital energies, or a prolonged debauch, furnishes the stimulus which they require. An inherited tendency to apoplexy quietly waits a fitting occasion for the fatal stroke. And yet the world wants no better argument against the plea of insanity in a given case, than the fact that its existence was never suspected before the act of violence, on account of which it is offered. In making up our opinion respecting the mental condition of the party concerned, the very act most significant of all is to be completely ignored!

Admitting the truth of our doctrine, it becomes our duty to inquire what practical consequences should rightfully follow it. If its legitimate effect were to furnish fresh license to passion and diminish the power of self-control, to encourage crime and endanger the welfare of society, I should be inclined to regard it as one of those truths which had better be known only to philosophers and saints. Believing no such thing, but rather that the highest interests of men will be best promoted by making the mental condition in question more correctly understood, I proceed to the next step of our inquiry.

When a criminal act is committed by one who has previously given no indications of mental disturbance though the circumstances of the act may raise suspicion of unsoundness, and we find any of those traits which are indicative of hereditary tendency to the disease, we are bound to allow this fact some weight, at least, in our estimates of responsibility. We are bound to allow ample scope and verge for the unmistakable manifestations of 
disease, before we lay upon the offender the usual consequences of crime. How far it should be allowed to affect legal responsibility can only be ascertained by a thorough and intelligent investigation of the circumstances of each particular case. The results to which we arrive must always be more or less conjectural, but they may, at the least, furnish ground for doubt where confidence might lead to injustice. They might stay the hand of the law until doubt should be converted into certainty, and the cause of truth and right be amply vindicated before men.

Let me not be misunderstood. It is no doctrine of mine that a man is irresponsible for any and every crime he may commit, or for any moral delinquency, simply because some of his progenitors were insane. What I contend for is, that, when such a fact appears in evidence, it should be investigated in all its relations to the party concerned, under the light derived from the present state of our knowledge on this subject, in order that it may be ascertained if the mental infirmity, by being transmitted, in some form or other, has determined, at all, his volitions, impulses, or acts. If, under such an investigation, it shall appear that his character or conduct has been marked by peculiarities like those which usually spring from the hereditary taint, and especially if it appear that the criminal act was accompanied by none of the ordinary circumstances of crime, then a reasonable doubt is thereby raised of his legal guilt, and a suspension of judgment justified, until farther developments shall have shown the true nature of the case. If, on the other hand, the act in question appear to have been a rational act, rationally done, - that is, prompted by the usual incentives to action, - and the individual has been free from any mental obliquities that 
might be fairly attributed to the hereditary taint, then it cannot be justly put forth as a ground of exemption from the ordinary consequences of crime.

The importance of a more intelligent appreciation of this class of cases was strongly exhibited in England, a few years since, where one of them occurred. Though scarcely distinguishable, at first sight, from the ordinary run of crimes, it became the subject of comment in Parliament, and divided the public attention with the Schleswig-Holstein difficulty and the American rebellion. It distracted the opinions of eminent experts, it jeopardized the popularity of a cabinet minister, and raised a general clamor throughout the kingdom. A young man of twenty-five, named 'Townley, was engaged to a young lady, both of highly respectable character and connection. Twice the engagement was broken by the lady, ostensibly because, on account of his want of business or means, it was disapproved by her grandfather, with whom she lived, but really - the last time - because of her preference of another, to whom she had become engaged. The affair moved him deeply, and in great agony of mind he solicited and obtained a final interview, which lasted two hours, in the evening, ont of doors. At the close of it, he killed her with a pen-knife, gave notice of what he had done, and assisted in rendering the necessary attentions. It was obvious that he had made no preparations for the act, and he made no attempt to escape.

It appeared in evidence that he had always borne a good character, and was of an amiable disposition, though somewhat excitable and peculiar. His grandfather's sister and a first cousin had been insane, and an aunt's aunt had had ten children, of whom five had been iusane. His own account of the transaction was, 
that he endeavored to ascertain from her the name of his rival, which she refused to give; that he kept down his feelings as long as he could, but was finally worked up to a pitch of madness, and did not remember any thing at the last. He admitted that the act was murder, for which he would be hanged, and said he was happier for having done it. Subsequently, he justified the act, on the ground that she had deceived him, declaring that the woman who deceived him must die; that she was his property as much as if they had been married; and that he took only what belonged to him. His statements, though free from all signs of delusion, unless some vague expressions about a conspiracy might be regarded as such, were full of that peculiar extravagance of sentiment, insensibility to moral distinctions, inconsistency, and contradiction, so characteristic of the insane The like of them may be found in the case-books of erery hospital for the insane.

On trial, insanity was pleaded in his defence, but he was convicted. The judge, however, regarding the medical testimony respecting his mental condition to apply to a period subsequent to the homicide (in which testimony was that of a distinguished expert, strongly in favor of his insanity), he transmitted the papers to the Home Secretary, Sir George Gray, and solicited his attention to the case. This gentleman requested three members of the Board of Commissioners of Lunacy to examine the prisoner; and they reported, as the result of their examination, that his condition was the same then as when he committed the act; that applying the law, as laid down by the court, he was justly convicted; but added that, "in view of the extravagant opinions deliberately professed by him, of his extraordinarily perverted moral sense, and of the hereditary taint 
alleged and apparently proved to have existed in the family of the prisoner's grandmother, we cannot consider him to be of sound mind."

In the mean time, in conformity to a statute on the subject, three justices and two medical men examined him, and pronounced him to be of " unsound mind," and he was accordingly sent to Bethlehem Hospital. Whereupon, a strong remonstrance, signed by forty magistrates of the county, was sent to the Secretary, who immediately appointed another Commission to examine and report on his mental condition; which Commission was composed of four physicians, of whom two were then Superintendents of hospitals for the insane, and two had been previously, but were then holding the office of "Visitors of Chancery Lunatics." These gentlemen arrived unanimously at the conclusion that the party was of "sound mind," and forthwith the Secretary ordered him into penal servitude for life, in Australia.

This case affords an apt illustration of the peculiar embarrassments occasioned by the mental condition in question. It is easy to see how the experts honestly arrived at such different conclusions. The absence of any symptoms of insanity previous to the criminal act, and of any conclusive one subsequently, was undoubtedly a good reason for believing that Townley was not insane; while his extraordinary notions of right and wrong seemed to indicate one of those selfish, reckless, godless spirits - too common, alas, to make their existence a matter of question - that stop at nothing in order to gratify an impulse or accomplish a desirable end. According to legal definitions, certainly, he was not insane, nor could he have been admitted into any hospital for the insane in Great Britain. On the other hand, considering the circumstances of the act, and the 
remarkable conduct of the prisoner immediately before and after it, in connection with his hereditary tendency to mental disease, there was ground for regarding him as insane rather than depraved. Had the homicide been unaccompanied by this hereditary tendency, or the latter not been followed by any act of violence, this conclusion would hardly have been adopted. As it was, however, the tendency rendered such an act not very improbable, - certainly, not extraordinary, - while the previous character excluded the supposition of consummate depravity. It is well known that, in most of those cases where the first, and, for a time, the only symptom of insanity was some terrible act, there was the hereditary taint. This was the essential element in the present case; and it cannot be doubted that, if the experts had all placed the same stress upon it among the agencies that led to the criminal act, their opinions as to the true character of the case would have been more nearly alike. Forced, perhaps, by the exigencies of the occasion, they accepted an alternative from which they would have shrunk in a purely psychological inquiry. The question of sanity or insanity, however proper in the administration of the law, was, in a scientific point of view, little better than a verbal quibble. With as much propriety it might be asked whether a person with tubercles in his lungs is or is not in a consumption.

Under our view of the subject, the true character of the case appears divested, in a great degree, of the difficulties that encumber the professional opinions on both sides. This young man inherited a tendency to insanity, which, however, up to the event in question, had given little token of its existence. In the ordinary routine of life, where there was nothing to try his 
power of self-control, or disturb the current of his feelings, he performed his allotted part quietly and correctly, if not very energetically. But when the woman whom he ardently loved cast him off under false pretences, the evidence shows that he became greatly agitated; and under all the excitements of a long, private interview, reason was easily driven from her seat. Whether he was unconscious while inflicting the fatal wounds, as he said himself, is not quite certain, but there can be no doubt that his feelings were agitated beyond all power of restraint. No sooner was the deed accomplished, than the inward tumult subsided, consciousness returned, if it had ever been lost, and his usual condition was renewed. Of course, he could hardly help giving some account of the feelings and motives which led to the transaction, and here he betrayed that sort of moral obliquity, which, though not necessarily indicative of insanity, is frequently witnessed in abnormal conditions of the mind. The manner in which he undertook to explain and defend his conduct was such as, in the opinion of a distinguished ex. pert, no sane man would have adopted. His discourse evinced something more than bad logic and outrageous sentiment, in both of which it abounded. It was full of wild and extravagant notions which no man, fairly claiming to be sane, would have regarded as likely to obtain the slightest credence from any one less credulous than the simplest child. Even if we suppose that such had always been his way of thinking, it was, unquestionably, the result of his peculiar mental imperfection, rather than of mature, deliberate reasoning, or of vicious habits and training. Not unlikely he undertook to defend his act by arguments that he scarcely believed himself. Such a fact is not uncommon in the 
operations of the insane mind, when called upon to explain conduct to which it has been impelled by the force of disease, but which it knows to be wrong. Now, in all this there is nothing extraordinary or improbable. Admitting the presence of the hereditary tendency, it might have been expected that, under faroring circumstances, it would affect the mental movements and disturb the moral perceptions, to such a degree even that a most horrible act might seem to be a matter of right and duty. Nor is there anything in the history of the case incompatible with this explanation. Every trait in it might find a parallel in the conduct, conversation, or manners of the decidedly insane. The view here taken of Townley's case was fitly confirmed by his final act, which was to destroy his own life by leaping from one of the galleries of the prison to the floor below.

The records of my own observation would furnish cases similar in character, if not in their incidents, in which the act of violence was equally sudden and unexpected, the reason of the patient apparently just as sound, and his reputation equally free from reproach. Had the incidents been similar, experts would probably have differed as widely respecting their nature, and the public would have been as deeply indignant at any show of judicial mercy. It is because they are not extraordinary, and because great injustice may be committed, and the humanity and science of the age discredited by such mistakes respecting their true nature, that I have ventured on this discussion. 


\section{STATISTICS OF INSANITY.}

[Is no department of medical inquiry, probably, has there been manifested so little of the truly scientific spirit as in the statistics of insanity. The plainest rules of philosophical investigation have been disregarded, things have been associated having no necessary relation, and conclusions have been drawn that had but an indifferent foundation in facts. It certainly might have seemed, at first blush, as if the large opportunities for studying insanity afforded by the hospitals of our times would have made us acquainted with many things respecting its origin, propagation, duration, curability, \&c., that could well be expressed in statistical forms. That they have not been entirely fruitless in this respect, I am glad to admit; but the actual result can hardly be regarded as a large contribution to our knowledge. The failure sprung, no doubt, on the one hand, from a mistake as to the true function and limits of statistics, and, on the other, from erroneous opinions touching some of the manifestations of the discase. The first mistake consisted in ignoring the distinction between matters of fact and matters of opinion, and in deeming the one as proper a subject of statistical record as the other. In this way many things were numerically recorded that were rather the expression of the observer's private conclusions than of any definite phenomena having the same significance to everybody else. The proportion of cases at different periods of life ; the weight, height, and complexion of the patients; the number of farmers, carpenters, shoemakers among them; how many died and how many eloped, - matters like these may be expressed in a statistical shape, if it is thought desirable, without giving rise to any misapprehension of their meaning. But when we undertake to give a numerical value to such events as the causes of the disease, the date of its origin, the number of recoveries, \&c., we are dealing with the uncertain and indefinite, differ- 
ently interpreted by different persons. What we record on these points might greatly differ from the records of other observers, and thus it may be worse than useless as a matter of statistics. And this objection must lie against every incident the meaning of which can be open to doubt or diversity of opinion.

Statistics which are not really statistics, I have said, are worse than useless; and the reason is, that they beguile the student with a show of knowledge, and thus take away the main inducement to farther inquiry. Why should he look farther for truth when it already lies before him? Some of the prevalent errors respecting insanity and the insane are fairly attributable to these vicious statistics, for figures make a deeper impression on the mind than the most cogent arguments. During the three and twenty years that have elapsed since this paper was written, some of the objectionable features here mentioned have disappeared from the statisties of our hospitals. Evidence of improvement in this respect is particularly manifest in the Tables prepared by a committee of the Association of Superintendents of North American hospitals for the insane, and recommended for general adoption by that body at one of its recent meetings.]

FEw persons, I believe, who are practically acquainted with the subject, are quite satisfied with the present methods of reporting the results of management in hospitals for the insane, or are prepared to place entire confidence in the general conclusions to which they lead. Certainly the wish has often been expressed that greater uniformity were observed in these methods, and that certain conditions and events connected with the subject were more accurately defined. The evil in question has often been deplored by writers who have the strongest and most enlightened faith in the utility of this kind of statistics; and, until it is remedied, our most carefully elaborated conclusions can claim but little confidence, and we never can be sure, after all our pains, that we have made any positive advances in knowledge. General rules and principles that are fairly drawn from observations have always been regarded as preëminently 
safe, and this strictly inductive method of inquiry is now universally considered as the most effectual means of arriving at the truth. It would seem as if results like these could not be otherwise than correct, because they are but the general expression of the facts themselves. It is this very appearance of certainty which sometimes, as in the present case, blinds us to the actual fallacy; and we go on accumulating and hugging our treasures of knowledge, as we fancy them, until we find at last that we have been ingeniously deceiving ourselves with an empty show, while the substance has completely escaped us.

Statistics has become a favorite instrument for developing truth, and is now applied to branches of inquiry which, a few years since, were scarcely supposed to be within its reach. That it was capable of eliciting physical truth with an extent and accuracy then not thought of, might not have been a rild supposition; but no one dreamed of seeing it used to elucidate the principles that govern the social position and moral conduct of man, his motives, impulses, and propensities. It is important that an instrument of knowledge so widely and confidently used should be thoroughly understood; its powers being judiciously estimated, and its application regulated by a suitable regard to the conditions of the case. It is a simple thing, no doubt, to add and subtract and divide columns of figures which a patient industry alone was needed to collect; and, if statistics consisted only of these operations, it certainly would be a very easy affair. But statistics implies something more than a process in arithmetic. It is, or should be, a profound, philosophical analysis of materials carefully and copiously collected, and chosen with an enlightened confidence in their fitness for the purpose in question. 
The large comprehension, the elevated conceptions, the masterly power of mathematical analysis, were not more essential to Newton in unfolding the law of gravitation, than the acute discrimination of materials and the correct appreciation of their bearing upon the principle in riew were to Quetelet in developing the laws that regulate some important events of life and springs of human conduct. Such views, however, have not been prevalent; and hence has arisen the fact that, thus far, statistics, with all its show of accuracy, has been, comparatively speaking, singularly barren of results. It would be difficult to mention any great principle of physical or moral science that has been established chiefly by statistical inquiries. A volume would not hold the instances in which they hare failed of success, though undertaken with every promise thereof; but I will mention only one, of recent origin, and very well known.

The taking of the census in 1840 was deemed by our government a favorable opportunity for collecting a mass of useful information of a scientific, moral, social, and economical character. The preliminary steps were judiciously taken, the information sought for was highly desirable, and the result appeared in the shape of a portly folio volume. To a stranger it presented peculiar claims to confidence. It was projected by an enlightened government, supported by liberal appropriations, and received the approval of some distinguished names. If statistical inquiries were ever worth anything, they certainly seemed to be in this instance. To those who had a nearer view of the undertaking, it was seen to comprise a mass of heterogeneous details intrusted to a multitude of individuals few of whom could comprehend their nature, or had the requisite skill for assorting and 
classifying their materials, and printed with an unparalleled carelessness that increased tenfold the original blunders. And yet, with all its pretension, the United States Census for 1840 can be received as reliable authority for no single fact whatever.

It is a common saying that figures will not lie; but it is very certain that in the hands of the ignorant, the careless, the undiscriminating, they may become most potent instruments of falsehood. The historian, the chemist, the naturalist, all require unexceptionable anthority for the facts that claim their belief, and never hesitate to subject them to a rigid scrutiny. It is probably because statistical facts have met with too easy a faith, that conclusions drawn from them have so often been swept away by the subsequent progress of knowledge. To those accustomed to the close and careful examination of facts that characterizes other departments of natural science, it is inconceivable what slender materials have served as the foundation of very important deductions in this we are now considering. On the faith of the Census of 1840 , it was proclaimed to the world, with no ordinary emphasis, that the free colored population is more liable to insanity than the white; and the fact was exultingly held up by one of our most distinguished statesmen, as an argument in favor of slavery. The Census has gone to every great library in Europe, but without the exposure of its errors; and in many a future work, no doubt, will be found the record of this strange deduction. A few years since, the world was inclined to yield us the credit of extraordinary success in the cure of insanity, because in a certain institution in our country the number of recoveries in recent cases had amounted to $91 \frac{7}{8}$ per cent of the discharges. It was not made known that this result was founded 
on the experience of one year in twenty-three cases only.

The results of experience in hospitals for the insane have been annually published with some minuteness of detail, both because the community is desirous of seeing how far its institutions have met their destined purpose, and because their physicians are actuated by the laudable desire to exhibit the result of observations which their position has enabled them to make upon a much larger scale than they possibly could in a private capacity. All this is well, and I doubt not much valuable information has been elicited. I trust, however, I may be permitted to question, without giving offence, whether the amount of information is at all commensurate with the real labor involved, and the ostensible accuracy of the facts and deductions. This remarkable failure is deserving of the most serious consideration, in order that its causes may be ascertained and removed, and our future inquiries be prosecuted in a more profitable direction. In this stage of the discussion it will be sufficient to say, that, to make our statistics profitable, they should embrace such facts only as are intrinsically important, and free from all admixture with mere opinion. Bearing in mind these tests, we shall be better prepared to measure the real value of the statistics usually contained in the reports of our asylums. Of course the limits of a paper like this must confine our attention to the most prominent points.

No subject connected with insanity possesses so deep and general an interest as its curability, and this fact has lead to the universal practice among asylums of reporting the number of their recoveries. The result is supposed, by implication at least, to be a fair measure of the professional skill and other curative influences 
with which the disease has been combated, and to indicate, with more or less exactness, the general curability of the disease. The question then is, whether these inferences are fairly deducible from the premises. It is admitted that there are various circumstances affecting the results of every large establishment that have no necessary connection with them. To leave these entirely out of view would be taking the first step to unlimited error and confusion, while to estimate exactly their respective influence upon the results would be beyond the reach of human penetration. The manner in which they balance and counteract one another, so as to embarrass all our conclusions, will be sufficiently apparent in the course of this discussion.

The number of recoveries will be affected by the physical constitution of the patients. The more robust and vigorous they are, the more readily will they recover. In rural districts there is a higher condition of health than in the manufacturing and commercial; and this fact, so far as it goes, gives to the asylums of the former an advantage over those of the latter, in respect to the number of recoveries. Again, the comparative sparseness of the population in the former, and the greater difficulty of gaining access to the asylum, will delay the admission of many, and thus protract, if not altogether prevent, their recovery. The smaller pecuniary ability of people in the country as compared with those in the city will also lead to premature removals, and consequently, so far, to a smaller number of recoveries. On the other hand, asylums on our sea-board which receive large numbers of foreigners worn down by hardships and exposure, many of them sent from home, it may be, because of their liability to insanity, have, in this circumstance, a drarvback scarcely known to those of the 
ural districts. Circumstances like these - and the list might be greatly extended - cannot be expressed in any statistical form: they can only be stated in general terms, and we can obtain only a general impression of their influence upon the result. They do not affect the facts, but only prevent us from drawing certain conclusions which, at first sight, they might seem to warrant. There is a very serious objection, however, lying against the facts themselves.

Statistics can be properly applied only to incidents and events that have an objective existence, for such only are cogniizable to all men and admit of neither doubt nor mistake. Just so far as they have a subjective relation to the mind, - are merely matters of opinion, - to that degree they are incapable of being statistically expressed. Thus the event of recovery, limited solely to its objective character, only amounts to a certain degree of improvement. Whether the change is a real cure of disease, or a state where diseased manifestations are absent merely from want of a suitable opportunity for displaying them, or a temporary intermission of disease governed by that law of periodicity to which nervous affections are closely subjected, these are questions which every individual will answer by the aid of his own experience and judgment, and consequently with all that diversity which is utterly incompatible with statistical accuracy. The cases are not few which one man would pronounce to be recoveries, while another of less sanguine temper, or more knowledge of insanity, would regard them as merely improvements. I presume that, as a matter of fact, we are often in doubt respecting the condition of patients discharged from our care, and hesitate long before we decide under what head of our general results they shall be placed. 
And when we finally make up our mind, is it with that degree of confidence that would embolden us to deny that anybody else could possibly arrive at a different conclusion? What then becomes of the value of such a conclusion considered as a statistical fact?

It is obvious therefore that the question must first be answered, what degree of restoration can be rightfully called recovery. Of course every one answers it for himself as he best can, but statistical accuracy requires that all should answer it alike. It is one of the laws of nervous disease, that it may be suspended or checked for a period varying indefinitely in length, and then, after intervals measured by weeks, or months, or years, be renewed in all its original severity. The intervals may or may not recur with the utmost regularity. They may continue for many months, or appear to be merely a transition state marking the passage of the mind from one paroxysm to another. The restoration may be apparently perfect, or marked by many a trace of disease. Now in regard to extreme cases there will be no diversity of opinion. An interval in which the mind presents its normal condition, and which extends over a period of years, no one would hesitate to call a recovery, while only a week or two of calm would be universally regarded as not entitled to the name. But it is clear that some conventional rule is necessary for determining, among the various intermediate forms and degrees of restoration, what should be reported as recoveries. Now admitting that such a rule might be made, for I would not prescribe limits to human ingenuity and acuteness, there is a more serious difficulty remaining, - that of recognizing the condition or event to which the rule is to be applied. Here would arise a diversity of views springing from diversity of temperament, education, and experience; and 
no one could be sure that his decision in any particular case is just what others would adopt were it submitted to them. For instance, we might agree to call a lucid interval which continues six months or upward a recovery; but as to the actual fact, whether a lucid interval has really occurred, how are we to prevent conflicting opinions? The truth is, however, that in the present statistics of recovery no conventional rule whatever has been followed. Every individual has decided what should and what should not be called recoveries, just as it seemed good in his own sight.

I do not see how the usual answer to these objections, that they apply to but a very small proportion of cases, can satisfy anyone having a practical acquaintance with the subject. How can we deny the fact, that, of the patients discharged from our hospitals, there is always a considerable number whose proper place in our annual summary of results is a matter of much doubt. It is not one of those trifling fractions that can have no perceptible effect, but large enough to destroy that precision and certainty which we expect in statistical reports.

In order that the proportion of recoveries may better represent the relative success of different institutions, it has been a very common practice to divide cases into two classes, the old and recent; it being implied that the curability of the disease is chiefly determined by its duration before admission. Certainly this distinction would have the effect in question, were it practicable; but no one, I presume, would deny that in a large number of cases we are unable to decide satisfactorily to ourselves whether the disease has or has not commenced within the period allotted to recent cases. The earliest aberrations of the disordered mind differ so little from its ordinary movements, that they are readily confounded by 
the careless or unskilful observer. And even when the attention is awakened and apprehensions excited, some psychological knowledge is required to prevent one from mistaking morbid for healthy manifestations. Of the persons on whom we have to depend for all our information respecting the origin of the disease in the cases that come under our charge, very few possess this knowledge, or have observed the cases very closely. To regard the narratives we usually receive with our patients as sufficient authority for a scientific fact, would almost indicate insanity in ourselves. Not that they are invariably false and unreliable, but that we are generally without the means of knowing when they are and when they are not so. We all know, undoubtedly, how seldom the account we first receive of a patient is entirely confirmed by those we subsequently obtain, and how often, in consequence, we are obliged to modify our first decision. But, even with the completest history of the case, it is not always easy to say when the disease actually began. For months or even years before the first decided and obvious manifestations of disease, the patient may lave evinced something unusual in his conduct or conversation, although engaged in his customary duties, and by the world at large regarded as in the full possession of his reason. In some cases the morbid peculiarities may be sufficiently developed to attract the attention of the world; but, not interfering with the performance of the ordinary duties of life, they are looked upon as a part of the natural character, and take the name of insanity only when accompanied by an extra degree of excitement and violence. In cases like these, who will take upon himself to indicate the precise point when disease began? Who will presume to enter that debatable land which lies 
between the realms of eccentricity and insanity, and assign to each its respective share of the peculiar manifestations?

The large class of periodical and paroxysmal cases present insuperable difficulties to every attempt to bring them under any general rule. The question of their origin is complicated with that of their recovery, and we are under the same kind of embarrassment in deciding upon the former that we experience with regard to the latter. If we are to regard every fresh attack that has been preceded by a distinctly marked lucid interval of considerable duration, as a recent case, can we adopt any rule that will prevent us from bringing within the same category those cases in which the interval is scarcely more than a brief remission of the disease? A single instance will be sufficient to illustrate the diffculty. A person is subject to paroxysms of high excitement when he is destitute of all self-control, and for the sake of decency and safety must be kept in close confinement. In this condition he is placed in a hospital where the excitement passes off, and he is discharged. He returns home, engages in his customary pursuits, and, for all practical purposes certainly, appears as sound as ever. In the course of a few weeks or months, the excitement returns. Again he is placed in a hospital, again he becomes calm and lucid, and again is allowed to go home. Are we prepared to say that every such admission of this person is a recent case, and every discharge a recovery? If, on the other hand, such cases are to be regarded as old, what shall we say of those in which the lucid interval continues for years? True, every chief of a hospital may have a rule of his own; but the consequence would be that we should have as many different rules and as many results as there are 
hospitals. And even admitting that a general rule were formed and agreed upon, that a certain number of weeks or months should mark the distinction between a mere lucid interval and a perfect recovery, yet no one with any practical acquaintance with the subject can imagine that the application of it would always be easy and uniform. During the alleged interval, is the mind really clear and unclouded by disease, or are its obscurations less dark only because the absence of excitement leads the patient to withdraw himself from the common notice, and refrain from obtruding his fancies upon others? Is the interval itself, whether clear or otherwise, so well defined that it can be bounded by days or weeks? These questions must be often asked. Does any one believe they would receive a uniform answer?

Dr. Thurnam, the Superintendent of the Retreat at York, whose faith in the value of the hospital statistics of insanity is unshaken by such objections, thinks that no practical difficulty will be experienced in determining the date of the disorder, "if it be understood that its origin should be dated from the period when selfcontrol was first decidedly lost, and when overt acts of insanity were for the first time actually manifested; and that it should not include the time during which, from the $a$ posteriori history, the existence of a latent state of mental disorder, as indicated by more or less of peculiarity, may be inferred." 1 In the spirit of this remark, he approves of the practice which has always prevailed in the institution with which he is connected, of subdividing their recent cases into two classes, one containing such as have been disordered according to the above rule three months or less, and the other such as have

1 Observations and Essays on the Statistics of Insanity. p. 52. 
been disordered not less than three nor more than twelve months. If Dr. Thurnam experiences no practical difficulty in applying his rule, I can only admire a sagacity which I cannot pretend to share. In a treatise characterized by such fulness of detail and acuteness of observation, it would have been gratifying to find how periodical cases are disposed of under the rule, because they peculiarly embarrass this question of recentness.

Still stronger objections may be urged against the division of cases into curable and incurable, because, when not determined by the duration of the disorder, it is chiefly by considerations that are purely matters of opinion.

The usual method of comparing the number of recoveries with that of the admissions or discharges presents a very unreliable indication of the curability of insanity, or even of the relative success of different establishments. When we consider how large a portion of our discharges originate in the impatience, or poverty, or nameless caprice of friends, or any other cause than the admitted incurability of the disease, it must be obvious that the number of recoveries can have no necessary relation to that of the discharges, nor to that of the admissions, so long as the latter are consequent upon the discharges. What the number of recoveries does indicate very strongly is the amount of perseverance and pecuniary ability exhibited by the friends and guardians of the patients; and any degree of merit which may accrue from the number of recoveries must be shared by the institution with the community itself.

For the same reason the proportion of recoveries reported by our hospitals cannot be regarded as a satisfactory test of the curability of insanity. Every case submitted to the treatment of an asylum may be consid- 
ered in the light of an experiment upon the curability of the disease. If removed before the experiment has been fairly tried, the result proves nothing. How many of these abortive experiments are annually tried in our hospitals, we all know to our sorrow. If, according to the opinion of Esquirol, in which he is supported by Mr. Samuel Tuke, who had peculiar facilities for forming an opinion on this point, the average duration of an attack of insanity is one year, it follows that in a certain number of cases it must exceed a year. Esquirol states that of the twelve hundred and thirty-three recoveries that occurred in a certain number of cases submitted to treatment, more than half of them were subsequent to the first year. If any confidence can be placed in this result as the expression of a general truth, it follows that any patient, not affected with a bodily disease, who is removed after only a year's trial of hospital treatment, cannot be considered as having had more than half a trial thereof. Without inquiring how many of the recent cases discharged uncured are thus prematurely removed, there are enough, we all know, to vitiate any result afforded by hospital statistics touching the curability of insanity. One step towards certainty would be taken, if it were always shown how long the disease has existed in this class of cases, and how long they had been under treatment; in other words, how many had, and how many had not, passed beyond the reach of those restorative influences which nature or art may be capable of exerting. I am not aware of a single instance of such information having been given.

If these objections to the present method of determining the results of hospital treatment have any validity, we should expect to find them varying from one another to a degree that cannot be explained by any of the ordi- 
nary causes of diversity. That such is actually the case, I think cannot be fairly denied. I cannot enter into a detailed examination of these results, but a glance at a few of them will answer our purpose. In Dr. Thurnam's book is a table showing the proportion of recoveries to admissions in cases of less than twelve months' duration in eleven different establishments, and they range from about 49 to 82 in the 100 . The causes of this diversity may be obvious enough in some instances, but very far from it in others. How can we account for the fact that in the State Lunatic Hospital at Worcester the recoveries in the above-named class of cases have reached to nearly $8: 3$ per cent, while in the Retreat at York, England, they fall short of 62 ? $^{1}$

Differences equally great and equally unaccountable might be adduced without number, but this is sufficient for the purpose of illustration. Even if they could be satisfactorily explained, if we could be made quite sure why in one institution the proportion of recoveries is ten or twenty per cent greater than in another, this very result would establish the existence of modifying circumstances that would deprive our statistics of every claim to accuracy. But, whether explained or not, I see not how any candid mind can help drawing from them the conclusion, that the curability of insanity is as far from being settled as that of many other diseases that have been scarcely subjected to statistical inquiries.

The number of deaths always appears in the statistics of a hospital for the insane. Over and above the simple

1 It is not improbable that Dr. Thurnam took his figures relating to the Worcester Hospital from its annual reports, without noticing that the recoveries are compared with the discharges. On comparing the recoveries of recent cases with the admissions during the period in question, I find that the former is about 78 per cent of the latter. 
fact of showing what has become of the patients, it is supposed to have an important bearing on the curability of insanity and the relative curative success of different institutions. As death is a matter of fact and not of opinion, it is free from one of the objections that lie against recovery as an object of statistical inquiry; and this seems to be its only advantage. When we endeavor to estimate the value of the relative number of deaths, as an indication of the mortality of the disease, we are embarrassed, as we were in regard to recoveries, with the very large proportion of cases annually discharged from our hospitals neither recovered nor dead. They cannot be left out of the account, and yet they prove nothing whatever as to the issue of the disease. The only perfect experiment on this point would be to trace a considerable number of cases from the commencement of the attack to its termination in recovery or death. This would indicate precisely the numerical relation of these two events. To show the proportion of deaths to the admissions or discharges, is to indicate nothing in relation to insanity, beyond the two naked facts, that a certain number entered or left the institution, and a certain number died. The absurdity of connecting together such incongruous facts as the deaths of certain persons with the casual residence of certain others in the same place is strongly illustrated by the practical result. At the Salpêtrière, for a certain term of years, the deaths were equal to twenty-six per cent of the admissions, while in many American institutions the proportion, up to the last year, has been between eight and nine per cent. Are we to infer from this fact, that insanity is three times as fatal at Paris as in America, or that the physicians of the latter establishments have been three times as successful as those of the former, 
in rescuing their patients from the jaws of the fell destroyer? If the facts will bear neither of these inferences, what are they good for?

Mr. Tuke, in his admirable introduction to Jacobi's work on the construction of insane hospitals, very properly proposed to estimate the mortality of these institutions like that of any other community; that is, by comparing the number of deaths with that of the average number of inmates. The event of death is thus regarded in the light of an incident natural to all mankind, rather than as the termination of a special disease, and therefore not so much indicative of the fatality of insanity as of the hygienic merits of different establishments. Even considered in this latter point of view, great caution is necessary in making the number of deaths the basis of any general conclusions. Local circumstances might give rise to considerable differences in the rate of mortality, independent of the means and appliances devoted to the cure of the disease. The remarks already made in reference to such influences upon the number of recoveries are equally applicable, mutatis mutandis, to that of deaths, and need not be repeated.

It may be very fairly questioned, too, whether the number of deaths indicates the mortality of insanity, because many of them are caused by diseases that have only an accidental connection with it. The tables usually printed in hospital reports, of the causes of death in the cases that have proved fatal, show - whether correctly or not is immaterial to the present point - that insanity itself destroys but few, if any, of its subjects. It certainly is not very clear how a death produced by diarrhcea, or apoplexy, can have any bearing upon the mortality of another and very different disease. Upon the only ques- 
tion that concerns us in this connection, viz., in what proportion of cases insanity proves fatal, the reports of hospitals fail to throw much light.

In American hospitals it is the prevailing practice to state the causes of death in the several cases in which it has occurred. What object is supposed to be obtained thereby has never, to my knowledge, been very clearly explained. No one, I apprehend, will venture to say that much light has been thrown on the pathological phenomena of insanity by these tables of the causes of death. 'The vague, loose, and indefinite phraseology, the heterogeneous mixture of popular and technical distinctions, of symptoms and specific forms of disease, by all which traits they are too often disfigured, might be pardoned in the report of a superintendent of burialgrounds, but in a document emanating from a scientific man for scientific purposes they excite a feeling of amazement, if not contempt. If these tables are to be considered as a mature and deliberate expression of opinion, and not merely as a matter of form drawn up in compliance with some antiquated rule, they indicate a pathology that has not been enlightened by dissection, and ideas of causation which the irreverent world might say are puerile.

The leading fact implied by these tables is, that the insane mostly, if not wholly, are finally carried off by other diseases than insanity itself. I do not recollect to have ever seen insanity or mania set down among the causes of death, although one may find almost every other form of disease. Now is the fact here implied true? Are we prepared to promulgate to the world, as an established thing, that nobody dies of insanity? On the contrary, are we not in the habit, in other connections, of speaking of insanity as a serious disease, 
and one that is more or less fatal? True, an insane person may be attacked by dysentery, or small-pox, and succumb to its violence, and his death would be as properly attributed to such attack as if he had never been insane. The presence of one disease does not necessarily preclude the occurrence of another; and, if death follows the supervention of the latter, their respective agency in producing this result is a question to be settled. In the larger portion of cases we should hesitate to attribute it solely to one of them, and yet this is habitually done in regard to the deaths of the insane. I am aware that in our hospital reports we always find some deaths attributed to "disease of the brain," some to "inflammation of the brain," and others to "acute cerebral disease," by all which terms it is probably meant, that the patients sunk under the violence of the maniacal attack. Then why not say so? As these terms are often used to designate other affections than proper insanity, I see no propriety in applying them to a form of disease characterized by very different conditions, especially as the term acute mania and its congeners have long been sanctioned by nosologists, and convey an exact, well-understood idea. If there were any pretension to consistency in the matter, it might be asked why, in the same table, some deaths are attributed to general paralysis, which is a specific form of mental disease, and not to disease of the brain, \&c., which may be as properly applied to it as to mania.

These tables indicate great confusion of ideas, evidently arising from the want of well settled, well understood views of pathology. Some of the diseases set down in them as causes of death were undoubtedly superinduced upon the original disease, with which they had no necessary connection, and produced death solely 
by their own means; while many others are just as clearly the natural and ordinary results or accompaniments of insanity, and only mark the last stage of its progress toward the final dissolution of its victim. Of the latter none makes so much of a figure in our hospital reports as marasmus. In acute mania and the latter stages of chronic mania, nothing is more common than more or less emaciation of the body ; and it probably has the same pathological relation to the original disease that it has to phthisis or fever when it accompanies them. It is one link in the chain of morbid processes which originate in the brain, and to call it the cause of death would be like saying that the victim of consumption dies, not by consumption, but by diarrhea which occurred a few days before death. Exhuustion, too, is a prolific cause of death in our hospital reports. To call exhaustion a disease, when, in so far as its phenomena meet our observation, it is merely a loss of muscular power incident upon a specific disease, is either to use language in a sense very different from its ordinary acceptation, or to thoroughly confound causes and effects with an utter disregard of every principle of sound pathology. All acute diseases of any duration induce an asthenic condition, but we are not in the habit of saying that patients die for lack of strength any more than that they die for want of breath. Exhaustion is, probably, a convertible term with those above-mentioned, " acute cerebral disease," "inflammation of the brain," \&c., and indicates the same pathological condition. The term acute mania expresses that condition as definitely as possible; and why not use it, instead of resorting to a kind of innuendo which is misplaced here, however excusable it might have been in the worthy Irishman who, in speaking of a brother that came to a sudden 
end in an elevated position, softened down the stern catastrophe, by saying that he died of a great rush of blood to the head? In this connection it might also be asked whether such terms as dysenteric ferer, gastric fever, congestive fever, have a signification sufficiently limited and precise for statistical purposes. If not, then what becomes of the utility of such statistics?

Perhaps no circumstance of insanity has excited so much speculation, both in the profession and out of it, as its causes; and in every hospital report a prominent place is allotted to thern. Inquiries that liave for their object to cast some light on the origin of such an appalling malady yield to no other in point of interest and importance. It would not be the first time, however, if the very importance of the subject have raised a determination to arrive at results of some kind, but not a corresponding anxiety for their soundness. It would not be the first time, if an imposing array of names and phrases were mistaken by their authors for substantial contributions to knowledge ; nor would it be strange if others were led to participate in the pleasing delusion. I fear that the careful inquirer will seldom rise from the examination of these tables, with the conviction that they have thrown much light on the origin of insanity. Perhaps no point within the range of our professional studies demands a clearer insight into the laws both of psychology and pathology than the successful elucidation of the causes which lead the mind astray from the line of healthy action. Here, if anywhere, it will appear whether our studies have led us to a higher philosophy than that which consists in repeating catch-words and echoing the popular voice. Nowhere else in our department of the healing art is a clear and able head more needed to overthrow the masses of error and prejudice 
that have been accumulating for ages, and, guided by the light of a strictly inductive philosophy, to place us in the path of successful investigation.

Without pressing the radical objection that might be urged against the attempts that appear in our hospital reports, to penetrate into the causes of insanity, I will only advert to a few of their defects which appear on the surface, and equally impair their statistical valne. Their total want of precision and uniformity in the use of language, now justly deemed essential in any scientific inquiry really worthy of the name, is not one of the least serious of these defects. The most remarkable step ever made in the pursuit of natural science - one which marks the transition from idle and anile speculation on the one hand, to sure and valuable acquisitions on the other - was the adoption of a language the terms of which are so precise and well defined as to convey the same idea to every mind, in every time and every land. In the department of inquiry we are now considering, as well as every other belonging to natural science, such a nomenclature is equally essential to progress. To suppose it may be advanced by the use of ordinary forms of speech, would be no wiser than to attempt to gain the most perfect mastery over the elements by such means as were furnished by the primitive inventions of Watt and Fulton. How little such views have entered into the tables of causes which appear in our hospital reports, will sufficiently appear from a few illustrations. In one and the same table are cases charged to " domestic trouble," " bad conduct of children," "Jealousy," "infidelity of wife," "ill-treatment of parents" and "abuse of husband." Surely, it would not be easy to find stronger manifestations of "domestic trouble" than are indicated by all these events; and we are 
therefore obliged to conclude that the term "domestic trouble," which appears to have given rise to so much insanity, is used in a sense very different from the ordinary, but one to which we possess no clew. In another table a number of cases are charged to the account of "disappointment," but whether they were disappointed in love or politics, in the struggle for honor or wealth, does not appear. Another gentleman is more precise, and subdivides the general affection into "disappointed love " and "disappointed ambition." Another uses all three terms, and cases are referred by him respectively to "disappointment," "disappointed affection," and "disappointed ambition ;" and another extends the list of disappointments by adding " disappointed expectation." What ideas are we to attach, also, to such vague phrases as "mental excitement," "anxiety," "exposure," "fright," and a host of others too numerous to mention?

Can we be quite sure, too, that the same or similar terms used to designate the causes of insanity mean precisely the same thing in the reports of different institutions? "Ill health" seems to be a prolific source of insanity. If this term were designed to embrace all the physical derangements that often precede the outbreak of insanity, and are supposed to be its cause, then it would convey some definite idea to the mind. In some tables, perhaps, this may be its meaning; but in others we find it side by side with "fever," "nervous debility," "dyspepsia," "disease of the liver," "gont," "rheumatism," "phthisis," "menorrhagia," "amenorrhoea," and consequently must indicate some condition of the system not embraced in any of these disorders. But what is it? The reporter may understand it perfectly well; but how are others to know his meaning, without a preliminary 
dissertation on the use of terms, which, however it might help the reader of a work on logic or philosophy, would be of little service in a statistical undertaking. Many cases are also referred to the puerperal condition. That this is often the efficient cause of insanity, I presume no one is disposed to doubt; but, until this condition is more accurately defined, this general truth can have but little statistical value. What period after parturition does it cover? the few weeks immediately following, or the whole period of lactation? Is every case which happens within the allotted period, be it long or short, to be referred to the same origin? and if not, by what rule are we to be governed in making the distinction? Until these points are settled, the results of different observers will admit of no comparison, and consequently can form the ground of no definite conclusions. The same objection may be urged against some other items usually found in the tables of causes. They are so vague that we never can know the precise meaning attached to them by different observers.

It is very obvious too that these tables often reflect the peculiar views of their respective framers, so easy is it to find whatever we think we ought to find. One gentleman, for instance, attributes one-tenth of his cases to intemperance, while another is not quite satisfied that he has had a single case arising from that cause. One who, for some reason or other, has been strongly impressed by the influence exerted on the female brain by those physiological changes called the "turn of life," regards them as a fruitful source of mental disease; and in his table of causes the "climacteric period" is made responsible for a very high proportion. One attributes five per cent of his cases to masturbation, while another whose experience is confined to similar cases sets 
down but half of one per cent to this practice. One expresses the opinion that tobacco gives rise to much insanity, but provides it with no place in his table of causes. Another delivers the same opinion touching the want of sleep, but also fails to place it among the causes.

There is also much reason to believe that many of the emotions and incidents that are set down as causes of insanity, such as "fear of poverty," "religious doubts," " anxiety," \&c., would often be more justly regarded as its effects. They are the first symptoms that arrest the attention; and, by means of that common disposition to confound the post hoc with the propter hoc, they are placed in the relation of cause to the subsequent aberrations. In a multitude of cases it must be difficult, with the slender means in our possession, to decide this point with the slightest approach to certainty.

Were the objections here urged against these tables of causes devoid of any weight whatever, there is another undeniable and unremovable, that strikes at the very root of their supposed value. The objection alleged against the event of recovery as an object of statistical record - that it is more a matter of opinion than of positive fact - lies equally against the causes of insanity. But there is this additional one, that they show not even the opinions of the observer, but of other unskilful and irresponsible persons. Every thing that we learn on this subject is derived from the friends of the patients, and even if they abstain - as they generally do not-from offering their own particular views, yet the facts are so related as to suggest certain inferences respecting the cause of the disorder. How crude and puerile the views of such persons often are, how partial and inaccurate their narratives of facts, are well 
enough known to us all. It might seem, at first thought, that a certain series of occurrences, which required only a little activity of attention to perceive, might be clearly and completely related by any tolerably intelligent person; but we know by the most abundant experience that few are able to describe phenomena that lie without the range of their ordinary thoughts and pursuits. To see events is one thing: to describe them is another and a very different thing. For the former a man has only to keep his eyes open; the latter requires an orderly arrangement of the thoughts, a skilful use of language, and some previous acquaintance with the department of knowledge to which the phenomena in question belong. Of the persons who bring patients to our hospitals, how seldom does one possess these qualifications; and yet their accounts are made the basis of all our conclusions respecting the causes of the disease. The most trustworthy lay particular stress on such events and incidents as, in their opinion, were connected with the production of the disease; their views, of course, being governed by their own habits of thinking and feeling. A hypothetical case will better convey my meaning. A lady about the "turn of life" becomes insane and is sent to an asylum. She has been addicted to potations somewhat stronger than water, and moreover has borne an active lart in the religious movements of the day. A friend who puts his frith in total abstinence does not hesitate to attribute the disorder to her indulgence in drink, and pays but little regard to any other feature in the case. Another of a cold or sceptical turn of mind, who has been strongly impressed with the evils of religious fanaticism, dwells chiefly on her disposition to plunge into the excitement of religious gatherings, and here finds the origin of her disorder. Her physi- 
cian, who is accustomed to meet with the derangements incident to that great physiological change in the female system, thinks only of this fact. Now, with all our caution, it cannot be doubted that we should be very liable to attribute this lady's insanity either to intemperance, religious excitement, or the climacteric period, according to the friend from whom we happened to obtain her history. I do not mean, of course, that we are obliged to coincide with the patient's friends on this point, for we may agree with them as much or as little as we please, but that we are obliged to form our opinions on such data only as they choose to present. No one of us certainly would believe that a patient had been bewitched because his friends think so; but does it show much deeper wisdom to make the narratives of such persons the ground of any opinions whatever?

There is a show of precision in the usual tables which, I apprehend, is not to be found in nature. If we insist upun evidence really deserving the name, the cases will prove exceedingly few, that can be satisfactorily traced to any particular, single cause. The history of cases generally discloses a series of incidents, each of which appears to have had some share in producing the disease. It is impossible to designate any one of them as the efficient cause, or to say that any particular one might have been absent without affecting the result. I cannot see therefore what benefit can be derived from affecting a precision which, instead of casting any light upon the origin of the disease, only conveys to the unprofessional inquirer wrong impressions respecting a matter of fact.

It has become a frequent though not a general practice, in reports of insane hospitals, to classify the different forms which the disease has presented, for the purpose, I presume, of showing their comparative curability. 
Every superintendent adopts that classification which seems good in his own eyes, and consequently no two of them are alike. For instance, in the reports of one institution the disorder is divided into eight classes; in another, it is divided into five; in another, twelve; in another, sixteen. If there were any foundation in nature for all or any of these classes, then their respective curability would be an interesting object of inquiry. But however convenient such distinctions may be sometimes, for indicating the general features of the case, they are not sufficiently well defined and understood to form the basis of a scientific classification. At any rate, until some particular system is generally adopted with its classes and orders accurately defined and distinguished, I do not see how we can be benefited by considering the disease in so many subdivided forms. No one, I apprehend, can be sure that by monomania, melancholia, moral insanity, and many other terms that are used to designate different forms of mental derangement, he understands precisely what his neighbor does, and that there would be no discrepancy between them in referring the same cases to their respective classes. Indeed it could hardly be otherwise; for these terms have never been clearly defined by any well-recognized authority, and consequently, without some preliminary explanations, can convey no accurate ideas to others.

Even without these objections, there is another equally fatal to such attempts at classification, and that is the fact that in a large proportion of cases the form of the disease changes in the course of its progress. The same case, at different periods, may present the aspect of melancholia, monomania, and dementia. To which of them is it to be referred?

I must terminate this examination of hospital statis- 
tics without suggesting any better methods of reporting our results. In so doing, I shall, no doubt, subject myselp to the usual reproach cast upon reformers, of making war upon a fancied evil, without offering any thing better in its place. This reproach I shall not trouble myself to repel, content if I have succeeded in placing in a stronger light difficulties and defects that have been more or less apparent to us all.

Before leaving the subject, however, it may be well to notice the usual reply to objections against the value of the kind of statistics we have been considering. The reply is, that we do not pretend to obtain the exact truth, but only an approximation to it; and it is implied by the use of this term that the approach is sufficiently near for any practical purpose. This is one of those fallacies which Lord Bacon has classed among the idols of the forum, whereby words and phrases that have a technical meaning are transferred to some other branch of inquiry, carrying with them by implication all their original minuteness and accuracy of signification. In pure mathematics we are seldom able to arrive at the exact truth. We can only draw near, or approximate to it, as it is called; but so close may this approach be made, that the deficiency occasions no practical inconvenience. The term is applier exclusively, by prescriptive usage, to that kind of inaccuracy which arises from the imperfections of mathematical analysis, never to such as arises from error of the senses or of instruments. We can never obtain the precise number which multiplied by itself will produce 50 , but we can arrive as near to it as we please. On the other hand, in natural history, for instance, living beings are arranged into groups that are distinguished by certain characters, but not so exactly as to prevent all embarrassment in referring indi- 
viduals to their respective groups. In the former illustration, the deficiency can be bounded by appreciable limits: it can scarcely be discerned without the magnifying aid of numbers, and presents no obstacle to the attainment of any legitimate object. In the latter, we can have but an indefinite notion of its extent. It is regarded as a serious drawback on the certainty of our results, and the worth and dignity of the science are deeply concerned in diminishing the evil. It is obvious, therefore, that we have no right to call our statistical shortcomings approximations to the truth, inasmuch as they arise from our own imperfections and errors. But without insisting on the prescriptive use of the term, I might ask by what possible latitude of meaning it can be applied to the statistical results of our hospitals for the insane. Is any one prepared to say, for instance, that they have shown the curability of recent cases with a degree of exactness that can be called, in any sense of the term, an approximation to the truth? Some would fix it at 90 per cent; others at 70 ; while an earnest advocate might be found for every intermediate number. And just so with the mortality of recent cases. We are equally far from any result that can challenge general confidence. Is it 5 per cent, or 10 , or 15 , or 20? Good authority might be adduced for any of these estimates. Surely we cannot have the boldness to call results like these approximations to the truth? That they form very suitable data for an opinion, I admit; but a candid consideration of the subject must convince us, that such an opinion is no more likely to be exact than a shrewd conjecture founded upon one's general impressions of his own experience. 


\section{MORAL INSANITY.}

[Is the following pages, the writer has endeavored to meet the current objections to the doctrine of moral insanity. Like most subjects on which opinions are apt to be formed under the pressure of strong feeling, it has been greatly misapprehended, and its advocates subjected to derision and obloquy. Of these objections, one of the most prominent is that it conflicts with the most approved theories of the mental constitution, in which the essential unity of the mind is recognized. That this objection should have found its strongest support among a people who have derived their metaphysics from such writers as Reid and Stewart, and consequently are well prepared, by a distinct recognition of the sentiments and emotions as active powers coexistent with the pure reason, to admit the possibility of their being controlled or modified by disease, is somewhat surprising. A priori, it would be difficult, certainly, to conceive why a sentiment or propensity is not as likely to be thus affected as the intellect. The rightful influence of the psychological teaching most in vogue among us has been counteracted, very probably, more by the misplaced use of a homely phrase than by any profound objection. To the common understanding, it is no better than a contradiction in terms to say that a man has lost his reason - the old English equivalent of insanity - while his reason is confessedly untouched. This play upon words has stood, unquestionably, in the place of facts and arguments, and still serves the opponents of moral insanity, as their great piece of resistance.

By some, the doctrine that the sentiments and propensities may be separately disordered is supposed to depend on the phrenological division of the brain into independent organs, and consequently can receive no countenance from the disbelievers of that system. If this were the only ground of our faith, the objection would be conclusive; but as we rely solely on the results of observation, we need not 
appeal to the anatomical arrangements of the brain. And yet they furnish a strong argument in favor of this view. Whether the brain consists of a congeries of organs, according to phrenology, or not, we know that it is necessary to the manifestation of the mental phenomena. As this is admitted by the firmest believer in the unity of the mind, he has only to extend very slightly the sweep of the proposition, to conclude that a diversity of organic structure may be necessary to a diversity of manifestation; or, in other words, that different portions of the brain may be necessary to the manifestation of different faculties or qualities of mind.

The other objection oftenest urged against the doctrine of moral insanity is the difficulty of distinguishing it from moral depravity, in consequence of which the boundary between vice and disease is liable to be effaced. This difficulty cannot be ignored; but, if it is not always overeome in practice, the fact may usually be attributed rather to the lack of suitable opportunities of investigation than to the obscurity of the subject itself. It is certainly not a very philosophical proceeding to ignore a fact merely because it is liable to be mistaken for some other fact. In moral insanity, sufficient opportunity only is needed to discover the element of derangement, disorder, change; while simple depravity seldom fails to make itself known by its ordinary characters. If men are sometimes unable or unwilling to see the difference, and thus mistake the former for the latter, it is unfortunate for them, no doubt, but the fact cannot weaken the doctrine of moral insanity.]

INSANITY, in the popular apprehension, is comprised under two different forms: one of them characterized by incoherence, noise, violence, or what is denominated raving; the other, by delusions more or less circumscribed, accompanied with tranquillity and some degree of reason. Until within a period comparatively recent, no other form of insanity was clearly recognized, even by medical men; every other mental disorder not obviously embraced in one or the other of these being regarded, perhaps, as hypochondria, hysteria, eccentricity, or malice prepense, - any thing, in short, rather than proper insanity. In the progress of science, the 
effect of which always is to reveal analogies and distinctions where none were supposed to exist, it began to be suspected that, besides the mental affections referable to the two general forms above mentioned, there are others dependent on the same essential conditions, and therefore to be regarded as manifestations of genuine insanity. Soon after the disease began to be studied by the methods and in the spirit of modern science, the fact was observed that many of the inmates of hospitals for the insane exhibit no obvious intellectual aberration or impairment. Pinel, who entered upon his labors in this department of the healing art with the current notions of the time, was much surprised, he says, to find many patients in the Bicêtre who presented no lesion of the understanding, but seemed to be under the dominion of an instinct of fury, as if the affective faculties were alone disordered. Farther observations by others once put on the track of discovery made known the existence of still other forms of moral or affective disorder unconnected with lesion of the understanding; and thus at last it has become the prevailing belief, among men of distinguished name in this department of medical science, that the moral faculties may be deranged while the intellectual remain apparently in their normal condition. Of late years a dissentient voice has occasionally been heard from the bench, the bar, the medical profession at large, and even from those who may claim some special knowledge of insanity and the insane. In regard to what might seem to be a plain statement of fact, easily proved or disproved by actual observation, it is a little surprising that there should be any room for difference of opinion among men who have had abundant opportunities for observing the disease. Such, however, is the case. Some of those most capable, 
it might be supposed, of appreciating the labors of Pinel, Esquirol, Marc, Georget, Combe, Conolly, Prichard, Winslow, Bucknill, and Guislain, do not hesitate to hold up these men as believers in a doctrine destitute of foundation and dangerous to society.

I propose now to examine, with some particularity, the principal objections against the doctrine of moral insanity, and among them some that derive their importance more from the position of those who offer them than from any foundation they may have in actual fact.

That an abnormal condition of the moral powers is a frequent manifestation of insanity, is now one of those well-settled facts that nobody thinks of questioning. It may be a simple perversion of some sentiment or propensity, or a morbid irritability of the affective powers, under certain causes of excitement. It may be a loss of those fine sensibilities which make the family relations a source of active interest and self-sacrifice, or it may be a feeling of hatred and hostility as bitter as it is unfounded. It may consist of some moral obliquity which is limited to a narrow range of persons or things, or it may produce a complete inversion of all the ordinary relations of good and evil. It may be hardly discernible under the greater prominence of the intellectual disorder, or it may be the most conspicuous element of the mental disturbance.

Thus far there is no diversity of opinion. So much may be considered as settled. We advance one step farther, and affirm that, for any thing that can be discovered to the contrary, the moral disorder may sometimes exist unaccompanied by intellectual disorder; and in proof thereof we produce a multitude of cases exhibiting this condition. Here our opponents join issue with us, and endeavor to maintain their position, not by means 
of cases, of course, - for those could hardly prove a negative, - but by metaphysical arguments, by objections to the fidelity of the observations, by presenting startling consequences, and too often for the credit of their cause by sneers and gibes. We are called visionary and crotchety, and the prejudices of all those worthy people who cling to the past solely because it is old are invoked against us for wishing to pull down all the time-honored barriers against crime and immorality.

In the first place, supposing the intellect to remain unimpaired, it is declared by our opponents that the mental obliquities which are attributed to insanity may be controlled, and therefore that the individual can claim no exemption from the ordinary measure of responsibil. ity for his acts. This assertion, - and it is nothing but assertion, - it will be observed, is a sort of begging of the question; and therefore it will be sufficient to reaffirm the position we hold on this point. So long as the moral sentiments remain in their normal condition, the power to control their manifestations is fully admitted. When, however, they become diseased, the normal relation between them and the intellect is destroyed, and the latter is unable to perform its rightful office. Its own power is not diminished, but that of the moral sentiments is inordinately increased by the intrusion of a foreign element. It is a matter of relative, not absolute, power; and it is immaterial whether the derangement of the ordinary relation is in the one or the other. The force of these morbid impulses cannot be resisted, because it is greater than that which the intellect was designed, in the normal constitution of things, to control. The fact is no more anomalous than that of the marvellous development of muscular power in high maniacal excitement, which defies all ordinary means of 
restraint. It seems hardly necessary to prove, to one who has taken the first lesson in psychology, whether normal or abnormal, that the affective and the intellectual powers work together, each in their proper sphere, in determining the thoughts, feelings, and movements of the individual, and that the absence of one or the other would produce an imperfect and disjointed result. It is but a plain corollary of this position, that a morbid condition of one or the other must produce a similar effect. In many of the cases where the person is impelled by an irresistible impulse to commit some criminal act, it is stated that the feeling was contemplated with horror, and successfully resisted, until at last, having steadily increased in strength, it bore down all opposition. And why this deplorable result? Not because the intellect sees the act in a different light, and willingly gratifies the desire of the heart, but because the control which, in the healthy condition, it exercises over the affective movements, is completely overborne by the superior energy derived from disease. To see any matter of blame in such a process is quite beyond our ability. The individual is entitled to commendation rather than blame for perseverance in resisting so long. This relation of independence between the two elements is not unfrequently observed in other forms of insanity. Patients with considerable delusions may recognize, and perhaps deplore, the mischief they commit. They admit that in striking or teasing others, in stealing or destroying property, they did what they knew to be wrong and contrary to rule. How often do we see a suicidal patient admitting that his attempts upon his life were wrong, in the sight of God and man; that he ought not to have made them, but something urged him on; that he is glad they proved unsuccessful, - and yet on the 
next opportunity renewing them ! Do we regard such a person, when he succeeds, as a felon, confiscate his property and bury his body at a road-crossing? Our ancestors did this; but we more properly, distinguishing clearly the moral from the intellectual elements of our nature, regard him as the victim of disease, and give him a Christian burial. It ought not, therefore, to be considered as an anomalous fact, that they whose intellect is not obviously disturbed should be conscious of and deplore the true moral quality of their criminal acts, without being able to refrain from committing them. These, then, are the facts of our case; and no objection to the doctrine can be valid which ignores any one of them. In this doctrine of irresistible impulse we see nothing inconsistent with our knowledge of mental dis. ease, or opposed to any true philosophy of the human mind.

Others endeavor to reconcile the absence of intellectual derangement with the irresponsibility which they are willing to admit, by the hypothesis that at the moment of the commission of the criminal act - in the height of the raptus maniacus - the intellect is practically obliterated, though immediately before and after it seemed to manifest its usual consciousness and power. We might admit the fact without abandoning, in the slightest degree, the doctrine of moral insanity. The point here made seems to be, at best, but a metaphysical subtlety, and the doctrine implied in it one of no very recent origin. The exact condition of the intellect, in these cases, at the moment of the criminal act, is something utterly beyond our reach, and unnecessary in fact for any judicial purpose. A disease is known to exist, - a morbid impulse to commit some crime. The patient is conscious of its existence, knows it is wrong, 
and resists its gratification. At last all resistance is overborne, and the deed is done. Certainly, it is more consistent with all our knowledge of diseased action to suppose that the morbid condition which is admitted to exist goes on increasing in intensity, until it passes beyond the control of the intellect, than that just at this point another morbid condition suddenly appears and as suddenly disappears. The general principle derived from this objection is, that although moral insanity has a real existence as a form of disease, it can never become the parent of crime. With this practical reductio ad absurdum, we will leave an objection which has detained us too long.

Others avoid these difficulties altogether, by recognizing no form of insanity exclusively moral. In the cases alleged to be such, they contend that there is more or less intellectual disorder, though we fail to discover it. It does not appear whether this doctrine is founded on the possible fact that, in their superior sagacity, they have always detected intellectual disorder in cases usually referred to this form of disease; or on the hypothesis conveniently assumed for the purpose, that insanity necessarily implies intellectual aberration, and therefore cannot be predicated of any mental disorder of which such aberration is not an active element. This idea seems to receive some support from the fact that, in other forms of mental disease, delusions, and other signs of a disordered understanding, do often remain concealed for lack of a suitable opportunity for their display, and especially from the fact that in many cases of moral insanity intellectual disorder, though absent in the early stages of the disease, becomes apparent enough in the last. Unquestionably, it is a well known pathological law, that serious lesions may 
exist in the bodily organs without giving any indications of their existence; but a negative fact like this furnishes no pronf of a certain positive fact. If it gives no indication of its existence, our belief in it must be solely a matter of conjecture, of no value whatever except as a guide to some demonstrable result. Unquestionably, too, certain manifestations of mental disease sometimes fail to occur, only because the fitting occasion therefor is not presented; but that does not help the matter at all, because in these cases of moral insanity where no intellectual disorder appears the most abundant opportunity is afforded for its display. The patient is at large, goes and comes as he will, makes visits, directs his domestic concerns, engages in business, and in all his movements is free to do or not to do, to speak or to keep silent. What better opportunity could he have for displaying the inmost thoughts and feelings of his soul? Neither do we deny that a symptom absent in one stage of a disease may appear in a subsequent stage, but that fact would not warrant us to believe that this symptom actually existed from the first. Is it so that we understand the course of disease? Does any one imagine, in any conceivable instance, that the various lesions which constitute our idea of disease all begin simultaneously? If we know any thing surely, it is that these lesions occur successively; and, so long: as the presence of any of them cannot be proved by positive evidence, we conclude that their time has not yet come. In mental, as well as in every other protracted, incurable disease, the progress is from bad to worse. Idle, ever changing fancies pass at last into strong and gross delusions; careless, inconsiderate, heedless manners gradually change into brutal ferocity; and the power to reason correctly about many things is finally 
succeeded by chaotic incoherence and stupidity. Moral insanity often passes into general mental disease, but this fact is no proof that the delusions which mark the latter existed from the beginning in a latent condition.

However this may be, the general doctrine implied by the objection is, that, in the absence of the intellectual element, the moral obliquity must be regarded as a matter of vice or unbridled passion. It would seem as if the authority on which such cases are reported should protect them from the charge of having been imperfectly observed. We should be slow to believe that the men whose names have already been mentioned were such incompetent observers as to overlook entirely an element of discase easily detected by their less illustrious successors. Of course, wisdom is not confined to the great. Many a humble explorer of nature's secrets, patient of labor, modest in his pretensions, despising not the light which others have shed on his path, has been rewarded with results that had escaped more distinguished observers. Is it among such that we are to include the marvellous discovery that moral insanity is a myth or a blunder? That question may be answered in a very ferv words. That cases like these have been observed, where the element of intellectual disorder was obvious, nobody doubts. They only mark the transition point between two different forms of insanity, and establish their close relationship. It is precisely what we might expect. Nature makes no dividing lines between classes and orders. They touch one another at numerous points, and thus reveal their close affinity. These cases show merely that, however much the traits of moral disorder may overshadow every other, a careful examination will sometimes detect indications of intellectual disturbance, and thus illustrate the propositions with which we 
started. It must be borne in mind, too, that this form of disease, like every other, is variable, and that cases which are purely moral in one stage of their progress may subsequently become complicated with aberration of the intellect. Nothing can demonstrate more forcibly the correctness of our views than the frequency of this fact; and the inference is irresistible, that cases which end in unequivocal insanity cannot, at an earlier stage of their progress, have been merely specimens of moral depravity.

Another class of our opponents contend, that in the so called cases of moral insanity there is no insanity at all, either moral or intellectual. What is regarded as such is nothing more nor less than depravity, for which the individual is accountable. For how are we to distinguish, they say, between the moral disorder which is the effect of disease, and that which is the natural result of bad education, vicious associates, and evil habits? If every trait of alleged moral insanity may be paralleled by one of unquestionable depravity, where are we to look for the element of insanity when it cannot be found in the intellect? Many of those who talk thus have no difficulty in meeting a similar objection when offered to the admission of some forms of intellectual disorder. The sayings and doings of many an insane man might be paralleled seriatim, by those of persons whose sanity has never been questioned. Every day, lawyers avail themselves of this fact to stultify some luckless expert who gives the grounds of his belief in some one's insanity. "Do you believe, sir, that every person who says or does such a thing is insane ?" "Certainly not." "Or a certain other thing?" "Certainly not." And so the whole catalogue of particulars by which the mental disease was manifested is exhausted, and the party is shown 
not to have been insane at all. A sort of logic, - in the vernacular of the day called a dodge, - pardonable in a lawyer who knows no higher forensic merit than that of cunning, could hardly have been expected from a scientific man discussing a question of science; and least of all from one who has any practical knowledge of mental disease.

The existence of insanity in any form is not always proved by the presence of any particular symptom, or even group of symptoms, but rather by changes of mind or character, which can be explained on no other hypothesis than that of disease. In other words, the party must be compared with himself, not with any imaginary standard of sanity or insanity. "It is the prolonged departure, without any adequate external cause," says Dr. Combe, "from the state of fecling and modes of thinking usual to the individual when in health, that is the true feature of disorder of mind." The soundness of this rule has never been impugned in court or out. In any alleged case of moral insanity, let the party be compared with himself. If it should appear that, though naturally mild and patient, respectful and courteous, upright and benevolent, kind and affectionate, the person has become restless and passionate, rude and boisterous, unscrupulous and unprincipled, tyrannical and cruel; and that this remarkable change had been rather suddenly effected, and apparently by none of the ordinary causes which affect men's characters, it is a fair, it is an inevitable conclusion, that the person in question is insane. If these changes of character have occurred more than once, the patient in the intervals exhibiting his normal disposition, then not a shadow of doubt can exist. Where the moral disorder is limited to a single trait, as in homicidal monomania, kleptomania, pyromania, \&c., 
the diagnosis is, no doubt, more difficult ; but it is seldom beyond our reach, under an exhaustive investigation. Murder, for instance, is sometimes committed in the most brutal and motiveless style by men who are unquestionably acting under no other influence than the bent of their nature or their manners. Shall we compare with them the tender mother who calls for her newborn babe and severs its head from its body, or the exemplary father and husband who feels impelled by an irresistible power to sacrifice his wife and children, till that moment dearer to him than his own existence? Shall we compare with the practised thief or pickpocket one who, towards the end of a life of honesty and many Christian virtues, purloins at every opportunity articles of little or no value? Shall we compare the midnight incendiary, governed by some motive of malice or interest, with the poor girl who, in consequence of abnormal cerebral action induced by other bodily ailments, is borne on, in spite of every good resolution, to burn down the very roof which affords shelter to herself and those she holds most dear? These are not imaginary cases. They have been actually witnessed, and the books abound with similar ones. True, cases of a disputable character sometimes occur, - cases in which we may well doubt whether the active principle is depravity or disease. I have no wish to conceal any difficulty which this subject may present. Science is full of difficulties, and the pleasure and dignity of its pursuit consist mainly in triumphing over them. The apparent identity of these cases is no reason why we should utterly ignore those where no doubt can exist of the essential differ. ence. Nobody asks us to drop the usual distinction between melancholia and dementia, between hypochondria and mania, because we occasionally meet with cases 
which cannot be unhesitatingly referred to either of these forms of mental disease. In fact, the argument is equally valid against any and every attempted distinction between any conditions or objects having some properties in common. It indicates no remarkable advance in knowledge, if, with all the opportunities which modern science and philanthropy have placed before us, we are unable, in a considerable number of cases, to distinguish those traits of character that result from vicious desires from such as are produced by the action of disease. At any rate, every principle of justice, every emotion of humanity, impels us to treat these cases with a sort of philosophic impartiality, and give them a careful and dispassionate examination.

If the difficulty of distinguishing between moral depravity and moral insanity is a sufficient reason for ignoring the latter altogether, the argument would be equally strong against admitting any kind of insanity in defence of crime. Was there ever a case on trial entirely free from doubt? Was a case ever tried in which the prosecution did not contend that the sayings, doings, looks, demeanor, alleged to be indicative of insanity, were compatible with mental health and soundness? McNaughton, who killed the secretary of Sir Robert Peel, and was acquitted on the ground of insanity, talked and acted for the most part like any sane man; and the notion which led him to commit the act might not, in the nature of things, have been necessarily false, or such as no sane man could possibly entertain. So, in fact, the English public believed; and fierce was the storm of indignation which his acquittal excited. But do we any the less believe that McNaughton was insane to such a degree as to be irresponsible for his acts? We might go through the whole catalogue of causes célèbres 
in which the plea of insanity has been successfully used during the present century, and observe, in every one, a similar state of facts; viz., notions which were the veritable offspring of insanity associated with mental qualities and operations indicative of a rational mind, and doubt and dissatisfaction on the part of the public. It seems to be forgotten that men whose insanity is apparent to the world are never put on trial. It is precisely because there is room for doubt that the case is tried, - that the evidence for and against may be heard and considered. True, a mistake may be made, and a criminal may unjustly escape the punishment of his crimes. Are we prepared to say, on this account, that insanity ought never to be admitted in excuse for crime?

It may be remarked, that some who would not deny the existence of moral insanity object to the name and deprecate its use. This form of disease is supposed to be confined to the moral faculties, as others are to the intellectual; and therefore, upon the ordinary principles of nomenclature, it is very properly called moral insanity. Emotional, or affective, might signify the same thing, but I am not sure that they would be more acceptable to our opponents. At any rate, until they furnish us with a better, we must of necessity keep the present. Others think that, somehow, the dignity of the profession is compromised by the term; that it provokes the censure and sneers of the world, and defeats the very object we have in view. I am unable to see how the honest results of a scientific investigation can be detrimental to the cause of truth and justice. If such be really the effect in the present case, it is attributable rather to the thing than to the name, and of course would not be changed by any modification of the latter. Names, unquestion- 
ably, are often more potent than things; but we might bring ample proof, were it worth our while, that such is not the case here.

Others who believe in the thing, and do not strongly object to the name, advise medical witnesses to abstain from its use in courts of justice. "If," say they, "an acknowledged expert will but testify, after a due and sufficient examination of the case of an alleged criminal, that he is insane, it matters not whether the insanity manifests itself through the intellectual or through the moral faculties: it is still insanity, in the eye of the law, and is entitled to the privileges and immunities of insanity, without splitting hairs betwixt north and northwest side to define the difference of one shade of insanity from another. . . . For all legal purposes, then, it seems idle to suffer the special defence of moral insanity." 1 The giver of this sage advice speaks, no doubt, in all the freshness of ingenuous innocence; but he was evidently never on the witness-stand. Had he ever experienced one of those inquisitorial performances to which lawyers are allowed to subject a medical witness whose testimony has damaged the cause of their clients, he would have discovered that it was not quite optional with him what he may declare and what he may withhold. No great stretch of ingenuity, or lack of courtesy, would be required to get from him the obnoxious word, in spite of his good resolves to abstain from "splitting hairs betwixt north and north-west side." The process may be easily imagined, as, for instance, in the following scene:-

Lawyer. You believe that the prisoner was insane at that time?

Witness. I do.

1 American Journal of Insanity, xiv. 319. 
L. What kind of insanity do you call it?

$W$. I beg your pardon, but I do not trouble myself with "splitting hairs," \&c. It is enough for me and for you to know that he was insane.

L. Perhaps so; but, nevertheless, please state for the information of the court and jury whether some of the best writers on insanity do not divide it into several classes and orders.

$W$. They do.

L. Esquirol is high authority, is he not?

$W$. He certainly is.

$L$. What is his classification? You are no doubt familiar with it.

W. He makes five classes, - Lypemania, Monomania, Mania, Dementia, and Idiocy, or Imbecility.

L. To which of these classes, do you apprehend, does the present case belong?

$W$. Mania.

$L$. Is not Mania divided sometimes into intellectual and moral, according as it is confined to the intellectual or moral faculties?

$W$. It is.

$L$. Do you recognize the correctness of the distinction?

W. I do ; but I protest against the name, noral insanity.

$L$. Very well. Since you admit the thing itself, we will not quarrel about the name it goes by. I choose to call it moral insanity. You may call it what you please, so long as you mean the same thing.

There is a class of objections to which I shall merely advert, for more than this would scarcely be allowed by a proper respect for the dignity of the scientific character. It is mortifying to our professional pride to see 
men who ought to consider themselves as the ministers and interpreters of Nature, rejoicing in their glorious office and receiving her revelations in a glad and teachable spirit, on the contrary turning away from them with a feeling of scorn because they conflict with some preconceived notions of their own. There is brought to their notice an order of facts, both numerous and wellauthenticated, exhibiting a common incident or quality of a lighly important character. But it affords no satisfaction to them. They do not ask if the facts are true, if the conclusions are legitimately drawn. They care for none of these things. It is enough for them that, in their opinion, the tendency is bad; and upon their shortsighted views of the moral consequences of a scientific conclusion they presume to decide whether it is true or false. A course so unworthy of the true scientific inquirer, so completely at variance with every principle of sound philosophizing, requires no formal examination. Our opponents are welcome to all the advantage which it may give them; and it has some effect, no doubt, upon all that description of men whose jealousy of medical science is equalled only by their ignorance of the manner and spirit in which it has been pursued. A single passage, in illustration of my meaning, will be sufficient for the present purpose :-

"The general tendency of the doctrine of moral insanity is bad, whatever show or real feeling of humanity there may be in it. It is bad in a religious view, because it tempts men to indulge their strongest passions, under the false impression that God has so constituted them that their passions are not generally governable by their will or their reason, and that, therefore, there is no punishable guilt in indulging them." 1

1 American Journal of Insanity, xiv. 321. 
It seems to be a matter of complaint among our opponents, that we do not hesitate, in the absence of other proof, to infer the existence of mental disease solely from the character of the particular act in question. Their idea is, that we are bound first to prove the existence of the disease, and then - not before - we may be warranted in attributing to it a criminal act that might possibly have been the offspring of moral depravity. They forget very strangely that the only conclusive proof of the existence of mental disease is to be found in the mental manifestations of the patient. He may have lost his appetite, his head may feel tight and oppressed, he may have become sleepless and restless, but these symptoms do not prove him to be insane. It is only what he says or dnes, as compared with what he said or did when supposed to be sane, that has any bearing on this point, although no doubt these symptoms of bodily ailment furnish confirmatory proof. We admit, with them, that the single criminal act, unaccompanied by other sus. picious circumstances, may sometimes be very unsatisfactory proof of insanity; but we apprehend that such cases are very infrequent. When such an act is really the result of insanity, we can usually find in the antecedent or subsequent history of the patient, if we will carefully look for it, some corroborative proof of its presence. Even without it, the act may be of such a nature that the common instincts of humanity impel us to refer it to mental disease; and this, I submit, is as good ground for an opinion as arbitrary rules and theoretical considerations. When a woman, previoụsly distinguished for every virtue, takes the life of her darling child, am I obliged to stifle my instinctive convictions of her insanity merely because no other symptom of mental dis. ease has been witnessed? In such a case we may be 
sure science and humanity render no discrepant testimony.

In a large proportion of cases, as is well known, the crowning proof of insanity is drawn chiefly from the character of some single act, the previous and subsequent manifestations of disease being too obscure and equivocal to possess much significance. Now it is going but one step farther, and that not a very long one, to regard such act as the sole proof. The force of the proof is not derived from the number of the diseased manifestations, or the precise time of their appearance, so much as it is from their significance; and in this respect the act of which the person is accused may be far more important than all other traits and incidents together. To leave this out of the account indicates not so much any especial regard for justice or scientific propriety as it does a total inability to comprehend its true legal and scientific relations. There is no reason why we should be cut off from any source of evidence whatever, touching the mental condition of one who pleads insanity in defence of crime. If it should stand alone, single and circumscribed, then certainly it is all the more carefully to be considered and estimated. So that if the act itself exhibit mental disturbance, if it be contrary to the characteristic feelings, habits, and principles of the person, it furnishes a no less valid excuse than something which may have occurred days or weeks before. But the act, it is said, is the very thing in dispute, and therefore cannot be fairly used in evidence for or against. This may sound plausible, perhaps; but it will prove, on examination, only a paltry sophism. It is not the act that is to be tried. It is the guilt or the innocence of the individual that is to be established; and, if the act in question furnish any evidence on this point, it may be 
legitimately used. Its sufficiency for the purpose is quite another matter, and can be properly estimated only by means of the light which is derived from a profound and extensive study of mental phenomena, both in the sane and insane condition.

Another fruitful source of arguments against the doctrine of moral insanity is found in its supposed consequences and collateral accompaniments. A specimen or two, by way of illustration, will answer my present purpose. "Almost any man may satisfy his mind, if not his conscience, - a sane man, perhaps, most readily, - that he has been surprised into a crime by some strange and irresistible impulse, some demoniacal instigation, some fatal propensity, or some unaccountable frenzy, that he could not master for its suddenness and its force. Such casualties may be, and doubtless are; but God only can judge of them. Human laws cainot: their nicest refinements are too gross for such subtleties." 1 Here it is virtually admitted that a person may be morally insane, but, inasmuch as the fact can be known only to God, it should not be received as an excuse for crime. Sane or insane, he must suffer precisely as if his sanity were unquestioned. The old maxim of the courts is to be reversed; for the sentiment of the passage is, better that ten insane persons be convicted than that one sane person should be acquitted on the ground of insanity. This indicates no advance in humanity, if it does in science; but it is really no more creditable to one than it is to the other. The writer may speak for himself, but we protest against his measuring the professional sagacity of others by his own. There are a few poor mortals, I believe, who, without

1 American Journal of Insanity, xii. 339. 
any great presumption, or uncommon exercise of skill, profess to be able to recognize moral insanity where it really exists. The fact implied in the opening sentence, if really true, which I strongly doubt, proves nothing as to the point in hand. In a criminal trial the question is not what the prisoner thinks of his guilt or innocence, but what can be proved to the satisfaction of the jury. If moral insanity is pleaded in his defence, proof of the fact must be found in the antecedents of the prisoner, the manner of committing the crime, his mental or bodily condition, all the circumstances, in fact, connected with the act. I have no hesitation in saying that a patient investigation of the case would always reveal at last its true character, and, I repeat, he must have but a low estimate of his own sagacity, or of his own resources, who can fear that, under such an investigation, a genuine criminal could succeed in passing himself off as insane. It may be said, no doubt, with some truth, that a criminal trial does not always afford the means of a thorough investigation, and that a jury is often governed more by the appeals of counsel than by satisfactory proof respecting the mental condition. The proper remedy for the evil, however, is not to abolish the plea because it is too readily accepted by easy, credulous juries, but, by some change in the mode of procedure, to have it satisfactorily disposed of one way or the other. To ignore and reject, utterly and forever, a plea, merely because it is occasionally abused, is a puerile folly hardly to have been expected of men who claim any respect for their opinions.

This question is important not so much for its pathological as its forensic relations. The expert, who believes that there is no insanity without intellectual 
derangement, is powerless before the courts in cases of what is called moral insanity. He regards the accused as insane, and clearly entitled to plead insanity in excuse for their acts; but, as no intellectual derangement is apparent, he is obliged to adopt the strange assumption that it is there, though he does not pretend to see it, - a sort of constructive presence to be recognized only by an exercise of faith. Now faith, though one of the strongest proofs of a profoundly religious spirit, is but a poor foundation for a scientific deduction. Courts rigidly insist on positive, tangible proofs. Eren opinions, though admitted as evidence, are worthless to them, except so far as they rest on facts; but worse than worthless are conjectures without the slightest pretence of support in actual fact. This doctrine of the constructive presence of intellectual lesion would, in practice, contribute as little to the benefit of the accused as it would to the reputation of the expert. Are such persons as those who are supposed to be subject to this form of disease, - who abound in private life and are found in every hospital for the insane, - are they to derive no benefit from the plea of insanity in courts of justice? This, certainly, is the legitimate effect of the position that intellectual derangement must necessarily exist, whether apparent or not, in every case of insanity. The proper course of the expert is to say that the person is insane, and that the insanity is confined, so far as he can see, to the moral or affective powers, being manifested in the conduct and not at all in the conversation. He thus neither affirms nor denies the existence of intellectual lesion. He simply says that none is perceptible.

I have thus disposed of what I take to be the principal objections to the doctrine of moral insanity. It 
may be regarded, perhaps, as a work of supererogation by most of those who have been much conversant with the insane, and in the habit of considering the existence of this form of disease as well settled as that of any other. They must bear in mind, however, that objections which seem too puerile for serious refutation are urged upon courts, paraded in newspapers, and patronized by amateur writers on the legal relations of the insane. In this way, they get a factitious authority which deceives the ignorant or unwary, and therefore procures for them a degree of attention they would never obtain by their intrinsic merits alone. When it is regarded as a mark of superior wisdom, and of elevation above the foibles and crotchets of well-meaning but simple-minded men, to scont at such results of faithful observation as happen to jostle the prejudices of the world, it becomes a duty to speak. 


\section{DOUBTFUL RECOVERIES.}

In most diseases we are seldom left in any uncertainty respecting the fact of complete recovery. If the rational symptoms leave any doubt on this point, we can often supply their deficiency by the direct evidence of the senses. The ear will reveal to us the slightest trace of disease in the heart and lungs, and the touch may enlighten us sufficiently respecting abscesses, morbid growths, and displacements. In mental diseases, however, the senses afford us no help whatever. ${ }^{1}$ No friendly tube, no arts of manipulation, will acquaint us with the organic movements going on beneath that bony dome. Whether the disappearance of all or most of the rational symptoms indicates the restoration of the cerebral organism to its normal condition, or only their temporary cessation, in accordance with a known law of periodicity, is a question which we must often hesitate to answer; and we are thus left in a state of embarrassing uncertainty as to a point of the greatest practical importance. And yet it is laid upon us to decide whether our patient is able to resume his place in the world, or requires weeks or months of farther probation.

If any hospital physician can say that he has never discharged a patient with all possible confidence in the

1 It remains yet to be seen whether the ophthalmoscope furnishes any exception to this rule. 
completeness of the recovery, and readmitted him a few weeks afterwards, in an active stage of disease, he certainly has reached a degree of skill to which I can lay no claim. I recognize the necessity of an ample period for the stage of convalescence, and am aware that the views of others on this point often prevail over our own. I admit that the impatience and self-sufficiency of friends generally render it too short, and procure the discharge of the patient when our own unbiassed judgment would dictate a longer stay. My proposition is, that in cases where we can no longer discover sure indications of disease, and where we are allowed to retain the patient as long as we please, without let or hindrance from others, discharge is occasionally followed by speedy re. lapse. Without exaggeration, it may be said that in our specialty, though the cure of the patient may be a veritable triumph of skill, yet to know precisely when he is cured may signify the far greater triumph of that keen insight which looks beneath the surface and discerns conditions utterly hidden from common sight. Under the guidance of books, or on a stated routine, we often succeed in effecting a cure. The course is plainly marked out for us, and it must be our own fault if we do not follow it. Here, however, we can obtain but little assistance from books. We must depend solely on our own resources; and, if these consist only of a little knowledge of routine, we can scarcely avoid some mistakes. If, however, they consist of an ample knowledge of the mental phenomena both in a liealthy and morbid state, and especially in a kind of sagacity or tact which enables us readily to apply this knowledge to the case in hand, we shall arrive at the right conclusion, where others, less abundantly qualified in these respects, would sometimes err. 
In the first place, to appreciate rightly the indications of recovery, one must be more or less acquainted with the healthy mind. A man who should undertake to make an autopsy, without the least familiarity with the healthy aspect of the various organs, conld claim as little respect for his conclusions as one who should decide a question of recovery from mental disease, with only the most superficial knowledge of the traits of character and operations of the intellect exhibited by the normal mind. How could it be otherwise? We regard it as a settled principle that the essential condition of insanity is a departure from the natural character without any adequate external cause; and that, in deciding the question of insanity in any given case, the person must be compared, not with any conventional standard of sanity, but solely with himself. Of course, it cannot be supposed that we should be acquainted with the mental character of every patient under our charge. In regard to the most of them, in fact, we are but imperfectly acquainted with the history of their disease, to say nothing of those moral and intellectual qualities which distinguish them in health. In order to accomplish our object, we must chiefly depend upon our knowledge of mental phenomena in the abstract or in the concrete, - as analyzed by the metaphysician, or exhibited in the living, thinking man. The secret of Shakespeare's unrivalled success in the delineation of insanity lay not in an extensive observation of the disease, - for he, probably, had seen very little of it, but in a profound knowledge of the springs of action, and an exquisite discernment of the countless varieties of human character. He recognized the preguant iruth that disease, whether of body or mind, is governed by laws as inflexible as those of health, and that there is an 
invariable relation between them, whereby, within certain limits, we are enabled to infer with no less certainty than we are to observe. One of these laws is, that the normal movements of the mind are not entirely lost in the abnormal, but impart to them their peculiar type and mode of expression. Thus, Lady Macbeth, while wandering in her sleep and reviewing the scenes of that terrible night, is but the reflex image of Lady Macbeth before the vision of regal state lured her to destruction. And so skilfully is this same principle applied in Hamlet, that the world is yet in doubt whether the poet intended to exhibit an actual case of insanity passing through its varions stages, or merely an irresolute, speculating youth, breaking out occasionally into a simulated paroxysm of frenzy. The faculty which in Shakespeare led to such wonderful results, must be possessed and exercised, more or less, by every successful student of morbid psychology.

Among the most common and prominent traits of insanity are many exhibited by persons considered sane, and who are so for all practical purposes. Who has not witnessed explosions of wrath as sudden, as unprovoked, as furious, as unreasonable, as any that are exhibited by the iusane? Who has not observed, in persons who pass for sane, fancies scarcely to be distinguished from delusions? How many men and women there are in the world, of unquestioned sanity, who sincerely believe that among those with whom they habitually deal are persons systematically bent on thwarting their purposes, traducing their character, and marring their peace! Such manifestations frequently spring, no doubt, from that mental obliquity indicative of a tendency to insanity, or the insane temperament, as it is callerl, and which, by the way, is far more prevalent than it is generally supposed to be; but they show, 
none the less, that the most thorough knowledge of the mental constitution is often needed to enable the psychologist to distinguish the manifestations of disease from those of reputed health.

The aspects of insanity are inuumerable and ever new. The longest life and the most diligent observation cannot exhaust their infinite variety. The ordinary observer recognizes no other insanity than that which is characterized by noise and incoherence, and for the same reason - a very limited experience - even a physician is liable to mistake the indications of disease for those of the soundest mental integrity. We all know that not unfrequently a patient may exhibit no positive trace of disease, for weeks or months together, while we are strongly suspicious, all the time, that he has not recovered his normal condition; and we know how often the event justifies the suspicion. Now, our view of such cases is determined not so much by any special traits they may exhibit as by those general impressions which long familiarity with the disease has left on the mind.

The result of these different degrees of qualification may be seen in another shape. A beginner in this department of our art hails every improvement as the commencement of convalescence, and is apt to regard the appearance of a few healthy traits as the unquestionable presage of recovery. It is not until a later period that he becomes acquainted with that peculiar oscillation which marks the movements of mental disease, and fully comprehends the fact that serious disorder may exist in connection with many sound, healthy manifestations of character. Lawyers, judges, men of the world, may ignore this fact altogether, and plume themselves on their superior sagacity; but no one in this department of the healing art can do it without making shipwreck 
of whatever reputation he may happen to have gained. I do not mean to convey the idea that the kind of professional sagacity here referred to will be exactly proportioned to the number of cases one has seen. It is not the number of cases observed, but the thoroughness with which they are studied, that imparts it. To one without the power to receive and inwardly digest what the eye sees and the ear hears, a multitude of cases afford but little light, for they leave on the mind only a vague and obscure impression. For years he may traverse the wards of a hospital, day after day, and learn little or nothing of that higher knowledge which his opportunities have placed within his reach. He may learn that most coveted of arts, the art of subduing excitement. He may outstrip his neighbors in all those little appliances which arrest the pupular attention, while the nicer shades of distinction between the healthy and the disordered mind, the deep under-currents of thought and feeling which determine the movements of both, ever remain as remote from his apprehension as the poles are asunder.

We must also bear in mind that no amount of observation or study will always lead us to true conclusions without the aid of that faculty of the mind which enables us to apply our knowledge to a case differing from all other particular cases within our experience; in other words, to eliminate the essential conditions of the case from the accidental circumstances that accompany them. To some men the case in hand conveys no idea apart from its special facts. Their knowledge consists exclusively in particular cases, ticketed, labelled, and filed away in their memory. When the occasion requires some power of nice discernment, - of deducing the unknown from the known by the ready perception 
of some necessary relation between them, - they can only fall back on their insulated recollections.

We are now prepared to consider some of those incidents and conditions which are of great significance in regard to the question of recovery.

It is a rule sanctioned by the highest authorities, that a patient cannot be considered as recovered who does not fully recognize the fact that he has been insane. As a general rule, it is undoubtedly correct; but the exceptions are neither few nor insignificant. In every case of complete recovery, - one in which no vestige of disease remains, - unquestionably, the patient is conscious of having been insane, but he may not openly admit it. This depends on his mental constitution. Men who have always entertained a high opinion of their intellectual gifts, in connection with a proud and haughty spirit, are naturally unwilling to admit so humbling a fact as that of their own insanity. They may have been nervous, they may have been excited, they may have talked fast and loud, they may have acted impetuously, or even imprudently, but they knew perfectly well what they were about, and a few days of quiet and seclusion would have effectually calmed their perturbed spirits. Such is their explanation of occurrences that cannot be denied, in which, to be sure, they are as wise as the creature that hides his head in the sand and then thinks he cannot be seen. This kind of attempted self-deception is most common in cases characterized by high excitement and extravagant discourse, rather than by delusions, incoherence, or violence. Delusions that were openly proclaimed are not so plausibly explained; but they are represented, perhaps, as only idle, fugitive fancies of little consequence, that soon passed away. If the patient is unprincipled 
as well as proud, he may resort to subterfuges that are false as well as weak. A $1 \mathrm{n}$. once came under my care while in a paroxysm of high excitement, who talked incessantly for two or three weeks of having been robbed, the day before he came in, of a lot of jewelry purchased by him shortly befure, on speculation. He finally ceased talking about it, and we heard no more of it, though he never admitted that he had been mistaken. Shortly after his discharge, he came to me showing what purported to be a bill of some $\$ 2,000$ worth of jewelry sold to him, and part payment received. The date of the bill corresponded with his previous story. I afterwards ascertained that this document was entirely fictitious, procured for a few dollars from an itinerant vender of jewelry. For several years, this man had had annual paroxysms of excitement, alternating with fits of depression, but he had never exhibited delusions, and had not been popularly regarded as insane. $\mathrm{He}$ was a physician in good repute, and had never ceased to practise on account of his mental infirmity. This contrivance was a desperate attempt to remove an humiliating imputation on his intellectual integrity.

This reluctance to acknowledge their infirmity is still more common in a class of patients whose usual condition is marked by striking eccentricities and perversities. Many of them, probably, labor under a genuine mistake on this point. Men who are always hovering near the line that separates sanity from insanity find it hard to believe that they have ever fairly passed over it; and this difficulty may be shared by friends and neighbors who are not accustomed to a very close discrimination of mental conditions. Their logic is, stated in the usual way, if he were insane at the time referred to, then he was always insane. It may be 
found, frequently, that the incident or erent which brought upon them the disabilities of insanity only implied the exaggeration of some innate quality of mind; and it is not strange, under the circumstances, that they should orerlook the distinction that in the one case they lost entirely the power of self-control which they possessed in the other, and were no longer amenable to reason.

It may seem paradoxical to say that a person has recovered who fails to recognize the delusions that possessed his mind; yet there are cases where the patient has passed from a state of agitation, excitement, and delusion into one of calmness, cheerful expectation, and apparent rationality, while still retaining some flagrant delusion. With this exception, his riews are correct and clear, all the mental processes are well conducted, apparently; and he performs his part in the world as well as ever. Such was the case of Greenwood, cited in all the books on the medical jurisprudence of insanity, whose will was the subject of much litigation. While unequivocally insane, he believed, with other things equally false, that his brother who then attended him had attempted to kill him by poisoning. This delusion he never relinquished, though for some years he practised his profession as an advocate, and seemed to the world to be in the complete possession of his senses.

It is seldom safe to discharge a patient while he continues to believe in the reality of any single notion or occurrence that was entirely the offspring of fancy, because such a belief indicates morbid action, which, however circumscribed at present, is ever liable to spread, and induce farther mental disorder. Indeed, the evil is seldom so limited as it seems to a casual 
observer. A long and close inspection of the mental manifestations is likely to reveal, deeply lidden beneath the surface, a broad vein of unsoundness, which a brief trial at large would display to the common gaze. If we could predict that the delusion would always remain insulated from all other mental processes, as in Greenwood's case, then we should hardly be warranted in detaining the patient; but this we can never do, with the slightest degree of confidence, without a long and careful observation.

Very ignorant, uncultivated people often fail to recognize their delusions as such, solely from inability to distinguish the subjective from the objective in their mental experience. This trait is not uncommon among the lowest class of the Irish, who will talk of certain imaginary occurrences as if they had really happenerl; though how, they do not pretend to know. It is enough for them that the impressions thus stamped on their brain remain as clear and vivid as the most recent images of sense.

There is another class of patients, and a very large one too, from whom we fail to obtain a decided recognition of their mental disorder. Their conduct and conversation while deprived of the noblest attribute of their nature excite so much unpleasant if not painful recollection, that they shrink from dwelling upon them, and may even endeavor to silence or divert inquiry respecting them, by seeming to deny that they had any serious disorder. I have often hesitated to inquire very minutely respecting certain extravagances of thought or feeling, lest I might hear a flat denial of their existence from patients who gave every other indication of recovery. Indeed, this kind of reticence, in some degree, may be observed in by far the larger part of 
those who recover. On the other hand, a full, free, and earnest recital of the thoughts, emotions, and acts produced by the mental disorder, is not, by any means, a sure indication of genuine recovery.

Another circumstance often bearing very significantly on the question of recovery is the duration of the disease. The course of insanity is much longer than that of most diseases of apparently equal severity. I do not say it is never transitory, for there are cases enough on record to settle this point beyond a doubt; but, with this infrequent exception, its duration is marked rather by weeks and months than by hours and days. Apparent recovery within the first six or eight weeks should always be followed by a longer probation than one at a later period. As in most nervous disorders, the course of insanity is marked by fluctuations in the severity of its movements; and the improvements thus occurring may often seem like convalescence, if not actual recovery. When occurring at an early period, or suddenly at any period, or soon after a state of intensely active disorder, such as high maniacal excitement, they are seldom permanent. Esquirol has made a statement, the correctness of which my own observations have abundantly confirmed, that in most cases of active mania " a very marked remission, amounting, perhaps, to a complete disappearance of every trait of disease, occurs within the first month of the attack, and is often followed by a renewal of the disease." My experience would lead me to say that such is the result in by far the greater number of cases. And I would also say that the more complete the remission, the less likely is it to prove an unequivocal recovery. I call to mind a case in which, during the first month, a remission consisting of the most rational exercise of the mind on all 
subjects, without excitement or depression, was soon succeeded by high maniacal excitement, terminating in death. True, this kind of improvement is of such brief duration that there is little danger of the patient's being discharged on the strength of it; but it may lead to a prognosis that will cause bitter disappointment and mortification.

As already intimated, these remissions are not confined to the first month; nor are they peculiar to any particular form of disease, though most common in acute mania. They are not rare even in organic affections of the brain more or less affiliated to general paralysis. A patient who came in recently, with what seemed to be simple mania, soon began to convalesce, and for two months or more presented not a trace of mental disorder. His conduct and conversation, his ways and habits, manners, opinions, and feelings were as free from singularity and impropriety as they were in his best estate. Having kept him as long as I pleased, he went home and resumed his customary employment. Three weeks afterwards he came back highly excited, full of gross delusions, and considerably demented. Thenceforth he passed through the ordinary phases of organic cerebral affection, and died. In another case, where the indications of organic disease were so strong from the beginning that I gave the friends the most discouraging prognosis, the signs of recovery became so satisfactory at last, that I began to doubt the correctness of my diagnosis. At any rate, they were so satisfactory to the friends that they removed him, and he recommenced business. In the course of a few weeks he broke down again, and the result fully justified the original prognosis. A less degree of improvement in this form of disease is still more common, and often 
leads to the removal of the patient from the hospital, in the delusive hope that a change of scene will complete the apparent convalescence.

I take the opportunity to remark, in passing, that, if these views are correct, we are forced to believe that too many are discharged from our hospitals as recovered, within the first three months after their admission. While admitting that recovery may not very unfrequently be completed in that period, I apprehend that this large class of cases which, in our hospital reports, are placed in the front rauk of successful results, must embrace many that relapse so soon after their discharge as to render it quite eertain that their recovery was never complete. It may have been only the remission so common in the early stages of the disease, to be certainly followed by a renewal of the disorder. It may have been that condition of mind resembling recovery, in which one essential quality of the nervous organism is wanting. No trace of disease can be discerned in the conduct or conversation, no perversion or obtuseness in the sentiments and emotions, but the patients have no power of endurance. In the hospital, where most of their movements are a matter of routine, ex. empt from care and responsibility, they pass along month after month, without let or hindrance; but the moment they begin to act for themselves, to assume responsibility and encounter trials, the latent irritability is revived, and proceeds, more or less rapidly, to utter loss of self-control. It would be a great mistake to suppose that this condition is confined to those who have had frequent attacks, and whose nervous elasticity may be supposed to have been impaired thereby. It is often met with in recent cases, and should always be considered in determining the question of recovery. It be- 
comes then a matter worthy of our most serious consideration, whether these early discharges do not multiply the risks of relapse, and, even when not followed by actual relapse, lay the foundation of a morbid irritability which, sooner or later, is converted into overt disease. There is much reason to fear that the frequency of secondary attacks - greater in this country, I suspect, than in any other - may be attributed, in a great degree, to the shortness of the probationary period which prevails among us.

Time, of course, will settle every doubtful case; but this means of deciding the question is not allowed to us, and we are obliged to come to a conclusion on the strength of the present circumstances. In other words, we are obliged to decide, without delay, whether the apparent recovery before us is spurious or genuine. In most of these cases there may be found some trait, incident, or condition, which properly interpreted may lead to the right conclusion. Among the most prominent are a certain impatience, restlessness, and constant divelling on the one idea of going home. The last is always a suspicious circumstance, and always a sufficient warrant for delay. Some manifestation of the feeling in persons who have long been separated from their homes, and are looking forward to the day which shall witness a renewal of their happiest relations, would not be strange. But this very natural trait can generally be distinguished from the kind of restlessness in question, upon a broad consideration of all the incidents connected with this point. A person fully restored, having in mind the sufferings he had experienced, and the liability to relapse, might be supposed to feel a distrust of his power to maintain his place under the trials of life, to shrink from the attempt, and resort to any excuse for 
delay. Occasionally such is the fact; but in most cases a very different feeling prevails. Most patients have little apprehension of another attack, even though they may already hare suffered many. They labor under a curious obtuseness which incapacitates them from ap. preciating considerations of the greatest moment in respect to their future health; and the plainest suggestions of reason fall unheeded on their ears. Rejoicing: in the buoyant sensations of returning health and vigor, they see no danger and cannot be convinced that it really exists. They use but one argument, - a sort of argumentum ad hominem, - and they care for no other. I never was better in my life, they say, and why should I stay here? Now, their self-confidence, however unsuitable, is quite natural, and is controlled, for the most part, by a regard to proprieties and conveniences. On the other hand, the morbid restlessness in question is far more persistent, and out of all proportion to the occasions that are used in justification of it. It is beyond the reach of argument and all the arts of persua. sion. The most patient and elaborate exposition of the reasons for farther detention is followed the next day by a renewal of the same restlessness and the same importunities. This trait is always accompanied, I think, by some acerbity of feeling. We are charged with acting from unworthy motives, and are trium. phantly challenged to show a single word or act of theirs indicative of insanity. After fully recovering, these patients admit that their restlessness was unreasonable and uncontrollable, and wonder they should have been so completely under its dominion. Such patients when discharged often do well at last; but in a large proportion the morbid condition which gives rise to the feeling: continues after discharge, and finally reappears in all 
its original severity. I recollect the case of a shipmaster who was attacked with acute mania in consequence of suffering and exposure in an open boat after shipwreck. After some five or six weeks, every symptom of mental disease had disappeared, and his conduct and conversation became perfectly correct, except that he was incessantly complaining about being kept while he was never better in his life. His wife yielded to his importunities for release, and about a month afterwards she informed me he was doing very well, and that she only regretted not having removed him before. I was not long obliged, however, to suspect that she understood the case better than I did; for the very next week he came back quite demented, and shortly after died. But with all our penetration we shall sometimes find it impossible to decide with much confidence as to the real significance of this symptom; and, speaking for myself alone, the best matured conclusion may prove to be wrong. It may seem no more than a pardonable degree of impatience under the circumstances, or only a trait of character natural to the individual in his best estate; when, in fact, as the event proves, it indicates a lingering spark of disease which the unrestricted liberty of home will fan into a devouring flame. On the other hand, it may look very like a manifestation of disease, though the subsequent event leads us to believe that it was only the way of the patient under any circumstances of trial.

Excitement or depression, occurring in connection with apparent convalescence, is always a suspicious circumstance. A little depression is quite common in this stage of the disease, and only indicates the natural reaction which might be expected after much excitement. But if the depression is very marked, and 
especially if it is accompanied by any degree of mental distress or anxiety, it is an indication of actual disease, and warrants us in a longer detention of the patient. It may be followed directly by recovery, but full as likely by excitement; and fortunate it is for the patient if these alternations of excitement and depression do not become habitual. We have no means of predicting, .with any approach to certainty, the next phasis after depression occurring under the circumstances here indicated. If it succeed excitement very suddenly, it is more indicative of farther trouble than when it occurs gradually. When it has been preceded for some time by a very satisfactory state of mind - apparently that of genuine convalescence - it must always greatly embarrass our prognosis. Happily, this conjunction is not common. I call to mind a case of puerperal mania, which, in the course of about eight months, passed through the various stages of raving, calmness, returning reason, convalescence and apparently completed recovery. The day was fixed for her discharge, and the usual preparations were begun. For five or six days previous to the appointed time, she became taciturn and sad, and manifested no eagerness to leave. Under the circumstances, however, it was thought better for her to go. On reaching home, she took to her bed, bewailing her own inefficiency, and taking no part in the management of her domestic affairs. After three or four months spent in this manner, she began to recover, and has had no subsequent attack, though she has borne several children. In another case, that of a young, unmarried woman, the several stages of acute mania were passed through in the course of a year. Convalescence began towards the end of the eighth month, and in the course of three or four months 
it became so firmly established, that farther stay seemed unnecessary, and a day was fixed for her removal home. Just then she evinced some depression, and within a day or two committed suicide.

Excitement under similar circumstances is not so common, but it is equally suspicious. While it exists as an immediate sequel of convalescence, I should hesitate to discharge the patient. In the seclusion of a hospital it may speedily pass away; while, under exposure to trying circumstances, it would, for the most part, steadily increase until it culminated, perhaps, in a fresh paroxysm of acute mania. It certainly is not always very easy to distinguish correctly that exaltation which is solely a matter of temperament from the excitement which reveals the lingering traces of disease. Bearing in mind that real recovery is generally accompanied by a staid and quiet demeanor, we should always regard with distrust a very different deportment. The transitory character of the remission already described is sometimes revealed by a certain exaltation in which the tones of the voice are loud and sharp, the movements brusque and hurried, and the discourse boastful. No matter how clear and acute the mind may appear, no matter how free from palpable marks of disease, if the patient is disposed to talk fast and loud, to whistle and sing, and to be incessantly on the qui vive, we may be pretty sure of a relapse.

Hardness of feeling towards the hospital, the friends, or any others who have promoted or favored the patient's restraint, must always throw doubt on the genuineness of any apparent recovery. One who is fully restored will harbor no other than feelings of complacency and gratitude towards those who have cared for him when unable to care for himself, and shielded 
him from a mortifying and dangerous exposure of his infirmity. He will never cease to entertain the most friendly feeling towards those who, under every provocation calculated to try their temper and patience, pursued the mild and even tenor of their way, returned his abuse with silence or with gentle words, and exhausted all the arts of kindness in soothing his troubled spirit and restoring it to peace and happiness. In fact, it may be justly suspected that a patient manifesting different feelings does not recognize the essential fact that he has been insane, and, generally speaking, this suspicion is confirmed by subsequent events. Sometimes, a patient, though he may not heartily acknowledge that he has been insane, will admit the existence of some mental disturbance not amounting, however, to insanity. "I did thus and so, I said this or that," he says, selecting some incidents too notorious to be overlooked; "but," he asks, borrowing a leaf from the practice of the lawyers, "do you contend that every man who does that thing, or says this, is insane?" $\mathrm{He}$ declares that his confinement was premature, not warranted by the circumstances of the case, and towards all who participated in the measure he has no other than feelings of indignation and wrath. Or he may say, "I admit that for a few days I was incapable of taking care of myself, and my friends did right in placing me in a hospital. But I soon came to myself, and during the weeks and months that have elapsed since then, there has not been the slightest reason for my confinement. In keeping me here, you have been guilty of high-handed oppression." The practical question here is, whether this is a transitory stage of disease, to be succeeded by some change for the better or worse, or only a phasis of character in which normal and abnor- 
mal elements exist in very uncertain proportions. In order to decide this question, the first step is to ascertain the natural temper and disposition of the patient, and oftentimes we need go no farther. If, in his best estate, he were accustomed to look on every one who stood in his way as an enemy, to be arrogant and exacting, to find fault with every attempt to serve and please him, and to lie without scruple whenever a lie would seem to serve his purpose, then it can scarcely be considered as entirely the result of disease, if in the hospital he is full of resentment towards those who have done him the greatest possible service, grumbling and complaining about every arrangement, rude and vulgar in his deportment, and totally regardless of the truth. Instead of passing through a stage of disease, he is not very far from his natural condition. In fact, patients of this description, who are far more numerous than the unprofessional world is aware of, must be regarded as having recovered to a certain point. That is, the more prominent traits of insanity have disappeared, their conduct is tolerably correct, and they are capable of managing their own affairs with their customary ability. To keep them in a hospital until they dismiss their angry feelings would be simply imprisonment for life. Beyond this point they never can recover, and it is better that they should be allowed the utmost freedom from restraint. It is one of the disadvantages experienced by hospitals for the insane, that the true character of this class of patients is not, and probably never will be, understood by the world at large. With sanity enough to make up a plausible story, they pour their grievances into the public ear, and succeed in creating the impression that they have suffered indignity and wrong from those who were 
specially bound to shield and protect them. Towards the institution which received them within its protecting arms when their malady rendered all domestic arrangements ineffectual, and led them by ways of gentleness and skill to as complete a possession of reason as their unfortunate mental constitution would allow, they are always particularly bitter. It would be satisfactory to know the exact proportion in which the two elements of actual delusion and conscious moral obliquity enter into the composition of this mental condition; but this will ever remain, no doubt, one of the unsolved problems of pathological psychology. That they are always both there, in some uncertain proportion, is a fact beyond dispute.

In females, the menstrual period may be accompanied by abnormal excitement after convalescence has seemed to be fairly established. By injudicious management, this condition may be so aggravated as to become uncontrollable. It is a safe rule, therefore, never to discharge a female patient until the menstrual function is performed without being accompanied by mental disturbance.

I have thus pointed out some of the conditions and incidents that throw a doubt on the question of recovery. However much or little assistance may be derived from these hints, we shall occasionally, in spite of all our skill and the utmost care, fail to discover the smouldering embers of disease on the one hand, or on the other commit the less likely and less mischievous mistake of extending the period of probation beyond the needful limit. 


\section{DELUSIONS AND HALLUCINATIONS.}

ON the trial of Hadfield, eight and sixty years ago, for shooting at the king, his counsel, Mr. Erskine, laid down the doctrine that delusion is that quality of insanity which renders a person irresponsible for his acts. Though never established by any judicial decision, yet announced as it was by the acknowledged leader of the English bar, in a case that appeared by universal consent to justify its correctness, it has, undoubtedly, exerted an influence on judicial opinions, and may be considered as the first considerable innovation upon the rules of the common law respecting insanity in connection with crime. For nearly half a century, its correctness, as a rule of law, went unchallenged in any British or American court of justice; but correct as it seemed, abstractly considered, it frequently proved unsuitable for practical application, owing to some uncertainty as to the true meaning of the trait in question. Many attempts have been made to remedy the deficiency; but, being suggested rather by metaphysical speculation than by the study of morbid psychology, they invariably failed to meet the requirements of any but the particu. lar case in hand.

One writer defines delusion to be "the belief of facts 
which no sane man would believe." Another defines it to be "a belief in something extravagant, having no existence whatever, and out of which the person cannot be reasoned by any conceivable degree of evidence." Another says, "delusion is a belief of facts which no rational reason would have believed." According to these definitions, Columbus must have been laboring under a delusion in thinking he should discover a new world; for such a belief was certainly extravagant,one which the rational men of his day rejected, but which he could not be reasoned out of. Many a worthy man entertains political or religious opinions which, to some of his neighbors, seem to be the height of folly; and holds them, too, with a strength of conviction that no evidence can impair. In these definitions, it will be observed, the very point to be proved is assumed. To say that a certain belief is a delusion because no sane man would entertain it, is just a begging of the question. Another says, a delusion is a belief in something impossible. But who is to decide what is and what is not impossible? What is impossible to one man is possible to another. Belief in something which is impossible in the nature of things, is, unquestionably, a delusion; but every delusion is not a belief in something clearly impossible. Many a delusion consists in believing, not something impossible, but something without any objective foundation. A man believes that he has fifty thousand dollars on deposit in a certain bank; but although a bank deposit is not an impossible thing, yet as this person never had a deposit in any bank, having always been little better than a pauper, such a notion is, nevertheless, a delusion. So, although a delusion may be defined very justly to be a belief in something impossible, it must be understood that the impossibility may 
be, not in the nature of things, but in the circumstances of the case. With this qualification, the definition may be found applicable in practice, with fewer exceptions than any other. Of course, instances will occasionally occur, where it is questionable whether the circumstances are such as to render the thing believed impossible, which only shows that psychological definitions are not quite so clear and precise as those of geometry and algebra.

The current philosophy respecting the nature of belief has not led to very clear conceptions on this subject. The tendency is to depreciate every other element of belief as compared with that of the evidence of the senses. To a great extent human belief must rest on that foundation; but much of the belief which determines the opinions and conduct of men springs from the prevalent philosophy, from tradition, from the force of imitation, from superstition, fancy, or fashion, from a nervous temperament, and mental eccentricities. Daily experience shows that, under the influence of such causes, no belief is too absurd and groundless, even for cultivated minds. The history of human progress in its various phases shows that the accredited belief of one age becomes an indication of insanity in the next; and the psychological student who extends his observations beyond himself into the highways and byways of society, into the purlieus of vice and the wards of the insane hospital, wherever the normal activities of the mind have been disturbed by the deteriorating influence of a faulty hygiene, of bad blood, of education in vice, of indulgence in drink, continued through several generations, will find at every turn how closely the domains of sanity and insanity lie to each other.

In order to determine whether a certain belief is a 
veritable delusion, or only the mistake of a sane mint, it may be necessary to scrutinize the psychological character and experience of the individual who entertains it. Such a scrutiny may show that what seemed to be the offspring of disease, - what would have been unequivocal delusion, under different circumstances, - was only a mistake of ignorance, a sottish superstition, a freak of eccentricity, or the suggestion of a peculiar temperament. A single instance will sufficiently illustrate the significance of these remarks.

In litigated cases of insanity where delusion is alleged, the medical witness seldom escapes being asked if he thinks Martin Luther was insane for having believed that he was sometimes visited by the devil in person, and that on one occasion he hurled his ink-horn at him and drove him out of the room. This the lawyers regard as an admirable dilemma, on either horn of which the expert will find an uncomfortable seat. If he says no, the answer conflicts with some definition of delusion which he has already given; and if he says yes, it is equivalent to stultifying limself. Thus the counsel achieves an easy victory over the expert, who, while perfectly aware of his awkward predicament, is sorely puzzled how to account for it ; for his opponent's facts are all correct, and his conclusions logically drawn.

Of course, the scenes related by Luther were all a figment of the brain; but, at the worst, it was only a hallucination, not a delusion. These differ from each other in this respect, that the false belief implied in the former is connected with impressions made on one or more of the senses, and does not necessarily prove, as the latter does, any derangement of the understanding. When a man declares that he hears a voice speaking to him from the ceiling of his room, and persists in the 
belief, he is certainly iusane; but if he recognizes and admits his mistake, it is only a casual and temporary derangement of the senses, which cannot, in any proper use of language, be called insanity. Even admitting that Luther persisted to the last in believing that there was no optical deception in the case, and that the devil, hoof, horns, and all, actually entered the room where he was writing, the proof is not complete that this belief was equivalent to a delusion. A close inspection of it shows that it was only a mistake arising from certain peculiarities of opinion, temperament, and cerebral activity, and wanting the indispensable element of insanity. It was, certainly, no delusion to believe in the personality of the devil. It has been the doctrine of the church in all ages, and men have been fond of representing him as going about like a roaring lion seeking whom he may devour. Stories of his bodily appearance among men have always been current, and credited by the ignorant and vulgar, if not by the cultivated and refined. His visits have not been confined to member's of this or that church, nor has his reception differed with their modes of faith. While the reformer salutes him with his familiar weapon, - that weapon by which he spreads cousternation among his foes, - St. Dunstan tweaks his nose with a pair of red-hot tongs. Indeed, in the Middle Ages, the devil's doings on earth were a favorite theme of the clergy, whereby they hoped to terrify the sinner and strengthen his sense of dependence on them. Legends of his pranks were rehearsed at every fireside and social gathering, and no philosophic doubts arose to weaken the intensity of this belief. Then as now he was regarded as at the bottom of all the mischief in the world, the only difference being that while it is with us, generally, a merely spec- 
ulative belief, like that of an old superstition which reason discards, but which maintains its hold on the mind by the force of early impressions, it was with the people of those times a real, active, earuest belief, verified by many a man's personal experience. From a belief in his personal existence and his license to do mischief, to that of his personal bodily presence among men, was but a step. Considering the power with which he was endowed and the great purposes that might be fulfilled by an actual visitation, its possibility could hardly be questioned. That Luther should have so believed, there were peculiar reasons over and above those of a general nature. 'Though an energetic reformer, he was no philosopher like Erasmus, and therefore was quite satisfied with the popular belief of his day. He never doubted that, in the great contest on which he had entered, the powers both of earth and hell were arrayed against him, and the pope and his priests were not more clearly discerned in the opposing ranks than the devil and his angels. Thus far, certainly, there was no delusion. $\mathrm{He}$ believed no more than everybody else believed. If there was any delusion at all in the case, it consisted in going one step farther, - in realizing his theoretical belief. $\mathrm{He}$ thought he saw the devil with his bodily eye, and felt his hot breath upon his cheeks. But this was not necessarily a delusion. It might have been merely a strong impression received in a moment of cerebral excitement, when the nervous susceptibility was sharpened by earnest meditation, by a glow of enthusiasm not many steps removed from the grossest fanaticism, and by a well-grounded assurance that his foes would leave no stone unturned to effect his ruin. Under such circumstances, the inward readily becomes the outward; the intense conception takes on a bodily 
form; in one word, to use a metaphysical phrase, the subjective becomes the objective. That such was actually the fact in Luther's case is rendered still more probable by other incidents in his psychological experience. He complained that the devil lay by his side when in bed at night, and caused him more annoyance than his beloved Catharine caused him joy. Not only that, but the devil would keep him awake disputing on religious subjects, and these disputes he reported in full. This phenomenon is admirably illustrated by Shakespeare, in the case of Macbeth, who saw a dagger in the air with its handle turned towards lim. Indeed, most persons, I apprehend, can call to mind something of a similar kind in their own experience, and many remarkable stories may be found in the books. Nobody ever regarded Macbeth as insane, and yet, psychologically considered, Luther's case was precisely similar.

It may be objected that as Luther never recognized the true nature of the apparition, and never admitted that he was deceived, therefore, according to present definitions, he must be regarded as insane. The objection is well taken; but a careful examination of it will enable us, I doubt not, to remove the difficulties which it implies. It has been just explained how the deception arose; that is, in consequence of a conjunction of circumstances not incompatible with entire soundness of mind. That Luther did not so understand the matter only shows that he was no philosopher, as I have already remarked, and that to his apprehension the incidents in question were within the line of natural occurrences. To believe in the reality of a hallucination necessarily implies delusion and insanity only when it refers to something impossible either in the nature of things or the circumstances of the case. One who be- 
lieves his leg's are made of glass, or that his head has been turned round, is insane and nothing less. He does not even pretend to give a reason for his belief. It is so, and he knows it is so. On the other hand, if the thing believed is not thus impossible, it may indicate only an error of opinion which the person shares in common with others of undoubted sanity. Thus the two elements of Luther's belief are easily accounted for without resorting to the theory of insanity. The apparition itself was the result of certain cerebral conditions of a casual, transient nature ; and, secondly, the persistent conviction of its reality was consistent with the common belief.

The world has always been willing to admit that supernatural occurrences are within the limits of possibility, and that they have actually taken place. How they are to be distinguished from those which, while they appear to be such at first sight, are, in fact, the offspring of cerebral disturbance, is a question not easily answered. As yet there is scarcely the beginning of an approach to unanimity of opinion respecting it. In practice, it has been generally decided rather by favorite habits of thinking than by any fixed rules of philosophizing. The celebrated vision of Colonel Gardiner, in which he saw the Lord Jesus Christ on a cross, and heard him reproach him for his crimes, is described by his pious biographer, Dr. Doddridge, as sent by God. Few, I imagine, would attribute to such an origin the vision of Lord Herbert, who, while hesitating to publish a book he had just completed against the Christian religion, made a formal appeal to the Deity, praying that he might be directed by some celestial sign whether he should or should not print it, and received a favorable response in an audible voice from the heavens. 
We know very well that hallucinations have been exhibited by men of great mental endowments and activity, as insulated facts having little or no connection with the ordinary mental movements. Dr. Johnson, while walking in the street, thought he heard the voice of his mother, then many miles away, calling to him, "Sam, Sam." Sir Joshua Reynolds, after being engaged many hours in painting, and then walking in the streets, said that the lamp-posts seemed to him to be trees and the men and women moving shrubs. Silvio Pellico had hallucinations in prison. He heard groans and stifled laughs. It seemed to him that while sitting at the table some one plucked him by his coat, and attempted to blow out his light. While young, when in a room alone at night, without any light, he saw phantoms all around him, and even after the lights came he would see them in the dark corners.

In most, if not all, of these cases, there rras, undoubtedly, some cerebral defect: but, although hallucinations may indicate that the highest quality and condition of the brain are not present, yet they do not imply unsoundness, - insanity. In fact, Moreau de Tours considers them a proof in favor of his theory, that insanity and genius spring from cerebral conditions essentially alike. ${ }^{1}$ In some of the cases just mentioned, the defect was an insane temperament, - that constitution of mind in which there is an hereditary tendency to insanity indicated by singularities of conduct, opinion, manner; in some, it was a high degree of nervous susceptibility readily inducing cerebral movements of an extraordinary character; in some, it was a casual determination of blood to the brain; and in some it was manifested by

1 La Psychologie Morbide. Paris : 1859. 
epilepsy or other nervous disorder. Luther's case furnishes no exception to the general rule; for, though technically sound, it can hardly be doubted that the genius of the great reformer was of that kind which is nearly allied to insanity. The fact need not be regarded as derogating from his mental ability, for it may have fitted him all the better for the part he was called to perform. A man of cooler passions and less intense conceptions might have written books less offensive to a refined taste, and avoided some injudicious courses, but proved unequal to the internecine war which any determined attempt at reformation was sure to provoke. In such conflicts it is not always the well-balanced minds that achieve the noblest victories. There, it would seem as if the individual must be moved by the quicker and stronger impulses that proceed, if not from disease, yet from some abnormal condition very like it.

I have divelt on the case of Luther, not so much because it represents a considerable class as because it indicates the line of inquiry on which all of a doubtful origin should be examined. It gives us a clew to the follies of witchcraft and to those popular delusions which prevailed epidemically in the fifteenth, sixteenth, and seventeenth centuries. Witcheraft, for instance, was a matter of popular belief. The clergy preached it, the courts punished it, and the Bible was supposed to teach it. Few doubted it, and fewer still ventured even to whisper their doubts. The first step thus accomplished, the next was not difficult. The arts of the devil and the malicious acts of his deluded followers, the compact written in blood and the hellish orgies of the witch-sabbath, the riding through the air on broomsticks, the witch marks found on the person, the potent efficacy of prayer and of the utterance of sacred names, 
- all these were topics of conversation in the family circle and in social gatherings, exciting wonder and awe, and leaving impressions never to be effaced. With few books and no newspapers, with scarcely any interchange of ideas beyond a very limited circle, with the hardships incident to a new settlement, the habitual dread of hostile neighbors, and the gloom of the surrounding forest, all combining to exclude the joyous and hopeful aspects of life, it is just what might have been expected, that, being thus early and constantly familiarized with the wondrous scenes of witchcraft, they should have become, at last, so vivid to the minds of our New England forefathers, as to assume, occasionally, the appearance of an objective reality. For this there was only needed, singly or collectively, a constitutional tendency to hysteria or insanity, an ardent imagination kindled solely by such material as witchcraft lore could furnish, and that propensity to imitation and thirst for notoriety which act so large a part in producing eccentric mental movements, especially in the female sex. Thus was the second step accomplished, and all without the occurrence of proper insanity.

Many false beliefs springing from a coarse superstition can be distinguished from genuine delusions only by a careful investigation of the individual's mental habits and associations. The difficulty of making this distinction is sometimes increased by the fact that such beliefs may have been modified and made the ground of criminal conduct by the presence of actual disease. A colored man who once came under my charge had killed his mother in a paroxysm of insanity. When asked, after recovery, what prompted him to commit such a horrid deed, he replied that he thought she was work- 
ing some fatal spell of witchcraft upon him, and therefore he acted in self-defence. On further inquiry, however, it appeared that, following the traditions of his race, he had always believed in witcheraft, and had always suspected, if not believed, that his mother practised it. So that the belief which led him to kill his mother was not a delusion; and yet it was none the less a valid excuse for the crime, for the reason that while the belief was, ordinarily, passive and harmless, it became, under the excitement of a maniacal paroxysm, an incentive to a most revolting murder.

For the most part, the true character of a false belief may be inferred from the accompanying traits and incidents. A single, independent, solitary delusion, accompanied with no other deviation from the normal condition, is a rare occurrence. It is usually associated with other delusions or singularities of thought, with peculiar ways and manners, with strange and irrelevant conduct. When any of these traits are present, there needs no refinement of definition to convince us that we have to deal with a genuine delusion. And yet we are hardly ready to accept the proposition of Dr. Forbes Winslow, "that no notion of the mind, however ridiculous, fallacious, and absurd, should be admitted to be a delusion or evidence of unsound mind, unless it be obviously and unmistakably the product of a diseased intellect." But Dr. Winslow's large experience must have made him acquainted with cases of unquestionable delusion unaccompanied by any other mental or bodily ailment. Even when accompanied by other minor disturbances, it is not a very philosophical proceeding to make them the proof of the principal and prominent one. If he means to derive the evidence of disease from the quality of the act which springs from the 
delusion, as he may very justly, we can only say that such an inference would receive little countenance from the courts.

There is another phase of belief of great medico-legal importance, which often proves no less embarrassing than delusions. I refer to such notions as are characterized less by false belief than by singularity and extravagance to a degree that may seem incompatible with soundness of mind. No rule or definition will enable us to distinguish such as spring from insanity and such as are only the freaks of what is called eccentricity. The reason is, that there is really no dividing line between these two mental conditions. The latter may exist from childhood and continue for life; but we know that it is often the precursor of insanity, and no amount of skill or sagacity can determine the limits of the transition period. To avoid mistake as far as possible, we must be guided by the antecedents of the person, by an enlarged knowledge of mental disease, and especially of diversities of character, always bearing in mind what our experience of men teaches, that very strange opinions have been entertained by persons of unquestionable sanity. We are not too readily to pronounce a man insane because he professes views that may be at variance with our notions of moral propriety. They may confirm the suspicion of insanity raised by other circumstances. Such is the view of an eminent American jurist, Judge Redfield (On the Law of Wills, 83), in commenting on an English case (Morgan $v$. Boys). A will was contested on the ground of insanity, the proof of which was to be found in one of its dispositions, that his executors should "cause some parts of his bowels to be converted into fiddle-strings, that others should be sublimed into smelling salts, and that the 
remainder of his body should be vitrified into lenses for optical purposes." In a letter attached to the will, the testator said: "The world may think this to be done in a spirit of singularity or whim, but I have a mortal aversion to funeral pomp, and I wish my body to be converted into purposes useful to mankind." The Judge does not insist "that the mere absurdity and irreverence of the mode of bestowing his own body as a sacrifice to the interests of science and art, in so bold and awful a mode, was to be regarded as plenary evidence of mental aberration," but he thinks that a jury would be very likely to regard it in this light - and not unjustly in case of an unnatural or unofficious testament. "The man who has no more respect for himself or for Christian burial, than this will indicates, has no just claim to the regard or respect of others." Still, it is to be considered that the present mode of disposing of the body is not so strongly fived in the instincts or custom of mankind as to prevent an occasional deviation, under the influence of some potent motive, like a devotion to science, a contempt of vulgar prejudices, a foolish but not diseased love of notoriety. Jeremy Bentham directed his body to be dissected, and accordingly it made its appearance on the table of one of the anatomical theatres of London. A distinguished surgeon of Massachusetts ordered that his skeleton should be prepared in the usual way, and placed in the museum of an institution of which he was President. A few years since an Englishman, who had lived much in the East and professed his belief in the Mahometan religion, left a will, bequeathing his property, with the exception of various legacies, to the poor of Constantinople, and also towards erecting a cenotaph in that city, inscribed with bis name, and bearing a light continually burning there- 
in. A thorough review of the habits and opinions of the testator showed that there was notling strange or absurd in this bequest, and it was finally admitted to probate. (Austen $v$. Graham, 29 Eng. L. \& Eq. 38.)

A remarkable case was recently published in the Annales Mledico-Psychologiques for July, 1866, under the title "Partnership with God," that is worthy of an extended notice in a paper like this, because it illustrates very strikingly the principles that should govern our judgment in this class of cases. In 1861 there died at Neufchâtel a notary, Isaac Vaugneux, eighty-two years old, married, but childless. He devised his property to his wife, who died four years after, and she devised it to her niece, who, when quite young, had been adopted by them. Among her uncle's papers this niece found one sealed up, bearing this inscription, Contrat de Société. On examination it proved to be articles of partnership drawn up some years before his death, when about to leave his legal employments and engage in the wine and liquor trade. Nothing less than a literal copy of this document can give an adequate idea of its character.

Articles of Partwership between the great Sovereign God, the all-powerful and all-wise Eternal on the one part, and me, the undersigned, Isaac Vaugneux, his very vile, very miserable, and very humble servant and zealous adorer on the other, have been drawn up as follows:-

Article 1. This commection has for its object the trade in liquors.

Art. 2. My very respectable and very magnanimous associate will deign to bestow, as his share in the capital, his blessing on our enterprise, in the manner he shall judge most agreeable to his paternal views and the accomplishment of the immutable secrets of his eternal wisdom.

Art. 3. I, the undersigned, Isaac Vaugneux, engage, on 
my part, to turn into the above-named partnership all the capital that may be necessary; to do all the business required in the hiring of cellars; in the purchases and sales; in keeping the accounts; and, in one word, to devote my time, my labor, and my moral and physical powers, to the best good of the concern, conscientiously and in good faith.

Art. 4. The books, kept by single entry, shall exhibit every transaction; and the several balances, carried to the debit and credit side, shall be increased by interest calculated pro rata, up to the 31 st of December of each year, when a settlement of the account shall be made.

Art. 5. The net profits shall be equally divided between my high and mighty Associate and myself.

Art. 6. A special account shall be opened with him, in which shall be passed to his credit his share of the profits, and to his debit the several sums which shall have been delivered by me, the undersigned, either to pious corporations, to the poor individually and collectively, or finally to any other pious work which the spirit of my God shall inspire me to do.

Art. 7. When my God shall deem it good to take me from this world, the settlement of the affairs of the partnership shall be immediately intrusted to my nephew, M. Frederic Preud'homme Favarger, who is hereby requested by me to undertake this oharge, after which the share of the profits coming to my great and well-beloved associate, is to be immediately delivered to the direction of the praiseworthy chamber of charity of Neufchatel, to which I now bequeath it.

With the liveliest satisfaction in having associated my God in my labors, I commit myself for success to the wise dispensations of Providence.

Thus done, covenanted, and settled, at Neufchâtel, in my house, under my private signature and the seal of my arms, the serenteenth day of September, in the year of grace one thousand eight hundred and forty-seven (1847).

\section{L.S.}


The great events which have occurred in my country, and the changes that have taken place since this partnership was formed, especially in respect to the persons engaged in the administration of affairs, have induced me to change the destination of that portion of the profits coming to my great and magnanimous associate; and in consequence thereof, and in conformity to the inspiration of his good Spirit, I make the following change in Article 7th:-

The net proceeds coming to my respectable associate, after settlement, if any such there be after my death, is to be remitted, not to the chamber of charity of Neufchâtel, but, on the contrary, to the pastors then in office in the parish of Neufchâtel, to be by them devoted to pious uses at their discretion, some portion to be given to evangelical missions designed to spread the knowledge of the only true God throughout the earth.

I have the confidence to believe that those gentlemen will willingly accept the charge I have assigned to them without consulting them, and that they will enter into my views, for which I here testify, in advance, my sincere and lively gratitude.

Thus done, written and signed in my house at Neufchâtel, the twenty-fifth of March, one thousand eight hundred and fifty (1850).

$$
\text { Signed, I. Vaugneux, Notary. }
$$

March 10, 1855. Our enterprise having been blessed, the share coming to $\mathrm{my}$ great and magnanimous associate, as it may appear on page 79 of my book (current accounts), and page 60 (account of my associate), is to be paid over, three months after my death or that of my wife, to MM., the pastors, as above named. The executor of my will, my nephew, Frederic Preud'homme, having deceased, it will be the duty of my successors to fulfil the conditions of the existing partnership, by paying over this share to MM., the pastors, 
if, as I expect, they should be willing to take charge of it, to be invested in the most productive manner, and the capital and income used according to their discretion under the divine inspiration.

A copy of this document was placed in the hands of one of the pastors by the writer before his death. After the widow died it was opened, and the pastors made application to the Council of State, according to the municipal law, for authority to receive the money. This was refused, for the reason, as the Council state, that the paper in question is "the act of a disordered mind." The niece, when she came in possession of the property, fulfilled the wishes of her uncle by making a gift of the money for the purposes he had indicated. This she did out of the high regard she had for him, and gratitude for care and kindness towards herself. She repels with a good deal of warmth the idea that he was insane. "Although he might have been regarded as somewhat original," she says, "yet it never entered into the thought of any one that his reason was deranged. I, who was always admitted to his closest inti. macy, know that he possessed all his faculties to the last moment, and I revere his memory as that of a just and upright man." It is also stated that no trace of mental disorder could be found in any of his writings; that his books were well kept, the entries made, the interest reckoned, and the balances got as correctly as possible, all according to the articles of copartnership.

No one can help suspecting, at first glance, that the head of this worthy wine merchant was somewhat turned. The astonishing audacity with which this really religious man associates the Almighty with himself in a mere matter of trade and traffic, the coolness 
with which he assigns to the partners their respective duties in the concern, and the perfect confidence on the part of one who had been accustomed to legal forms and proceedings, that such a paper would not fail by reason of any legal defect, would certainly justify such a suspicion. But a broader view of psychological diversities of character will lead us to doubt whether the case is not one of those occupying that border land between sanity and insanity which bears the name of eccentricity, oddity. Taking into view the prominent incidents of the case, it may be satisfactorily explained without resorting to the theory of insanity.

Here was a worthy old man, accustomed to see the hand of God in every event of life, and to look to God at every turn for help and direction, about to embark in a new undertaking. Feeling that men must labor in vain without the blessing of God, and feeling it, too, not as a glittering generality, to be coldly acknowledged and then forgotten, but as a vital principle of action directing and controlling every movement, his first thought was naturally to secure that blessing for himself. Both reason and religion assured him that nothing could more effectually accomplish this object than, while working for himself, to work for the glory of God. What more acceptable service could he render than to devote a portion of his earnings to charitable and religious uses? That this purpose may not be lost sight of, that it may be ever kept before him as the sole, animating, all-pervading principle of his life, he resolves to recognize and consecrate it in a form the most solemn and imperative. Thus far, surely, there is no trace of insanity. The purpose is worthy of the strongest endeavor and the purest aims, and is steadily and successfully pursued for years. The logic, too, is all correct, without 
fault or gap. The only thing to which exception can be possibly taken is the form which he has chosen for the expression of his intentions and motives. This seems to savor of insanity, but it will hardly bear the test. Be it observed that it conflicts not at all with the object proposed, but rather aids and promotes it. It exhibits no trace of delusion or even irrelevance. True, the idea of forming a partnership with God seems most extravagant and presumptuous, and the language used is perfectly shocking to a correct religious taste. The presumption, however, is more apparent than real. This old man, having been accustomed all his life to the use of legal forms, with a high opinion, no doubt, of their fitness for the expression of all ideas whatever, not unnaturally, though somewhat pragmatically, chooses them on this occasion. It only shows the force of habit and the narrowing tendency of a professional routine. Any other man, having resolved upon accomplishing the same thing in a similar spirit, would have formally declared his intention to devote one-half the profits of the new enterprise to charitable and religious purposes, and reverently invoked the divine blessing on his labors. And he might have opened an account on his books with "Charity Fund," or something equivalent, making the same entries to debit and credit, and directing his executors to pay over the balance that might exist at his decease to some institution or trustee. The document in question exhibits a very common mark of eccentricity, - that of saying or doing a very proper thing in a queer, singular manner. In insanity the mental affection as often appears in the design as in the execution. In fact, the latter may be all right, while the former is all wrong. We must bear in mind, too, the effect of religious associations and of the prevailing style of 
religious thought and feeling. That must vary with the moral and intellectual culture, the form of faith, the customary observances, the temperament and spirit. All this must be considered before we can properly estimate the true pathological significance of this extraordinary contract. Nany a prayer and sermon may still be heard, once more frequently than now, implying a close participation in the counsels of God, and administering advice, suggestion, and even reproof, more befitting a member of a mercantile firm writing to his partner than a worm of the dust addressing his Creator. In the works of English divines, two hundred years ago, may be found passages relating to the counsels of the Almighty clothed in terms of such gross familiarity that to quote them even would be enough to expose one to the charge of irreverence. We venture upon one quotation, however, that the reader may see how conventional are all proprieties of speech on sacred subjects, and thus understand that much latitude in this respect does not necessarily imply insanity. It shows very strikingly that such things must be judged not by any arbitrary rule, but by the light of prevailing practices, modes of thought, and forms of expression. It is from Flavel, a non-conformist divine of Charles the Second's time, whose writings have been held in great repute, and frequently reprinted, even down to our own day. The following extracts are from a sermon setting forth the scheme of redemption, the text being Isaiah liii. 12 :-

"Having told God how ready and fit he was for this service, he will know of him what reward he shall have for his work, for he resolves his blood shall not be undervalued: hereupon, verse 3 , the Father offers him the elect of Israel for his reward, bidding low at first (as they that made bargains use to do), and only offers him that small remnant, still 
intending to bid higher; but Christ will not be satisfied with these, he ralues his blood higher than so; therefore, in verse 4, he is brought in complaining, I have labored in vain and spent my strength for nought. This is but a small reward for so great a suffering as I must undergo; my blood is much more worth than this comes to, and will be sufficient to redeem all the elect dispersed among the isles of the Gentiles, as well as the lost sheep of the house of Israel. Hereupon the Father comes up higher, and tells him he intends to reward him better than so, and therefore, verse 6 , says, It is a light thing that thou shouldest be my servant, \&c. . . . Here you may suppose the Father to say when engaging this bargain with Christ for you:-

"Father. My Son, here is a company of poor miserable souls that have utterly unlone themselves, and now lie open to my justice. ... What shall be done for these souls?

"Son. O my Father, such is my love to and pity for them, that rather than that they shall perish eternally, I will be responsible for them as their surety: bring in all their bills that I may see what they ore thee, Lord, bring them all in that there may be no after reckoning....

"Father. But, my Son, if thou undertake for them, thou must reckon to pay the last mite, expect no abatements; if I spare them, I will not spare thee."

The feature in the proceeding of Vaugneux which raises the strongest suspicion of insanity is the testator's unhesitating belief that such dispositions of property would be confirmed by the law. It might be supposed that a person professionally acquainted with the laws of his country would have avoided a mistake so fatal to the fulfilment of his own wishes, and provided for an object he had so near at heart, by measures strictly conformable to law. There would seem, at first thought, to be something in this; but, practically, such mistakes, I apprehend, are too common among lawyers 
to be a strong indication of mental aberration. M. Vaugneux is not the first nor the last in his profession who has drawn a will that could not be executed, or shaped it in such a manner as to frustrate the strongest wishes of the testator.

In this connection, it is proper to consider another fact that may have had some bearing on this case. The idea of forming a partnership with God did not originate with M. Vaugneux. In the fourth volume of an old collection of Causes Célèbres, published in Paris in 1736 by Jean de Nully, may be found a similar case that was adjudicated in Paris a few years before. A young Frenchman, named Duhalde, after various unsuccessful business enterprises, "resolved," as he expressed it himself, in his diary, "to form a partnership with God, promising and vowing to fulfil all the conditions, as here set forth, and engaging my heirs, whoever they may be, to execute them, in case I shall die before being able to do it myself." The business of the firm was to be trading in precious stones, and was to continue five years, from 1719 to 1724. By the conditions of the partnership, he was to furnish the funds, fifteen thousand livres, - all he possessed, - and God was to bless the enterprise. He obligated himself to form no other partnership during the five years. At the end of this period, the accounts of the firm were to be settled; and, after deducting the original capital, fifteen thousand livres, any dowry a wife might bring him, and any legacies he might receive, the remainder was to be equally divided between him and God. In October, 1724, when the partnership expired by limitation, Duhalde made up the books and presented an exact account of receipts and disbursements. After making the deductions just indicated, the profits were represented by three collections 
of precious stones, one of which was in Amsterdam, one in Madrid, and the other in Paris. The last-named he placed in a packet, and marked it, "Half for the Poor," and at the foot of the account he wrote the following words :-

"Cursed be my heirs, whoever they may be, if, under any possible pretext, they withhold from the Poor half of the proceeds of the sale of the stones above-named, in case I die without executing my own wishes. And if, by some extraordinary chance, my fortune shall be reduced to this single amount, let it be considered as a sacred trust which is to be sacredly paid."

Duhalde died shortly after, learing a wife and child, and the "Hôpital Général" claimed of the executors of his will the portion of stones indicated to be given to the poor. The widow, by her counsel, resisted this claim, chiefly on the score of some legal objections drawn from the provisions of the Coutume de Paris respecting wills, whereby the contract and its results were shown to possess no legal validity. Another objection, extra legal in its nature, was that in this arrangement there could be created no obligation on the part of God. A partnership supposes equal and reciprocal obligations. Eren Duhalde himself was not obligated, for he had not signed the articles of partnership. This very objection was urged in the Vaugneux case. The fact was also stated that Duhalde was a very singular man, with odd, strange ways; but it does not seem to have been contended that these mental peculiarities amounted to testamentary incapacity. By the counsel for the will, one of whom was the son of the celebrated Chancellor D'Aguesseau, it was contended that there was nothing in reason or Scripture to forbid the idea of 
a contract with God. He contributed nothing directly to the funds of the firm; but was not the testator indebted to him for the capital on which he started? "Considered as a contract with God, the present case is not without precedents in the dealings of God with man. Did not the Lord make a covenant with Abram, whereby the latter, in reward for his fidelity, obtained the land of Egypt for his posterity? Did he not also make a covenant with Noah, promising never again to cut off all flesh by the waters of a flood, and to place the bow in the cloud as the eternal seal of the promise? The sacrament of baptism, too, - is not that in the nature of a contract with God? Will it be said that this being a contract for spiritual purposes has no analogy to a business partnership like Duhalde's? But what was the animating spirit of the latter? Was it not the love of God and our neighbor? Was not the object of this connection a purely spiritual good? In thus renouncing his earthly goods, and associating himself with the Almighty, did not Duhalde form a more perfect union with God?" The court, governed solely, it may be presumed, by the legal considerations, decided in favor of the will.

It can scarcely be doubted that Vaugneux's professional studies had made him acquainted with this old case, because the collection in which it is contained is well known to every French lawyer. It might have suggested to him the bold idea of associating himself with God, and the decision of the court would have removed any doubts respecting its legality.

In consideration of all the circumstances necessary to be considered, we can scarcely hesitate to believe that this testator can be charged with no mental defect equivalent to insanity, and was competent, of course, to 
devise his property as he did. Had he, on the contrary, as Dr. Chatelain, who reports the case, observes, completely disinherited his heirs, who had a moral right to rely on his bounty, then the case might have borne a different construction. 


\section{CONFINEMENT OF THE INSANE.}

UNTIL within a comparatively recent period, hospitals for the insane were used only for those who were supposed to be dangerous to others, or who needed public support; and admission was procured, on the order of the judicial or municipal authorities. As the nature of mental diseases became better understood, the hospitals began to be regarded as being well fitted for the cure of curable cases, and, at last, this has got to be their principal purpose, insomuch that those who were held merely for safe keeping have had to give place to those who sought for recovery under their healing influences. This change of function occurred so gradually, and in such strict accordance with an enlightened humanity, that no additional legislation seemed to be necessary to sanction a step which, though prompted by the best of motives, was unaccompanied by any of those legal formalities that were required for the admission of other classes of patients. The danger of these institutions being converted to the nefarious purpose of depriving sane persons of their liberty was scarcely thought of. A crime so revolting to every sentiment of right and humanity, and requiring the coöperation of parties so unlikely to work together, seemed to be too improbable to make any special legislation supererogatory. So, too, the duty of placing the insane in establishments 
that were regarded as best calculated to effect their restoration, seemed to spring so naturally from the purest affections of our nature as to require no act of the legislature to give it force and validity. Fifty years ago, it struck the people of that generation, that to legalize such a duty was like reënacting a law of nature.

Of late years, with little or no foundation therefor, a change of sentiment has occurred, whereby admission to hospitals for the insane has come to be regarded, by some per'sons, as exceedingly liable to be perverted by bad men from its proper purpose. To prevent this result, additional legislation has been proposed, which should surround this measure with safeguards commensurate with the abuses that threaten it. Such legislation, varying considerably in its character, has been actually adopted in a few States. In some, it has refrained from disturbing the right and duties of friends as prompted by natural affection and consecrated by time-honored practice. In others, it has substituted for these the action of public authorities; and a service of love and liumanity has been replaced by an unfeeling process of law. With these exceptions, however, there has been no change of law respecting the confinement, or, technically speaking, the isolation, of the insane. How far the right of friends exists, under the common law, to provide for the insane as they would for any other description of sick persons, - that is, by giving: them the benefit of all the means and appliances which a progressive philanthropy and science have furnished, - is not very clearly defined; for, in the few cases that have been reported, the decisions of courts have been somewhat conflicting. Nor has all uncertainty been removed, even where laws have been specially enacted 
for this purpose. And thus it happens that, in regard to a measure involving the highest welfare of a large class of persons, we have the utmost diversity of opinion; and the public mind is vexed by wild and extravagant projects utterly inconsistent with existing modes of thought and established customs. In a matter so closely connected with the dearest interests of families, one, too, which so easily arouses the prejudices of the multitude, the law should give no uncertain sound. No one should be in doubt how far his duties to the victim of disease are modified by the single fact that the disorder is seated in the brain, rather than in the stomach or lungs; nor should any one run the risk of finding an office of kindness and humanity made the occasion of a troublesome suit at law. As to the necessity of some legislation on this subject, there can scarcely be two opinions; but we shall be better prepared to determine exactly what it should be by considering the existing law as declared by judicial authorities.

The case of Colby $v$. Jackson, 12 N.H. 526 (1842), was an action of trespass for assault and battery, and false imprisonment, in which the plaintiff claimed damages of the defendant, for having placed him, while insane, in confinement, without having strictly complied with the requirements of the statute. The selectmen of the town, one of whom was the defendant, being solicited to take charge of Colby, who was supposed to be dingerously insane, applied to the Judge of Probate for authority to act, and were accordingly directed by him to make inquisition into the case. This they did, but made no return of the inquisition, though they found him to be dangerously insane, and had him confined in a cage at the poor-house for two or three months. 
It was urged by the defendant that the dangerous element in the patient's case atoned for the irregularities in the mode of commitment; but a verdict was given for the plaintiff, with nominal damages. The defendant excepted to the rulings of the court at the trial. Chief Justice Gilchrist, in rendering the decision of the court, declared, in the most unqualified manner, that an insane person, however dangerous he might be, could not be kept in confinement beyond the period necessary for obtaining an inquisition, or some other legal process. "The right to imprison the plaintiff," he said, "was an authority given by law. . . Such an authority is possessed by no person unless under the sanction of, and after compliance with, the forms of law. No relationship, however near, no ties of friendship, however close, between the lunatic and his keeper, would render the existence of such a rule consistent with the safety of the community. . . Every cage could be a licensed private mad-house. . . . Any citizen could confine his neighbor, provided only he were insane; and, if the confinement were to continue as long as the insanity, both would probably end only with the life of the patient."

In Nottidge $v$. Ripley, 12 Law Reporter, 279, which was an action to recover compensation in damages for incarcerating the plaintiff in an asylum, tried in the Court of Exchequer, June 23, 1848, it appeared that the plaintiff was placed in a private asylum by her mother and brother-in-law; all the requirements of the statute for the admission of patients into asylums having first been strictly complied with. The insanity was not denied; but, inasmuch as she did not appear to have been dangerous, the counsel for the plaintiff contended that the confinement was illegal, and claimed heavy 
damages. Their view of the illegality of the measure was fully sustained by Sir Frederick Pollock, the Lord Chief Baron, and for the reason alleged. His views are summarily expressed in one of the head-notes of the case. "Unless a person alleged to be insane is of unsound mind, and dangerous to herself and others, no person can remove her from her home to an insane asylum, without the sanction of a commission of lunacy." To one of the Commissioners in Lunacy, who was a witness in the case, and whose especial business it was to look after the asylums, he said: "It is my opinion you ought to liberate every person who is not dangerous to himself or to others."

In the first of these cases, the rule is laid down in the most unequivocal manner, that, under the common law, no person can be confined on account of insanity, without some process of law. In the other, an exception is made in favor of such cases as are supposed to be dangerous. As the statute ( 8 \& 9 Vict. c. 100) prescribes certain conditions without which no person can be received into any asylum or hospital for the insane, this may be fairly considered as equivalent to a grant of authority. It can hardly be supposed that this provision was overlooked at the trial, though it is a curious circumstance that it was not once mentioned by either party. However this may be, it appears none the less clearly what was the opinion of the court respecting the common law on this matter.

In the matter of Shuttleworth, 9 Q. B. 651 (1846), a somewhat different view was taken. This was an attempt, by means of a writ of habeas corpus, to obtain the discharge of a lady from an asylum in which she had been detained several months, for the reason that one of the queries which always accompany the order 
of admission was not answered precisely in the words prescribed by the act. The return to the writ was, that she was " of unsound mind, memory, and understanding, and incapable of governing herself or her property, or managing her affairs, and unfit and unsafe to be at large." Governed by this return, Mr. Justice Coleridge observed that "he was not prepared to concede that if the certificate were deficient, they were to discharge." To the counsel who claimed the discharge on the ground that the confinement was illegal, the Chief Justice, Lord Denman, said: "Is not the confining. of a dangerous lunatic founded on common law principles?" And, as if to recognize in the most distinct manner the right of friends to care for the patient, even though it involved confinement, he further said: "If the court thought a party unlawfully received or detained was a lunatic, we should still be betraying the common duties of members of society, if we directed a discharge. . . Should we, as judges or individuals, be justified in setting such a party at large? . . . I should be abusing the name of liberty, if I were to take off a restraint for which those who are most interested in the party should be most thankful."

In Commonwealth, ex relatione Nyce $v$. Kirkbride, county of Philadelphia, March 7, 1868, 2 Brewster, 400, the relator claimed his discharge from the Pennsylvania hospital for the insane, where he had been kept several months, on the ground that if insane he was not dangerously so. The return to the writ was that he was insane, and that his discharge would be dangerous to his family. Upon this point much evidence was given on both sides. The two physicians of the hospital, and seven other witnesses, most of them relatires, concurred in establishing the correctness of the return, while a 
few others testified, quite positively, that he was sane. The court, not being satisfied that he was dangerous, directed him to be discharged. In rendering the judgment of the court, Judge Brewster declared " that the power to remand, where there has been no finding of lunacy, should be confined to the preservation of the patient, and the public peace and morals."

Shortly after the hearing of the case just mentioned, Moore, an inmate of the same institution, was brought before the same court, on a writ of habeas corpus. His discharge was claimed on the ground that he was not then, and never had been, insane. In declaring the opinion of the court, Judge Allison, while distinctly recognizing the fact of Moore's insanity when admitted into the hospital some eleven or twelve weeks previously, regarded him as so much improved, "though manifesting, in court, considerable excitement of manner," as to conclude that "it would not be unsafe to discharge him from custody, or that he would not do violence to himself or others." On this ground, mainly, " aided by the belief that his entire recovery would be aided by freedom rather than by farther restraint of liberty," the court directed his discharge.

In January, 1845, Josiah Oakes was brought before the Supreme Judicial Court of Massachusetts, on a writ of habeas corpus; the object of which was to procure his discharge from the McLean Asylum for the Insane, to which he had been committed by his family, on the 16 th of the previous month. Chief Justice Shaw, in delivering the opinion of the whole court, replied to the allegation of counsel that the constitution makes it imperative upon the court to discharge any person detained against his will; and that, by the common law, no person can be restrained of his liberty, except by the judg- 
ment of his peers, or the law of the land. "We think," said he, "there is no provision, either of the common law or the constitution which makes it the duty of the court to discharge every person, whether sane or insane, who is kept in confinement against his will., The provision, if it be true, must be general and absolute, and not-governed by any questions of expediency to suit the emergencies of any particular case. The right to restrain an insane person of his liberty is found in that great law of humanity which makes it necessary to confine those whose going at large would be dangerous to themselves or others. . . The necessity which creates the law creates the limitation of the law. ... If there is no right to exercise that restraint for a fortnight, there is no right to exercise it for an hour. And if a man may be restrained in his own house, he may be restrained in a suitable asylum, under the same limitations and rules. .. The provisions of the constitution, in relation to this subject, must be taken with such limitations, and must bear such construction, as arise out of the circumstances of the case. Besides, it is a principle of law that an insane person has no will of his own. In that case, it becomes the duty of others to provide for his safety and their own. ... The question must then arise, in each particular case, whether a person's own safety, or that of others, requires that he should be restrained for a certain time, and whether restraint is necessary for his restoration, or will be conducive thereto. The restraint can continue as long as the necessity continues. This is the limitation, and the proper limitation." The court being satisfied that Oakes was insane when admitted into the asylum, and that he had not yet fully recovered, refused to discharge him, adding, that "the restraint should 
last as long as is necessary for the safety of himself and of others, and until he experiences relief from the present disease of his mind." 8 Law Reporter, 122.

Here the point is well made, that, if the common law does not authorize the confinement of the insane, its operation must be absolute and unconditional. No exception is made in favor of those who are dangerous, or are offensive contra bonos mores. Its silence creates no warrant for depriving a person of his liberty, even for a single hour. If, on the other hand, the apprehension of danger does warrant us in law to restrain a person's liberty, then, for a reason equally strong, the promotion - of the person's comfort and restoration should have the same effect. The court takes care, by repeated iterations, to have it understood that to promote the recovery of the patient is a sufficient warrant for his confinement in an asylum. It is required also by the law of humanity, which, like the common law, is founded in reason, and thus may be justly regarded as part and parcel of the common law.

The views of Chief Justice Shaw were fully indorsed a few years later, in Pennsylvania, in the well known case of Hinchman $v$. Richie, Brightly, 143 (1849). The plaintiff having been placed in an asylum by his friends, without any legal process, his counsel contended that the act was contrary to the Bill of Rights, and a violation of the constitution of Pennsylvania. The court, Judge Burnside, said: "I do not agree to that proposition: it would have been true, had he been charged with a crime; but the right to restrain an insane person of his liberty is found, as expressed by Chief Justice Shaw of Massachusetts, ' in the great law of humanity.' The Pennsylvania hospital was in existence half a century before the adoption of the constitution of 1790 , 
and it was in existence and operation, as well as this asylum, when the amended constitution of 1838 was adopted. So that those gentlemen (and they were men of talent and distinguished ability, in both conventions, and especially the convention of 1790 ) who formed this constitution, had the practice of the Pennsylrania hospital before them; and the late convention had before them, in addition to that, the practice of this asylum. I then negative the proposition that it is a violation of the constitution of Pennsylvania so to arrest and confine an insane man."

Alluding to this case, Wharton and Stille, in their Treatise on Medical Jurisprudence, say: "There are, necessarily, cases when the safety of property, and the health of the patient himself, require confinement in an asylum, though there be no danger of violence to himself or others; and it is not likely that the existence of such cases will be again judicially questioned. . . . The law, in such a case, undoubtedly is, that confinement is justifiable, if either the safety of the patient or others require it, or it is necessary for his restoration to health."

The doctrine clearly implied in most of these cases is, that, without some legal process, insane persons cannot be held in confinement under the common law, though exception is made of such as are proved to be dangerous to themselves or others. Danger, then, is the element which is to legalize that which, without it, would be manifestly illegal. It is proper that a doctrine of such extreme importance, determining, as it must, the question of confinement or liberty, should be thoroughly understood, in order to avoid mistakes involving the most serious consequences. Let us, therefore, consider it by the light of professional observation, - the ouly 
light that can be trusted on a strictly professional sulject, remote from men's ordinary thoughts and experience.

A proclivity to mischief is one of the most common traits of the insane. Yielding to passions unchecked by moral or prudential restraints, controlled by delusions that are mistaken for the most vivid of realities, moved by impulses that are completely irresistible, delighted by what would otherwise have caused unutterable pain and disgust, they are, necessarily, by the very conditions of the case, dangerous. Not that the danger is always imminent, or always extreme. If passionate and quarrelsome, the patient may, for a while, be kept in good humor by adroit management; if suicidal, he may merely revolve the idea of self-destruction until a peculiarly favorable moment invites him to make the attempt; if strong delusions lead him to regard his dearest friends with distrust and aversion, he may long refrain from actual violence by lack of a rigorous will that may come, sooner or later. Under the skilful management of a hospital, removed from countless causes of excitement, and guided by those who are well acquainted with the ways of the insane, he may cause no alarm; and, indeed, may seem, to a casual observer, quite free from dangerous dispositions. This element of insanity is so dependent on circumstances, so shielded from observation, so masked by amiable traits of character, so modified by physiological conditions, - by a little more or a little less blood in the hear, by the approach of a menstrual period, or some unusual nervous movement, - that it may be easily overlooked by an unpractised eye. A long, close observation of a certain patient may enable one to say that he is harmless; but it would be the height of foolhardiness to say this of 
any patient on the strength of one or two interviews. The records of insanity show that some of the most fearful acts of violence have been committed by those who were supposed to be harmless, and who, for years, had possessed unrestricted liberty. We do not deny that some insane persons may go all their days without harm to person or property; but we do deny that we ever can predict with any tolerable degree of certainty that such will be the case.

The prominence given by courts to this matter of danger seems to imply that the only function of hospitals and asylums sanctioned by law is to take the custody of such insane as are unsafe when at large, and without friends to care for them. Hundreds of years ago, such was undoubtedly the fact; but in our days, thanks to modern philanthropy, these establishments are arranged and managed with the special purpose in view of curing the disease, and restoring the sufferer to society. For this eminently proper and commendable purpose they are resorted to by thousands, as medicinal springs and water-cures are for the relief of bodily diseases, with as little thought of law in the one case as in the other. It is not easy to see why the legislature should prohibit the friends from doing that for the restoration of the patient, which may be done for the protection of society against contingent danger. The remarkable change that has been effected in hospitals for the insane, whereby, instead of heing dreary prisons for the safe keeping of dangerous people, they have become pleasant abodes, furnished with every appliance for promoting the mental and physical comfort of their inmates, and fitted by all their arrangements to reclaim the wandering mind, should not be ignored by the legislative power. It is to be regretted that from any 
quarter countenance should be afforded to the vulgar notions which represent these useful and benevolent institutions as prisons, Bastiles, into which those who enter leave all hope behind.

But it is not merely for the curable and the dangerous classes that hospitals are established. There are a multitude of other mental conditions that require their peculiar ministrations, and many other ends to be obtained besides the cure of the patient, and the safety of his friends. The comfort of individuals, the peace of families, the good order of society, are objects as clearly within the scope of the operations of a hospital, as the cure of the curable and the custody of the dangerous. There is that large class without near friends or relatives, whose freaks and fancies render them improper inmates of a private family. There are those who wander from their homes, and expose themselves to serious privations and dangers. There are men who preach or proclaim their delusions in the streets, followed about by a rabble of men and boys. There are women who fancy themselves in love with men, and persecute them with their unseasonable attentions. There are those who disregard all the conventions of society, entering houses at unsuitable times, dressing without thought of the customary proprieties, or even decencies, stirring up strife between neighbors, spreading discord and confusion wherever they go, and exciting the alarms of the weak and timid. There are those who, while under the easy and uniform restraints of a hospital, are harmless and comfortable, but become dangerous subjects the moment they take their accustomed place in society, in full control of themselves and their families. Now, are all these afflicted ones to be denied the care and protection of the hospital because they are neither curable nor 
technically dangerous? If such is the law, have we not good reason to say that the law is regardless of that advance in Christian sentiment, which, in these our days, wonld bring within the benign influences of the hospital all the unfortunate victims of mental infirmity?

In the Nyce case, the judge had some conversation with the patient, on the strength of which he remarks, that "it must be conceded that the relator has sufficient intelligence to remember and detail the history of his family and business life;" and concludes that, "even if partially insane, it might be a serious question whether a conrt upon a finding of lunacy would order his confinement in an asylum." In other words, the opinion of the judge is, that partial insanity does not warrant the confinement of the insane. We are not told precisely how this form of disease differs from other forms; and yet, if this is to be the rule, such knowledge would seem to be indispensable. Let us see, then, for ourselves what ground there is for this distinction.

The use of certain terms, as a matter of conrenience, rather than as an expression of a scientific fact, has led to a widely prevalent error respecting the nature of insanity. Excepting in a few forms of mental disease, such as raving mania and the last stages of dementia, where the power of correct reasoning is entirely lost, some of the mental operations of the insane are conducted with ordinary correctness. On many subjects the judgment is as sound as ever, the power of arlapting means to ends is unimpaired, the perception of moral relations is scarcely obscured, and to the casual observer no indication of insanity whatever may appear. We are not referring to monomania, strictly so called, - a mania which is confined to a single idea, - but to insanity generally, in which time and occasion only are needed 
to show that the mental operations are extensively involved. They may show that this person, so calm in his manner, so judicious in his remarks, so pure and high-toned in his feelings, entertains notions respecting the doings and designs of certain individuals, as baseless as the fabric of a vision, which no argument nor proof of any kind can make him abandon. Impelled by these notions, and utterly ignoring the laws of God and man, he is ready to commit some violence upon the supposed offender, as if it were something both right and necessary for him to do. Every week the newspapers relate some dreadful atrocity committed by persons who were only partially insane. Indeed, it is this very ability, still left them, to pursue a connected train of thought, to make plans and arrangements for future action, that makes them far more dangerous than those are whose minds are in a state of general bewilderment and confusion. This great mistake respecting the extent of the morbid influence exerted by disease is one which the world is reluctant to correct. It meets our notice on the bench and at the bar; in the circles of the refined and educated, as well as of the coarse and ignorant. It is made an occasion of hardship and wrong to the unfortunate and helpless, and blocks the way to every improvement in the administration of the laws.

- Another reason assigned by the judge why a person partially insane should not be kept in an asylum is derived from Dugald Stewart. "It is a question," says this eminent philosopher, "whether certain kinds of insanity have not a contagious tendency. That the incoherent ravings and frantic gestures of a madman have a singularly painful effect in unsettling and deranging the thoughts of others, I have more than once experienced in myself; nor have I ever looked upon this most 
afflicting of all spectacles, without a strong impresinn of the danger to which I should be exposed if I were to witness it daily." All this amounts to nothing except to show what wretched logic eren a great metaphysician may be guilty of. It is very much as if he had said: "I am so terribly afflicted with bunions, that it gives me extreme pain to walk a quarter of a mile: therefore I advise everybody to refrain entirely from walking;" or, "I have more than once experienced great pain and irritation in my eyes when reading by gas-light, therefore every man who reads by gas-light does it at the peril of his eyes." Although not strictly germane to the matter in hand, we cannot forego the opportunity to say that Mr. Stewart's experience is exceptional; that of the hundreds of sane people, within our cognizance, who have been closely associated with the insane in large establishments, for year's together, we cannot call to mind one who became insane, or was likely to be so. No doubt where there is a strong disposition to the disease, such association tends to develop it; and this effect is especially obrious where the parties brought together are nearly related, and the offices of care and attention naturally incident to such relation draw largely on the bodily strength and the moral emotions. The danger arising from this cause is often a sufficient reason for removing the patient from lome and the customary surroundings. But, however that may be, the question is not as to the effect upon sane people of intimate association with the insane. Even if it were as bad as the court would bave us believe it is, it would not follow that the partially insane would be likely to lose the little sanity that remains. by associating with persons more insane than themselves. Such is not the experience of men who have had charge of thousands of patients and 
observed them under every possible variety of influence. For the most part, the insane are too much occupied with their own condition to be troubled by the conduct or discourse of others. A few, perhaps, would find fresh occasion for their morbid suspicions and alarms, by being exposed, indiscriminately, to other patients; but it must be understood that, in modern hospitals for the insane, the means of classification are so ample that the mischief which might result from improper associations is reduced to almost nothing. Those who are likely to annoy one another are easily kept apart, and those are brought together who would exert a salutary, or at least a negative, influence on others around them. If the court supposed that the relator, in this case, was in langer from his associations, it is to be regretted that the medical gentlemen who had charge of him were not particularly examined on that point. Their testimony would have furnished far better grounds for a practical conclusion, than the nerrous apprehensions of Dugald Stewart.

Another reason advanced by the court for the discharge of Nyce is strictly legal; yet, without undue presumption, we think we may venture to examine it. "A judge," it is alleged, "has no power upon habeas corpus, to make a decree which may result in imprisonment for life, without the chance of a jury trial. . • . A man is sent to an insane asylum by his relatives and family physician. They institute no proceeding in lunacy, but deprive him of liberty and property, without any direct sanction of law. . . At last he is able to sue out a writ of labeas corpus, and comes before a judge who cannot be expected to be an expert upon such a question, and who, looking at the evidence, concludes that the man is insane, and remands him. It is 
then res adjudicata, and it might be that no other judge would review the decision. Thus, without a finding of lunacy, without the right of traverse to a jury, or appeal to the Supreme Court to correct errors in the proceeding, a man may be detained for life."

Now, to our apprehension, no mode of legal procedure is so well calculated to determine the truth in cases like these, as a hearing under a writ of habeas corpus. The judge is not an expert, it is true; neither are jur men. $\mathrm{He}$ can have the testimony of experts, and they can do no better. In regard to these as well as other witnesses, he enjoys a privilege that does not exist in a jury trial. He can continue the hearings until he has had the fullest opportunity to learn the merits of the case. Supposed, as he is, to be a man of considerable culture and some knowledge of men, he would be far more likely to weigh the evidence correctly and discern its real significance, than the majority of jurymen, who are totally unfitted by education and habits to appreciate the value of testimony on a question so strictly professional as that of insanity, to say nothing of their liability to be governed by prejudices or whims. Surely, if there is any description of cases more likely to be adjudicated correctly by a judge than by a jury, this is it. We cannot see how a case thus disposed of becomes res adjudicata, in the sense attributed to it by the court. What is to prevent the same or any other judge from reviewing the case after the lapse of a few months? The condition of the person may have so changed within that period as to furnish satisfactory reasons for again issuing the writ. Certainly, no judge would refuse to grant the writ, under such circumstances. Neither is it very clear how the decision of a judge can keep a patient in confinement for life any more effectually than the verdict of a 
jury. They both fulfil their appropriate purpose of declaring authoritatively as to an existing state of facts. What the facts may be at some future period, it is for future judges to determine. The verdict of a jury convened by a commission of lunacy does not place a man in confinement. It may anthorize the guardian or committee to do it, and his action could be traversed only by a writ of habeas corpus. Without that, it may be a confinement for life, if he and the keeper will it.

Another reason assigned by the court for its decision in this case is, that a judge may err; and in this connection the opinion of Spurzheim is quoted, that even experts may err, for they certainly disagree. Unquestionably, judges and experts are both liable to mistake; nevertheless, the law requires that in certain cases the judge shall decide without the intervention of a jury, and permits experts to testify, however widely they may differ from one another. Their differences may embarrass a jury even more than they would a judge, unless it determines in the outset, after the manner of juries, to give no heed to them whatever. "Spurzheim," says the court, "was not willing to trust the solution of such questions to the medical experts." What Spurzheim actually said will hardly bear this construction; for his statement, as quoted by the court, is, that, "as sometimes the most experienced and able men are at a loss and find it impossible to decide whether there is insanity or not, it must be obvious that not every one who knows how to compose some prescriptions ought to be trusted with the privilege to dispose of the liberty of his fellow-citizens;" meaning, of course, that, as the most accomplished expert may sometimes doubt, it would be improper to rely on the opinion of a mere compounder of prescriptions. He expresses neither willingness nor un- 
willingness to trust the solution of such questions to inedical experts, for that was not the point he was considering.

The reason assigned in the case of Moore, for the discharge of the patient, would be equally applicable in a large proportion of the cases in our hospitals, and therefore deserves to be carefully examined. Undoubtedly there is a patient, now and then, whose convalescence would be as speedily conducted to the last stage of recovery at home as in a hospital; but it is difficult to distinguish them from the much larger portion who would be grievously injured by the change. Friends often solicit it, and no duty incumbent on the physician is more embarrassing, requiring a readier discernment of the countless phases of mental disorder, more practical sagacity in penetrating beneath the surface, than that of meeting their wishes judiciously. In most instances where the step is taken against his advice, the experiment fails; and a protracted continuance of the disease, if not an utterly incurable condition, is the result. And the cause will be obvious on a little reflection. The period of convalescence is precisely the particular stage when the peculiar management of the hospital is most needed to complete this process surely and safely. The patient's reason has returned: he sees things and persons in their true aspect; he feels that buovancy of spirit which usually accompanies returning health; he becomes impatient of confinement because he cannot see its necessity; his friends yield to his importunities, and he becomes again the master of his own movements. With a brain still weak and irritable, wanting that firmness which only time and rest can give, he turns a deaf ear to all advice, resumes at once his ordinary habits and pursuits, soon uses up all his little power of endur- 
ance, loses all self-control, and again passes under the cloud.

Such was actually the result in Moore's case. A few weeks after his discharge he died of brain disease, precipitated, probably, by the premature removal of all restraint. Had he continued a few weeks longer under the gentle restraints of the hospital, and its carefully measured indulgences, the requisite degree of nervous firmness might have been acquired, and he would thus have been prepared to encounter successfully the trials of unrestricted freedom. The courts may only claim the right to discharge those whose convalescence is fully established; but, in thus deciding what is a purely medical question, let them consider that they assume the functions of the physician. If the physician hesitates to take this, perhaps the most important, step in the management of an insane patient, still discerning under his constant observation some lingering traces of disease, some indications of irritability that might be readily converted into uncontrollable excitement, well may the judge shrink from assuming the delicate and responsible duty.

This review of the judicial aspects of the case shows that the common law is quite unreliable for any practical purpose. By one court, it is decided that the friends of an insane person have no right to confine him, except to meet some pressing emergency, and then only for a period long enough to enable them to resort to some legal process. By another it is decided that they may thus dispose of him as long as he continues to be dangerous. By one court, this matter of danger is regarded as strictly medical, to be determined by experts; by another it is treated as if it were clearly within the province of the court, the opinions of the experts being 
overruled, it may be, by the opinions of the judge. One court recognizes this right of friends to confine the patient without regard to any particular element of the disease, but decides that it terminates when the stage of convalescence begins. Another decides that this right is absolute and unconditional, unrestricted by any stage or quality of the disease. It is obvious, therefore, that additional legislation is required in most of the States, and the question is thus directly before us as to the legal provisions that would most effectually meet the necessities of the case. And let us first clearly understand what these necessities are.

In the first place, the law should put no hinderance in the way to the prompt use of those instrumentalities which are regarded as most effectual in promoting the comfort and restoration of the patient. Secondly, it should spare all unnecessary exposure of private troubles, and all unnecessary conflict with popular prejudices. Thirdly, it should protect individuals from wrongful imprisonment. It would be objection enough to any legal provision, that it failed to secure these objects, in the completest possible manner.

It is a fair question, certainly, whether the forms and processes now in use would not sufficiently answer the purpose, if applied to all cases indiscriminately. This question we propose to answer.

In every State, the law provides for the appointment of a tutor, guardian, trustee, or committee, who has charge of the person and estate of the insane person. In some States, the mode of procedure is a simple hearing before some judicial officer, who, if convinced of the person's insanity, appoints a guardian. In others, some court appoints a commission, who, acting in connection with a jury, inquire into the facts, and make report to 
the court, by whom a guardian or committee is appointed. Now, it is proposed to make it obligatory on the family or friends of the patient to place him under guardianship, in order to procure his admission to any hospital for the insane. It would be a sufficient objection to this course, that there is no necessary relation between the two things, - placing a person in a hospital for the purpose of procuring his recovery, and subjecting him to interdiction. This is clearly shown by the customs of our people; for of the thousands of persons in our hospitals and asylums, not one in twenty is under guardianship. Had there been any thing essentially wrong in this, it would hardly have been left to this day and generation to discover it. No one, with any practical knowledge of the matter, - of the feelings and motives that govern men when brought face to face with the question of confining an insane friend, - can fail to see that this course is quite incompatible with the first two requisites above mentioned. What is implied by interdiction? It implies the taking of property out of the hands of its rightful owner, and giving the control of it to another. It implies, perhaps, the settlement of his affairs, the termination of his business relations, the dissolution of partnership, the resignation of every office of honor or trust, - all in a manner more or less prejudicial to his interests, and solely to meet an exigency that may be of very brief duration. Surely an attack of insanity is afflictive enough, without any supererogatory misery like this. It would be difficult to give even a plausible reason why a person laboring under a disease of the mind should be treated so differently, in this respect, from one sick with pneumonia or fever. Nobody thinks of placing the latter under guardianship, in order to get him into a fever hospital; and 
yet he may be confined to his house, and incapable of taking care of himself, for as long a period as the former.

There is another and a very important reason why this measure should be avoided if possible. When the patient comes to himself, and learns that his business, successfully established by many years of industry and enterprise, has been wound up, perlsaps, at considerable sacrifice, and that he is unable to dispose of a single dollar of his hard earnings, the intelligence will scarcely help to promote his recovery. It would lead many to think that admission to the hospital is purchased at too dear a rate; and, if they had been filled with suspicions and apprehensions, they would find in it confirmation of their fears, and imbibe feelings of hostility that might remain after all other traces of disease had disappeared. And when released from restraint, instead of being welcomed back to their old pursuits and the familiar scenes, and cheered by the fact that their business relations had been maintained at little or no loss, they find themselves obliged to renew the struggle of life, in new ways and with new associates; and fortunate will they be if the effort prove not too much for a brain rendered morbidly irritable by recent disease. Physicians who have charge of hospitals for the insane are in the habit of advising the postponement of interdiction to the latest moment; and in a public communication the English Commissioners in Lunacy once gave similar advice. "It is hardly necessary to observe," they say, " that proceedings by commission are, generally speaking, advisable only where the insanity is likely to be of a permanent character. . . . Wherever a reasonable hope of recovery exists, and the income of the lunatic can, in the mean time, be properly administered 
for his benefit, without a commission, the general practice among the friends and relatives of the insane is to avoid resorting to proceedings which entail unnecessary cost, which, by the disclosures they occasion, are most painful to the feelings of the family, and which, by the excitement they produce, are sometimes injurious to the patient himself."

It is easy to see, in view of such discouragements, what would be done with the patient, or rather what would not be done with him. He certainly would not be sent to a hospital, if by any possibility he could be kept at home, or somewhere else. Every makeshift would be resorted to that friends and neighbors could suggest, every experiment would be tried offering the least prospect of success. Not until all these had had their turn and failed, and the friends had become wearied and worried to the last point of endurance, the patient meanwhile getting more and more difficult to manage, would the hateful measure be submitted to, which is needed for his admission to the hospital, too late, probably, for any benefit from its kindly influences.

It is now well understood that, in most cases, an attack of insanity is most speedily conducted through its various stages towards recovery, within those establishments that have been expressly designed for this purpose; and that the sooner they are resorted to, the better, unless special and exceptional circumstances forbid it. Experience shows that the sooner all connection with domestic associations and familiar scenes is severed, and all intercourse with friends and acquaintances suspended, the sooner the morbid process will be stayed, and the work of restoration begun. Whatever tends to discourage this measure, - to favor its post- 
ponement until every other has been tried and has failed, must prove prejudicial, both to the patient and his friends. It does not meet the difficulty to say that this reluctance is unreasonable, a mere matter of prejudice, and that if people refuse to comply with the laws they must abide by the consequences. It is not very unreasonable, surely, to wish to avoid a certain positive evil, though at the risk of encountering a greater one that may never happen. It is immaterial whether the measure in question were aroided for the wisest of reasons or for the most senseless of prejudices. We must legislate for men as they are, not as they should be, having reference to their customs and feelings, as well as their abstract sense of right and of the fitness of things. Larvs, the best in the world, theoretically considered, fail to effect their purpose when not in harmony with the ways, manners, usages, and spirit of the people for whom they are made. Believing, therefore, that to make interdiction preliminary to isolation would cause infinitely more mischief than it would prevent, we are obliged to look for some other way less burdened with objections.

In most if not all of the States, there is a provision whereby a magistrate, generally of the lowest grade, is authorized to send to some place of custody any insane person going at large and declared to be dangerous, though these conditions are much like those fictions of the law that are not to be literally construed. Although originally intended as a measure of police, applicable to insane vagrants, it is sometimes used to secure the isolation of persons having friends and social position. But there are serious objections to its being employed for this purpose. Having been in use from time immemorial as a police measure, and consequently associ- 
ated with the idea of vagrants and dangerous subjects, the friends, naturally enough, shrink from it; and the patient, if not entirely devoid of reason, conceives that he is treated as a criminal, and is vexed and irritated accordingly. Nevertheless, it has some advantages over the last-mentioned measure. It is prompt in its operation, and affects the person only, and not the property.

People who have little knowledge of insanity, and a great deal of faith in time-honored phrases, have proposed, as a preventive of the abuses incident to isolation, a trial by jury, impanelled especially for the purpose. This method has been actually adopted in Illinois by legislative enactment, under a pressure of popular excitement arising from accidental causes. Except that it leaves the property undisturbed, it is open to all the objections that lie against the measures already considered. It is equally shocking to every notion of domestic propriety, and equally repugnant to that instinctive delicacy which shrinks from exposing the infirmities of those we love. A jury trial is a public affair; the proceedings may be printed in the newspapers, and the griefs of a stricken family become food for heartless gossip. A grosser perversion of this noble institution from its proper ends can scarcely be imagined. Although an admirable contrivance for eliciting truth in disputed transactions between man and man, it is totally unsuitable as a means of obtaining correct results in regard to questions purely scientific. When we are told that in the place where it was adopted, all the patients in a large public hospital - the epileptic and the paralytic, the idiotic and the imbecile, the raving maniac and the poor demented creature not knowing his right hand from his left - were subjected to its 
operation, it seems more like a phantasmagoric jumble of social and legal proprieties, -

"The brood of folly without father bred," -

than the work of the assembled wisdom of a large and intelligent State.

Let us look at it for a moment. The question for the jury to decide is whether the person before them is sane or insane. The friends and attendants tell their story, the family physician, and perhaps other experts, give their opinions, and then the jury must agree or disagree upon a verdict. In will or contract cases where the mental condition of the party is in question, there are always side issues on which a verdict may be made to rest, irrespective entirely of the principal issue. But here the naked question, sanity or insanity, covers the only possible issue, and it must be squarely met. If they are sensible men, they will be governed by the views of the experts. If, as is more probable, they think that they, as well as doctors, know something about insanity, they will have an opinion of their own, and decide accordingly. Now, in the former instance, it is the experts who really decide the case, and the jury becomes a superfluous appendage to the procedure. In the latter, a question of medical science, involving the happiness of families, and the highest welfare of an individual, is determined by men completely ignorant of the whole subject. In all jury trials, the jury are not allowed to be judges of the law. Are they any more competent to be judges of medicine? If it were a question between medical men whether a certain patient had this or that affection of the heart, or whether another is suffering from rheumatism or neuralgia, who would think of submitting it to a jury of twelve men 
drawn from the common walks of life? And yet this is just like what we propose to do when we undertake to settle the question of insanity by means of such a tribunal. Only those who are well acquainted with the popular notions of insanity can conceive how futile the result would be. For twenty-five years the writer of this was in charge of a hospital for the insane; and of the many hundred patients under his care,-setting aside the raving and the demented, - there was scarcely one who was not regarded by some friend, neighbor, or acquaintance, as unequivocally sane. The most common forms of insanity - those which include the great majority of cases - are regarded, by many people, no small portion of whom may be found among the refined and educated classes, as any thing but insanity. So surely as this question is given to a jury who undertake to think for themselves, just so surely will they err in their verdict or fail to agree upon any.

People who expect to find in legislation a panacea for all social evils have imagined that the requirements of the case would be met by the appointment of a commission whose business it should be to take cognizance of every case proposed for admission into a hospital, and give or withhold its sanction. It might be a permanent board consisting of a few members, or the duty might be performed in each town or county by some resident therein appointed especially for this purpose. While this is regarded as a mere matter of form, very little can be said against it, or for it. But, in order to prevent the abuses which are supposed to be so imminent, a regular inquisition is necessary, conducted strictly according to the forms of law. Any good which this procedure may possibly accomplish would be obtained at the sacrifice of many important objects. For observe how it would 
work practically in a case of acute mania, as it often appears. The patient is noisy, boisterous, and selfsufficient, bent on going out about his business, and threatening violence to all who endeavor to prevent it. He refuses proper food and medicine, perhaps insists on having stimulants, and requires the unremitted attention of two or three men. The house is in confusion, the family are frightened, attendants are obtained with difficulty, and every day reveals some fresh phase of the trouble. Endurance is possible no longer, and application is made to the commissioner. He appoints a day for hearing the case, and notice is given accordingly in the public papers. Counsel appear for the patient and solicit more time for preparation. Of course, the request must be granted, and another week or ten days of agonizing care and anxiety must be endured. At the trial, the affairs of the family are laid open to the public gaze; the actions and the discourse of the patient are described in his presence by those who would, in the natural course of things, regard them as something they were bound by every sentiment of honor and propriety to conceal; and when, at last, the commissioner signs the order for his admission to the hospital, he goes with redoubled excitement, and with tenfold hostility towards those who have never ceased to love and protect him. If the patient is really insane, - and such is admitted to be the fact in the great majority of cases, - what method could be better calculated to exasperate him to fury, and, on recovery, to fill him with mortification and bitter feeling.

In view of the very strong objections that lie against all these methods, it becomes a fair question whether we can do better than to retain the old one, whereby the relatives assumed the management of the case, acting 
according to their best judgment under the advice of friends and physicians, and legalize it by a statutory enactment. That it possesses the first two requirements above mentioned, - the prompt isolation of the patient and the relief of the friends, - is not disputed. Can it not be accompanied by conditions that would secure most effectually the third requirement? If it can be shown that this matter has been much misunderstood; that the apprehended evil, judging from the past, is one of the very smallest dimensions; and that by suitable safeguards it may be rendered as little liable to abuse as any transaction between men, then, surely, there can be no reason why a practice so natural, so consonant to our best feelings, and so conformable to our customs, should not be continued. The complaint is, that under the exercise of this privilege sane men and women have been imprisoned for an indefinite time. That such a thing is possible, that it may have actually occurred, we do not deny. But, at the worst, it must have been of very rare occurrence, because superintendents of hospitals who have had charge of thousands of patients, and whose opportunities of knowing, therefore, are larger than those of all other persons put together, tell us they have met with scarcely a single case of wrongful imprisonment; and because the alleged cases when impartially investigated do not sustain the complaint. The prevalent notion on this subject has been derived, in some measure, from novels and periodicals, where cases of this kind, by the license allowed to such writers, have been used to heighten the interest of the story. It only indicates that change in modern civilization whereby much of the old machinery of the poet and story-teller has become effete; and thus it happens that the castle and convent and poor debtor's prison, as places 
for confining luckless heroes and heroines, have given way to lunatic asylums. They have many qualifications for this purpose. Their walls are strong, their windows barred, their doors locked; and, though utterly devoid of cells and dungeons, it required no great stretch of the imagination to conjure them up. Thus, it is not strange that readers who readily believe whatever they find in print should get the impression that cases so represented are, if not literal facts, founded in fact, and express an actual reality.

But the most prolific source of the prevalent impression on this subject is, unquestionably, the stories of the insane themselves. Generally, insane people do not regard themselves as insane, and consequently can see no reason for their confinement other than the malevolent designs of those who have deprived them of their liberty. And they are all the more inclined to this conclusion by feelings of hostility already engendered towards their friends and all others who have exercised any control over their movements. Nany of them are discharged, much improved, perhaps, but before they have fully come to themselves, and regained the power of seeing their relations to others in the true light. They are ready, on the first opportunity, to spread their fancied grievances before the public, and often with a degree of ingenuity that deceives even the cautious and intelligent. And the task is not difficult. A story circumstantially and plausibly told is universally regarded as presumptively true; and, if it is one of oppression and wrong, it enlists the deepest sympathies of the hearer. The hero or heroine of the story is invested with the character of a martyr, and people are filled with rdignation and wrath at the thought of an act of highanded oppression having been perpetrated in the very 
midst of them. Even if the exact truth of the case ever comes to light, - even if a trial at law reveal scenes of violence occurring day after day for weeks and months together within the family circle, a wife or mother beaten and cursed, children frightened and running in terror from the house, and prove the existence of delusions as gross as ever usurped the seat of reason, - it fails to meet the eye of many who heard the original story, or, if seen, is received with a stronger feeling than mere distrust. Many are reluctant to admit that they have been deceived, and many are loath to give the lie to what has afforded them a thrilling sensation.

In England and France this right of the friends of an insane person to place him in a hospital without any process of law has always existerl, and is now secured by acts of the legislature. The same may be said of Pennsylvania, Massachusetts, New Hampshire, Rhode Island, and several other States. In all these places the law requires compliance with certain conditions, the general purpose of which is to prevent abuses. The principal of these is a certificate of insanity signed by one or more physicians, and the application of some responsible person. In the "project of a law for regulating the legal relations of the insane," which was unanimously sanctioned by the "Association of Medical Superintendents of North American Hospitals for the Insane," we find the following section: "Insane persons may be placed in a hospital for the insane by their legal guardians, or by their relatives or friends in case they have no guardians, but never without the certificate of one or more reputable physicians, after a personal examination made within one week of the date thereof; and this certificate to be duly acknowledged before some magistrate or judicial officer who shall certify to 
the genuineness of the signature, and of the respectability of the signer."

Under such a provision the insane may be promptly, quietly, and, with a ferw possible exceptions, rightfully, placed by their friends in some hospital for the insane. For the possible exceptions, we would have a provision applicable to them alone, and not, at the same time, subjecting all the rest to positive discomfort and injury. In the "project of a law" just mentioned, we find the following provision: "On a written statement being addressed by some respectable person to some high judicial officer, that a certain person then confined in a hospital for the insane is not insane, and is thus unjustly deprived of his liberty, the judge, at his discretion, shall appoint a commission of not less than three nor more than four persons, one of whom, at least, shall be a physician, and another a lawyer, who shall hear such evidence as may be offered touching the merits of the case, and, without summoning the party to meet them, shall have a personal interview with him, so managed as to prevent him, if possible, from suspecting its objects. They shall report their proceedings to the judge, and if, in their opinion, the party is not insane, the judge shall issue an order for his discharge." True, this only abbreviates the wrong: it does not prevent it altogether. But when we consider how small it is, compared with the good which is accomplished, may we not fairly regard it as one of the unavoidable results of that imperfection which is incident to all human arrangements, and which we witness every day of our lives, even in this matter of wrongful imprisonment? Men are arrested, kept in durance, charged with a criminal offence, and yet found on trial to be innocent of the charge, - the victims, perhaps, of conspiracy or perjury. This is no rare, ex- 
traordinary thing, - one case in ten thousand, - kindling the wrath of every newspaper-writer in the land, and calling for special and summary legislation, but an everyday occurrence, exciting as little feeling as the most common operations of nature. We are told very calmly that such wrongs are a part of the price we pay for public order and good government.

Justice to all parties requires some such legislation as we have indicated. That it would prevent all popular clamor, we do not believe. Inasmuch as the notion in question - that sane people are shut up on pretence of insanity - has little or no foundation in reason, it would hardly be expected that it would be amenable to reason. As long as men are swift to believe any plausible story of wrong-doing, without inquiry or hesitation; as long as newspapers can find in such stories the materials of a great sensation; as long as there is a prevalent belief that no one is insane who is not furiously mad, so long will the confinement of the insane in establishments expressly designed for the purpose be viewed with feelings of distrust, whatever may be the legal provisions by which it is regulated. 


\section{THE CRIMINAL LAW OF INSANITY.}

Is all modern Christian communities, insanity has been theoretically considered as a sufficient excuse for criminal acts. In practice, however, it has not always had that effect. In fact, it has never been regarded with great favor, either by the learned or the unlearned, as a plea in defence of crime. This sentiment has probably sprung from various causes, among which may be mentioned the prevalent ignorance respecting its manifestations, the obscurity in which it is often involved, the facility with which it may be offered to screen the guilty from merited punishment, and, of late, the frequency of the plea arising from the increased prevalence of the disease. Of these, the principal, no doubt, is the one first mentioned, though it is that which people are least willing to admit.

In some of its forms, insanity can scarcely be mistaken, and especially in those which are marked by raving; but persons thus affected are never brought to trial. If, however, the patient is tolerably quiet, says but little, and that little coherently, and exhibits only a few delusions mixed up with rational ways and thoughts; if he is only filled with dismal forebodings and overwhelmed by a sense of despair; if he has only yielded to an irresistible impulse, - then the presence of disease 
is not so obvious, because not manifested by what are popularly supposed to be its proper characters. The traits here mentioned were either not regarded as those of insanity, in any proper sense of the word; or, if considered to be the result of disease, and to that extent implying insanity, they were not supposed to deprive the mind, necessarily, of all self-control, which may and should be exerted by the faculties that remain beyond the sphere of the morbid influence. Or, to adopt the distinctions of the law, they may not deprive the mind of those elements of crime which consist of intention, free will, and malice. On these points every one feels at liberty to have an opinion of his own; but, being matters of scientific observation, it is obvious they can be correctly judged, with authority, by those only who have had professional skill and experience. Whether a certain trait or combination of traits is or is not the offspring of disease, is a question of fact to be determined by observation; and to undertake to determine it without such qualification is, certainly, no mark of wisdom. Yet this lawyers virtually do, when they lay down rules respecting the effect of insanity on responsibility.

Another reason for the backward condition of the law in reference to insanity is the persistent habit of regarding it strictly from the legal point of view, ignoring entirely its medical aspects. It would seem to be a sufficiently clear and satisfactory notion, that a certain person is innocent of the crime imputed to him, because he is insane, mad, deranged, beside himself, bereft of his reason, as the fact of mental disease is variously designated. But it is not enough for the lawyer. It is immaterial to him whether the person is technically sane or insane. He only wishes to know whether the mind 
is deprived of either of the essential elements of crime, above mentioned. Under the dominion of these technical views, lawyers are unable or unwilling to recognize the fact well understood among medical men, that insanity exerts an influence over men's thoughts and actions completely suigeneris. How far they are willing to receive it as an excuse for crime depends upon the question how far they can make it square with their notions respecting the proper ingredients of crime. Did the person alleged to be insane, they say, know that the act was wrong and illegal? Or, in other words, did it indicate those qualities of mind which would have made it criminal in one whose mental condition had not been questioned? The thoroughly legal mind, while admitting the impropriety of punishing a person for an act whose nature and quality he could not discern by reason of mental impairment, is quite unwilling to regard insanity as, per se, an unconditional excuse for crime. "If, notwithstanding the madness of the accused," says Mr. Stephen, "he did commit a crime, it is impossible to suggest any reason why he should not be punished for it." 1 Which is equivalent to saying, he is undoubtedly innocent, but, on any proper construction of the law, he is undoubtedly guilty. In fact, a madman reasons absurdly, of necessity, and is unable to distinguish a gross delusion from an objective reality; but, says the lawyer, having once started upon a course of reasoning from false premises, the successive steps of his reasoning should follow one another with logical precision. "A man is tried for wounding with intent to murder," says Mr. Stephen. "It is proved that he inflicted the wound under a delusion that he was breaking a jar. The intent to

1 General View of the Criminal Law of England, p. 96. 
murder is disproved, and the prisoner must be acquitted; but, if he would have had no right to break the supposed jar, he might be convicted of an unlawful and malicious wounding. Wrongfully to break a jar is a malicious act; and if a man wounds another in so doing, he wounds him unlawfully and malicionsly. In other words, the delusion must, for the purposes of the trial, be taken to be true." 1 This is virtually saying to the insane man: "You are not to blame for mistaking a man's head for an earthen jar. Such was the force of your disease, you could not help it; but it ought to have been as clear to you as to everybody else, that you had no right to break the jar, and therefore you can claim no immunity from punishment for making such a sad mistake." As if the disorder which caused the mistake could not possibly, at the same time, have deranged his notions of right and wrong.

The same inability to perceive the radical difference between the operations of the sane and those of the insane mind, has led to other conclusions equally un. founded. One of them is, that madmen must be punished, in order to deter other madmen from doing wrong. As if every madman regarded himself as insane, and, at the same time, were capable of learning a lesson of caution from the fate of other insane persons. As if most of them do not regard their own acts, how. ever injurious and wrong, as perfectly right and deserv. ing of commendation rather than punishment; or, if technically wrong, as conducing to proper and desirable ends. In the whole range of fallacies respecting the effect of insanity on legal responsibility, not one is so destitute of foundation as the idea that the punishment

1 General View of the Criminal Law of England, p. 92. 
of the insane will have the slightest effect on the conduct of others who are insane.

In the trials of criminal cases in England, where insanity was pleaded in defence, there was always substituted for the real question at issue some metaphysical dogma utterly irrelevant to the guilt or innocence of the prisoner. Did he know the act was illegal? Did he know the act was wrong, contrary to the laws of God and man? Did he manifest contrivance in committing the act? Was he led to it by the ordinary inducements to crime? Such are the questions on which responsibility has been made to depend, instead of the single and only essential question, whether the act was, or was not, the offspring of disease.

The first approach to a sound and rational theory of legal responsibility in the case of the insane was made in the trial of Hadfield, where his counsel, Mr. Erskine, declared that the only question for the jury to determine was, whether the act did, or did not, spring from delusion. Sound as the principle is, it was not immediately appreciated; for in the next notable trial, a dozen years afterwards, that of Bellingham, the customary tests were offered, and not a word was said about delusion. But it made its appearance occasionally in the courts, until on the occasion of the trial of McNaughton, some thirty years ago, it was authorita. tively declared to be the law of the land, that delusion does not necessarily annul responsibility, even when the criminal act is its direct offspring. Since that time, trials of this kind have been more frequent than ever before, all over Christendom; and though in many of them were exhibited a commendable knowledge of insan. ity, and a great advance, in fact, beyond the notions that once prevailed, no sound, settled principle of responsi- 
bility has yet been generally recognized. Every case, whatever the issue, has given rise to public complaints, and excited some bitterness of feeling.

In this country the practice of the courts has followed pretty closely that of England, and there was a sufficient reason why it could not have been better. In the entire absence of institutions for the cure and custody of the insane, no opportunity was afforded for seeing on a large scale the less as well as the more demonstrative forms of the disease. Consequently, the prevalent notions of insanity were associated with the sight of those wretched creatures whose violence required the closest confinement in the jails or poorhouses, under circumstances that deprived them of almost every attribute of humanity. Those subjects of the disease who were still allowed to mingle with their fellow-men were supposed to be not insane in the strict signification of the term, but merely strange, singular, or queer, without being deprived of all power of self-control, of all notions of right and wrong, and of the nature and consequences of crime, - certainly not to that degree which rendered them irresponsible for their acts. In the early settlement of this country, they were generally regarded as the willing subjects of Satan. Governor Winthrop, in his History of New England, mentions the case of Dorothy Talbye, who was executed for killing her child. It needs no great knowledge of the disease to see that this poor woman was insane; but the worthy Governor speaks of her as "so possessed with Satan, that he persuaded her (by his delusions which she listened to as revelations from God) to break the neck of her own child, that she might free it from future misery." The idea of insanity seems not to have entered his head. And yet Governor Winthrop well represented the intelli- 
gence and culture of his time. During the next humdred and fifty years, our forefathers scarcely enlarger their knowledge of mental disease, except to discard, in some measure, the notion of Satanic influence. In 1785, one Goss was executed in Connecticut for killing his wife. He believed she was a witch, and that he was haunted by witches and wizards. He called himself the second Lamb of God; said he was the brother of Jesus Christ, and sometimes said he was the child born of the woman mentioned in the Revelation of St. John, before whom the dragon stood ready to devour the child. $\mathrm{He}$ declared the sheriff could not hang him; that his heavenly Father would interpose, if the attempt were made, and liberate him. Thirty thousand males above fifteen years old, he said, would be instantly killed by the shock.

Here too, as in England, the progress of improvement has been slow and vacillating; but, on the whole, our record is better than hers. We can call to mind only three cases of insane persons executed during the last thirty or forty years, - Prescott, in New Hampshire, 1834 ; Baker, in Kentucky, 1845 ; and Maude, in New Jersey, 1860. The cases of Rogers in Massachusetts, and of Freeman and Thurston in New York, gave rise to very full discussions, both in court and out, respecting the effect of insanity on the mental operations and its relations to the law, which left a marked impression on the criminal jurisprudence of the country. In the cases which elicited the following notices were displayed either some curious traits of insanity, or some remarkable administration of the law, or some signal development of public sentiment; and therefore they are well worthy the attention of the thoughtful inquirer. 


\section{TRIAL OF ROGERS.}

[No criminal trial in this country, in which insanity was pleaded in defence, has become more widely known and been oftener cited than that of Abner Rogers. Still, there was nothing extraordinary in the incidents of the case. The insanity of the man was quite demonstrative, and entirely free from those questionable features that sometimes give rise to serious donbts. Nevertheless, the character of the prisoner, who belonged to that class of social Pariahs which seem destined by their blood and breeding for a life of vice and crime, the eminent virtues and services of the deceased, and the strongly expressed opinion of the surgeon of the prison, who stood high in his profession, that the apparent mental disorder was simulated, raised a very general prejuctice against the plea of insanity. The ability of counsel and the intelligence of the court and jury, however, did not suffer it to prevail.

To the medical jurist this trial derives its interest chiefly from the attempt of Chief Justice Shaw to correct what seemed to him some defects in the criminal law of insanity. He enters into no elaborate examination of these defects. He presents no cases in point. We only know that the law, as he found it, seemed to him inadequate to afford protection to a class of persons who are clearly entitled to it. The precise object he had in view in his manner of stating the law is not very apparent. He was convinced, probably, that Rogers was insane, but was doubtful as to his acquittal under the existing rule. We are left in doubt whether he was seeking for some general statement that would admit of universal application, or for something that would be sure to cover only the case before him. It is evident, from the manner in which he handles the subject, that he finds himself on uncertain ground, groping about for something sure and stable which he may lay hold upon. He hesitates and vacillates, returns again 
and again to qualify what he has said, or to add some condition for the purpose of enlarging or restricting the range of its application. As might be supposed, his ideas lack precision and lucid arrangement, and the reader is not always sure of his exact meaning.

"The person tempted," he says, "must have memory and intelligence, to know that the act he is about to commit is wrong, to remember and understand that, if he commits the act, he will be subject to the punishment; and reason and will, to enable him to compare and choose between the supposed advantage or gratification to be obtained by the criminal act, and the immunity from punishment which he will secure by abstaining from it." These ideas he repeats in the next following sentence, with some unessential change of language. On the next page, as if suspecting that there might be conditions of irresponsibility not fairly represented by these terms, he declares that a man is not punishable, "if his reason and mental powers are either so deficient that he has no will, no conscience or controlling mental power; or, if through the overwhelming violence of mental disease his intellectual power is for the time obliterated, he is not a responsible moral agent, and is not punishable for criminal acts." Then, as if apprehensive that these tests may not cover " cases of partial insanity, where the mind may be clouded and weakened, but not incapable of remembering, reasoning, and judging, or so perverted by insane delusions as to act under false impressions and influences," he lays down the rule of law, as he understands is; but it is impossible to see how it differs materially from that which he first stated. The phraseology is slightly changed, and it is added that the person must be able "to recollect the relation in which he stands to others." All this, excepting the last named condition, is repeated in the next sentence. This is shortly afterwards followed by a repetition, more than once, of the test furnished by the fact of the prisoner's being overwhelmed by the force of disease, and driven by an irresistible and uncontrollable impulse.

The course of reflection pursued by the Chief Justice is a matter of conjecture, but he has furnished us with a clew sufficient to indicate it with tolerable correetness. He finds, at the start, among the tests of responsibility sanctioned by authority, that of knowing the act to be contrary to law. This he is obliged to discard because it conflicts with the ancient maxim, Ignorantia legis neminem excusat. The other tests usually associated with it he adopts; and accordingly he tells the jury that insanity is a sufficient excuse, if the prisoner did not know right from wrong in regard to the particular act, and could not 
understand that he would deserve punishment by doing it. He is not aware of what any attendant in a hospital would have told him; viz., that many of the insane do things, every day, which they know and admit to be wrong and deserving of punishment. He might have learned the same thing from the case of Hadfield, who admitted that it was wrong and unlawful to kill the king, and deserving of punishment. He had learned, however, that insane persons are sometimes blindly and automatically urged to criminal acts by "the overwhelming violence of disease," so that the deed is "the involuntary act of the body without the "oncurrence of a mind directing it," and he might have suspected that the case before him was one of that description. It is a little surprising that one so accustomed to the incisive logic of the law did not perceive that this eondition of irresponsibility is embraced in the other; for a person who is impelled by the overwhelming violence of disease, meaning thereby the blind fury of active mania, can scarcely be said to know right from wrong, or to have any fear of punishment. In any case, the plea of irresponsibility must rest on the fact that the person was under stress of disease, the difference in different cases being merely one of degree. The insane man who commits a criminal act, perfectly conscions that it is wrong and punishable, is, most certainly, overborne by the force of disease.

Again, it appeared in evidence, that the prisoner entertained delusions, and it seems to have occurred to the Clief Justice that they ought to furnish the sought for test of irresponsibility. Rogers's special delusion was, that the warden intended to shut him up and then take his life. Believing thus, he would have felt justified in taking the warden's life, as an act of self-defence: and this he did, perfectly conscious, all the time, of what he was doing, and never regretting it. But it is not thus that the Chief Justice puts it to the jury. His question is, whether the prisoner, under the influence of the delusion, did not experience an "outbreak" that "must for a time have overborne memory and reason, and become an uncontrollable impulse." He thus confounds two mental conditions as different as possible. The man who, prompted by a delusion, kills another, acts from a motive, baseless, no doubt, but still to him a sufficient motive. The man who, in a fit of homicidal mania, commits murder, is urged by an irresistible impulse, and is afterwards surprised and grieved by what he has done. It is a little surprising that the Chief Justice, abandoning all other tests, had not been content with giving to the jury that alone - delusion - which was so successfully and satisfactorily pressed by Erskine in the Hadfield case. 
It can hardly be supposed that he was deterred from it by the gloss put upon it by the English judges on the occasion of the McNaughton case, which occurred just before, for it does not appear that their opinion had come to his knowledge; nor is it likely that he rejected this test because it afforded no protection to the victims of moral insanity. As it is, we are left in doubt whether he understood delusion to be a sufficient excuse for a criminal act committed under its influence, unless accompanied by an outbreak of violence.

The judge's instructions to the jury in the Rogers case illustrate the utter futility of seeking for a universal test of irresponsibility in any particular impairment of the mental operations. When a watch or an engine gives out, nobody supposes that it is always the same wheel or lever or spring that is at fault. It needs no special instruction to convince us that this result will follow a derangement of any part of its complicated machinery. The brain is a machine of the most delicate and complex character, whose working, as indicated by the mental manifestations, will be deranged by imperfection or iupairment in whatever part of the structure it may occur. The better knowledge of insanity which now prevails demands that these tests and definitions should be abandoned, and the teachings of science be accepted as the only proper rule of law.

One statement made by the Chief Justice, in his charge, has a peculiar interest now, as indicating a near approach to the position which has since been so happily taken. He tells the jury that, if they find that the bomicide was "the result of disease," they are bound to acquit. Had he discarded every other condition of irresponsitility. and planted himself firmly upon this, saying to the jury, "You have only to consider, first, whether the prisoner was laboring under a mental disease, and, secondly, such being admitted, whether the act in question was the offspring of that disease," he would have achieved the honor of making a signal advance in the criminal law of insanity. Thirty years after, this very principle was declared, in State $v$. Pike, 49 X. H., by Chief Justice Periey of New Hampshire, whereby " his nane will be associated with the final settlement of this important branch of the law as long as our legal system shall endure."]

$W_{E}$ are glad that this trial ${ }^{1}$ has been fully reported. The very unsatisfactory condition of the law on the sub-

1 Report of the Trial of Abner Rogers, Jr., indicted for the nurder of Charles Lincoln, Jr., late Warden of the Massachusetts State Prison; 
ject of insanity as a defence of criminal acts is, perhaps, attributable, in a great measure, to the circumstance that, while the principles which have been laid down at different times were more or less shaped by the particular facts of the case in hand, the latter have been but imperfectly reported; and thus, the principles being divested of their main support, their truth is not at once and universally recognized, their applicability to practice is entirely misconceived, and new principles are again laid down, supposed to be sounder, and to better meet the requirements of the disease. Hence, cases essentially alike have led to new and even conflicting constructions of the law, by judges who might have agreed respecting the legal principles applicable to any particular case which they tried together. A judge who has heard, from the lips of various witnesses, numerous circumstantial details of the freaks and vagaries of the prisoner, and the strong testimony in his favor of experts, with whom he may be personally acquainted, cannot resist the conviction of the prisoner's insanity ; and he feels bound, as a matter of necessity, to construe the law in such a manner as to afford due protection; and yet such a construction might not have been thought of, had only the general features of the case been presented to him in chambers. A rigid application of the principles laid down by the English judges, in their recent exposition of the law on this subject, would have consigned to the gibbet several prisoners who were previously tried by some of these very judges, and acquitted with their approbation. So different is the position of

before the Supreme Judicial Court of Massachusetts, holden at Boston, on Tueslay, Jan. 30, 1844. By George T. Bigelow and George Bemis, Esqs., Counsel for the Jefendant. Boston: Charles C. Little and James Brown, 1844. 
him who speculates upon a case in his study, from that of lim who beholds it clothed in mortal form, breathing and moving before him.

Without going into a detailed account of the trial, we would call attention to some of its most important medico-legal features.

It appears that in the afternoon of the 15th of June, 184:3, as Mr. Lincoln, the warden of the Massachusetts state prison, was passing through the shoe-shop, Abner Rogers, one of the convicts, seized a knife and inflicted upon him several wounds of which he instantly died. Rogers was tried for murder. The act was admitted, and the plea of insanity made in defence. The evidence relative to the existence of insanity was remarkably copious, explicit, and satisfactory ; and though much of it was given by convicts, yet every material fact was abundantly confirmed by witnesses of unquestioned credibility. In cases much less clear than this, grand juries have often refused to find a bill; and probably nothing but the relation of the parties to each other, and the state of public feeling, led to a different course. It seems that the disease was first manifested on Monday the 12th of June, about two o'clock in the morning, when Rogers was heard crying or groaning in his cell, as if in great distress, and was found by the watchman stand. ing before the grated door, with his hands crossed upon his breast, and trembling. When reproved for making. so much noise, he replied that "he couldn't help it, that he was going to die ;" that he had "heard Cole and Sam Robinson [convicts] say that the warden was going to keep him in solitary the rest of his time, which would kill him;" that "he should never go out of his cell until he went out feet first." Between this period and that of the homicide, scenes like this were repeated 
several times. He often spoke of hearing voices that forewarned him of impending punishment, which consisted in being shut up by the warden, and having the checkerberry or popo game played upon him; complained of pain in his head; appeared to be laboring under much mental distress; would beg of one and another to intercede for him with the warden; disregarded his dress; and, though employed in the shop, was so unsteady in his work and irregular in his ways as to annoy the others, and induce those who had charge of him to represent to the warden that he was deprived of his senses, and to request that he might be removed. The most prominent features in his disorder were the hallucinations of hearing, which occurred chiefly in the night. They were confined to one or two expressions, and proceeded from only two or three individuals. For a few days after the homicide the mental manifestations were not materially different. In conversation, he talked much of the voices, and appeared to be unconscious of having committed the fatal act; he had a bewildered, unnatural look, and ate his food voraciously. Gradually he admitted that he had killed the warden, that the voices were probably only imaginary, and that he must be necessarily punished as an example to others. In the course of ten or twelve days, all manifest traces of his delusions had disappeared, and then he declared that when he committed the murder he knew not where he was or what he was doing.

In a case like the present, it may be worth our while to see how the ingenuity of the prosecuting officer, sinking under the difficulties of a bad cause, disposed of the facts which, in the opinion of the medical witnesses who had spent years in the observation of the insane, established the reality of insanity beyond a 
doubt. The only course left for him was, to show, if possible, that these symptoms were feigned, or capable of being explained without resorting to the theory of insanity. The hallucinations he regarded as mere dreams, the effect of disturbed sleep or nightmare. That a person may dream that he hears voices, and for a time believe them to be real, is not improbable. But we venture to say that the instance was never known of a person of sound mind hearing false voices, night after night, uttering the same expressions, and coming from the same individuals. To confirm his view of the matter, he suggested that Cole aud Robinson, for the sake of teasing Rogers, might have really told him these things during the day, though the impression abroad is, that the convicts have no conversation with one another. Finally, as if dissatisfied with both these explanations, he doubts if Rogers heard any voices at all, and attributes them, as well as every other sign of disease, to simulation. In one word, he denies the fact and calls for proof. The only proof we can ever have in such a case must be drawn from the accompanying circumstances, which will always furnish sufficient for the purpose. If the hallucination is described with an air of sincerity and good faith, if it be attended by other symptoms of deranged mind, and by indications of bodily disease ; if, in short, its origin, progress, and termination are in accordance with our ordinary experience, then there can be no reasonable ground for doubting its reality. That such proof existed in the present case, we hare the authority of the medical experts for believing. If a young man, thirty years old, many of which had been spent in prison, and possessing less than an average share of intelligence, could succeed in deceiving a person of such eminent skill and ability as Dr. Bell, who 
repeatedly examined him, we may as well conclude, at once, that simulation of insanity can seldom be detected. The common opinion is, among those who are at all qualified to form such an opinion, that, sufficient opportunity being given, simulated insanity can always be detected by those who have much practical knowledge of the disease. Rogers's insanity did not present those indefinite, negative characters generally selected by simulators, but was a form of disease quite common in hospitals, and one whose features are easily recognized. To simulate it with the least success requires a degree of knowledge and a continuity of vigilance and selfcontrol possessed by few; certainly not by such men as Rogers. It forms no part of our present object to mention the particular grounds on which the medical witnesses rested their belief in the genuineness of the manifestations. We would take the opportunity, however, to remark that the testimony of Dr. Bell presents one of those happy instances of thorough and sagacious investigation, peculiarly satisfactory and gratifying to those who best know the difficult and delicate nature of the duty he had to perform.

If Rogers were not insane, then, of course, in killing the warden, he must have been actuated by motives. In trying to convince the jury of this fact, the district attorney adopted a course which evidently shows that he was not himself convinced. He says that Rogers "was a lazy, reckless, and wicked person;" that "Mr. Braman was in the habit of reporting him for not doing. his work right;" that "he was frequently punished;" that he consequently contracted a strong resentment against Mr. Lincoln, uttered threats, and avowed a purpose of revenge; that for some time prior to the homicide he manifested his usual steadiness and self-control; 
that his manner of doing the act was deliberate and well managed; and that subsequently he confessed he had done wrong and expected to suffer. All these points, except the last, are the offspring of the district attorney's own brain. Braman never reported Rogers for not doing his work right, nor did any one else. On the contrary, all the witnesses on each side who spoke at all on this point agreed in representing his behavior as good,-_ "better than the average of convicts;" and the district attorney himself remarked that Braman and Crowninshield spoke well of his conduct and work. So far from having been frequently punished, it appears that during the six months previous to the 12th of June he had been punished but once, and then slightly. The district attorney said he frequently received minor punishments which were not recorded; but we find no evidence to that effect. That Rogers may have uttered threats is not at all unlikely; for we presume it is not uncommon for convicts, when unusually irritated, to vent their spleen in this manner, without entertaining any serious, settled purpose of revenge. In regard to his conduct and mamer during the three or four days previous to the homicide, the testimony is unanimous in representing them as very unusual. All the witnesses testified that he appeared as if in great distress, and acted irregularly and strangely. We do not see that his manner of perpetrating the deed evinced more deliberation or contrivance than any one not quite an idiot would have displayed. But, had it been otherwise, who needs to be told that forecast, caution, and ingenuity are not incompatible with the existence of insanity, - that they are evinced by a large proportion of the insane? Neither is his manner of speaking of the act any more indicative of thorough sanity. 
When an insane person first becomes conscious of having committed some grievous wrong, he does not sit down to reflect upon the matter, and coolly come to the conclusion that he was deprived of reason at the time, and consequently irresponsible for his acts; but the sense of wrong-doing and guilt is generally excited at once, and he speaks of the expected punishment as something which may be hard to bear, but not unjust or improper. It is not until reason is quite reëstab. lished that he views this point in its true light. Rogers's remark, therefore, that " no mortal could save him from hanging, for it would not do to overlook his offence," is very like what an insane man would have said on first becoming conscious of such a dreadful act. At any rate, he would not have been likely to say it, had he been simulating. If any doubt of Rogers's insanity could remain after the evidence given at the trial, it must have been effectually removed by his subsequent history as related by Dr. Woodward, physician of the lunatic hospital to which he was sent on being acquitted on the ground of insanity. ${ }^{1}$ We have no hesitation in saying that his last performance, that of bolting through a closed window without attempting

1 It appears from Dr. Woodward's account that, during the four or five months he was in the hospital, Rogers had turns of great restlessness, when he complained of headache, vertigo, and loss of appetite. At these times he was very irritable, and his pulse was over a hundred. He also looked anxious and distressed, and was apprehensive of being poisoned. He said he saw evil spirits in his room and smelt corpses under his bed. He told an associate that the food offered him was a corpse, - he could smell it. At last, while at prayers in the chapel, one evening, he became very uneasy, said the room was full of dead bodies, and begged to go out. His request not being heeded, as the service was nearly over, he bolted head first through the window, so rapilly that the noise was mistaken by those near him for the report of a pistol or gun. He fell fourteen feet, and died within thirty-six loours. 
to raise it, is one no man in his senses could have done.

The remarkable testimony of Dr. Walker, the physician of the prison, derives some importance from his official character, and therefore we are constrained to subject it to a close scrutiny. He testified that, in his opinion, Rogers was not insane when he committed the homicide. To some, this gentleman's name may be a sufficient guaranty for the correctness of this or any other opinion he may offer; but the medical jurist will be satisfied with nothing short of the amplest proof. What, then, are the grounds of this opinion? On the morning of the homicide, Rogers went to the hospital for medical relief, approaching the physician in a quiet, steady manner. "I asked him," says the doctor, "what was the matter. He threw himself into gesticulations at once, put his hands to the side of his head, and said: ' $\mathrm{I}$ am in great distress here; I am in pain all over. I am in pain right through here, and feel as if I could not govern my mind.' I said to him, 'I understand this. If you will do your part towards meriting kind treatment, you will receive it.' He became collected immediately, was attentive to my advice, and went quietly away." From this interview alone, - for the doctor never put eyes on the prisoner afterwards until he saw him in the court-room, - he was satisfied that Rogers was of perfectly sound mind, and came to the hospital for the purpose of deceiving him. "My reasons for this opinion are, that, when he passed the door of the room where I was, I saw his countenance, and there was nothing unusual in its expression. $\mathrm{He}$ approached me at first with his common gait, and with his usual calm appearance and collected manner, and without any manifestations of distress. On making his statement to 
me, he threw himself into the position I have described. He did not feel the pain he pretended to have in his head: if he had, he would have walked more carefully, so as not to jar it, and his distress would have shown itself in his countenance. He made no remonstrance against my advice. He said nothing about hearing voices." We venture to say that never was a case of suspected simulation so summarily disposed of before. Distinguished medical jurists have thought that long and repeated interviews with the prisoner, vigilant observation of his movements, the trial of various tests, a knowledge of his past history, and a careful examination of his physical condition, were all required, in a greater or less degree, to establish beyond a doubt the true nature of the case. They have thought that no investigation less thorough and patient than this could satisfy the requirements of justice and of their own professional reputation. Dr. Walker reached his object by a shorter - we doubt if it will prove to have been a smoother - path. Mortals less happily endowed cannot but wonder at the marvellous sagacity which, without the slightest intimation from others respecting the prisoner's designs, could discern at a glance the sigus of simulation, and in five minutes or less become convinced beyond the reach of a doubt. Not a word did he care to know of Rogers's previous conduct or conversation, nor did he deem it worth while to ascertain his present thoughts and feelings. The prisoner said he had great pain and distress all over; but to look at his tongue, to examine his pulse, to feel of his skin, \&c., did not seem to be among the doctor's means for ascertaining the existence of physical disease. He looked at him for the space of five minutes, saw him walk, and heard him say he had a pain in his head, and could not govern his 
mind. That was enough. What need of a multiplicity of examinations and a long report?

IVe find some difficulty in examining particularly $\mathrm{Dr}$. Walker's " reasons" for believing Rogers was not insane, for they seem to have but little to do with the question. We are quite unable to see how his change of manner, as noticed by the doctor, can be regarded as indicative of simulation. It certainly was not inconsistent with the most perfect sincerity; while, if simulating, he would, in all probability, have begun to act his part the moment he came in sight or hearing of his physician. His not favoring the alleged pain in his head by a more careful gait might perhaps indicate that the pain was a mere pretence, provided he were of sound mind, which was the very point to be proved. Few insane men would take any such precaution. They would be as likely to stand on their heads, or beat them against the wall, in order to relieve their distress, as to walk with a slow, measured gait. His not mentioning the subject of the voices is, at best, but a negative proof of simulation, and had as little to do with this point as the opposite fact would have had. Had he been simulating, he would probably have spoken of the voices; but regarding them as realities, and not the offspring of disease, why should he have spoken of them? Dr. Walker could not prevent Cole and Robinson from addressing him. Indeed, it was not the voices which he considered a grievance: it was the designs of the warden and others, revealed to him by the voices, of which he complained; and it was that feeling of distress in the head, so common in the initiatory stage of mania, that he sought the aid of the doctor to remove.

We observe that in this trial the utmost freedom was allowed to counsel, in quoting from medical books on the 
subject of insanity. Page after page, from French, English and American authors, was read to the jury, without the slightest check from the court, except the remark that, at some future time perhaps, the practice might be subjected to some regulations. In Maine it has been expressly decided, contrary to the custom in every other State, that in criminal cases medical books cannot be read to the jury; and in civil cases only by consent of parties. The principal reasons assigned for this rule of the Maine court are, first, that in receiving books as evidence - in which character they really appear, in whatever shape they may be introduced - we are debarred of that invaluable means of eliciting truth, cross-examination; and, secondly, that books without the least authority among scientific men may be represented to be worthy of the utmost confidence of the jury. These reasons are not without some weight, but they seem to be more than balanced by others; and thus we are reduced to the alternative of choosing the least of the two evils. If the practice in question is an anomaly in judicial procedure, the idea of submitting the fact of the existence of insanity in a given case to the decision of twelve men, not one of whom, perhaps, ever saw a case in his life, or ever made the disease a matter of study, is no less an anomaly in the common sense and common practice of mankind. Men charged with such a duty would seem to have a claim to all the light that can be furnished them. If they are to decide professional questions, let them have access to the fountains of professional knowledge, - to the Marcs and Esquirols who have spent their lives in acquiring it. Their extensive means of observation may have given them the opportunity to become acquainted with facts, unknown to any witness that can be summoned, but which are essen- 
tial to the correct adjudication of the case in hand. True, a book cannot be cross-examined like a witness, and there is not equal reason why it should. Scientific works present us the results of their authors' observations, without reference to any particular purpose for which they may be used; and, if their ability and good faith are acknowledged by those most competent to judge, it would seem as if there could be nothing gained by cross-examining in regard to any point they may have treated. When Esquirol says that one quarter of the insane have hallucinations; and Marc, that a majority are unconscious, when they recover, of any thing that occurred during the violent stage of their disorder, does anybody believe that a cross-examination of these writers would show that the above proportions are incorrectly stated? Unquestionably, juries may not always be able to satisfy themselves exactly what degree of confidence this or that writer is entitled to; but they labor under the same difficulty in regard to witnesses. We have known the opinions of the shallow and conceited pretender to science avail as much with the jury as those of the most accomplished expert. It would seem as if it came within the province of the court to instruct the jury in regard to the relative authority of different books that may have been read, as well as the comparative credibility of different witnesses. Considering how often the subject of insanity comes before our courts, is it unreasonable to expect that it should be embraced among their studies, so far at least as to make them acquainted with the degree of authority respectively possessed by the leading writers? Shall a judge commend to a jury the conclusions of Lord Hale regarding insanity tivo hundred years ago, while utterly ignoring 
the works of men of our own time, who have spent years in observing its phenomena? ${ }^{1}$

In charging the jury, the court adopted no particular, concise principle relative to legal responsibility, but used a multiplicity of expressions variously modified, to designate that condition of mind which absolves from the legal consequences of crime. This fact might seem to indicate some dissatisfaction either with the principles or phraseology of previous decisions. Its frequent recurrence to this point, and each time with some modification of language, may have been, perhaps, only the result of a very proper anxiety to lay down no principle which would either fail to protect the victim of disease or furnish immunity from punishment to genuine guilt. Collating the various passages in which the court mentions the mental conditions of irresponsibility, and rejecting all expletory and equivalent expressions, we have the following as the sense of the court on this point: viz., A person is not responsible for any criminal act he may commit, if, by reason of mental infirmity, he is incapable of distinguishing between right and wrong in regard to the particular act, and of knowing that the aivitself will sulject him to punishment; or has no will, no conscience, nor controlling mental power; or has not sufficient power of memory to recollect the relations in which he stands to others and in which they stand to him; or has his reason,

1 A few years afterwards, the Supreme Judicial Court of Massachusetts male a rule, Commonwealth $v$. Wilson, 1 Gray, 389, prohibiting the reading of books altogether. "Facts or opinions," says the court (Chief Justice Shaw), "on the subject of insanity, as on any other subject, cannot be laid before the jury except by the testimony, under oath, of persons skilled in such matters. Whether stated in the language of the court or of the counsel, in a former case, or cited from the works of legal or medical writers, they are still statements of fact, and must be proved on oath." 
conscience, and judgment so overuhelmed by the violence of the disease, as to act from an irresistible, uncontrollable impulse.

We are not sure that these conditions of irresponsibil. ity would furnish protection to all who might require it. Rigidly construed, they certainly would not. No general propositions of this kind not in accordance with the phenomena of insanity can meet the requirements of the case; and the above, as well as others like them, we are quite sure would never have been formed by one practically acquainter with the insane mind. To such it is matter of daily observation, that many an inmate of an insane hospital is capable of distinguishing between right and wrong, knows well enough the relaitons between himself and most others, and never acts sum irresistible, uncontrollable impulse, but deliberately and cautiously, with a full consciousness of the consequences. No inconsiderable portion of the insane know perfectly well when they do wrong, and may sometimes be deterred therefrom by the fear of punishment or deprivation of privileges. Ask a patient of this kind why he did this or that wrong thing, whether he was driven thereto by an irresistible impulse, and he will be likely to reply, "No. I acted as I did because it gave me pleasure. I suppose the devil was in me."

When will the world recognize the truth, as well established as any in nature, that insanity not only impairs the intellectual or reasoning powers, but perverts the moral faculties, vitiating the tastes and sentiments, and furnishing strange motives and impulses. The radical error in all these principles of responsibility is to suppose that in any case of insanity we can say exactly how far the operations of the mind are, or are not, affected by the disease. For it is conceived to be the 
duty of the jury to satisfy themselves that the prisoner is not only insane, but so insane as to be irresponsible for crime. Why then do courts persist in attempting to analyze, define, and describe mental operations which are confessedly beyond the reach of our apprehension? Simply because more than one hundred and fifty years ago, a distinguished judge, following the lights of his time, declared that " partial insanity seems not to excuse men in the committing of any offence for its matter capital." 1 We trust, however, the time is near when such authority on such a subject will be regarded by our courts as entitled to but little weight amid the superior lights of our own time.

1 Lord Hale, Pleas of the Crown, 30. 


\section{THE TRIAL OF BAKER.}

[THE case of Baker painfully illustrates the misehief that may be produced under our legal system, by popular ignorance and passion. The jury went to their seats possessed of the idea that pervaled the whole community, that an audacious attempt was to be made to screen a murderer from merited punishment by means of that last resort of unscrupulous counsel, the plea of insanity. Of course, on minds thus prepared, the testimony of friends and experts, showing, unquestionably, the presence of disease, had no more weight than an idle tale. As might have been expected among a people of little culture, and with ample leisure for discussing passing events, this case was, undoubtedly, a topic of frequent and exciting conversation; every damaging circumstance being exaggerated, and many invented by their inflamed imaginations, until the prisoner became, in the eyes of every man, woman, and child, an embodiment of the most fiendish iniquity. The historian, the orator, the jurist, setting forth the inestimable blessings of trial by jury, and the man of the world brought up to believe in it as the palladium of personal liberty, make little account of some of the elements that enter into a verdict in a ease that has been discussed in every villarge gathering, and has provoked from partisans on both sides every species of persuasion and menace. This is no exaggeration. Who has not, in a jury trial, seen the ties of relationship sundered, and a man set at variance argainst his father, the daughter against her mother, and the daughter-in-law against the mother-in-law?

Amidst a sparse population, it needs only some effort to ascertain how every individual feels in regard to the pending case, and but little ingenuity to adapt the proper arts of persuasion accordingly. 
It needs no prophet to predict the result when one party is weak and the other is strong, in position and influence. Not many have the courage to brave the ill-will of parties able and ready to punish them for daring to perform their duty on the witness-stand. To incur the hostility of a powerful family, in a matter involving the deepest interests and exciting the strongest feelings, is a kind of moral suicide that few are disposed to commit, without some stronger inducement than the simple love of justice. Consequently, it may happen, as it did in this ease, that under the forms and solemnities of a judicial proceeding an outrage is committed upon justice which one can scarcely allude to but in terms of the severent reprobation. If this were an exceptional ease, happening accidentally, as it were, it might not be well, after so long an interval, to bring it again before the public eye. But inasmuch as such cases spring from ertain principles of human nature, and are indicative of certain phases of our sorial system, and therefore are liable to be repeated, - as indeed once occurred to the fullest extent under my own observation, - it may be profitable for reproof and correction that the trial of Baker should be kept in remembrance.]

THe document, whose title-page ${ }^{1}$ we have quoted below, discloses one of those revolting cases of judicial ignorance and barbarity which fill us with horror and amazement. It is with feelings of muspeakable mortifieation and sorrow that we find it reserved for the year of our Lord, 18t5, in the State of Kentucky, to present us, in the administration of the law, with a triumph of passion, revenge, ignorance, and political faction, over the pleadings of humanity and science, unparalleled, we venture to say, in the judicial history of our country. We shall not spend words upon the

1 Life and Trial of Dr. Almer Baker, Junior (a Monomaniac), who was executed Octoher $80,184.5$, for the Alleged Murter of his Brother-in-law, Daniel Bates; including Letters and Petitions for his Pardon, and a Narrative of the Ciremmstances attending his Execution, \&c., \&c. By C. W. Crozier. Trial and Evidence, by A. R. M'Kee. Louisville, Ky., Prentice \& Weissinger, Printers. 1846. 
actors in this affair, for such persons would heed the strongest expressions of public indignation as little ae the winds. People who are addicted to such pungent arguments as bowie-knives and pistols would scarcely feel the paper bullets of the brain. Is faithful journalists of matters connected with insanity, we conld not overlook this case; while it will give those worthy people who mourn over the prevalence of the plea of insanity in defence of crime an opportunity to see the other side of the matter, and derive what consolation they can from the sight of a wretched maniac proclaiming his wild delusions from the gibbet.

Dr. Baker, the accused in this case, was a practising physician in Clay County, Kentucky, of a well-known and respectable family, and at his decease about thirty years of age. One of the editors of this publication states that as early as 1838 and 1839 he manifested some singularities of deportment that caused much speculation among his friends. Once while attending the medical lectures he suddenly, and without the least prorocation, began to abuse a fellow-student for looking at his head, suspecting him of looking at a lock of white hair, and threatening to take his life if he did it again. He then resided with this editor, who also says, though neither of these facts appeared in evidence at the trial, - "That he would frequently alarm the family at a late hour in the night by crying out that some persons were in the house. We would light a candle, and, followed by Dr. Baker, who was armed with the tongs or shovel, would examine every apartment, even to the garret; and he would after this still insist that there were persons in the house, as he heard them whispering." We hear nothing more of his mental irregularities until within a year of the homicirle, when some 
notions he expressed to his father respecting Bates's treatment of his wife awakened in tho father's mind the suspicion which he had previously entertained, that his son was becoming deranged. This, and the following facts respecting his mental condition, we find in the evidence given at the trial.

In May, 1St4, he married a young girl of a wealthy and respectable family, herself of an unblemished character, and went to reside in the family of this James Bates, whose wife was a sister of Baker. From this time till the day of his execution he was possessed with the idea that his wife was unchaste, - a subject, indeed, of mymphomania. On this point he seems to have spoken very freely and with almost everybody; and among a multitude of persons whom he mentioned as having criminal intercourse with his young wife, at one time or another, were her teacher, her uncles, this brotherin-law Bates, and even negroes. He believed that she commenced this infamous conduct as early as her ninth or tenth year, and continued it at every opportunity subsequently: In regard to some of these persons, he declared that they came into his sleeping-room at night, and accomplished their purpose even in his own pres. ence ; and that on one occasion, whilst visiting his father's family, his own mother lent her assistance. He also imagined that his mother and sisters kept a house of illfame; that Bates treated his own wife with great cruelty, and had debanched her younger sister, and that in conjunction with his (Baker's) wife he once attempted to poison him. Me told a witness that they gave him some toddy, and, though he took but a sip of it, yet "it swelled up his head mintil it felt as large as a bushel; and that, if he had drank as much as usual, it would have blown him to hell in five minutes." $\mathrm{He}$ 
frequently expressed his belief that Bates was at the head of a conspiracy to kill him, and that for this purpose he had collected muskets and other weapons in his house, and had set his negroes to waylay him in secluded places.

During the period between his marriage and the homicide, he manifested various symptoms of bodily illhealth. His brother, also a physician, testified that "his bowels were costive, stomach irritable, mucous membrane covering the mouth and fauces red and much swollen," and that he was "watchful and restless." Another witness stated that "his countenance had a haggard expression," and he "looked as if just recovering from a spell of sickness." He seems to have neglected his business, and taken but little interest in any thing beyond the circle of his delusions. Finally, after one attempt, in which he was defeated by the rigilance of Bates, he succeeded in shooting his rictim on the 13th of September, 18tt. He made no attempt to escape, was quietly arrested, tried by a magistrate, and discharged on the ground of insanity. His brothers took him home with them, and endeavored to restore him to health; but, not completely succeeding in this purpose, they concluded, at the end of some three or four months, to send him to Cuba, for the benefit of change of air, scene, \&c. While here, Governor Owsley of Kentucky issued a proclamation in which Baker was described as a fugitive from justice, and a reward was offered for his arrest. This immediately induced lis family to get him home and surrender him to the authorities of the State.

His trial began on the 7th of July, 1845, before the Hon. Tunstel Quarles, judge of the fifteenth judicial district. Public feeling seems to have been much ex- 
cited. The friends of the deceased and of the prisoner, respectively, made unusual efforts, the former to obtain his conviction, and the latter his acquittal. Armed men were observed in every part of the court-room; and a long array of eminent counsel appeared on each side. A considerable number of witnesses were examined, to whom the largest liberty was allowed in giving their testimony, much of which was mere hearsay and rumor. Whether the courts of Kentucky ever pretend to be governed by any rules of evidence is what we do not know; but in this case, certainly, there was a complete defiance of all rules recognized in this part of the world, for the witnesses were permitted to ramble on pretty much as they pleased. The two following passages, each of which is a continuous extract, will give the reader some idea of what is considered evidence in Kentucky :-

"Witness was at the Lunatic Asylum in Lexington, and saw the inmates, and did not then believe that a man could be deranged upon one subject and not upon all. Witness was told by Mrs. Dr. Reid, that Dr. Reid said that Dr. Baker was deranged, and had been in that condition for twelve months. Said, damn his derangement. Witness had a conversation with Mr. Woodcock, the clerk of Clay, and attorney Einsworth, and they said that the best ground of Abner Baker's defence wals derangement, and witness said then that was a fashionable way of lefence. Witness has since read upon the subject a little, and heard some conversation, and now has no doubt that Alner Baker is a monomaniac." p. 31 .

"Witness told Baker that a neighbor woman had told his (witness's) wife, that Bates hard said that if he (Baker) ever came down he would kill him." - p. 15. 
After this specimen, no one can be surprised that most of the witnesses, though not medical men, were allowed to express their opinion respecting Baker's mental condition; and the manner in which some of them expatiated on this point is certainly curious, if not very instructive. Two medical witnesses only were examined, one for the government, the other for the prisoner. The former, Dr. Reid, seems to have obtained some new light on the subject of insanity, which we feel bound to notice for the sake of our professional brethren, who might not otherwise receive its benefits. He states that "he had not expressed the opinion that Dr. B. was insane, but he has been of the opinion that Dr. B. was laboring. under illusions of mind in regard to his wife." Again he says, that "a person who can lay all his plans for carrying out any thing desired to be accomplished would not be laboring under insanity." This gentleman's answers seemed to be the mere echo of the questions put to him by either side; for he finally admitted that, supposing the facts respecting Baker's extraordinary notions, as we have mentioned them above, to be true, he was unquestionably insane. Dr. Richardson, of Lexington, who, for many years, had been a professor in the Transylvania University, was called by the other side; and though he had never been devoted expressly to the care of the insane, yet he appears to have seen somewhat more of such patients than most practitioners. He had visited Baker in jail, and heard the testimony at the trial, and could have no doubt that he was insane. His notion, howerer, that the position Baker sat in was strongly indicative of insanity, savors more of the fanciful than the scientific. But the evidence established beyond a doubt the existence of Baker's delusions, while it disclosed not a shadow of foundation for them in the 
conduct of his wife or of Bates. Indeed there was no attempt to prove that their characters were otherwise than irreproachable, or that his delusions were not as baseless as the fabric of a vision.

All the counsel declined to furnish their speeches to the editor, except one who pleaded for the prisoner, so that we do not know on what ground precisely his conviction was urged. Neither does the charge of the court to the jury appear; and therefore we are left in the dark as to the views of the court on the law of insanity. The jury were out two days; and it is not the least remarkable trait of this remarkable trial, that, "during a great part of the time," as the editor states, "a large body of influential men, most of them armed, stood in full view of the jury." It is not surprising that the result of such deliberations was the conviction of the prisoner. A motion was made for a new trial, but without success; sentence was pronounced and a day appointed for the execution. Thus ended another act of this judicial tragedy. A sadder is to follow.

The friends of Baker now made every effort to procure his pardon. Six of the jury signed a paper recommending him to merey, - we say signed, though two of them made their inark, "like honest, plain-dealing men," - in which they say that Baker "was in a state of mental excitement and delusion respecting his wife and said Bates, which may be considered insanity." One of this number also certifies, among other things, that, "from the evidence, they believed that Dr. Baker was deranged upon those subjects, and not a fit subject for example; but from our understanding of the law applied to the evidence we had to find a rerdict of gnilty. I do further certify," he continues, "that, if the delusions which were proved upon Baker had been facts, it 
would have been a full and good excuse for killing him (Bates)."

Another certificate, in which the same sentiments are expressed in the same words, was signed by four other jurymen. Such a juxtaposition of the most latitudinarian indulgence to crime with the most servile obedience to the letter of the law is without its like, we apprehend, in all the annals of criminal jurisprudence. Applications for his pardon were made by hundreds of persons, comprising some of the most respectable and best known citizens in the State. The leading medical men in Kentucky, among whom were several professors of the Transylvania University, and our frield Dr. Allan, the worthy superintendent of the Kentucky Linnatic Asylum, after examining the testimony given at the trial, declared their belief that he was deeply insane when he committed the homicide. The result of the movement was only to procure a reprieve of a few weeks, and he was finally executed on the $3 d$ of Octrober, 18+5. Under the gallows he made a speech, rehearsing his delusions respecting his wife and Bates, and glorying in the bloorly deed for which he suffered. Taking hold of the rope, he exclaimed, "Behold the necklace of a whore!" Thus, under the sacred names of justice and law, was en. acted a fearful tragedy which outraged both. A proper pride of country would have induced us to bury in oblivion, if possible, a case indicative of a state of civilization more like that of the middle ages than of the nineteenth century. But an imperative sense of duty impels us to hold up its atrocities to the public view, in the hope that such exposure will convey an impressive and a salutary lesson. When a gross outrage is com. mitted on the rights of humanity, we regard it as the duty of every honest man, when reasonable opportunity 
offers, to proclaim his disapprobation in tones that shall reach the wrong-doer, even in his most secret refuge.

In taking leave of this case, we would express the hope that no similar one will ever be permitted again to disgrace our country and the age. 


\section{CASE OF C. A.}

[The following case presents one of those forms of insanity which are very apt to be misunderstood by people not practically conversant with the disease. The patient is depressed, certainly, but it is a kind of depression that may proceed, apparently, from the ordinary troubles of life, and indicate no pathological disturbance. He is regarded as low-spirited, moory, cross-grained, and absorbed in his own reflections; and, as he is obstinately taciturn, nothing more is learned of his mental condition. This form of disease begins with simple depression, which gradually deepens until every ray of light and hope is extinguished, and a sense of intense ant inexplicable wretchedness excludes every other thought and care. Ordinary pursuits have lost their interest, the sweet influences of life are all unheeded, and the time is spent in reverie or restless movement. Then succeeds suspicion of the designs of those around the patient, - members of his own family, or even intimate friends, - and this finally grows into a settled conviction that plans and conspiracies are forming against his life and peace. In most cases, probably, the persons suspected are not at first identified with any particular individual. They are a sort of abstraction; and, when asked who they are, the only reply is, "They do or say so and so." The movements and expressions of others are watched, scrutinized, and misunderstood; and the most innocent occasions are tortured into proofs of hostility and hate. The perceptive powers are morbidly quickened, until they give rise to false impressions. Sounds and sights the most insignificant are thus distorted into some painful relation to bimself, and when all is silent he may hear mysterious voices charging him with crimes and revolting indecencies. Thus far he may give no intimation of the thoughts and feelings that possess his mind, for he avoids 
conversation and seeks solitude. The end of it all is mania, demonstrative enough to satisfy the most incredulons. But before this takes place, his delusions, rendered for a while unusually intense, may precipitate him upon some fearful act of violence. A dear friend or an utter stranger coming before him at such a moment, he suddenly, and with an irresistible impulse, avails himself of any means at hand, and takes the life of his fancied tormentor.

In no form of insanity are the mental processes more completely beyond the government of right reason than in this; and yet it is a kind of derangement not apt to be reeognized by the ordinary observer. IIe only sees a person quiet, speaking coherently, pexhaps rationally, when he speaks at all, inoffensive, unsocial; low-spirited, perinps, even deeply despondent, but, to all appearance, not erazy. IIen e the difficulty of convincing people of the existence of mental disease when disguised by so much outward propriety; for thongh the looks, manner, turn of thought, and mode of expression are as demonstrative of insanity as the raving of mania, yet these things signify little or nothing to the common observer. Had this person been tried, any number of people might have been bronght to testify that they had known him well, and, though rather strange in some of his ways, they never supposed be was insane. And if he had been poor and friendless, and the publie sentiment strongly against him, he, probably, would have been convicted.

Seventeen years have passed since this sad oecurrence, during which period A. has been in the hospital. His eondition during the first few months after admission is described in the following notice. Since that was written, the manifestations of disease have been steadily getting more positive and numerous. The first of this kind were paroxysms of fury that broke out suddenly, on some trivial occasion, in which he raved at the top of his voice, and struck ont wildly right and left. They lasted but a few minutes, and the next day he appeared as usual. Not long after these began he beeame suicidal, and made several attempts upon his life. In the course of a year or two more, he assaulted violently fellow-patients on little or no provoeation, and once came near killing his attendant. Thenceforth he was treated as a dangerous person, and prevented by suitable restraint from doing harm to others. Ile was visited by his family from tine to time, but he never spoke to them, nor manifested any interest in their visits. After the first few years, he became completely silent, uttering not a syllable to any one from year's end to year's end. For the last three or four years he has been peaceful, and required no 
restraint. In fact, there is little reason to doubt that lie has lecome somewhat demented.

He has probably entertained delusions from the beginning, though his extreme taciturnity has prevented their detection. In regard to his moral condition, the indications are more positive. To maintain an unbroken silence for a dozen years or more, to express no wish for his liberty, to make no inquiry for family or friends, to manifest neither joy nor sorrow at any event within his knowledge, all show a profound derangement of the moral sentiments.]

Is August last I was requested by the Attorney-General to hear the evidence which was to be presented to the grand jury, touching a homicide committed by a young man, in a neighboring town. From this evidence and my own personal observations, I have compiled the fullowing history of this interesting case.

\section{THE PARTIES.}

C. A. and T. A. were cousins, the sons of respectalle, thriving farmers who had always lived in the same neighborhood, and were, respectively, twenty-three and twenty-five years old. They had been very intimate and fond of each other from childhood, and had the reputation of being remarkably correct and amiable young men. They had been at the mines in California, and while there had lived together much of the time. $\mathrm{V}$. came home in the spring of 1855 , and shortly after became a merchant's clerk in Buston. C. came home on the 9 th of June, 1855 , and resided in his futher's family.

\section{INCIDENTS OF THE HOMICIDE.}

On the 13th of August, V. came to his uncle's liouse on a friendly call, between nine and ten o'clock in the morning, and after conversing with some of the family 
went into the corn-crib, where he met C. Shortly after, he was seen walking away from the crib, and when a few rods from it he was struck down, mortally wounded, by a shot fired from the window of the crib by C., and died about twelve hours afterwards. This was the second time the cousins had met since their return from California.

CONDUCT OF THE PRISONER ON THE OCCASION.

While they were raising the wounded man, C. came out of the crib, passed by them and went towards the house, but said nothing and offered no assistance. He soon went to his room as usual. To the question repeatedly put to him, why he had killed his cousin, he gave no other reply than to say that "they had had no difference." The gun had been kept in the crib, and was not carried there by him. During the two days that elapsed between the act and his arrest, he appeared as usual; and, though strongly urged to fly by those who were not aware of his real condition, he showed no desire to go. When taken by the officer, he made no resistance nor objection, but wept a little. This was the first time he had shown any emotion. When questioned by the officer, he said that the act was accidental, that he put on a cap to try the gun, and it accidentally went off. V., during the few hours that he lived, said repeatedly that he could conceive no reason why $\mathrm{C}$. should have shot him, that they had always been on good terms, and that nothing passed between them while in the crib calculated to irritate him. He merely asked C. if he had been to see the girls. 
CONDITION OF C. BETWEeN THE 9TH OF JUNE AND $13 \mathrm{TH}$ OF ACGCST.

On his return from California in June, his family and others observed a notable change in his appearance and demeanor. Though naturally cheerful and lively, interested in his friends and fond of society, he had now become shy and taciturn, avoiding his friends, and evincing no interest in any person or thing. The most of his time he spent in his room alone, occasionally going out to fish, or to work on the farm, and once or twice he visited a neighbor. He seldom came down to see persons who called on him, and when, out of doors, he observed any one approaching, he would avoid him. He refused to see an old acquaintance who called three times, and his own relatives he treated in the same manner. A married sister and her husband, neither of whom he had seen since his return, visited the family, and he scarcely spoke to them during the six days they stayed. In order to see him at all, they were obliged to go to his room. All the witnesses who had previously known him, as well as some who had not, stated that they thought him, at that time, strange and singular. Some of them, in fact, expressed their apprehension that he was losing his reason.

He kept his bed much of the time, and was often heard at night, pacing his room; had, at first, some diarrhœa, perspired much, and complained of headache. He refused to take medicine.

\section{CONDITION IN CALIFORNIA.}

From the few witnesses who had known him in California, it was impossible to gather a complete account of his mental condition while there. None of them had 
much communication with him, and they could give only a few facts that incidentally came under their notice. One witness stated that the change in his manner began to be exhibited during the summer of 1854 . He became silent, secluded himself from company, worked irregularly, and spent much of his time in bed. Witness accompanied him in the journey home from California, and represented him as manifesting no interest nor forethought in the arrangements. When they reached Sacramento, he seemed bewildered, and had to be directed at every step. Witness bought the tickets. On board the boat he kept aloof from everybody, and when spoken to he got up and moved off. While at San Francisco, he showed no wish to go out of the house, and did not call upon an uncle living there. Here, too, the witness had to buy his ticket, as well as at Panama. Through the whole journey he was silent and indifferent about every thing. After having arrived at New York, and engaged their passage in one of the Fall River boats, they proceeded to a clothing-store to obtain such articles as they needed. While there, C. was suddenly missing; and the witness, being unable to find him, went home alone. A few days afterwards, C. made his appearance at his father's house, and subsequently told the witness, when inquired of ahout this affair, that he had got lost. Witness was told by another man that C. asked him if he had heard $V$. say any thing about a girl, and, at the same time, said that he (C.) heard folks say, as they went by, that he had fallen in love with a girl, who died in consequence. This same man also stated to witness that C. would sometimes talk to himself about this affair. Another witness testified that once he went to his cabin to spend an evening with him and his companions. C. soon went out and stayed outside all the time he 
was there. Had heard other people speak of his peculiarities.

On the morning of the inquisition before the grand jury, I visited the prisoner in the county jail. I found him a stout, strongly built young man, with a ruddy face, and having, at first glance, the aspect of high health. I soon observed that he averted his eye, and that his countenance had a dull, vacant look. He sat down before me, benling forward, with his arms on his knees, and his eyes turned to the floor. I put to him various questions, beginning with ordinary topics, and ending with his health, his relations to others, his feelings to his friends and relatives, and his motives in killing his cousin. In no instance did he reply without a long delay, and when the answer came it was very brief, and, for the most part, very indefinite. To many of my questions I got no reply at all. When asked if his friends or anybody else had worried him in any way, he replied that they had not. After the question had been repeatedly put in different forms, he finally admitted that they had "talked about him." "When they went by my cabin they said, "What do you make out of this fellow ?" This was all I could get from him on that point. When questioned ahout the homicide, he replied that it was accidental, but offered no explanation. At the begin. ning of the interview the pulse was 110 , but before I left him it fell to 100 . He was perspiring very freely, though the weather was not hot.

Having heard the evidence, I testified that, in my opinion, the prisoner was insane when he committed the homicidal act. The grand jury did not indict him, and the next day his friends brought him to the hospital. When they took him from jail, he made no inquiries as to where he was going, expressed no wish of any kind, 
walked through the streets without the least interest in any thing he saw, and came to the hospital without a single remark about it.

\section{CONDITION IN THE HOSPITAL.}

Here his deportment has been uniformly correct, and his manners gentle and gentlemanly, though very quiet and retiring. He manifests the same reluctance to converse, and seldom speaks, except in reply to questions, and then only after a long pause. He spends much of his time in reading books, which he selects himself from the library, but until lately has shown no interest in the news of the day. At first he kept limself aloof from other patients, but, after a week or two, he would join them in a game of cards or draughts. He frequently goes out to work on the farm, but, of late, has declined going, unless in company with a gallery-attendant, instead of a farm-laborer. When out, he is very diligent and does his work well. The Sunday services, and lectures at other times, he constantly attends, though he declined at first. During the first ten weeks he saw no one whom he had ever seen before, and made no mention whatever of his family or friends. At the end of that period he was visited by some of the family, - his father, mother, uncle, and aunt. He shook hands with them all, but asked no questions, and manifested no interest in what was told him.

Twice only have I conversed with him respecting his mental experience and the motives of his conduct. $\mathrm{He}$ spoke with great reluctance, pausing long before replying to my inquiries, and declaring, rather emphatically, that he did not wish to converse on the subject, as it was very painful to him. In the first interview I endeavored to ascertain the range which his suspicions had taken. 
After a tedious questioning, I obtained nothing more than the admission, witliout any explanations, that his parents had not treated him exactly right. At the second interview, after some inquiries which led to nothing, the following questions and answers passed between us. Having first assured him that the only ohject I had in view was his own welfare, which I represented as being deeply concerned in my knowing the truth, I presented other considerations to the same effect, which need not be stated.

Q. - Was the shooting of your cousin accidental, as you once told me it was?

A. - It was not accidental.

Q. - Had you thought of doing it previous to that interview in the corn-crib?

A. - No.

Q. - Were there any differences between you; did he annoy you in any way? It is said you lived happily together in California.

$A$. - There was something.

Q. - When did it occur?

$A$. [after a long pause]. - Seven or eight years ago.

Q. - What was it about?

[No reply; countenance flushed; much agitated.]

Q. - Was there a young lady in the case?

A. - Yes.

To all further inquiries on this point, he steadily refused to reply.

\section{OBSERYATIONS.}

Had this case occurred in the ordinary manner, and unaccompanied by any homicidal act, no one, with a professional knowledge of the subject, would have hesitated to regard it as one of unquestionable insanity. Of 
all the indications of this disease, he manifested the strongest, - a striking change of manners, habits, conduct, and appearance, without any sufficient cause. When, in connection with this trait, we consider the loss of all interest in his friends and customary pursuits, his unconcern respecting things which once would have concerned him deeply, his quitting work and lying in bed, though without any bodily ailment, his taciturnity and avoidance of his friends, his dull and racant look, - considering: all these, the existence of the disease seems to be beyond a reasonable doubt. How far this view of the case is affected by the homicidal act, is a point not quite so clear. That an insane man should commit such an act, certainly is not very strange; but we must be satisfied that the circumstances of the act do not militate against the supposition of insanity. If the prisoner had acknowledged the act, and given some reason for it drawn from his delusions, it would justly have been regarded as confirmatory proof of the disease. On the contrary, he denied at first that the act was intentional. It is not usual, certainly, for the insane to deny their bloody deeds. Acts of petty mischief perpetrated in their calmer moments they will frequently ignore, and with some ingenuity, perhaps; but, when urged on to some fearful deed by that overpowering sense of its necessity which springs from strong delusion, they acknowledge and justify what they have done. If the prisoner had shot his cousin under the belief that he was one of those who had ammoyed him in some way or other, we should have expected that he would instantly and openly declare, "I killed him designedly, and he richly deserved his fate. I am satisfied.". Supposing, therefore, his subsequent admission to be true, - that the shooting was really intentional, - it is a question of much importance 
whether the first statement is compatible with the existence of insanity. After a careful consideration of all the circumstances of the case, I cannot see in this fact a sufficient reason for doubting the correctness of my opinion respecting the prisoner's mental condition. It is probable that he was governed by a sudden mental movement, more or less directly connected with his delusions, for it is obvious that the act was not premeditated. The sight of his cousin, while his mind was harassed with suspicions and apprelsensions, called up some old passages between them which, probably, had never raised an unkind feeling in the heart of either ; but then, by a confusion of ideas not uncommon with the insane, they led him to associate his consin with those who were disturbing his peace and destroying his comfort. The means and opportunity concurring at that moment, he obeyed the impulse thus suddenly produced, to sacrifice a persecutor. Now, it is well known that when an impulse of this kind has passed off, and the person has become conscious of the havoc he has committed, it sometimes happens that he is ashamed of, and frightened at, the consequences of his conduct, and, under the influence of those feelings, endeavors to conceal it, and, perlaps, takes to flight. His mind was not so far deranged after the violence of the homicidal paroxysm had subsided - as to prevent him from seeing and appreciating the legal consequences of the act, thongh even these could not arouse him from his habitual listlessness, and inspire him with the requisite energy for avoiding them. He did, therefore, what was consistent with his apprehensions and the temper of his mind, - he denied that the act was intentional, and passively waited for the result. When, subsequently, he found there was nothing: to gain or to lose by telling the truth, he admitted that 
the act was intentional, and assigned a very inadequate motive for his conduct, - a motive which, under the circumstances, is clearly indicative of insanity.

It may possibly be regarded as a suspicious circumstance, that his victim had become obnoxious to him, not by being associated with those who were embittering his existence, but by reason of an old event which, probably, had long since ceased to excite any hard feeling whatever. Usually, no doubt, the maniac seeks for the objects of his vengeance among those whom he believes to be engaged in machinations destructive of his present peace. Actual occurrences make less impression on his mind than the images that crowd upon his distempered fancy, and a real enemy excites less emotion than one of his imaginary tormentors. But neither observation nor a knowledge of the laws of association will warrant us in saying, that, in the mind of the maniac, old grudges never get mixed up with present delusions. In his readiness to mistake the suljective for the objective, he is apt to overlook the single step which separates real wrongs and annoyances from such as have only a delusive existence. We know very well that, in some forms of insanity, the patient finds his grierances among incirlents and events that malle no impression, apparently, at the time, and had been almost forgotten by every one else. After the lapse of weeks or months, an innocent remark, or look, or gesture is called up, and ingeniously tortured into a damuing proof of hate and hostility. We may fairly suppose, therefore, that in the present case an old love-passage suddenly obtruded its rekindled heart-burnings among the suspicions and jealousies that agitated his distracted mind, and thus prompted the fatal deed.

IIad the case gone to trial, this old affair would prob- 
ably have been presented as furnishing a rational motive for the criminal act, and thus invalidating the pite of insanity as a ground of defence. Leaving out of view all the positive indications of the disease, it would be sufficient to say, in regard to this point, that the subsequent intimacy between the parties, and the declarations of the dying man, show that the wound had been healed, if it had really existed. However suspicions this denial of the intention may seem to those not much acquainted with insanity, it will be regarded in a very different light, I think, by all who have had the opportunity of witnessing, on a large scale, the operations of the insane mind. Difficulties like this are not uncommon in cases which are subjected to judicial investigation. Not unfrequently the medical jurist is puzzled by some particular incident or trait, apparently adverse to the general conclusion which is warranted by all the other phenomena of the case. It only shows how multiform is nature, even in its wanderings, and how feeble are our conceptions of its infinite variety. 


\section{CASE OF BERNARD CANGLEY.}

[Sixce the following paper was written, a case of homicide, Commonwealth $v$. Andrews, was tried in Marsachu-etts, in which transitory mania was pleaderl in lefence. The plea gave rise to much discussion; and, by one or two who engaged in it, and probably by others who never published their opinions, this form of insanity was strenuonsly denied. It was alleged that the relitted cases were carelessly observed, or were reported by men of a fanciful turn of mind, and that among the thousands of patients in our hospitals for the insane not one of the kind has ever been found. Of course, the proof of the oceurrence of a form of disease so sudden and evanescent must necessarily be wanting.in that fulness and accuracy always desirable for such a purpose, because the eases are observed, mostly, by those only who happen to be at hand,- persons not likely to understand the true meaning of such a manifestation. What they do report, however, is more or less significant to others acquainted with mental diseases, and ought not to be rejected as utterly worthless. It may be legitimate ground for a scientific conclusion, and, for lack of any better, must be used when the exigency arlmits of no delay nor farther investigation. In the following case, the evidence was ineomplete; and though consistent, probable, and sati-factory, so far as it goes, yet leaving much to be desired. Upon this evidence, such as it is, it was necessary to adopt that conclusion which seemed least encumbered with difficulty. The theory of transitory insanity explains the phenomena of the case better than any other; and, in alopting it for this reason, we certainly violate no rule of philosophy. And this position is none the less tenable because the law requires something more, holding the criminal to be of sound mind and responsible for his acts, until the contrary is rendered, not probable, but proved.

I do not see how we can refuse to believe in the existence of this form of mental disorder, for it is supported like many other facts in 
physical science that are generally accepted. Cases enough have been observed - some sixty or seventy, as stated by Dr. Jarvis, who has written an elaborate paper respecting it - to preclude the idea of chance, accident, or mistake, and by men whose standing and attainments forbid our considering them as incompetent fur the purpose. There is no furce in the objection that eases are not found in our hospitals; for, being just what they are, transitory, suddenly coming and suddenly going, there is little occasion for sending them to hospitals. As a matter of liat, however, they are sometimes found in hospitals for the insane.

Caspar, a German writer on medical jurisprudence, of some note, disbelieves it to be a distinct form of mental disease, because he has seen several cases of melancholia attended with a violent outbreak, where the signs of any other derangement were so faint that the cases may have been readily istaken for transitory mania; and so he jumps at the conclusion that all the reported cases only represented other forms of disease obscurely manifested. That an observer not much conversant with insanity might make such a mistake, one can readily conceive; but to regard this as a valid objection in the face of such observers as those whose authority is invoked, is, certainly, no proof of superior penetration. Caspar himself relates a case preceded, as he admits, by no mental disturbance, which he designates as a "sudden outbreak of mental derangement," and thus avoids, as he supposes, any sanction of the doctrine of transitory mania. The difference will not be very obvious to his readers, probably, if it is to himself.]

Nот less interesting to the student of morbid psychology, than the well-defined, well-recognized forms of insanity, are those obscure, anomalous conditions of mind which occasionally appear, but in regard to which he fails to obtain any light from the standard books. Though more numerous, probably, than they are generally sup. posed to be, yet they are comparatively so rare and so imperfectly understood, that, for the most part, after ex. citing a little temporary curiosity, they pass away and are forgotten. And yet they must ever constitute a very important class of mental disorders, for the reason that their existence, however infrequent, must necessa- 
rily modify the conclusions that might be drawn from the more common forms of mental disease. In fact, no physician needs to be told that many important steps in the progress of his science have been made by the careful and persistent observation of what, at first, seemed to be anomalous or exceptional cases. In this way have neuralgia, pyæmia, diphtheria, albuminuria, and many other diseases, obtained a local habitation and a name, and thus become easily recognized and intelligently treated. In the more special department of mental disease there occur to us, as instances of a similar kind, delirium tremens, general paralysis, homicidal mania, pyromania, kleptomania, and Bell's disease. These views would furnish a justification, if any were needed, for occupying a few minutes with some account of a case lately reported in the public prints, and presenting some traits of peculiar interest to the medical jurist.

In the Belfast (Ireland) Journal of March 4th, 1864, is a report of the trial of Bernard Cangley for the murder of Peter Reilly. As all the essential facts are given in the evidence of Reilly's wife, they camnot be better presented than by quoting it entire :-

"I am the wife of Peter Reilly. He lived at Coolnacola, in this county. He had eleven acres of a farm. He was pretty well off. He was in the habit of lending money to people in the comtry. At all times he was in the habit of keeping money in the house. I was yesterday married a year and a half to him. I never saw the prisoner since thirteen or fourteen years ago. He lived in the same neighborhood with me. I recollect the $22 \mathrm{~d}$ of January; after dusk my husband and myself were sitting by the fire. The prisoner opened the door and came in. A little boy called James Molloy was in the kitchen with my husband and myself. $\mathrm{He}$ was a servant. We three were the only occupants of the 
house. The clock was after striking six. When the prisoner came in he asked, 'Is it here that Peter Reilly lives?' Either myself or my husband answered,'Yes:' after the answer was given, the prisoner got a seat and sat down at the fire. I lighted the candle, seeing a stranger. When he sat down at the fire, my husband asked him, did he come far? He said, 'A pretty good piece; do you know me?' 'How should I know you?' said my husband. 'Do you not know Cangley, that the ass took the hand off?' said Cangley. When he said this, my husband shook hands with him, and said, 'You are welcome.' Mr husband told me to get some supper ready. I then went into a room besirle the kitchen; I signed at my husband to follow, to know from him what I would get reary. I got tea. We took tea together in the parlor, off the kitchen. We then came out and sat down by the fire as before. Cangley read to us out of a newspaper. I sent Cangley with Molloy to sleep in the apartment above my sleeping-room. They went to it by a ladler out of the kitchen. I told Molloy to go to bed a few minutes after ten. Cangley went up after Molloy. Before Cangley went up to bed he went out of the house for a couple of minutes, and then went to bed. During the time we were talking at the fire, we were talking about his mother and about his family. There was no quarrelling: He told us that since he harl left us he had herderl with a gentleman farmer in Meath. He said that he was employed there and used to go to Smithfiel, market with cattle. Myself and my husband remained up after the others went to bell, about half an hour. I fell asleep after twelve o'clock. I think my husband went to sleep at the same time. Some time after, I was awakened by something like a foot moving on the loft over my head. That was after one o'clock; nearer two than one. All was orer about two. When I heard the noise, I said, 'James, good boy, take care you don't fall.' I thought it was Molloy. My husbamd was not awake when I said that. When I spoke, Cangley answered and said, 'It is not James, Mrs. Reilly, it is me.' 
From his voice, I thought he was standing at the room door. The door was at the ladder and behind it. I asked what it was that he eould not sleep. He said that he saw flishes of fire through the window. There is no window in the loft. Any person in the loft conld see the kitehen window. Any person in bed could see the light on the floor, but not the window. My husband awoke when I spoke a word or two. I was in bed all this time. The door was laid to, but not fastened. My husband said it was the moonlight. It was a nice moonlight night. When my husband said that, he got out of bed. I remained in bed. $\mathrm{He}$ opened the room door to go out into the kitchen. When he went out he had nothing on him but his shirt. He had nothing in his hand, - no weapon of any kind; as far as I know he walked to the street door. The first thing that next attracted my attention was his shouting, 'I am murdered.' I then jumped out of berl. I had nothing on me but my night-clothes. I saw Cangley standing beside my husband. [Witness here became much affeeted.] Cangley ran at me as hard as he could. He made a stab of a knife at me. He stabbed me in the belly. I harl no weapon in my hand at that time. When he stabbed me I eaught him by the side of the neck somewhere. He made three more stalbs at me. He stabbed me with one in the side of the belly. He had on his trousers, suspenders, and shirt. I attempted to eatch the knife, and he pulled the knife through my hand. Altogether I was stabbed twice in the belly and got cut in hand and arm. After my hand was cut, he got the knife and went back from me. I then took up the hedge-slasher. I made a blow at him, but did not hit him. I had not this weapon before he stabbed me. He was standing close at the door, and the ladder at the door prevented my getting the blow at him. He then went out. I shut the door after him. I heard the ery of my husband about a minute after he went out into the kitehen. My husband was at the back of the kitchen door, standing. After Cangley went ont, my hus- 
band came toward the room door. I went to light a candle, but he fell on the floor before I lighted it. From the time Cangley went out, it was two minutes when my husband fell. I went to lift my husband. He could not speak. He was bleeding so that one conld hear the blood coming out like out of the pipe of a kettle. The little boy then came down. I sent him out for the neighbors. I fainted. When I came to again, I found Pat Smith and the little boy in the house. My husband died at three o'clock. He lay on the floor. I could see the features of Cangley when he was coming towards me. It was a moonlight night. I did not see any weapon in his hand. I can only speak from what I felt. I had knives in the house. None of them was used."

On cross-examination, she said that the prisoner had not been in that part of the country for ten years; that he did not seem to have any grudge about the ass having: bitten off his hand; and that they were not talking of money matters.

Immediately after the act, Cangley went to the nearest police-station and gave himself up, saying that he had stabbed a man. He told the man's name, and where the man lived, and said the weapon he used was a claspknife, which he had thrown into a bog.

It was testified that shortly before the homicide Cangley had been in prison, but for what cause, or how long, it was not stated.

When asked by the Court why sentence of death should not be pronounced upon him (for, of course, he was convicted), he replied that "he was unconscious of the act."

The counsel for the Crown, in referring to the motives for the act, suggested that he might have been actuated by a feeling of revenge on account of the mutilation he had suffered while in Reilly's service, or that his in- 
tention was to get possession of Reilly's money. It was not pretended, however, that either of these suggestions was supported by one tittle of evidence. The counsel for the prisoner rested his defence on the plea of insanity. No medical expert testified; but the surgeon who was called to the Reillys was asked some questions respecting insanity. The Court laid down the rule of law according to one of the oldest patterns; viz., if the prisoner did not understand the nature of the act, or, if he understood it, did not know it was wrong, then he is not responsible for the act. The verdict of GuILty was approved by the Court, who seem to have been much scandalized by the pretence of insanity.

Regarding the case from a very different stand-point, we are necessarily led to very different conclusions. The act in question was prompted, of course, either by some rational motive of interest or passion, or by an insane impulse; and although we are obliged to found our conclusions upon a very meagre account of the case, yet we can scarcely doubt their correctness.

The counsel for the Crown did not pretend to assign a motive for the act, for he was well aware that the circumstances attending it absolutely forbade it. Who ever heard of a man arising in the night for the purpose of robbing or murdering his host, walking so heavily as to wake up his wife, and calmly speaking to her as he approached her door? It is impossible to believe that any one in his senses would proceed to execute such a purpose in such a manner. And the absurdity. of the notion is heightened by the fact that the person, after accomplishing his end, straightway goes to the police and tells them what he has done. The annals of crime, we venture to say, furnish no parallel to such a case. If his purpose were to kill, he scarcely accom- 
plishes it; and if it were to rob, he leaves the house without even making the first attempt.

The only other theory on which the prisoner's conduct can be explained is that of insanity. The indications of this disease, it must be admitted, were ferv and indecisive; but this is just what might have been expected in the form of mental disease supposed to have existed here. It must have been a paroxysm of transitory mania, suddenly beginning and as suddenly ending, after the briefest possible duration. The cases of this kind on record, though few, certainly, are so well attested that we can scarcely deny the existence of the form of insanity which they illustrate. And it is a noticeable feature of most of them, that the patient is bent on destroying life. Apart from the absence of all rational motive, the grounds on which we must rest our belief that Cangley's was a case of transitory mania are his own declarations, that at the moment he saw flashes of fire, and that he was unconscious of the act. This statement about the flashes of fire does not look like one made up for the occasion. Such a notion would not be likely to occur to a person of his grade of culture; and the perception which it implied has been often noticed in abnormal movements of the cerebral system. The simulation of such a trait implies more knowledge of disease and a nicer art than can be fairly attributed to the prisoner. Indeed, a sane man would have so committed the act as to render simulation unnecessary. He had only to get down quietly into the room of his hosts, and either rob them or inflict the fatal wound while they were yet sleeping, and hurry away before being recognized.

It cannot be, as he declared at the trial, that he was "unconscious" of what he was doing, using the term in its ordinary signification, because after the homicide 
he told the police precisely what he had done. He probably meant what multitudes of the insane have said before, under similar circumstances, that he did not know why he should have done such a thing. He may have heard others use the word "unconscious" in speaking of his mental condition, and naturally supposed that to be the proper word for him to use in order to describe this unusual state of mind. Of course, such a person must not be held to a very correct application of metaphysical terms.

There can scarcely be a reasonable doubt that Cangley committed the bloody act in a short and sudden paroxysm of mania, and under an impulse that he could neither understand nor restrain. Of course, he was entitled to an acquittal, while society was equally entitled to such a disposal of his person as would have prevented any repetition of the murderous act. The occurrence of the homicide shortly after going to bed, and probably going to sleep, would naturally raise a suspicion that Cangley was in a state of somnolentia, or sleep-drunkenness, as the Germans call it, when the person suddenly awakes while dreaming of being assaulted or threatened in a frightful manner, some minutes elapsing before he fully comes to himself. In this state of mental confusion and alarm, he mistakes the first person who comes within reach for his imaginary foe, and attacks him with whatever weapon comes to hand. It is possible that Cangley's was a case of this kind; but the evidence, lamentably meagre as it is, would hardly warrant this conclusion. He did not pretend that he had been dreaming, though, if such had been the case, it is inconceivable that he should have omitted to speak of it when describing his state of mind, unless we suppose - and this is not at all unlikely - that such an 
cxplanation seemed to him less credible by others than that which he actually gave. His acquaintances might have thrown some light on the matter, but it is one of the many curious features of this case that not one of his family or old friends appeared on the witnessstand.

Here this account of a rare and interesting case might properly end, but it gives rise to some reflections that deserve to be very thoughtfully considered. It appears that no expert was called to testify respecting. the prisoner's mental condition, or to enlighten the court and jury respecting the nature of transitory mania; he was not recommended to mercy, nor was any attempt made to obtain a farther observation of his case. How striking the contrast, in this respect, presented by the case of Townley! He was examined by a distinguished expert, before the trial, who testified that he was insane. Next, a board of magistrates, assisted by medical men, examined him, and pronounced him insane. Then a committee of the Board of Commissioners in Lunacy, appointed by the government, examined him, and pronounced him insane; and, finally, another committee of experts was appointed by the government for the same purpose, by whom he was declared to be sane. The result of these proceedings was, that execution was stayed until the question of his insanity was effectually settled by his killing himself under remarkable circumstances. The difference between these two cases was, that one had friends able and willing to obtain for him every possible privilege, while the other had none. Had Cangley been subjected to the same sort of inquisition that Townley was, who can suppose that his fate would not have been averted? Inequality like this is discreditable to any system of criminal procedure, for the acquit- 
tal of the innocent is a no less essential end of justice than the conviction of the guilty. The law says, that when insanity is pleaded in defence of crime it must be proved; but it ignores the fact that the party, if really insane, is necessarily incompetent to prove it, and, if poor and friendless, is unable to procure the assistance of others to the fullest extent. Are we not warranted by the united voices of humanity and science in claiming, as a right, not as a favor to be purchased by wealth or influence, that when reasonable doubts are raised respecting the sanity of the prisoner in a criminal suit, the law shall provide for a satisfactory inquisition into his mental condition?

Medical men have been much reproached for the facility with which they allow themselves to support the plea of insanity in defence of crime. For their efforts in this line of duty, they have sometimes been exposed to a degree of public odium not calculated to enhance their peace or prosperity. We are quite willing, for one, to bear this reproach, provided it be considered in connection with that practice of the law which was exemplified in Cangley's case. If those are reprehensible views which, one time in a hundred, promote the acquittal of a guilty man, how shall we characterize a system which no less often, at least, procures the conviction of one really irresponsible for his acts? Are we to be charged with arrogance and disrespect because we speak in fitting terms of those who thus ignore the teachings of science, and, guided only by some poor metaphysical conceits that have nothing to recommend them but their age, sit in judgment on their fellow-men? When we are told, for instance, that delusion is not a valid defence for a criminal act, unless the act is amply warranted by the circumstances, supposing the notion that prompted it to 
have been really true, instead of a delusion, are we to speak softly and blandly about such a rule of law, and refrain from saying, with all possible plainness of speech, that it conflicts with the elementary truths of insanity on which only such rules should be founded? It seems to be a spurious kind of comity that would oblige us to withhold our censure, even in the face of the whole bench of English judges.

One of the results of the more careful and extensive study of insanity in these latter days is the discovery that, in the state of mind which is characterized by delusion, the patient may have lost all power of dis. tinguishing right from wrong, even to the utter destruction of all moral responsibility. Another is the discovery of a mental condition in which the understanding and will are completely dissevered, and the patient is borne on to the commission of some bloody deed by an irresistible impulse. These are not speculations or conjectures, but well observed, well authenticated; and not to recognize them as such in any attempt to fix the limits of legal responsibility is no more a mark of wisdom than it would be to teach chemistry now as it was in the days of Priestley, or to try old women for witchcraft in the spirit and understanding of Sir Matthew Hale. Medical jurisprudence can be of any worth only so far as it faithfully represents the acknowledged truths of science. 


\section{TRIAL OF WINNEMORE.}

ON the 29th of April last, George W. Winnemore was indicted by the grand jury in Philadelphia, Pa., for the murder of Dorcas Magilton, on the 25th of April, four days before; and the $3 \mathrm{~d}$ of May following was assigned for his trial, before the Court of Oyer and Terminer.

It appeared in evidence that the husband of the deceased came home one day, after an hour's absence, and was let in by the prisoner, who said he had just before come in and found Mrs. M. with her throat cut, and quite dead. The prisoner went for a policeman, and was himself arrested while leaving the premises, shortly after. The evidence against him was circumstantial, of course, and consisted of but few facts. A razor identified as his was found in the privy; two bankbills of two dollars each were in the possession of the deceased the day before, and two bills of two dollars each were found in the prisoner's pocket. His own statement, that he entered the house a ferw minutes only previously to the husband, was disproved by two witnesses, neighbors, who had been looking in that direction from their windows, steadily, for half an hour before they saw Mr. M. go to the door. To meet this evidence, the prisoner's counsel contended that it was impossible 
to identify so common a thing as a razor, hundreds of thousands of which may be made after the same pattern; that, though the bills were of the same denomination, yet their identity was not established; that he was not pressed for money, and could have borrowed it from his brother, if necessary; that he had never been guilty of any criminal act, and was regarded by all who knew him (and the evidence on this point was quite satisfactory) as a quiet, inoffensive, well-disposed young man.

The defence did not consist solely in an endeavor to prove an alibi. It appeared that the prisoner began to suffer from epilepsy at two or three years of age, and continued so to suffer until he was ten or eleven years old. Evidence respecting his disease subsequent to that period was entirely wanting, except that on his way to court one day, in the course of the trial, he had a fit. It appeared, too, that when seven years old he had a fall on the head, described as being a very serious one, and now indicated by a scar. The witnesses who testified to his having fits said he would sometimes have thirty or forty in a day. Of late years, his brother said, he professed to be able to see the dead as plainly as he saw the living. At times he imagined himself to be an Indian chief, and would talk the Indian language. The words of the witness would seem to imply that this sort of clairvoyance was paroxysmal, because "when I thought he was himself," he said, "I would ask him about it, and he would know nothing of it." He also professed to be able to know what was going on miles away. His sister stated, that at times during the last eight or ten months "he acted very foolish," "would make motions with his hands, and talk strangely," and that she was afraid to be alone with him. To another witness he seemed to talk very incoherently, saying, 
among other things, that he saw about him spirits the size of a pin's head. His mother and elder sister both testified to strange manifestations during the last few months. The former said, "He would laugh, jerk about, make queer faces." "He would dance around the room like an Indian." "Sometimes his eye looked very vacant, sometimes very glassy." "I often felt afraid of him." The sister said, "He would make peculiar grimaces, and twist his fingers in a peculiar manner." "I sometimes feared he would do me harm." Others spoke of his being in an unconscious state half an hour at a time; and others, of his being very absent-minded. It appeared that he had made two attempts, at least, upon his own life, and that an uncle had committed suicide.

Upon this state of facts, the counsel set up the defence of insanity. Several physicians were examined, only one of whom could be regarded as an expert in insanity; but their testimony was not founded upon such a knowledge of the case, either in its general or particular relations, as was needed to make it very satisfactory. Their testimony was confined to some desultory remarks respecting the effect of epilepsy on the mind, but it embraced nothing like a complete methodical statement of facts. Indeed, the counsel for the government were not disposed to have it, and did what they could to prevent it. When the testimony referred to the nature of epilepsy generally, they interposed the objection that it had no connection with the prisoner's case; and, when it had special reference to the prisoner, it was stopped, on the plea that the witness had not heard all the evidence in the case. No medical witness had made a particular examination of the prisoner, nor heard all the evidence given at the trial. The plea of insanity, thus feebly supported, could hardly be ex- 
pected to prevail; and accordingly the prisoner was convicted, and on the 29th of August was executed, persisting to the last in declaring that he did not commit the deed.

The counsel, feeling that the trial had not been a fair one, endeavored to obtain a new trial, but failed. They then requested the Governor to appoint a medical commission for the purpose of investigating the prisoner's mental condition, and in this too they failed. As a last resort, a few days before the execution they requested some gentlemen, who were familiar with epilepsy and insanity, to have a personal interview with the prisoner, the result of which was the following petition addressed to the Governor: -

\section{To his Excellency, Johx W. Gears:}

The undersigned, all of whom have been engaged for many years in the care of the insane, have, this day, at the request of Damon Y. Kilgore, had an interview with George W. Winnemore, and, in consequence thereof, beg leave to make the following statement:-

Winnemore now, and probably for some time past, shows indications of an abnormal state of mind; of a mental condition which may be attributable to the epileptic fits to which he has been subject from infancy. In regard to its degree and kind, we feel unable to speak exactly, because one interview, though prolonged to between two and three hours, was not sufficient for the purpose.

We would also state, that epilepsy, especially when of long duration, oftener than otherwise impairs the mental powers, sometimes in one way, sometimes in another; and therefore, whenever an epileptic is charged with crime, nothing less than an exhaustive investigation of his history and of all the circumstances of the case can remove the suspicion that the crime may have been committed in one of those abnormal conditions that are so often the sequel of epilepsy. 
In consideration of these facts, therefore, we respectfully pray your Excellency to stay his execution for a few weeks, in order that a deliberate scientific investigation of Winnemore's case may be made by the undersigned.

$$
\text { Isanc Ray, M.D., }
$$

Late Superintendent of the Butler Hospital for the Insane at Providence, R.I.

J. H. Worthington, M.D.,

Superintendent of Friends'Asylum for the Insane, Philadelphia.

,S. Preston Jones, M.D.,

Assistant Physician Penn. Ilospital for the Insane.

In the interview referred to, the prisoner was found to be a spare, slim young man, of a decidedly nervous temperament, with a quiet, ingenuous manner, and a cheerful expression. He was disposed to talk, and answered all inquiries freely and fully. His language was free from low, coarse expressions, and indicated some degree of intellectual culture. He showed a little carelessness of dress, and a certain kind of untidiness, very characteristic of some classes of the insane.

He said he had been an epileptic from his earliest recollection, the fits occurring sometimes several in the day, and sometimes at intervals of a twelve-month. They were generally brief, and within half an hour or so he was himself again. Occasionally he did not so readily recover, and was disabled for a week or two. He had no premonition of the attacks, though sometimes they were preceded by a little exhilaration, indicated by unusual laughing and talking. Neither did he experience the epileptic aura, nor was he aware that the fits were ever simply epileptiform, scarcely visible to the observer. He was not aware that the fits were preceded or followed by an unusual sense of distrust or suspicion or apprehension. He could call to 
mind two occasions of being quite unconscious for several hours, though continuing his employment, and appearing to others as usual. On the first, which happened while quite a boy, he got a boat and spent the day in rowing about on the river; and, when asked about it the next day, he hack no recollection of the occurrence, the period being an utter blank in his mind. During the last few years, this paroxysmal kind of unconsciousness had occurred several times, but had not extended beyond half an hour or a little more. He believed in all the notions of spiritualism as professed and practised at the present time, but he also believed something more than this. His spirit, he said, had the power of leaving the body at will, and going to distant lands and to other worlds. The spirits of both the dead and the living often appeared before him, clothed in bodily shape and perfectly visible to the bodily eye, and they conversed together in audible language. He regarded himself as made a victim to serve some ulterior purpose; and when asked what enemies he had who would persecute him so, he intimated that the matter originated in deeper counsels than those of man. When pressed still farther on this point, he declared that for some good and wise purpose, known only to God himself, he was to be sacrificed; and he was perfectly willing. On the subject of his approaching death he spoke calmly, and even cheerfully. He said he did not expect a reprieve, nor did he wish to live. Life had no charms for him. He had tried repeatedly to take his own life, and while in the service he always had exposed himself in every possible way, in the hope that an enemy's bullet would do for him what he had been unable to do for himself. $\mathrm{He}$ wished for no clergyman, because no clergyman could tell him any thing about the spiritual world that he did 
not already know. He believed in God, and in future rewards and punishments; and being perfectly innocent of the crime laid to his charge, why should he have a clergyman? He stoutly maintained that he did not commit the act for which he was to suffer. He had been in the habit of visiting the deceased occasionally, their common belief in spiritualism having led to the acquaintance; and on this occasion, going into the house as usual, he found her dead-murdered. In this interview he exhibited none of the traits of a criminal, either in his language, manner, or countenance, but rather those of a dreamy, visionary youth, whose speculations had carried him far beyond the common experience of man, - so far, in fact, that he hardly knew, at any time, whether he was in the body or out of the body. In these statements respecting his own mental experience, there is no reason to doubt his entire belief. The air of sincerity and good faith by which they were accompanied could not have been counterfeited even by a consummate actor. We ought, perhaps, to except from the scope of this remark the denial of his guilt; for there was nothing peculiar in that, considered apart from the rest of his discourse.

Here our knowledge of the prisoner's history ends. Farther investigation might have removed all the obscurity resting on his psychological condition; but we need not, on this account, withhold the impressions made by the facts that came within our reach.

Whether from hereditary predisposition or not, it is obvious that the prisoner was born with a nervous system strongly inclined to morbid manifestations. One of these, which actually made its appearance at a very early period, was epilepsy, which, of all the forms of cerebral disorder, stands among the gravest. Coinci- 
dent with this, either as a direct effect, or a collateral result of the original nervous defect, there appeared in childhood instances of unconsciousness, which, pathologically considered, may be affiliated to somnambulism and catalepsy. And these continued to occur through the latter years of his life, though not perhaps in so well marked a form. It could hardly have been expected that his intellectual operations would entirely escape from the influence of this abnormal condition of the nervous system. Hence, his distaste for exact and practical knowledge requiring continuous attention and effort, and his fondness of reverie and dreamy speculation, which needed neither discipline nor preparation. This trait strengthened with advancing years, until his whole intellectual life became little better than a dream, in which the inward and the outward, the real and the imaginary, were inextricably mingled and confused.

For legal purposes, it might seem necessary to separate the epileptic element from the rest, and ascertain the precise amount of its influence upon the moral character and conduct. But the elements of nervous disorder were too long and too intimately associated to allow of this. Even under very different circumstances, the effect of epilepsy on the mental manifestations is often determined, somewhat, by the training and habits of the individual. Not to the same extent, certainly, that mania is, but enough to be taken into the account in any estimate of its psychological consequences. In this case it may have had the effect of rendering his notions on certain subjects still more extravagant and remote from the line of common belief than they would otherwise have been. Whether or not it ever produced unequivocal delusions, is a point on 
which the evidence is not very clear. His spiritualistic experience was that, for the most part, of thousands of other people never supposed to be insane; and yet it is difficult to draw the dividing line between this kind of experience and downright insanity. That the one passes into the other is a matter of common observation, and, if some of his most extravagant notions respecting his intercourse with spirits be held in common with a few other spiritualists, it may be questioned whether these are not of the class who have entered this transition state, or even completed their passage through it. The probability of such a fact can scarcely be doubted. We know that the delusions of the insane are often merely exaggerations of their habitual belief. Belief in spiritualism in any shape is more a matter of temperament than of evidence and reason, and thus is furnished an additional proof that Winnemore was endowed with a nervous system peculiarly liable to abnormal activity. I do not mean to convey the idea that the facts of spiritualism are entirely the creation of fancy or of fraud. Many of them are susceptible of proof, and are attested by evidence that places them beyond a reasonable doubt. They indicate the existence of agencies, certainly, that have not yet been admitted into the philosophy of the schools. It is to be regretted that the prevalent tendency is to ignore them entirely, rather than to make them a subject of scientific investigation. It is surprising that physicians, especially, with such well recognized affections before them as catalepsy, somnambulism, ecstasy, and double consciousness, should jump to the conclusion that all the facts of spiritualism and animal magnetism are utterly anomalous and impossible.

Winnemore's notion about his being a victim, which might seem at first sight to be a genuine delusion, was, 
probably, only a rational notion carried to the utmost verge of extravagance. When his innocence should be proved hereafter to the satisfaction of everybody, as be believed it would, the consequence would be an utter change of popular opinion on the subject of capital punishment, and thus he might regard himself as a sacrifice offered up for the good of humanity, - not merely as a martyr whose blood, in the ordinary and regular course of events, would become the seed of a great benefit, but as the favored child of a magnificent destiny prepared and arranged in the counsels of the Almighty.

It was not alleged that his disease had produced any moral perversion. On the contrary, the evidence showed that he always displayed the same mild, quiet, inoffensive disposition, from first to last. An attempt was made on the trial to prove that he had stolen, or. was suspected of having stolen, from his friends; but it came to nothing.

If the deed was committed under the influence of his disease, - supposing the charge to have been true, — we are necessarily led to inquire what particular phase of it was present. No one supposes that his mind was generally so impaired as to be incapable of discerning right from wrong, of knowing that murder is forbidden both by human and divine law, or of controlling the feeblest impulses of passion. The act could not have sprung from such a condition as that. Neither is there any ground for the supposition that he was under the dominion of that blind fury so frequently exhibited by epileptics immediately before or after a fit; or that his mind was overpowered by apprehensions of danger; or a sense of persecution and outrage from persons, real or imaginary, around him. Neither of these phases of the 
disease had he ever exhibited, and though it is not impossible, perhaps, that the latter occurred on this occasion for the first time, there is not the slightest reason to believe that such was the fact. We then come to the only other epileptic condition in which the act could have happened, - that of utter unconsciousness; and though we have no direct evidence respecting it, neither are we met by any circumstance of the case that would render it impossible. He had been in this state more than once before, and it was one of its incidents that he had no idea whatever of what he thought or did while in it. It appears that the woman was fond of making pictures of a peculiar kind; and he declared that it affected him very strangely and painfully to look at them, insomuch that when they were exhibited in court during the trial he begged that they might be removed, for he could not endure the sight. Coming upon them, suddenly perhaps, as he entered the room, they might have had the effect of inducing one of those abnormal conditions of mind in which his acts were beyond the reach of consciousuess or proper will. To a person of his very susceptible nervous organization, already the subject of many morbid manifestations, such an event might not have been impossible. True, the supposition borders on the marvellous; but we must bear in mind that Winnemore manifested a class of phenomena confessedly curious and obscure. If any one supposes that the marvellous is incompatible with true science, deserving only rebuke and derision, let him consider that every step in the progress of science has been but the repetition of a marvel, derided at first as unworthy of the serious attention of the philosopher, and welcomed at last with triumphant admiration and joy. Whether, as a matter of fact, the deed was committed as here sup- 
posed is a question that cannot be conclusively answered. Of this, however, we may be assured, that it was either thus committed, or was prompted by the ordinary motives of crime, - interest or passion. Difficulties surround both hypotheses, while the question is also complicated by very grave doubts as to whether the deed of violence was done by the prisoner at all. If he killed the woman unconsciously, he might also have thrown the razor into the privy unconsciously; but all this would not have prevented his knowing, when he came to himself, that he entered the house with the razor in his pocket, for such must have been the fact. In this connection, it must be borne in mind that he almays denied that the razor found in the privy was his, for that, he declared, got broken and was thrown into the street, several days before. On the other hand, it was not pretended that he was a hardened criminal, and it did not appear that he had led a vicious life. It seems to be quite incredible that the alleged motivethat of getting a few dollars - would have induced such a man to murder a woman, deliberately and designedly, from whom he had experienced nothing but kindness.

Farther observation and inquiry might have thrown more light on this interesting case. At subsequent interviews his manner and manifestations might have been different, indicating a wider reach of the pathological element. His counsel told us that he varied considerably at different times, and that during the trial he was sometimes so dull that they could hold no intelligent communication with him. Something might have been learned from those who had been conversant with him during the last four or five years, while he was serving in the army at a distance from his home and friends. That 
period must have embraced many interesting facts in his psychological history, and it is to be regretted that no opportunity occurred for learning them. Left as it is, it gives the physician scope for abundant speculation, but no certain conclusion; while to the lawyer its results must seem more like a triumph of ignorance and passion than of professional skill overcoming every device and obstacle and arriving at last to a sure and satisfactory end.

It is a wise constitutional provision that enables the executive, in certain cases, to remedy the mistakes of the judicial authority, and secure to the criminal the benefit of those mitigating circumstances of which the courts can take no cognizance. Hampered by no rigid rules of proceeding, enjoying a certain freedom of choice in the use of the means at his disposal, allowed to go behind and beyond the records of the courts, the Governor of a State is able, in the exercise of his prerogative, to perform a service of the highest importance to society. Although the power thus given to him is to be used discreetly, yet its use is not a matter of caprice or arbitrary will. Whatever course he may take, whether he interposes or refrains from interposing, he is responsible for his decision to the conscience and understanding of the community, - not merely to that aggregate of individuals whose suffrages have placed him in power, but to that immense society which has some regard for the triumph of right and the progress of humanity. Failing to obtain a new trial, Winnemore's counsel appealed to the Governor to appoint a medical commission for the purpose of ascertaining, by a suitable investigation, the prisoner's mental condition. The appeal was unsuccessful. Almost at the very last moment, they engaged the gentlemen whose names have 
been already given, to visit the prisoner, with the hope that even in a single interview, for no more was possible, they might find enough to warrant them in asking for a stay of the execution, in order that they might have a suitable opportunity for making a thorough examination of his case. The result has been already given. The wisdom of the Governor's course is not very obvious. It would seem to be the very case for executive interposition. The prisoner had had a hasty trial; important evidence had arrived too late; those who were well acquainted with his history, psychological and pathological, during his latter years, were too far off to be available; though laboring under a disease which almost invariably impairs the mind, no physician had examined him for the purpose of ascertaining the precise effect which it had exerted upon him; poor, and comparatively friendless, he was without the usual means of securing the favorable regards of men. Circumstances like these pleaded trumpet-tongued for every privilege and indulgence which the laws and customs of the land allow. A medical commission, whatever might be the result of its inquiries, could not change the legal status of the prisoner. If unfavorable to the idea of mental impairment, the execution would have happened all the same, though delayed for a week or two. If, on the other hand, it showed that the prisoner was really irresponsible, from the long continued effect of disease, the executive might have felt obliged to save him, and far be it from us to intimate that this would not have been gladly done. We can only suppose that the Governor had too readily received the impression, somewhat current among intelligent people, that the defence of insanity is generally a contrivance of ingenious counsel, favored by fanciful doctors, for saving a criminal from 
merited punishment; and consequently that no proper purpose would be served by disturbing the results of the trial. However that may be, one camnot but regret that he should have lost the opportunity thus offered of adding to the laurels so nobly won in the field another not less durable earned in the humbler service of humanity.

The case of Winnemore has brought to mind that of Fyler, also an epileptic, who was tried in Onondaga County, N. Y., in 1855, for killing his wife. It was the first time, in this country, to my knowledge, when epilepsy was pleaded in defence of crime. The two cases were strikingly similar in many important points. Both men were young; in both the disease had existed several years, but without producing any very obvious mental impairment beyond the immediate effects of a fit; in both there was no evidence that a fit had occurred about the time of the homicide, or that they had exhibited any of the ordinary signs of a fit; in both the proof that they committed the act at all was only circumstantial, and both protested their innocence to the last; in both there was an apparent absence of any adequate motive. In other respects they exhibited a remarkable contrast. In Fyler's case the homicide occurred in February, 1854. The Grand Jury indicted him the following March, and he was arraigned for trial the next June. 'The prisoner's counsel not being ready, the case was postponed, and a special term for the trial was ordered by the Governor, in November. Another postponement was obtained, and the trial finally came on in February, 1855, or a year after the act was committed. A verdict of guilty was rendered, when his counsel moved a suspension of sentence, on the ground that the prisoner was then insane. In this they succeeded. 
A medical commission was appointed to investigate his mental condition, who reported that he was then insane, and he was thereupon committed to the asylum at Utica.

A word or two more before I close, on the general issue presented by such cases as Winnemore's and Fyler's. It can scarcely be denied that epilepsy, considered as a source of mental impairment, has not been so thoroughly studied as most other forms of cerebral affection. Physicians have given their attention too exclusively to the fit, and the state of things immediately preceding and succeeding it; and this is not strange when we consider that most epileptics, during the first few years, continue their customary employments, and to the world at large seem to have suffered no mental deterioration. Indeed, they are seldom the subjects of any medical observation at all. It is not, generally, until the mental powers have become very obviously impaired that they find their way into a hospital, where their mental condition is closely observed. What we need, above all things else, in the medical history of this disease, is more information respecting that general impairment of the mind which, sooner or later, in a greater or less degree, is sure to follow. The frequency of the disease makes its medico-legal relations a subject of the highest importance, for the trials in which it will be offered in defence of criminal acts will be steadily increasing in number. The older medical jurists were disposed to make its exculpatory effects a matter of time, and sought for an arbitrary period before and after the fit within which they should be confined. We know enough more of epilepsy than they did to be sure that such views are too narrow, though quite unable, certainly, to say precisely in what degree. The more conversant we 
become with epilepsy, the more strongly is the conviction forced upon us that its damaging effect upon the mind begins at an earlier period than that usually assigned, and that some of the phases of this process are as yet imperfectly understood, even when recognized at all. There is reason to believe that some epileptics lose their proper consciousness occasionally, even when not under the immediate influence of a fit. In what proportion of cases this may occur, how often it may appear and how long it may last, - these are questions for future inquirers to answer. It is our duty, however, to see that the general fact, imperfectly as it is understood, should have its legitimate influence on judicial decisions. The excessive susceptibility of epileptics to nervous impressions, which become distorted if not utterly changed on their way to the sensorium, is a phenomenon not clearly recognized by the profession at large, although it cannot have failed to meet the attention of the close observer. In medico-legal inquiries it should never be ignored or forgotten; for it may be the very phase of mental disturbance which prompted the criminal act. Let it not be objected that these are dangerous innovations, because such a thing ought not to be said of any scientific conclusion, honestly and intelligently reached. The distrust naturally felt towards any considerable advance upon existing views is no proof against it with any well-disciplined mind; and no class of persons has had better evidence of the fact than that which is engaged in the study of insanity and the insane. It is not long since it was proclaimed, from many a high place in the world, that to make any other form of insanity than idiocy and raving mania an excuse for crime is a dangerous innovation, to be frowned upon by every friend of public order. 
In view of what we already know of epilepsy and of what still remains to be learned, we have a right to require the utmost circumspection and the closest inves. tigation whenever the legal liabilities of epileptics are in question. The fact of its existence being established, is it going too far to say that legal responsibility is presumptively annulled, and that the burden of proof lies on the party that alleges the contrary? People are scarcely ready for it yet, perhaps, but to that complexion must they come at last. 


\section{THE INSANITY OF SEDUCED OR DESERTED WOMEN.}

The acquittal of Mary Harris, lately tried in Washington, has greatly exercised the public mind, and given rise to an unusual amount of objurgation. And the leading facts of the case, superficially considered, seemed to warrant this state of feeling. A young woman, smarting under the loss of her lover, provides herself with weapons, travels hundreds of miles to find him, watches patiently for a suitable opportunity, and at last deliberately shoots him dead at his desk in a Government office. She is then tried, with the sym. pathies of the court, jury, and audience all in her favor, acquitted on the plea of insanity, under a more liberal rule of law on this subject than was ever admitted before in any English or American court, and immediately, without the slightest let or hindrance, is set at large. Thus regarded, and in that aspect alone has it been regarded by most persons, the result seems to have been but a mockery of justice, worthy of the severest condemnation. But, for all that, the girl may have been insane, and therefore very properly acquitted; for there was nothing in the case incompatible with the phenomena of insanity. Among the medical witnesses who thought her insane was Dr. Nichols, 
Superintendent of the Government Hospital for the insane, who, for more than twenty years, has been exclusively engaged in the care of the insane, and is well fitted, both by his mental qualities and his abundant experience, to pronounce an opinion on such a case; and it is not strange that the jury shrunk from a conviction in the face of his testimony.

It is no part of my present purpose to discuss the question of this woman's insanity; and I shall therefore say but little more about it than to express the conviction that the existence of the disease, when she committed the homicide, was satisfactorily proved. The evidence of the fact was more full and decisive than it usually is in cases of such a character, or of any character in which the marks of the disease are not obvious to the most superficial observer. The essential features of the disease were there, easily discerned by all who were willing to see them. The heaviest blow that a proud and sensitive woman could receive suddenly fell upon her, and reason reeled under the shock. A change of character took place, in which strange moods of mind, marked sometimes by depression and sometimes by excitement, were frequently exhibited. Acts, sometimes of petty mischief, sometimes of fearful violence, towards those she had most reason to love, astonished and alarmed her friends. These effects of the moral shock were intensified by a considerable degree of uterine derangement, and rendered somewhat periodical and paroxysmal in their manifestations. Her mind thus unsettled, and drifting about under the influence of every morbid feeling, was finally led to contemplate the idea of murder, and, after accomplishing. the act, to regard her conduct with no very definite sentiment of joy or of sorrow, - with no realizing sense 
of the enormity of her crime, or of its legal consequences to herself.'

The psychological and pathological aspects of the case were presented by Dr. Nichols with a force and clearness seldom exhibited on the wituess-stand, and evincing a profound and sagacious observation of mental phenomena resulting from disease. Altogether, the case is full of instruction, and deserves to be carefully pondered by all who are engaged in psychological studies.

In any notice of this case, one is bound in duty to speak in terms of the severest reprobation of the closing scene of a trial that abounded in discreditable incidents. As soon as the verdict was announced, without one murmur of disapprobation, the prisoner was set at large. The evidence of the experts, on which the verdict must have been founded, implied that she was insane, not only when she committed the homicide, but also at the time of their examination, which was shortly before the trial. It was not pretended that she had recovered. Indeed, such an admission might have been fatal to the defence. And thus a woman, having committed a capital crime under the influence of insanity, is again let loose upon the community, to repeat the act whenever an occasion may be offered. It is to be presumed that no law of the district would have authorized her detention; though, in the face of so many irregularities that marked the course of the trial, we are not sure on this point. If such is the fact, however, it is to be hoped that Congress will not suffer another winter to go by without providing by law, as many States already have, that every person acquitted on trial for a criminal act on the ground of insanity shall be remanded to custody, and not be relieved therefrom until fully recovered. 
As already stated, it is not my purpose to discuss the points of this case, but rather to call attention to a class of cases of which this may be considered as a fair representative. They are greatly misunderstood, for the double reason that the mental impairment alleged to exist is not readily discerned, and that the offence is committed under the ordinary prorocatives to crime. And the misunderstanding is not confined to the unprofessional public; but medical men are found, and among them even some practically conversant with mental disease, who can see in the plea of moral insanity only a lawyer's dodge, aided by the easy subservience of crotchety doctors.

Differing as these cases do in some respects, yet they have many features in common which establish their essential identity. In all, there has been a grierous disappointment or outrage, more calculated than all others to try a woman's temper, and disturb the healthy balance of her mind. In all, there has been a strong and sudden revulsion of feeling, in which love and confidence were succeeded by the deadliest hate. In all, there has been more or less mental disturbance exhibited, not so much in the form of delusion as in that of paroxysmal fury and uncontrollable criminal impulse. In all, there has been an entire abandonment of every interest and feeling not comnected with the single purpose of revenge. In all, the person gives herself up to justice, glories in the bloody deed, and is careless of the future.

In the condition thus indicated, the thoughtful inquirer cannot fail to perceive the peculiar influence of those organs which play so large a part in the female economy; and this fact must be duly pondered if we would avoid serious mistake as to the true character of 
the mental disturbance. An act not to be distinguished, perhaps, on a casual inspection, from the ordinary run of crimes, may, nevertheless, have been prompted more by those physiological movements characteristic of the female constitution, than by well-considered motives, or strong, healthy feeling. With women it is but a step from extreme nervous susceptibility to downright hysteria, and from that to overt insanity. In the sexual evolution, in pregnancy, in the parturient period, in lactation, strange thoughts, extraordinary feelings, unseasonable appetites, criminal impulses, may haunt a mind at other times innocent and pure. Dr. William Hunter, who certainly was neither superficial nor crotchety, contended that young, unmarried women, guilty of killing their new-born offspring, are so distracted by conflicting feelings, sharpened to morbid acuteness by the great physiological movement of parturition, as to be hardly responsible for their acts. ${ }^{1}$ Some dozen or fifteen years ago, a young woman, on one of the steamers running between New York and Fall River, gave birth to a child, and immediately threw it into the sea. At first she denied the act, but seemed to manifest some bewilderment of mind. Not much was known of her history. The case was tried before the late Judge Story, who, if he had been guided by the rules of law, rather than the instincts of his kind and generous nature, would have favored her conviction; but, on the contrary, as if sharing the humane sentiments and intelligent views of Hunter, he gave the jury to understand that the ends of justice would be best promoted by her acquittal, and the jury followed his advice. ${ }^{2}$

1 Medical Observations and Inquiries, by a Society of Physicians in London, vi. 266.

2 In the course of the discussion that followed the reading of this 
It is no mark of wisdom to ignore the presence of the sexual element in the phenomena displayed by this class of cases. It is no whim, but a suggestion of sound physiology, that the nervous erethism, excited even by courtship, has a controlling influence over the female will.

Among the circumstances above mentioned we have two very efficient agencies in the production of insanity, - a strong moral shock and an irritable condition if the nervous system. Is it strange that a person thus: situated should become insane? It would be strange, indeed, if this event did not occasionally happen.

The common reluctance to attribute insanity to this class of persons arises principally, no doubt, from the fact that they act from a rational motive,- from that prolific parent of crime, revenge. That this should be considered incompatible with insanity only indicates how imperfect are the prevalent notions respecting this disease. It needs but little observation of the insane to see that they often act from rational motives. Strike an insane man, and he will be very likely to strike back. Promise him a reward for good behavior, and he will probably endeavor to earn it. Put him upon his honor,

paper to the Association of Superintendents of Hospitals for the Insane, Dr. Walker, Superintendent of the South Boston Hospital, related a case strongly illustrative of the intimate sympathy between the uterine and cerebral systems. While on his way to the meeting, by one of the Sound boats, his attention was called to a young woman of delicate constitution, who had some uterine ailments. The bedding being cold and damp provoked an unusually severe attack of these ailments, so that "for half an hour," the doctor said, "she was a complete maniac. She did not know what she said or did. If she had been alone she might have thrown herself overboard, or have done herself any injury whatever, and in my judgment no responsibility would have attached to the act." In the course of three hours the paroxysm passed off, and the mind cleared up. 
and he will be likely to keep his word. Do lim a grievous wrong, and he will remember it and retaliate, perhaps at some distant day. And when a man has been made insane, ostensibly by insult and abuse, the disease is not calculated to soften his feelings towards the offender, unless it crushes them altogether, or to deter him from inflicting punishment. It may be disproportionate and cruel, and therein consists the manifestation of disease. Insanity may lead a man to regard his friends as no better than enemies; but it seldom leads him to consider his enemies as friends, and treat them accordingly.

The common sentiment respecting this class of cases was expressed by Erskine in his admirable defence of Hadfield, while discussing the doctrine, which subsequently became an authoritative rule of law, that delusion constitutes the criterion of that form of insanity which renders a person irreponsible for criminal acts. A woman, he said, had been recently tried for killing the man who, after cohabiting with her several years, utterly cast her off; and inasmuch as she acted from the spur of a real and not an imaginary grievance, he thought she should have been convicted. But, as if his instincts were a safer guide than any rule of law, he said it must be a consolation to those who prosecuted her that she was acquitted, because she was then "in a most undoubted and deplorable state of insanity." And generally, if not always, such must be the practical result. The testimony shows neither delusion nor hallucination; neither incoherence nor incongruity; the experts render a hesitating, indecisive opinion; the public sentiment, completely dazed by the coolness and contrivance which marked the murderous act, scouts at the idea of insanity. The jury, however, in that tale of outrage and afliction, related with all the force and distinctness peculiar to 
legal evidence, cannot help seeing the rise and progress of a mental distraction, call it by whatever name you please, in which the sense of the right and the good is overwhelmed or distorted, and the spirit of revenge seeks for its victim, as if moved by an automatic and irresistible impulse. The verdict of acquittal is not the fruit of a morbid sentimentalism, or of a fashionable indulgence to crime, but of a true humanity enlightened by true science. Let those who suppose that such verdicts are rendered only in this country and at this time consider that the case alluded to above occurred in England more than sixty years ago, - a period when English juries were not supposed to be influenced by any superfluous leniency to crime.

What we are greatly in need of now is a collection of these cases, accurately reported; and one could hardly do a better service for medical jurisprudence than to supply this deficiency. One of them came under the writer's notice with such unusual opportunities for observation as to render it worthy of a place in such a collection.

An Irish girl, about twenty years old, handsome and high-spirited, while living at service in the family of an eminent lawyer in Providence, became acquainted with a young man, an dmerican, who, as she said, promised to marry her. One evening he got her on board the steam-boat in which he was employed, and there treacherously attempted, though without success, to violate her person. From that time forth all communication between them ceased, her love was turned into hate, and she determined to have revenge. She procured a knife, and at every opportunity sought him in his accustomed haunts, all the while performing her duties properly, and attracting no attention by her man- 
ner or discourse. In the course of a few weeks she met the false lover in the street, and plunged the knife in his bosom. She went home quietly, where she was arrested next day, and thence sent to jail. The wound was severe; but the man finally recovered, though for a time it was thought he would die.

While she was in jail, the writer was requested by her counsel to visit her, for the purpose of ascertaining her mental condition. The warden said she had been an exceedingly troublesome subject; that she often got terribly ugly, when she would curse and swear, break whatever was breakable in her room, and destroy her clothing, and that consequently he was obliged to keep her very close. During our interview she was calm, good-natured, and communicative. When asked about the fits of passion spoken of by the warden, she said the other women provoked her, and then she could not help getting mad. She conversed correctly enough on ordinary topics, showing a mind rather bright, though uncultivated; but when the assault was referred to, she became grave, shed tears, and broke out into some passionate expressions. The night before her trial she made an attempt at suicide, and came very near succeeding. At the trial all went smoothly until the young man was put upon the witness-stand. The moment she caught sight of him, and before he had spoken a word, she began to pour out a torrent of vituperation which no efforts of her counsel or her female attendants could stop. As this was uttered at the top of her voice, the confusion and embarrassment that ensued can be better imagined than described. To go on with the trial was impossible, and the court directed the officer to take her to the hospital.

For a few days after her admission she was tolerably 
calm, but protested against being confined as a lunatic, and demanded that she should be sent back to jail. She was willing to be tried, she said, and to be punished if she had done wrong, but they must not suffer that man to come in sight. In this style she talked to the last, and no person in the house disclaimed the imputation of insanity more loudly than she. It was not long before she had a paroxysm like those the jailer described, and for several months they recurred once in two or three weeks. With little or no provocation she began to scold and curse, vociferating with all her might, and tearing off her clothes. This continued two or three days, when she became calm, regretted what she had done, and promised to be good. But even during her quiet interrals she was more or less cross, querulous, and quarrelsome. Collisions with the attendants and patients were of frequent occurrence, and all rules and regulations she utterly contemned. Several benevolent ladies who had visited her in jail called to see her, but she was always averse to seeing them, and finally refused altogether, for she said she wanted neither their help nor their sympathies, - she could take care of herself. During the last few months of her stay the paroxysms became less frequent, and the intervals ex. hibited a more comfortable frame of mind. But from first to last she declared she had no regret for what she had done, that she had a right to do it, and was determined to kill him if he ever came in her way. After staying eighteen months in the hospital, she was discharged by order of the Attorney-General, and went to reside with some friends at the South.

The psychological experience of this poor girl - the successive steps that intervened between the first shock to her feelings occasioned by her lover's treachery and 
the state of raving mania in which it culminated - it is not very difficult to understand. In the course of a few hours, undoubtedly, her love was succeeded by hate and resentment. With her whole heart and soul absorbed in a sense of the wrong she had suffered, burning with shame at the indignity with which her warm, trusting attachment had been repaid, and ever dwelling on this one idea, these feelings became intensified every day she lived. The shrinking delicacy of the female character, the sense of right and wrong, the fear of man and the fear of God, all disappeared, utterly extinguished by the immovable determination to be revenged. With the accomplishment of her purpose, it might be supposed that she would regain her ordinary tone of feeling; but after such extreme tension the proper elasticity of the mind is not easily recovered, and often it is hopelessly lost. The nervous excitement, instead of passing quietly away, like the electric fluid, at numerous points, could find escape only in successive explosions of fury. In this state of mind it is not strange that her moral perceptions were blunted; that wrong seemed to her right, and a murderous assault justifiable. In all this it is easy to see the strict relations that existed between the normal and the abnormal manifestations of her character, between the essential and the accidental incidents that marked the development of the mental affection. Had she been a girl of a higher grade of culture, or blessed with a larger religious element in her education, she might have borne her wrongs in a submissive, Christian spirit. Had she been endowed with a less irritable, nervous temperament, she might have maintained her equanimity, and, severely as she may have felt her wrongs, still restrained her thirst for revenge within the limits of the 
law. Had the offender gone away far out of her reach, the tumult of her feelings might have gradually subsided, and her ordinary serenity been regained. But constituted as she was, controlled by circumstances as she was, disappointment, shame, and outrage could be followed by only the saddest possible consequences. 


\section{THE HINCHMAN CASE.}

[THE following case presents an extraordinary instance of the triumph of popular passion over justice, reason, character, and common sense; and it is interesting now, not so much on account of any unusual phase of mental disease, or of any new principle of law involved in it, as of the fearful amount of injustice that may be committed under the forms of a judicial process. When reading the narrative of a star chamber trial, there is apt to be mingled with the feeling of wrath and indignation provoked by it a comforting sense of security against any renewal of such performances. With a childlike reliance on the aid of counsel, the independence of juries, and the integrity of courts, people who derive their notions from books fondly imagine that they are no longer possible. The pleasing thought must vanish before such a case as Hinchman's; for, though the government is shorn of its influence, yet a power mightier than the government, and unchecked by scruples, is ever ready to shape the conclusions of a jury trial.

The practical effect of this case is mischievous beyond measure. It must lead every one with the least degree of salutary prudence in his nature to shrink from an act of duty or neighborly kindness, exposing him as it might to popular odium and pecuniary ruin. So long as it is held to exemplify a correct operation of law, who will venture to lay his hands upon a maniac, though destroying the peace, perhaps threatening the lives of those around him? The judge said that such interference might spring from mercenary motives, and if the jury should find that to be the fact they were bound to convict, notwithstanding the acknowledged benefit that was derived from it. We would like to believe that this is an exceptional case arising from a fortuitous concourse of adverse circumstances not likely to happen again. So long as the action of conspiracy is recognized by 
our courts, we have reason to expect its repetition; for the same elements might be there, and as potent as ever. We might have the same artful appeals to the passions of the jury, the same manipulation of their opinions outside of the court-room, the same timidity and vacillation of the court, the same disregard of truth on the part of witnesses. One must have been a dull observer of the times to suppose that a concurrence of all these things would be a very improbable event.

The point to which I would call particular attention is, that Hinchman represents a class of cases grossly misunderstood, and consequently giving rise to much injustice. Unfortunately, insanity is one of those subjects of which everybody knows, or thinks he knows, something; and, in accordance with a common tendency of the mind, people readily imbibe the notion that, beyond their little attainments, nothing more is possible to be known. And when this notion is entertained, as it generally is, with some pride of opinion or strength of prejurlice, it bids defiance to every attempt to eradicate it. Many a man will admit in general terms that insanity is an object of scientific investigation condıcted according to the strictest rules of philosophizing, with abundance of materials at command, who, when it comes to a case in hand, though he may not have observed a half dozen insane persons in his life. and pretends to no scientific culture of any kind, will scout at the idea of yielding his own opinion to the authority of the Esquirols and Conollys of the time. Daily experience teaches that it is often easier to enlighten a man profoundly and confessedly ignorant than one who knows a little. This explains the difficulty of convincing people that a man apparently sane may be actually insane. If it were a matter of navigation, or mechanics, or any other subject to which they had never given a thought, nothing would be farther from them than to presume to have an opinion of their own. And yet who will estimate the range of observation, the keenness of perception, the careful deduction, the acquaintance with mental manifestations, sane and insane, which are required to decide correctly in an obscure case of insanity!

Insanity is a disease from which, frequently, the patient completely recovers, having relinquished all his delusions and fancies, regarding his thoughts and actions in their true light, and contemplating all his relations to others as he did while confessedly sound. On the other hand, there is a proportion of cases in which recovery is not so complete. All the prominent delusions may have disappeared, the conduct may be conformed to the ordinary rules of propriety, the dis- 
course may be coherent and even shrewd, and to any casual observation the patient may appear to be, as the phrase is, all right, and yet all the while many of the morbid notions that sprung from the disease still linger in his mind. Though aware that he was under a cloud, he cannot believe that he was really insane; he thinks his friends acted maliciously in putting him under restraint; is utterly insensible to the suggestions of affection, of reason, and of common sense; takes counsel of mischief-making advisers, and finally devotes his time and his means to the work of harassing his own flesh and blood in vindictive suits at law. The friends, to avoid exposure of his infirmities and keep their private griefs from the public gaze, may offer little or no resistance to his legal measures; the law gives him whatever he asks for; the ease goes forth to the world as another "unparalleled ontrage," and is made the text of many a diatribe against physicians guilty of the presumption of signing a certificate of insanity. It is to the impression made by this class of cases that we are to attribute a very prevalent belief that sane persons are often confined in our hospitals for the insane by the aid of medical men, induced by some corrupt motive to participate in the crime, and abetted therein by the officers and directors of these institutions. The world is reluctant to believe that facts so clearly and circumstantially related and storics so plausibly told are solely the offspring of an insanity that gives no other indication of its presence. It is because the world is generally ignorant respecting a very common trait of this disease. In a large proportion of cases it is attended by more or less moral obliquity, by reason of which the normal relations of good and evil are so distorted as sometimes to be completely inverted. In this demoralization we seldom fail to witness a remarkable disregard of truth. Whether the disease has so obscured their perceptions as to render them unable to distinguish between the real and imaginary, or whether, perceiving correctly enough, they wilfully choose the false rather than the true, is not always apparent. Sometimes it is one and sometimes the other, and not unfrequently, perhaps, both have a share in producing this trait. However this may be, it is certain that among the lingering traces of their disease exhibited by many of the partially recovered is a mendacity so audacious as to defy all conception, except with those who have had a long professional acquaintance with mental derangement. And even they are sometimes misled by that cunning which is another element of the moral perversity engendered by insanity. In view of these facts, it is not strange that these persons make an impression upon people 
of culture and reflection, scarcely less strong than upon the ignorant and thoughtless. The number of those who are governed as to what they believe by the most elementary laws of evidence is extremely small, and that knowledge of insanity which would furnish a clew to the true character of the revelations they hear is confined to a still smaller number.

The incompleteness of recovery just mentioned is not confined to insanity. It may be witnessed after an attack of almost every other disease. For a period, longer or shorter, morbid action in any organ may leave it in a weak, irritable condition; while the patient may have resumed his customary duties, and appeared to his friends to have fully regained his health. The trouble will be manifested by some slight pain or uneasiness in the part affected, some irregularity in its action, some imperfection in its performance, some loss of its power of endurance. These conditions either disappear after a while, or they may continue with more or less severity, until succeeded by another attack of the original disease. To expect the nind immediately after an attack of insanity to be as clear, as bright, and as strong as erer, and as free from all hitch and obliquity in its movements, would be as unreasonable as to suppose that the lungs, or stomach, or liver, just after recovering from an acute inflammation, would perform its functions without a single trace of the disease which so thoroughly deranged its action. $\left.{ }^{1}\right]$

ON the 12th of March last, before Judge Burnside, one of the judges of the Supreme Court of Pennsylvania, sitting at Nisi Prius, in Philadelphia, began the trial of the cause of Morgan Hinchman $v$. Samuel S. Richie, Edward Richie, John M. Whitall, George M. Elkinton, John Lippincott, John D. Griscom, Anna W. Hinchman, John L. Kite, Elizabeth R. Shoemaker, Benjamin H. Warder, Philip Garrett, Joshua K. Worthington, Charles Evans, William Biddle, and Thomas Wistar, Jr. The defendants were charged with a malicious conspir-

1 For the facts in this case I have depended on the report in the Public Ledger newspaper, and a pamphlet called "Speeches of Defendants' Counsel, and the Charge of Judge Burnside in the Case of Hinchman $v$. Richie et als., reported by Dyer and Murphy, Philadelphia, 1819.” 
acy to confine the plaintiff in the Friends' Asylum for the Insane, near Frankford, Penn., either for the purpose of compelling him to settle his property on his wife and children, or of obtaining it for some one or more of the defendants. To help the reader to understand the case, we will state that the Richies are brothers, one of them a relative of the plaintiff, and took the leading part in the act of arresting him and conveying him to the asylum; that Lippincott, Elkinton, and Whitall assisted in this act; that Kite, who is a pliysician, gave a certificate of insanity ; that Elizabeth R. Shoemaker is his wife's sister, and Anna W. Hinchman his own sister, both being charged with abetting in some way the conspiracy; that Griscom was the plaintiff's family physician, and advised him to go quietly; that Wistar was charged with having some connection with the sale of plaintiff's property; that Warder is one of the managers of the asylum, and gave the order of admission; that Biddle is charged with being corruptly placed on the sheriff's jury that tried the question of his insanity after he was placed in the asylum; that Evans was the visiting, and Worthington the resident physician, and Garrett the stervard of the asylum. The jury found a verdict against the first seven just named, and assessed the damages at $\$ 10,000$. The rest were acquitted, - Evans at the close of the plaintiff's evidence.

It appears that the plaintiff had been for three or four years previous to this event a farmer in the neighborhood of Philadelphia, prior to which he had been a teller in a bank. In 1839 he married Miss Shoemaker, a woman of exemplary worth and respectable connections, and a member like himself of the Society of Friends, as were also the families of each. They were equal in point of property, the wife's being settled upon her by him, but 
with a power of revocation which she subsequently used at his request, and for his benefit. It was testified by Hinchman's mother, whose character as a careful, intelligent, and affectionate parent was placed beyond the reach of doubt, - and her testimony in every essential respect was corroborated by that of many others, - that soon after his marriage his conduct became so strange and unnatural as to raise the suspicion of insanity; that this suspicion was finally turned into positive belief, and that she and his wife came to the conclusion that the discipline of an asylum was necessary, in order to arrest the farther progress of the disease, and restore his mental health. To aid them in effecting this measure, they applied to the Richies, one of whom was a relative of the family, and with both of whom they, as well as the plaintiff, had been in habits of frequent and familiar intercourse. They met him at a tavern, disclosed their intentions, and forthwith carried him to the asylum, 7th of January, 18+7. Soon after, a commission of lunacy was issued, which found him insane for some months previous. After a residence of six months he was discharged as recovered, but has not lived with his family, and has been chiefly occupied in preparing this suit.

In the present case the defendants rested their defence on the plaintiff's insanity, of which they presented uncommonly clear and abundant evidence, although prevented from calling those who were most capable of furnishing it. The persons who had always been on the footing of a familiar acquaintance with Hinchman and his family, who had known him intimately from his childhood and marked every phase of his mental condition, who had been made acquainted with every incident of his domestic life, and been his confidential friends and advisers, were made parties instead of witnesses in 
the case, - many of them apparently for no other reason than to shut their mouths. True, there was one, not included in the band of conspirators, who might have unfolded a tale of moodiness and excitement, of attempts at suicide, of frequent unkindness and annoyance towards those most entitled to his regard, but it was not for her to lay bare to the public gaze the privacies of her domestic hours. The witnesses who did testify to his insanity seem to have labored under the usual difficulty, that of conveying to others the strong and well-grounded convictions of their own minds. Where the disease is evinced in gross delusions, it is comparatively easy for one to describe them with clearness and precision, and thus give an intelligible reason for his belief; but where the disease is chiefly manifested in the conduct or disposition, appearing in acts unseasonable or inappropriate to the circumstances of the patient, in moods and freaks not incompatible with sanity, perhaps, but quite foreign to his natural character, then the witness is naturally embarrassed in endeavoring to convey to others the impressions so strongly felt by himself. His opinion is founded upon a general view of the life and character of the person for the period under consideration. On the witness-stand he finds that this view is to be analyzed; and each particular, in itself alone no proof of unsoundness, is to be subjected to the unrelenting scrutiny of court and counsel. They are satisfied only with manifestations which in and of themselves, independent of all others, are unequivocal proofs of mental unsoundness. How little of insanity is manifested in this manner is well known to those practically acquainted with the disease, but by most others it is supposed to be always associated with gross delusions, or acts of ungovernable fury and frenzy. Still, the evidence was sufficient, we 
should imagine, to satisfy any unprejudiced mind that Hinchman was unequivocally insane; and that his friends were perfectly justified by the kind and degree of his malady in placing him in an asylum, whether for curative or merely custodial purposes. Of course our limits will scarcely permit us to give more than a general summary of its most important parts.

The mother of Hinchman testified that soon after his marriage she observed a change in his temper and demeanor, that showed itself in turns of moodiness and dejection, in rudeness and ill-nature, in inconsiderate and unkind treatment of others, and appeared with more or less frequency up to the time of his going to the asylum. Several specific instances were related of rude and unfeeling treatment which she received from him when visiting his family, although from his childhood upward he had ever evinced a kind and affectionate disposition. Many witnesses bore testimony to similar freaks and caprices of temper during the period in question, and among them were mentioned repeated instances of the most heartless disregard of the feelings of his wife, of his mother, and his sisters. The mental disturbance was sometimes so great that he abandoned himself to acts that bore the impress of madness on their very face. One witness found him kneeling on the floor, sighing and groaning, then rolling himself over the floor, and finally breaking away and running into the street. In 1844 he severely whipped a child he happened to meet in the street, but whom he did not even know, for the reason, as he afterwards told the father, that he feared he would hurt the other little boy with whom he was playing, and then asked the father's forgiveness. More than once he stripped himself stark naked in his kitchen in the presence of a female domestic, in order to 
bathe. In 1844 he became a defaulter to the bank of which he was teller, and in informing his mother and wife of the fact he added that it was revealed to him that, if he did not stand up in meeting and confess his sin, his first-born child would be taken from him. Once, having invited some ladies into his carriage, he drove through the streets with a young, unbroken horse, much to their astonishment and fright. After selling a couple of pigs, he insisted that one was bigger than the other, and worth just two cents more, which the buyer paid.

Coming down to the period near that of his removal to the asylum, a witness stated that he came to her house in December, 1846, to sell some pork, saying that he had killed a pig on purpose for them, though they had not engaged any. He talked fast and wildly upon a variety of subjects, no one else speaking. To another in the same month he insisted on selling two pounds of butter, for the purpose of raising a thousand dollars; and said if he did not take the butter, he (the witness) must find him (Hinchman) a purchaser for his Marshall Street property. He left on the minds of witness and wife a strong impression of his derangement. Three witnesses stated that he came into the monthly meeting on the 4th of January, 1847, and spoke several times, incoherently and unintelligibly, so that they could not tell which side he was on. He was not dressed like a Friend, his face was flushed, and he had a wild look. Another stated that the day before Hinchman was taken to the asylum he came to her father's house, where he was not in the habit of visiting, and dined with them; that while at table he went into a long conversation about his property and his money; that he poured out his money upon the table and counted it over, telling them that Judge Fox had promised to get money for 
him, but could not do it, because people said that he (Hinchman) was crazy. He left the impression upon her and the family that he was deranged. Two others testified that on the same day he came to their house and behaved in such an unusual and extraordinary manner that they thought he must be insane. Hinchman's mother testified that she concluded from his wife's statements that he was getting worse, that he had no intervals between his turns of excitement, that he complained much of his head, and that his memory was leaving him. Dr. Griscom, his physician and friend, who knew him intimately, advised him to accede to the wishes of his family, and go to the asylum. Dr. Evans, the physician of the institution, testified that he found him laboring under some functional derangement of the digestive organs, accompanied by delusions. He imagined that he had syphilis; and although told that he had no such disease, and he admitted that he had not been exposed to it, yet he still persisted in the notion. $\mathrm{He}$ assured the doctor that his wife, mother, and sisterin-law were entirely deranged, a delusion he had manifested previous to his admission into the asylum, and once expressed his belief that he was placed in the asylum as a punishment for taking the money from the bank, as already related. Shortly before leaving, he said he was sensible that when he entered the asylum his mind was not right, but that then he was relieved. The witness also stated his belief that Hinchman's disease was more likely to be cured by the discipline of an asylum than by any other measure. It may also be mentioned, in this connection, that two of his fellowclerks in the bank to which he was a defaulter, and one of its directors, expressed at the time their belief that he was insane when he took the money. A committee of 
the Friends' meeting to which he belonged, to whom was referred the subject of his treatment of his mother, reported that he was insane, and on that ground ought not to be disowned.

To meet such evidence as this the plaintiff produced some sixty or seventy witnesses, who testified substantially that they never saw or knew him to be otherwise than sane. Their means of observation were occasional interviews in the streets, in meetings of a horse company, and petty business transactions. Few of them were ever in his house, and not one was an intimate acquaintance. Their testimony was merely negative, and did not invalidate a particle of the evidence presented on the other side. Similar testimony might be given respecting the majority of insane men. It was not pretended that Hinchman was habitually deranged during the whole period in question of seven or eight years. His mother expressly says that at times he appeared like himself, and she as well as others described his disorder as manifesting itself in "spells," or "turns," in the intervals of which, of course, he behaved with his natural correctness and propriety. 'It was to be expected, therefore, that to the most of those who saw him but seldom, and were comparative strangers to him, he would exhibit no symptoms of mental derangement.

The motive of the conspiracy, as set forth in the declaration, was either to compel Hinchman to settle his property on his wife and children, or obtain it for some one or more of the defendants. Now, in regard to the latter, there does not appear to be one tittle of evidence in support of this charge, nor indeed could there be. In no event could any of the defendants be benefited by his property, except his own and his wife's sister, and 
they could only upon the contingency of the death of Hinchman, of his wife and of his children, and this contingency was brought no nearer by lis being placed in an asylum. Indeed, the plaintiff"s counsel scarcely attempted to prove this charge. They mainly endeavored to convey the impression that the object of the conspiracy was to change the control of the property from his hands to his wife's. That it was placed in charge of a commission was a necessary consequence of his being insane and in an asylum; but they attempted to show that the defendants made his liberation from the asylum contingent upon his conveying his property to his wife, by giving her a deed of trust. The only proof they offered was the testimony of some of the attendants of the asylum, which was substantially that, in passing along, they heard, or thought they heard, Dr. Worthington and Mr. Garrett, while in conversation with Hinchman or his friends, say something about a deed of trust. That is, a man declared to be insane by a jury of inquest, and whose property is placed in charge of a commission, is solicited to execute a deed of trust of that property! Were his counsel serious in making. this point, or did they suppose that the defendants were fools as well as knaves? The facts really established by the evidence in regard to the management of his property by others were, that on the discharge of the commission his real estate was restored to him just as he left it, and his personal property accounted for to him within two hundred dollars of his own estimate, a number of debts having been paid, his family supported, and an execution advantageously satisfied by the good offices of Edward Richie.

It was also suggested by Hinchman's counsel, that another motive which induced his mother to procure his 
removal to an asylum was to gratify her revenge for some rude treatment she received from him a year or two before. Not a particle of evidence is offered of the fact; while, on the other hand, several ladies of the highest respectability, who had been intimately acquainted with her from her youth, testified, in the strongest manner, in favor of her character as a kind and affectionate mother. If the counsel possessed any proof of such an object, we cannot but wonder that she was not placed upon the roll of defendants. That they should have made the insinuation without proof, stabbing a defenceless woman in the dark, was probably one of those innocent liberties which are supposed to be compatible with professional honor and dignity. Taking this view of the case, they were obliged to change the part previously assigned to the wife on the theory that the object of Hinchman's imprisonment was to throw the control of the property into her hands, and accordingly the senior counsel declared that "she was imposed upon, and had no hand in it." In regard to this position, we need only repeat the remark of the court upon it, that we can see no foundation for it in the evidence. There seems to be no end to the puzzles and contradictions presented by this most extraordinary trial, but our limits will confine our notice to one more only.

On the close of the plaintiff's evidence, it was moved that Dr. Griscom, Miss Hinchman, Dr. Evans, and Messrs. Warder and Wistar should be acquitted, no evidence appearing against them. The court advised the acquittal of Evans and Hinchman, but the jury acquitted only the former. This gentleman is the visiting physician of the asylum, in which capacity he makes himself acquainted with the mental condition of the patients, prescribes their medical and much of their moral treat. 
ment, and decides when they have recovered. It is for him to say whether the patient is or is not insane, and by his opinion the managers are guided in settling the question of the patient's discharge, or further detention. He it was who decided the fate of Morgan Hinchman for six months and more; who pronounced him insane, treated him as an insane man, and finally discharged him as recovered from the disorder. If any wrong was committed upon this man, Dr. Evans was unquestionably the principal offender. The others merely conceived and initiated the wrong, while he consummated and continued it month after month. All their efforts to gratify the unnatural passion of the mother, or strip him of his property for their own or his wife's benefit, would have been powerless without his coöperation. If Hinchman were really not insane, who was more deeply responsible for his confinement than $\mathrm{Dr}$. Evans? If, on the other hand, he were insane, - and the acquittal of Dr. Evans was tantamount to the admission of the fact, - wherein consists the guilt of those defendants who conveyed him to the asylum? If Dr. Evans were correct in his opinion of Hinchman's insanity, and consequently entitled to an acquittal, why should $\mathrm{Dr}$. Kite have been punished, who had no other connection with the case than to give a certificate of insanity?

If we are to receive the construction put upon the law by the court, - namely, that " a conspiracy to do a lawful act, if for an unlawful end, is indictable," - then perhaps the innocence of some of the defendants would not necessarily follow the admission of Hinchman's insanity. That is, although they might lawfully carry him to the asylum on account of his insanity, yet, if they were to be benefited thereby in a pecuniary respect, then it would be an unlawful act, whether he 
were sane or insane. However much this construction might affect the Richies and some others, we cannot see how it could bring Lippincott into the conspiracy. He was on his way to the coach-office, in order to take his seat for Frankford where his daughter was ill, when he was met by some of the defendants, who told him they were about to take Hinchman to the asylum, and invited him to take a seat in their carriage. There is no proof that lie had the slightest reason to suppose that they had any other object than the ostensible one,an act of humanity. And, even if he had, it does not appear that he laid a finger upon Hinchman.

Notwithstanding the great pains taken by the plaintiff's counsel to give a strong coloring of guilt to this transaction, and the vindictive character of the verdict, we can see in the act no unusual features, no suspicious circumstances. It was a reasonable, an honest, a humane measure, deliberately and conscientiously planned, and judiciously carried out. For several years a gentleman has been regarded by his family, and many of his relatives, friends, and neighbors, as subject to occasional derangement. He purloins money, and the act is attributed to insanity. He offers violence to his mother, and the meeting to which he belongs forbears to deal with him, becanse he was insane. He disturbs the peace and comfort of his family, but the partner of his joys and sorrows bears and forbears, hoping that his malady will finally yield, and every "spell" will be the last. Finding their hopes disappointed, and the disease steadily gaining strength, the wife and the mother, after deliberately consulting with their and his friends and relatives, finally resolve to place him in one of those institutions which are supposed to possess peculiar facilities for restoring the health of the disordered mind. To 
carry this measure into effect, they solicit the good offices of a couple of gentlemen, one a relative, and both his tried and faithful friends; and they, like good friends and neighbors as they are, perform the unpleas. ant duty. A petition is immediately offered for a com. mission of lunacy, and a jury of inquest find him insane. All the privileges and indulgences at the command of one of the most excellent establishments in our country are afforded him, so far as they are found compatible with his condition and comfort. He corresponds with and visits his friends, and receives their visits. Under this wholesome discipline his mental health improves; and after a few months, without the slightest objection from any one, he is discharged as restored to his usual health. Now, in this whole history we cannot discover a single strange or unusual feature, - not a single mark of fraud, or malice, or unfairness. To discover in it such qualities, required feelings perverted and embittered by disease, a public sentiment poisoned by the machinations of artful and unscrupulous men, and a jury with imaginations inflamed by pictures of a worthy and harmless man seized at mid-day by a band of ruffians, torn from the embraces of his wife and children, immured in a prison worse than the Bastile, denied the sight of his friends, stripped of his property, and in daily peril of his life from the assaults of raving maniacs.

In another and a very important point, this case is not without a frequent parallel. We are satisfied that Hinchman belongs to a class of patients - not a small one by any means - who recover so far as to be able to resume their customary pursuits and to conduct with tolerable correctness, but never obtain a healthy tone of thought or feeling on the subject of their infirmity. 
Instead of manifesting any gratitude towards those who watched over and cared for them when unable to care for themselves, and conducted them safely from under the clond that enshrouded their minds, they regard themselves as having suffered a grievons wrong in every step of their management. They are unwilling to admit that their intellect has been obscured for a moment; and this kind of pride, joined with a certain moral obliquity attributable to disease, makes them burn with hate and hostility towards every one who had any agency in effecting their seclusion, - the very partner of their bosom, as well as the institution under whose restorative influences reason has regained some measure of her lost dominion. Such feelings have only to be artfully stimulated and managed by mischievous acquaintances to find vent in law-suits and criminal prosecutions.

The court, we are glad to see, afforded no countenance to a notion of the plaintiff's counsel, that a person could not be deprived of his liberty, even on account of insanity, without a trial by his peers; and distinctly approved of the doctrine laid down, and settled, we trust, for all coming time, by Chief Justice Shaw, of Massachusetts, ${ }^{1}$ that the right to restrain an insane man of his liberty is to be found in the "great law of humanity." Subsequently, however, the right is so often affirmed by the court in connection with some condition or qualification, that we are left in a little doubt as to the exact principle which it would assert. "If," it says, "Morgan Hinchman was placed in this asylum for the mercenary purpose of getting him to convey his property in any way, it was a foul conspiracy; if it was honestly and conscientiously done for 
the purpose of restoring him to health, they conscientiously believing lim to be diseased, and you should be of that opinion, it presents a case in which, as I have told you, the patients may be taken in charge by relations and friends, by wives and by mothers." This is very plain, but how are we to understand the following remark? "If you are satisfied that Morgan Hinchman was so partially insane that it was dangerous to himself, dangerous to his wife, and dangerous to his chil. dren, for him to be at liberty, and that these men acted from pure motives, and placed him in the asylum for the purpose of restoring him to health, restoring him sound to his family, I hold them justified." Again, one of the points offered by the defendants is, "that if they acted under circumstances such as would have induced a man of ordinary intelligence to believe the plaintiff insane, and requiring medical treatment in an asylum, the plaintiff cannot recover." To this the court answers: "I accede to this if the jury find it was their only motive to restore him in health and soundness to his family." By this language it seems to be implied that the insanity of a party will not necessarily justify another in placing him in an asylum; because the motive of the latter may be bad. To extend to an insane man the benefits which an asylum affords is usually supposed to be a sufficient and justifiable reason for placing him in one. If in the deep recesses of the heart there lurks a mercenary feeling, - a consciousness of benefit to be derived, some day or other, from this measure so salutary to another,- we respectfully submit to the common sense of our readers whether such a sentiment can be made a subject of judicial inquiry. We cannot learn, from the judge's charge, on which side the burden of proof respecting the character of the motive is to rest. This 
would seem to be an important point. The practical consequence of this doctrine of the court, if confirmed, would be to deter the relatives of any patient from taking measures for his seclusion, because it may result in their pecuniary benefit, and thereby subject them to the charge of being actuated by mercenary motives. While they keep aloof, no one else will interfere; and the unfortunate patient is left to his own courses, until his disorder has become incurable, and seclusion is rendered a measure rather custodial than curative. Such a result the court certainly could not contemplate with favor; and it is to be regretted that the opportunity was not taken to rebuke, in the strongest manner, that jealous, intermedaling spirit which, with the most imperfect knowledge of the facts, and no personal interest whatever in the matter, presumed to condemn the most salutary measures, and to poison by its machinations the very fountains of justice. This notion of improper motives pervades the charge of the judge, starting up before him at every turm, like a troubled ghost, and frightening him from every position that common sense and common justice invite him to take.

The defendants declare that the finding of the inquest " that the plaintiff was insane is a justification of the arrest and confinement, so long as it is necessary for the health and improvement of the party." The judge replies substantially that this position is correct, provided there were no corrupt nor fraudulent contrivances in the proceeding. It had been testified by one of the plaintiff's witnesses, that Edward Richie told him that he (Richie) and Biddle handed to the sheriff a list of jurors for the inquest of lunacy, who were accordingly summoned. 'This fact was flatly denied by the sheriff', who emphatically declared that every member of that jury was 
selected by himself, without the slightest suggestion from any one. The acquittal of Biddle shows that the jury chose to believe the sheriff; and consequently, there having been no fraud, the finding of the inquest, upon the above admission of the court, was a justification of the arrest and imprisonment. With what consistency, then, could the jury render a rerdict against Elkinton, Lippincott, and Whitall, who had no other connection with the case than to assist in such arrest? We are almost forced to the conclusion, by this and other similar inconsistencies, that some victims were deemed necessary to appease the wounded pride and morbid feelings of the plaintiff, and that the jury were guided in their selection by any other consideration than that of guilt.

Our limits will prevent us from adverting to every objectionable feature presented by this case. A volume would scarcely suffice for that, but the specimens given will enlighten the reader respecting its general character, and especially of the animus that pervaded the trial. It is perfectly obrious that, by artful appeals to the popular passions through the newspaper press, the defendants had been tried and condemned in the public mind long before they went through the formalities of a legal trial. This explains why it was that a band of men and women, than whom our sister city has few more eminent examples of moral integrity and worth, were arraigned like felons, held up to the scorn and contumely of the world, and stripped of their property as a punishment for their crimes. But we are not anxious to prolong an examination which, the farther we go, only deepens our mortification and grief. Thus much we felt bound to say, in our character of faithful journalists, of a trial which can scarcely find its parallel, except 
in the trials for treason that disgraced the reigns of the Stuarts.

$$
\text { "Can such things be, }
$$

And overcome us like a summer's cloud, Without our special wonder?" 


\section{THE PARISH WILL CASE.}

[THE case which forms the subject of the following opinion will take a foremost place among the cruses célèbres of our country; for, in regard to the curious patbolocical questions it raised, to the number and distinction of the experts whose opinions were obtained, to the social prominence of the parties concerned. to the magnitude of the pecuniary interests involved, and to the dramatic element that characterized the movements which led to the testamentary acts, it is certainly unprecedented in our judicial annals. It occasioned an immense amount of inquiry and discussion respecting the effects of apoplexy, paralysis, and epilepsy, on the mental condition. The records of hospitals were searched, the personal experience of paralytics exhibited; and, besides the written opinions of gentlemen specially conversant with insanity, several eminent physicians contributed the results of their learning and observation. Never, in fact, were the mental and pathological effects of paralytic affections more thoroughly investigated; and in the numerous papers thus produced the medical student will find a rich mine of information.

Most of the testimony was submitted in print to several gentlemen supposed to be specially skilled in mental diseases, and their opinion requested as to the mental condition of the person to whom it referred. Among the opinions obtained in reply to this request was the following, from the writer of these remarks.

Since it was written, it happens that the prominent feature of the case, aphasia, or loss of speech, has been considerably investigated by various observers. These investigations have greatly increased our knowledge of its anatomical and pathological relations; but I am not aware that such knowledge would have thrown any light on the questions presented in Mr. Parish's case. Had an autopsy, for instance, revealed a serious lesion in a certain convolu- 
tion of the brain, the fact would have been interesting as a confirmation of a general law, but would not have helped us to decide whether that gentleman was competent to make a will. For the question was not whether his brain was diseased, but whether it appeared from actual observation that he had or had not a testamentary capacity.

It is a noteworthy fact, in the trial of this case, that the Surrogate wisely determined that the medical opinions should be given in writing, with the understanding that, though not clothed with the authority of legal evidence, they would be carefully considered and credited with all the weight to which they were really entitled." Such a remarkable disregard of technicalities was at once significant of his own breadth of mind, and conducive to the most exact and complete expression of belief. It enabled the expert to utter - what is impossible in the usual method of examination and cross-examination - his opinions and the reasons for opinions, with that coherence and logical relation absolutely necessary to show their full force and significance. This was a movement in the right direction, and is well worthy of imitation wherever the mode of procedure admits of it.

The Surrogate admitted the first eodicil and excluded the other two. The case was taken to the Supreme Court, which decided against all three codicils; and this decision was affirmed by the Court of Appeals, - the court of last resort.]

Henry Parish, a prosperous New. York merchant, made his will in the year 1842 , being then fifty-four years old. It is a long and elaborate instrument, distributing his property, supposed at that time to be worth about $\$ 750,000$, among a considerable number of relatives, and indicating a nice balancing of their respective claims on his bounty. Having provided liberally for his wife, and distributed a large share of the estate among his kindred, he constitutes his brothers Daniel and James the residuary legatees. While in Europe, in 1843, he had what seems to have been an apoplectic attack, from which, however, he shortly recovered, and continued as well apparently as ever, both in body and mind, until the 19th of $\mathrm{July}, 1849$, when he had another apoplectic attack, much more severe. In the course of 
about a fortnight he was out of immediate danger, but never recovered his ordinary condition. His right side (including the upper and lower limbs) was found to be somewhat paralyzed, the power of articulation was lost, and his natural elasticity and vigor were gone. These traits continued with little change until he died, in 1856 .

Within a year from the date of the attack he became able to walk with a crutch, and the aid of another person generally. It does not appear that he ever obtained the use of his right hand. Until within a few months of his death he continued able to utter a few monosyllables, described by some of the witnesses as "oh, dear," "yes," and "no," and a few inarticulate sounds. During this period he had several attacks of bodily illness, such as cholera morbus, inflammation of the lungs, abscess under the jaw, and intestinal inflammation.

'The functions of the bladder and rectum were somewhat disturbed, a part of the time at least; and hence arose an increased frequency of evacuating these organs. Epileptic fits occurred within a few months of the apoplectic attack of $\mathrm{July}, 18+9$, at intervals varying from eight days to six months or more. When not laboring. under a particular illness, he sat in his library, walked to market with his servant, or drove out in his carriage with his wife, or one of her brothers.

On the 29th of August, 1849, his cross in lieu of a signature was subscribed to a codicil to his will, which gave to his wife the house he then occupied, and a certain store and lot, all which had come into his possession subsequently to the execution of the will, the house devised to his wife by the will having, in the mean time, gone out of his possession. This codicil was, in like manner, executed the 17 th of December, 1849. 
On the 15th of September, 1853, a second codicil was subscribed in like manner, which repeats the bequests of the first, and bequeaths to his wife some $\$ 350,000$ in certain stocks and bonds. It also bequeaths $\$ 50,000$ to various charitable institutions, and revokes the appointment of Daniel Parish as one of the executors of the will, as well as the bequest to him of $\$ 10,000$ as executor.

On the 15 th of June, 1854 , a third codicil was made, which substitutes his wife, as residuary legatee, in the place of Daniel and James Parish.

These codicils were contested in the Surrogate's Court on the ground that, when they were made, the testator had not a testamentary capacity, and the question before us now is, what was the mental condition of Henry Parish during the period between the attack in $18+9$ and his death in 1850 .

Paralysis, the sequel of apoplexy, is not invariably accompanied by very obvious mental impairment; but such is very frequently the case, especially after the attacks have been repeated once or twice. The occurrence of epilepsy in the present case, subsequently to the paralysis, is an additional indication of a high degree of morbid action in the brain. Under these circumstances, therefore, some degree of mental impairment might have been naturally expected.

The manifestations of mental impairment may not be very patent in a person deprived of the power of articulation, but they cannot easily be mistaken by those who are practically conversant with mental affections. Speech is but one means of expressing ideas and emo- 
tions. Signs, writing, actions, may be less easy, but are none the less accurate or accessible. Deaf mutes are a standing exemplification of this fact. The mental condition of the testator, therefore, is to be ascertained by his acts and demeanor,-by observing what he did, and by considering what he omitted to do.

For a few years previous to his attack in 1849 he had retired from business, except the investment of his income in real estate, bonds, mortgages, and stocks. There is nothing in this requiring much exercise of thought. The essential points in any transaction of this kind are few, easily accessible, and easily comprehended. If he had retained his mind unimpaired, it might have been reasonably expected that he would continue to manage his affairs in this way, especially as it had been a favorite occupation with him. If he were competent for any thing, he was for this. He could have indicated the securities he wished to purchase, by pointing them out in the paper's or writing the name. If he wished for commercial paper, he had only to visit or send for a broker, and select from his stock such as he preferred. His dividends he might have collected for himself, and the little assistance he might have needed in any of these transactions could have been furnished by his book-keeper or some friend. With his love of accumulation, and the gratification he derived from a good bargain, he never would have delegated, in any degree, the business of inresting his income, even to his own wife. It appears, however, that within a year from the attack he gave her a power of attorney for selling his securities, and that she usually collected his dividends. While it is impossible to say how far his opinion was consulted in the greater portion of his purchases, it is doubtful at best whether 
any single transaction was entirely the result of his own free will and unguided understanding. The usual practice of his wife was to drive into IVall Street with him, and there, stopping before some broker's office, to send for one of the firm, who eame to the carriage, and, having ascertained how much money was to be invested, the broker offered various notes and stocks. It is said that, as these were read to him, he expressed what was regarded as his token of assent or dissent. Sometimes the business was finished at this interview; at other times - and this seems to have been the more common proceeding - a day or two was taken for consideration, when the result was communicated to the broker by Mrs. Parish. In the latter case we have no means of knowing how much Mr. Parish had to do with the result; and in the former his agency, even if apparently independent, might really have been only the expression of her wishes. There was no reason why she should interpose, except to prevent him from accepting unsatisfactory paper, - a contingency not likely to happen when dealing with such men as the Wards. If his sign or sound was thought to indicate a refusal of what he might as well have accepted, it was of no consequence, because there was enough more equally good from which a choice might be made. His assent or dissent, therefore, might have been expressed without the slightest reference to the quality of the paper offered, and yet the actual purchase been perfectly satisfactory.

In the loans, too, which were habitually made, it is impossible to discern his controlling agency. Dr. Markoe, who hired $\$ 10,000$ of his funds, says he applied for the loan through Dr. Delafield, and never exchanged a word with Mr. Parish about it, except to 
thank him for the accommodation. Mr. Youngs, the builder, applied to him for loans of money, but always in the presence of Mrs. Parish, and the result, whatever it was, was always by her knowledge and consent. The same is true of the loans to Wiley. One of them, it seems, was larger than the amount of his funds in the bank; and when the fact was pointed out by his wife he appeared to be much irritated, became "furiously mad," the witness said, "and rapped his hand as hard as he could on the table three or four times." Mr. Tileston's account of his negotiation with him for the use of $\$ 200,000$ worth of United States scrip, besides exhibiting the agency of others in the matter, throws much light on the question of Mr. Parish's capacity. When asked on what terms he would allow the bank to place this stock in the hands of the Comptroller, he held up two fingers, which, Mrs. Parish said, meant $\$ 2,000$ per annum. Then he began to manifest some uneasiness; and after repeated unsuccessful attempts to ascertain his meaning, Mr. Tileston was obliged to leave the transaction unfinished. Two or three days after, he was told by Mr. Delafield that Mr. Parish was not satisfied with the security, viz., the capital of the bank and the liability of the stockholders for $\$ 1,200,000$ more, but required the individual security of the directors. This Mr. T. declared to be out of the question; but he offered a mortgage of the bank building, appraised at $\$ 175,000$. This also was declined, and further negotiation was abandoned. Now, if Mr. Parish understood the matter correctly, and the three witnesses present are quite sure that he did, the transaction shows very equivocal proof of any capacity for business; the more striking, because a fer years before he had loaned the same stock for the same purpose, and on security far less perfect. 
than that now offered; and if Mr. Parish did not comprehend the matter, it shows that these witnesses entirely misunderstood the meaning of his signs and looks.

The exclusive agency of others in some of these investments is established by the testimony of Mr. Kernochan, who says that Mrs. Parish often consulted him about the "investments that were being made, or about to be made."

From all these transactions, I cannot resist the impression that Mr. Parish was no longer the same man. In all probability, before his illness it was not his custom to consult his wife about investments, nor her custom to consult others.

The testimony also shows abundantly that Mrs. Parish took a prominent part in many other matters of business, which men do not usually delegate to their wives. Mr. Kernochan speaks of their both coming to the office, and of Mr. Folsom's showing and explaining the books to Mrs. Parish. On these occasions she commonly spoke to him, he says, about the renting of prop. erty and the collection of dividends.

In regard to much smaller matters in which he seemed to take a part, the indications of capacity are not very obvious. At one time, in the summer of 1850 , he was in the halit of accompanying his servant to market, where he would point to various things; but no one could understand what he wanted, and if they guessed at his meaning, and sent the articles to his house, portions of them were sometimes returned as unsuitable. Austin, the poulterer, says that on one occasion when various kinds of poultry and game were carried out to him, in order that he might choose for himself, he only flourished his cane, and acted as if he were crazy. When accompanied by his wife in his visits 
to the market, it seems to have been the custom for her, finally, to order the dinner. Just before going to bed he usually went to the kitchen and ordered his breakfast, which order, as interpreted by the cook, was sometimes countermanded by his wife, and something more suitable for his condition substituted. The evidence of Sammis shows that his wife regarded him as not competent to purchase his own shoes, and Jones's testimony shows the same thing in relation to his clothes.

Again, it appears that during the whole period of his illness he never played a game of whist, nor engaged in any other amusement. Now, when we consider that he had of late years been passionately fond of whist, that it was often played by his wife and her friends in his presence, and that if his mind were unimpaired he must have been ready to adopt any means of whiling away the tedious hours of confinement, it seems impossible to account for his abstinence from this game, on any theory which supposes his mind to have been untouched by disease, or reduced to any grade much above the lowest form of dementia. The knowledge of such games is among the last things that fade from the disordered mind; and in every hospital for the insane, patients reduced to an almost vegetative existence may be seen playing at games of checkers or whist, if not as skilfully as in their best days, yet in compliance with all the rules of the game, and with more or less gratification.

Among the facts which seem to be relied on as proofs of the testator's mental soundness, I need notice only some of the principal. He recognized his old friends. He went through the ceremony of taking wine with his guests. To a person standing by him in the open air uncovered he made the motion to put on his hat. He is said to have smiled at the time when a joke was 
uttered in his presence on one or two occasions. He would point to his head or other parts to indicate that he had pain there. When the affairs of a neighbor were spoken of, he is said to have pointed out of the window in the direction of that neighbor's house. He indicated a wish to change his clothes when soiled. One attendant says he had taught him to turn down the coverlet when he wanted the urinal. He listened with apparent attention to certain conversation, and manifested displeasure at interruption. A nurse says when the hour for taking medicine came around he would point to the pill-box. These incidents, even if correctly represented, indicate but a very small measure of mental capacity. They are not incompatible with any of those forms of dementia in which every idea of cause and effect, of the value of property, of the ties of consanguinity, and the relative claims of family and friends, has long since disappeared.

A few other facts of a higher character are mentioned in the evidence, which may seem to require a more particular notice. Youngs, the builder, says that, when he read to him bills for work, Mr. Parish would sometimes stop him, and look inquiringly, whereupon Youngs would ask if he wanted any explanation, when Mr. Parish would say "yes." The force of this testimony is greatly weakened, if not entirely destroyed, by Youngs himself, who says that Mr. Parish made two sounds, uttered in quick repetition, "eh, eh, eh," and "nah, nah, nah," as he spells them, and which, he supposed, meant respectively yes and no.

The same witness says, that after some repairs of the roof had been projected, but not begun, Mr. Parish would call his attention to it whenever he saw him, "by pointing upwards with his first forefinger, though it might have been two sometimes, raising his hand as high as the 
lower part of his face, and at the same time looking upward." On being asked if he referred to the roof, "he would nod his head "yes." "This piece of testimony is open to the same objection as the last, - the point on which its whole value depends is a matter of guessing. Mr. Parish did not really say yes, but only something which, the witness supposed, meant yes; and even if Mr. Parish really intended to remind him that the roof needed repairing, the fact would only show a degree of intellect far below what is required for testamentary purposes.

Mr. Wiley says, that, having borrowed some money of him, he handed him a promissory note. "After looking. at it, he made a motion to me, uttering a continued kind of sound, putting the note on his knee, and striking it with the ends of his fingers several times, as much as to call my attention to it, I thought; I took hold of the note then, and looked at it, and I saw there had been omitted 'interest from date.'" Another note, correctly written, being given him, he looked at it as before, "bowed his head several times," and put it into a satchel. Now, even if Mr. Wiley were perfectly correct in his conjectures respecting Mr. Parish's meaning, the fact would prove little. A man who, like Mr. Parish, had been giving or receiving such notes all his life, would readily observe so important an omission as that, if he observed any thing. It would show only one of those automatic movements of the mind, like those concerned in playing games, and implying no more exercise of thought.

Again, the same witness says, "He would sit quietly on the reading of the paper, and when the price of any particular stock had advanced from the previous day's sales, he appeared to take notice of it; would rise in 
his chair, make a motion with his hand, and sometimes nod his head, and sometimes shake his hand, always uttering a noise." The witness thought that Mr. Parish would make no such sound, gesture, or motion when any other subject was read about. At the best, this fact would indicate only a little attention and memory, such as are generally witnessed in all but the lowest forms of dementia.

The Rev. Dr. Taylor states that he administered the Lord's Supper to him at least seventeen times during his illness. He says, "His manner was uniformly devout and humble. He seemed to be always very much impressed with the solemnity of the occasion." In place of the regular responses he "made a sound of acquiescence," and with his left hand he conveyed the bread and cup to his mouth. All this displays but little intelligence. Like every person born and educated in a Christian land, he was well acquainted with the ordinances of religion, and in partaking of them no more exercise of thought was required than in partaking of his regular meals.

The fact that during these six years he never entered a church would seem to imply that the religious sentiment had little of that activity which might have been expected in a sane mind. The same witness states that after every service Mr. Parish gave him money from his own pocket; but this act, with the thousand others which are performed by the insane with the utmost correctness, shows no exercise of the reasoning powers.

Fisher says, he would put the newspaper on his knee and point to the part he wished to have read. If this were so, it would only prove that he knew how to read, but nothing at all respecting his mental capacity. Without noticing other acts of a similar character, 
many of which appear in the evidence, let us see what inferences may be drawn from the manner in which he was managed by his family and attendants.

Wingrove's description of a morning's operations of his motions with his hands and head; his "yanne, yanne, yanne;" his searching his wife's wardrobe, though assured that it contained nothing belonging to him; his taking up his pantaloons one after another, putting them to his mouth, and repeating his customary sound, "yanne, yanne, yanne;" of his visit to the market, where he would sit in a chair, and take the game handed him, and put it to his mouth as he did the pantaloons strikingly illustrates that mental decrepitude so frequently the sequel of paralysis. Nany other scenes in his domestic life tell the same story. Clark, the coachman, who was in his service during the whole of his illness, says it was his custom to visit Mr. Parish in his room, every morning, between nine and ten o'clock. "I would go in," he says, "he would nod his head, a smile on his countenance, and then he would put up one finger or two, and say, 'nea, nea,' or 'aney, aney', to know how the horses were; then he would hold up the fingers again, just repeat it; then I would ask him if it was about feed; I would tell him the horses were very well, and I had plenty of feed; then I would say, 'Good-by, Mr. Parish,' and then he would nod his head, a smile on his countenance, and say, 'Neay, neay, neay', as much as to say 'Good-by ;' I took it for that." Henry Delafield says that it was his custom to drive out with him on Sundays, and that when they drove down town the carriage would stop near his stores in Wall, Pearl, Water, and Pine Streets. "He would point at the building; then looking at me inquisitively, I would ask him if he wished any information about the building; he would 
say, yes; I would then tell him the building appeared to be in order and all occupied."

Mr. Wiley says, that when he visited him at Hell Gate, as he often did, "I would recount the business of the day in the city, such as I would think would be interesting to him." "How long a time," he was asked, "would you spend in talking with him?" "From two to five minutes," was the reply.

The only possible theory whereby all these indications of mental infirmity can be explained consistently with the supposition that his mind was unimpaired, is, that being unable to express his thoughts by means of speech he necessarily appeared deficient in understanding. This theory receives but slender support from the facts in the case, and the general experience of men. Let the question be put to any one in the full possession of his faculties: "Were you to be suddenly deprived of the power of speaking, and of the use of your right hand, your mind remaining unaffected, do you suppose that, for six or seven years, you would continue as incapable of making known your thoughts as Mr. Parish was?" There certainly would be but one answer to that question. A tolerable facility of writing with the left hand could be obtained by a little practice, and in the mean time a dictionary, bluck letters, hieroglyphics, and maps, would enable him to convey his meaning without fear of mistake. Every day would also witness an improvement in the use of signs and gestures. In every actual case of this description on record (i.e., mere loss of speech), so far as I know, the integrity of the mind was shown either by what the patient did, or by the ideas communicated in the manner here mentioned. In one, the patient, a collector of taxes, pursued his customary duties; in another, a blacksmith went to his shop, and 
gave directions to his workmen; in another, an old gentleman continued to enjoy his game at whist as much as ever. ${ }^{1}$ The facts that through this whole period of six years or more Mr. Parish never wrote, unless, indeed, it might be that he wrote his own name, in a few instances, - a fact not clearly established; that his signs and motions were very few, not one of them having an unmistakable meaning; and that, notwithstanding his great desire at times to make known his wishes, he frequently failed, much to his own discomfort and irritation, render the conclusion unavoidable that his mind was reduced to a very low grade of dementia, - that state in which its operations consist of a few feeble, disjointed efforts of perception and memory. His whole pantomime consisted of a nod and shake of the head, and a motion in which he raised his left hand (with two fingers pointing upward, and the rest closed on the palm) towards his mouth, and finally rested his fingers upon his teeth. The nod and shake of the head were supposed by some to indicate assent and dissent, and his communication of ideas was confined entirely to making one of these motions in reply to any question whatever. Thus every thought or wish attributed to him originated with somebody else. This, of course, might not be objectionable, necessarily, provided there could be no doubt respecting the meaning of these motions, and also that the questions were clearly understood. Kernochan and Folsom, however, state that the same question repeated after a short interval, or in different terms, elicited both the nod and the shake. Jones, the

1 For cases of this kind, see Pinel, Sur l'Aliénation, 90; Ray, Med. Jurisprud. of Insanity, p. 163 ; Cooke on Nervous Diseases, p. 246, Boston ed., 1824; Ed. Phrenological Journal, II. 410 ; III. 316 ; IX. 17 ; IX. $471 ;$ X. 352. 
tailor, makes a similar statement. In regard to the motion of the hand, Kernochan says that those about him supposed that he meant by it to invite suggestions, or gain information, but that he could never make that out with any certainty. In reply to Mr. Tileston's proposition to hire his United States stock, it seems that he made this motion, or something very like it, whereupon Mr. Tileston says, "I believed that he intended to conrey the idea that he required $\$ 2,000$ per annum for the loan of the stock, which was confirmed by Mrs. Parish saying that that was exactly what he intended to convey." Gibson states that when he solicited from him a subscription to some charity, he made this motion, and that Mrs. Parish, who was present, immediately asked if he meant $\$ 200$; to which he assented, bowing his head.

By some of the witnesses it was stated that he, at times, said, "oh, dear," and "yes," and "no," quite distinctly; but Kernochan, who visited him more or less frequently, during his whole illness, says that he never heard him utter an articulate sound. He was in the habit of making a few inarticulate sounds, always repeating them rapidly, but as each witness expresses the sound in his own way, there is some doubt as to their number and identity. As written by them, they are "yanne, aney, yah, neay, yey, yet, nay, nan, nin, niah, nich," and some others. The first five or six were probably the same sounds differently rendered by different persons, and by some supposed to express assent, as the others were supposed to express dissent. This, certainly, was not always their meaning, for some of them were used when he was irritated; and at other times the same sounds were uttered when he was under no excitement. Some of them were regarded by some of the witnesses as equivalents of yes or no, but 
they seem to have been used at times when he was supposed to have the power of uttering distinctly those words. It is certain that the nod and shake of the head were not always accompanied by any sound, articulate or otherwise. The most probable conclusion is, that these inarticulate utterances had no meaning at all, but were merely ejaculatory sounds accompanying the feeling or emotion of the moment.

On the question of Mr. Parish's mental capacity, these signs and sounds are not without great significance. Considered under any possible aspect of the case, it is quite impossible to believe that a person in the full posses. sion of his mind, though without the power of speech or of his right arm, would not, during the space of six or seven years, have acquired greater facility in the communication of his ideas.

The moral traits which made their appearance after the attack are also very significant in this connection. Some degree of irritability is not an uncommon sequel of paralysis, and does not necessarily imply intellectual impairment. But in this case there was a kind of petulance and of anger, never exhibited in connection with soundness of mind. It was not merely excessive and frequent, but irrelevant and puerile. It was the anger of a child, and signified as plainly as any other fact in the case that the manly, vigorous, and well-balanced mind of Henry Parish had been reduced by the shock of disease to a lower level than that of the feeblest child's. Dashing at and striking his wife, with other manifestations of childish displeasure, seem to have been a frequent incident; and many witnesses speak of his exhibiting irritation when the people about him failed to ascertain his wishes. The scene at Root's, where the violence of his movements, occasioned solely by his 
wife's not returning to the carriage the moment he expected her, attracted the attention of the passers-by, was a striking illustration of this trait of disease. And so was his conduct with the box, as related by Dr. Markoe. On this occasion, after much questioning, which failed to elicit his wishes, his wife asked if he wished her to get a certain box; "and as soon as this suggestion was made to him, he assented to it most vehemently." Accordingly, the box was obtained from the bank and placed in his lap; but, says the doctor, "he was very much displeased with something connected with the presentation; the box was left unopened, and conveyed back to the bank that same afternoon." Another witness present says he threw it upon the floor, and pushed it about with his hand. Is it possible that a person of sound mind, or any mind at all, would indulge in such conduct as this? He is supposed to be exceedingly anxious to obtain his will; and when, after much trouble, he has succeeded in getting it within his grasp, he dashes it upon the floor unopened, and cares for it no more!

It would appear that many persons of intelligence, education, and knowledge of the world, who visited Mr. Parish more or less frequently, came to the conclusion that his mind was not materially impaired; that he understood any proposition made to him, and was capable of transacting business.

This fact may be easily explained without discrediting their honesty or sagacity. They arrived at their conclusion through a series of errors, both of fact and opinion, which any one might readily commit who had no practical knowledge of abnormal states of mind. To form a correct opinion in a case of doubtful sanity requires, in addition to this kind of knowledge, a mind free from bias, and full opportunitie; of oliservation. Few, 
if any, of the gentlemen who bore testimony to the mental capacity of Mr. Parish possessed these qualifications. They called on him, some for business, and some for old acquaintance sake. They were impressed, in the outset, with the idea that he labored under no other disability than the loss of the power of speech; and for the most of them, if they entertained any suspicion of the correctness of this impression, it would have been neither convenient nor proper to test the measure of his capacity by appropriate means. He greeted them with a look of recognition, and perhaps a shake of the hand, and they put to him questions respecting his health or a matter of business. To these he replied by a motion of the head, to which they very naturally affix the same meaning that they rould to a similar motion in any other person. Any doubt on the point is removed at once by the suggestion of others, who are supposed to be familiar with all his signs and sounds, and perfectly to understand their meaning; and they go away quite satisfied that he understood every thing they said, and was capable of understanding a great deal more that was not said. The conversation, if such it may be called, was confined, with one or two exceptions, to simple ordinary matters which required no exercise of thought, and which were within the comprehension of any degree of mind not unequivocally imbecile. Matters of greater moment, requiring some effort of the reasoning powers, such as testamentary dispositions would imply, were never introduced.

It will be observed that these persons also committed the common mistake of supposing that if $\mathrm{Mr}$. Parish understood the terms of a question he necessarily understood its merits. This is not true of sane people 
always, while nothing is more common among the insane than expressions of assent or dissent in reply to propositions far beyond their comprehension. In every institution for the insane may be found patients with the dress and deportment of gentlemen, performing all the little commonplaces of life with unexceptionable correctness, but ready to assent to any proposition however absurd. Without the careful application of some test, most persons would conclude that these patients, who replied so promptly with a yes or no to the question asked them, really understood the subject talked about. Thus, when asked to purchase the paper of a certain mercantile house, Mr. Parish might have recognized the name, estimated the sum correctly, and been conscious that a bargain was to be made, without having any clear idea of the standing of the house, the nature of the security, or the actual value of the paper.

In interpreting the meaning of such signs and sounds as Mr. Parish used in his interviews with these gentlemen, it is obvious there would be much room for the play of the imagination. Even careful and cultivated minds might easily be led astray by some casual bias, and thus have mistaken their own fancies for actual facts. Mr. Isaac H. Brown, in describing one of his interviews with him, says that he held up his hand with the first two fingers crossed, signifying, as he understood it, that he wished Mrs. Parish to give him (Brown) ten dollars. Mr. James Watson Webb says that, on meeting him once and referring to a former acquaintance abroad, he burst into tears, indicating, as he (Webl) supposed, his inability to speak. The Rev. Dr. Taylor speaks of his "sensible and intelligent replies," and Major Delafield of his "complaining of his sight," and of "his eye beaming with intelligence." So difficult 
it is even for the most honest and sagacious to refrain from mixing up their own inferences with the impressions made upon their senses.

During the period in question Mr. Parish was attended by several physicians for some bodily ailment: and these gentlemen, though not professing to be particularly conversant with mental disease, and though at the time of their professional attendance they made no investigation of mental condition, were requested, on their examination before the Surrogate, to state their opinions respecting it. Their opinions are entitled to most respectful consideration, but can claim our assent only so far as they are supported by facts. Whether a certain person is sane or insane, imbecile or demented, is a question not to be decided by vague impressions, or a superficial observation, but by facts sufficiently numerous, definite, and clear, to admit of but one construction by those who are qualified by their studies and experience to appreciate them properly. Dr. Johnston, who visited him professionally from the beginning of the attack till the 27 th August next, thought he understood the questions put to him about his ailments; but the Doctor declined to express any opinion respecting his mental condition generally. Drs. Wilkes, Dubois, Markoe, and Delafield, who visited him more or less frequently (the two latter during the greater part of the period in question, and the two former during a few weeks only for affections of the eyes), concur in the opinion that his mind was unimpaired by his disease. The kind of facts which led them to this result has been already indicated and examined. Nothing stronger is adduced. Indeed, few of those facts were witnessed personally by any one of these gentlemen; and the only ground on which they can claim some confidence in their opinion must be that im- 
pression which was made upon them by signs or sounds that cannot well be imitated, or by facts which, while they might be well enough described, might be differently interpreted by others. It cannot be denied that this may be legitimate ground for an opinion. Facts which indicate little or nothing to one person may be pregnant with meaning to another. Still they should be facts, and admit of an accurate description; otherwise, the opinions that are founded upon them cannot obtain the confidence of others. Such facts, though they be more significant to one and less to another, will at last be appreciated at their true value. Dr. Markoe states that at an early period he and Dr. Delafield recognized the importance of the question respecting Mr. Parish's mental condition, and that they had several consultations about it; and yet, in reply to the question, "Did you ever make any examination of Mr. Parish, or apply any test to him, for the exclusive purpose of ascertaining the state of his mind?" he says, "I never did in any shape or way." This is to be regretted. Many insane persons are free enough in their communications to retider experiments and tests unnecessary ; but Mr. Parish's case was just one of those where the spontaneous manifestations are so obscure and uncertain, that nothing less than a course of systematic observations, managed expressly for this purpose, could establish the fact of mental soundness against all the presumptive evidence to the contrary. The Doctor puts it forth as one of the grounds of his opinion, by implication at least, that Mr. Parish "possessed the faculties of memory, perception, comparison, judgment, and, in fine, all the ordinary faculties of the mind." What is meant exactly by this last phrase is not very obvious, but surely it cannot be denied that all the faculties here mentioned are manifested more or 
less in almost every form of mental derangement, including even imbecility and dementia. The fact proves nothing as to the soundness or strength of the mind. In any case of doubtful mental condition, the question at issue is not whether the patient possesses these faculties, but whether they exist in their normal state. Dr. Delafield also says that he never applied a test expressly for the purpose of ascertaining Mr. Parish's mental condition, for the reason that he had no doubt about it, and that every visit he made was a test. Such a reason is calculated to produce surprise rather than conviction. Dr. Delafield must be aware that in any scientific inquiry the object is to obtain a degree of proof satisfactory, not only to the inquirer himself, but to every one else. He is quite sure, no doubt, that Mr. Parish could read, but the fact is disputed by others; and yet how easily it might have been placed beyond the reach of contradiction by some simple test! We are therefore forced to conclude that the medical testimony, laboring as it does under these defects, cannot affect any position respecting Mr. Parish's mental condition which the other testimony warrants us in taking.

Before closing my remarks on the medical testimony, I would advert to Dr. Markoe's explanation of Mr. Parish's inability or unwillingness to learn to write, though perhaps there would be no danger of its passing for more than it is worth, even if left unnoticed altogether. It seems that within a few months after the attack, various trials were made to teach $\mathrm{Mr}$. Parish to write with his left hand, but, beyond writing his name wholly or partly a few times perhaps, nothing was accomplished. After a number of trials, estimated by $\mathrm{Dr}$. Delafield at from five to twenty, he refused to proceed, and at no subsequent time were the trials resumed. This 
unwillingness to persevere in the attempt to obtain a means of communication, which would have been of inestimable value, is attributed by Dr. Markoe to " his early discouragement acting upon a somewhat peculiar temperament." This explains nothing. It only substitutes one difficulty for another. The proper question is, why a man like Mr. Parish, naturally of a strong will and much firmness, and supposed to be in full possession of his mind, on finding himself deprived of the power of speech, should become so easily discouraged in atternpting to learn what was so necessary, not only to his interests, but to his hourly convenience and comfort. Any one who will make the experiment will find that it is not impossible to write with the left hand, even at the first attempt, and that a little practice will enable him, as it has many others, to write with considerable facility. Another and an insuperable objection to $\mathrm{Dr}$. Markoe's theory is, that it does not explain Mr. Parish's unvillingness to make up words by means of the separate letters of the alphabet on cards. This device was tried after the attempts to induce him to write were abandoned, but with no better success. He would not try to use them, and refused to have any thing to do with them. I find it impossible to account for his refusal to avail himself of so simple and easy a means of communication, upon any theory which supposes him to have been able to read, and competent to the transaction of the very smallest matter of business. Unquestionably he was easily discouraged, and the cause of it is obvious enough. The same stroke which shattered his intellect also deprived him of his firmness, his perseverance, his resolution, his manliness, and, in respect to all these qualities, reduced him to the condition of a child. This statement is confirmed on almost every page of the 
testimony. Every witness who saw much of his daily life, and some who saw but little of it, speak of his frequent tears, his petulance, his freaks of ill-humor, and his gusts of passion, characterized in every instance by extreme puerility. How much of this unwillingness or inability to learn is fairly attributable to discouragement is not very obvious. It scarcely required the resolution of a child to construct words with the separate letters of the alphabet; and his refusal to make the attempt admits of no other explanation than extreme insensibility to the importance of the object, - an explanation utterly incompatible, of course, with the measure of understanding which is claimed for him.

Enough has been said, perhaps, to prove the mental impairment of Henry Parish during the latter years of his life, but it may be proper also to scrutinize the performance of those acts which are the subject of the present contest. Here, if anywhere, we ought to meet with unequivocal traits of a judgment and sagacity equal to the occasion, - unquestionable proof that he fully understood both the terms and the merits of the various testamentary dispositions which he adopted. They might counterbalance many facts of an opposite character observed under other circumstances, if not turn the scales decidedly in his favor. The actual facts, however, are of the same complexion as the rest.

Mr. Lord, who prepared all these codicils and witnessed their subscription, says that in each instance he received the necessary instructions, not from $\mathrm{Mr}$. Parish, but from another person deeply interested in their provisions, and present on the occasions when the various dispositions were discussed and adopted. Each particular provision was read aloud, and $\mathrm{Mr}$. Parish was asked if he acknowledged that as a part of his will. $\mathrm{He}$ 
replied by nodding or shaking his head, implying thereby assent or dissent, and that provision was retained or rejected accordingly. These motions were accompanied by a sound represented as being, on the occasion of the second codicil, a pretty distinct yes or no, but on the occasion of the first they were supposed to be only an attempt, scarcely successful, to imitate those words. By the second codicil he gave to his wife various stocks, most of them then standing in her name (having been purchased by the receipts from his property since his attack), and also gave a considerable sum to various charitable institutions. Considerable difficulty occurred, ostensibly, in perfecting the different arrangements according to his wishes. When desirous of making a communication, the usual practice was resorted to of mentioning interrogatively various things; and, if the right one happened to be hit on, it received his assent, and was supposed to express his will. It was not until after several interviews and much ineffectual questioning, that this codicil was finally executed. Mr. Lord, observing that this new arrangement of the property would place Mr. Daniel Parish in an awkward position as one of the executors, suggested the revocation of his appointment as executor, and of the legacy of $\$ 10,000$ that accompanied it. This suggestion was adopted. At the re-execution of the first codicil, Mr. Lord was told by Mrs. Parish that Mr. Parish wished to revoke the legacies to his nephews and nieces; but he says (although Mr. Parish assented to it in the usual way) that he dissuaded her (Wrs. Parish) from pressing it, because it would fatigue and disturb him, and might as well be done at some other time. "In this he (Mr. Parish) acquiesced, with an expression rather of pain or regret." At the making of the third codicil, be- 
tween three or four years after, the same suggestion was made again, and again Mr. Lord dissuaded, telling. Mr. Parish, " that would be harsh."

A careful examination of the circumstances connected with the preparation and execution of these codicils reveals some incidents strikingly incompatible with soundness of mind.

At the execution of the first codicil, and also at its reexecution a few months afterwards, neither the will nor a copy was before them. This, certainly, is not the way such things are usually managed; and it appears still more strange, when we bear in mind that either just before its execution, or between that and the re-execution, Mr. Parish was supposed by those around him to be exceedingly anxious to get possession of his will; yet when the box containing it was placed in his hands, from some unaccountable caprice it was thrown upon the floor, and returned to the bank unopened. Such conduct admits of no other explanation than that of insanity.

The fact, too, that it was left for Mr. Lord to suggest the revocation of the appointment of Daniel Parish as executor, shows a dulness of perception that could hardly have been expected from Henry Parish in the normal condition of his mind.

Then, again, his course respecting the proposed revocation of the legacies to his nephews and nieces deserves attention. At the making of the first codicil he is, apparently, very desirous of revoking these legacies, but is easily diverted from his purpose. Four years after, when he is engaged in making new dispositions of his property (having meanwhile allowed the matter to pass over in silence), he again reverts to it, and is again turned from it by Mr. Lord. Now, all this a perfectly 
sane man might do; but in one of doubtful sanity, and surrounded by those whose interests were advanced by these contested changes in his testamentary dispositions, it certainly has a very suspicious appearance.

Again, it is not denied that every item in these contested codicils originated in the mind of some one else, though sanctioned and adopted ostensibly by him. This, too, might occur with a testator of unimpeachable soundness; but when we bear in mind that Mr. Parish was undeniably unable to communicate his wishes in regard to any person or subject, unless such person or subject were first mentioned to him, then it is obvious that these codicils might have only very partially expressed his will, - namely, just so far only as others chose to help him to express it. True, this may not have vitiated these codicils necessarily; but, under all the circumstances of the case, it must weaken our confidence in his testamentary capacity.

It may be contended perhaps, that, even if a considerable amount of mental impairment were proved, he might still have retained mind enough to constitute what the law regards as a testamentary capacity. What this is exactly, has never been authoritatively decided; but it has been a favorite ductrine of courts, that, in case of mental decrepitude, much less capacity is required to make a will than to make a contract, and that, in the exercise of the testamentary privilege, men's minds are not to be too accurately gauged. As the recognition of a pretty general fact, there can be no objection to the doctrine; but to apply it as a universal rule, without discrimination, would be unphilosophical and unjust.

In a case of admitted mental impairment, where the extent of that impairment is involved in doubt, certain other considerations should have place in deciding upon 
the validity of a testamentary act disputed on the ground of incapacity in the alleged testator. Some wills require more capacity than some contracts; and many a man who might be able to sell houses or lands, with a tolerable understanding of the matter, would be quite incapable of making a proper and judicious distribution of a large estate among a considerable number of relatives, friends, and public institutions. So, too, the same understanding might be adequate to one description of will and not to another. A man having a small estate, and no relatives besides his wife and a single child to leave it to, might be safely trusted to indicate the proportions he would wish them to have, but would be utterly incompetent to devise his property under wholly different circumstances; viz., large and complicated possessions, and a host of relatives with very unequal claims on his bounty. The only practical principle is, sufficient capacity for the occasion; and that implies, in the testator, a memory strong enough to bring before the mind all those who would naturally be remembered on such an occasion, judgment enough to discriminate fairly between their respective claims on his bounty, together with a knowledge of the value of property and the relations of number. And, inasmuch as the moral sentiments are often weakened and perverted by the same disease that enfeebles the intellect, it is also required that his own proper intellectual discernment should appear by affirmative proofs to be unaffected by the direct and special influences of others holding at the time a relation to the individual which made him dependent upon them for everything, especially if such others are wholly or mainly interested in the contested act. That Mr. Parish had not sufficient capacity for the occasion, according to the requirements here 
mentioned, is, I believe, abundantly shown by the facts in evidence, already referred to concerning the testamentary acts and his ordinary mental manifestations.

The conclusion to which I have been led by a careful examination of the evidence in this case, may be expressed in the following propositions:-

In consequence of the apoplectic attack of 1849 , the power of speech was lost and the mind greatly impaired during the rest of his life.

This impairment was sufficient to render him incapable of transactions requiring any exercise of thought.

The codicils in question disposed of large amounts of property in various ways, and required, in a much higher degree than can be supposed to have been present, the exercise of memory, judgment, and discretion, an appreciation of the numerous claims on his bounty, and a knowledge of numbers and quantities.

The mental powers here indicated were not possessed by Mr. Parish subsequent to the attack in July, 1849; and consequently these codicils, so far as they exhibit any of those powers, express, not the will of Mr. Parish, but the will of other persons, and are therefore invalid. 


\section{THE ANGELL WILL CASE.}

[FrEqUENTLY as wills are disputed on the score of mental incompetence, the rules of law by which such cases have been adjudicated present but a small approach to harmony of opinion. Considering the many forms of mental disorder and the imperfect knowledge respecting their effect on the mental operations possessed by those whose duty it is to administer the law, the fact could hardly have been otherwise. Not that legal opinion on this subject is quite so unsettled as it once was; not that some principles may not now be considered as generally received. No court would presume to establish the will of a man who had disinherited children, brothers, or sisters, believing them, as a matter of delusion, to be plotting against his life, or peace of mind, however sensible and prudent be might have been in all other respects. But would the existence of partial insanity in any form whatever be regarded as sufficient ground for invalidating a will which did not recognize some very distant heir-atlaw? In the following case, the reader will observe, a question of this character had to be met; and, though the decision may have been correct, it can hardly be received as a precedent for any other case with conditions not very like its own. Exactly how far in the line of kindred the invalidating effect of delusion may reach, is a point that yet remains to be settled.

Well settled, however, as the doctrine respecting the legal effect of delusion seems to be, there is always manifested, in cases of this kind, a lingering apprehension of its insufficiency, especially if accompanied by indications of mental vigor and clearness in other directions. Hence arises a strong endeavor, as in the case before us, to prove that the disease embraced within the range of its influence other subjects than those directly connected with the will. Although the testatrix was shown to have barbored most gross and persistent 
delusions respecting the designs of her relatives, yet she seemed so correct on many other subjects, and that to a class of persons whose culture and habits of observation gave much weight to their impressions, that it was deemed to be of the highest importance to show that ber insanity was exhibited in regard to other persons and things. And this fact being satisfactorily proved, was, probabiy, no less potent in shaping the verdict of the jury, than the principal delusion itself; though it would have hardly sufficed to set aside a will that made a tolerably natural distribution of property among her relations. However this may be, I think we are warranted, by our present knowledge of the effect of insanity on the mental operations, in adopting the general conclusion of this notice, that, whatever may be the mental condition of the testator in other respects, the testamentary capacity should be denied, when disease of any grade or form has been allowed to obtrude its shadow between the mind of the testator and the natural objects of his bounty.

Another point of great medieo-legal importanee, illustrated in this case, is the essential psychological distinction between mistake and delusion. The will was impugned on the ground of delusions entertained by the testatrix respecting the designs of her relatives, who had been engaged, for more than one generation, as she supposed, in defrauding her of her property and making attempts on her life. To overthrow this position, it was ingeniously alleged that all the notions cited as indications of a disordered mind were fairly deduced from a very natural mistake respecting the meaning of certain expressions contained in some old letters of her uncle. Other persons, it was said, would have adopted the same construction; moreover, an effort was made to establish the facts as she understood them. This argument was well calculated to effect its purpose with men who had never given a thought to such subjects, or who would have been not much wiser if they had; but it has no support in our knowledge of insanity, or the facts of the case. A mistake respecting a state of facts will always be admitted by a sane person, upon adequate prouf of error. The false belief of the insane, call it mistake or delusion, is never relinquished. No array of proof, no force of argument, even by those in whom they always had the fullest confidence, can make the slightest impression. On the contrary, they cling to their belief all the more firmly, the stronger the reasons offered against it. Such was the case with this lady, who steadily resisted to the last, proofs of her mistake, if so it may be called, that would have been all-powerful with any sane mind. In fact, however, 
she had contracted this belief in the evil designs of her relatives long before she met those old letters. They only made it a little more circumstantial.]

To the medical jurist, no class of cases can be more interesting than that of wills involving questions of mental condition. In the litigation of a will, a wider range of inquiry is opened, a larger variety of relations is exposed, than is permitted or required in that of a crime or a contract. The investigation may extend over a lifetime, and be pushed into the inmost recesses of the imner life. In no class of cases is there more needed a familiar acquaintance with the operations of the mind, sound as well as unsound, in order to reconcile seeming discrepancies of testimony; an extensive observation, to show the full significance of many a trait; and the tact, springing from long experience and sagacity, that can enable one to appreciate the nicer affections of mental competence that result from cerebral disturbance. In the following account of a will-case recently tried in Providence, the psychologist will see a curious exhibition of mental obliquities extending over the greater part of a long life, the jurist will see some old principles under new phases, and the general reader will be struck by many an incident which gives to the narrative an air of the strange and marvellous.

In the year 1780, Joseph Angell was married to Desire Hopkins, daughter of that Commodore Hopkins who, in the Revolutionary war, dealt the first successful blow at the enemy on the water. The match was not a happy one. The husband proved improvident and dissipated, left his family some seven or eight years after the marriage, and went to Maryland, where he engaged in teaching school. Their only child was a daughter, Eliza, the 
testatrix in this case, born in 1783. In 1790 , the deserted wife, receiving neither aid nor comfort from her spouse, obtained a divorce, and in 1793 married Samuel Leonard, a prosperous widower, residing in Taunton, Mass., with three children by a former wife. By the last marriage there were two children, both of whom survived to adult age, Samuel and John B. The advent of the bride and her child into the family of her second husband was not followed by the utmost harmony, and some hard feeling apparently existed between the Angells and Leonards from the beginning to the end. In 1807, Mr. L. died, and in 1820 the widow with her own children moved back to Proridence. Two years afterwards, they came into possession of the Commodore Hopkins estate in North Providence, and there they resided ever after. In 1834, Samuel died; in 1843, the mother; in Narch, 1853, John; and on the 12th of October, 1860 , the testatrix.

In 1846 , both $J_{0 h}$ and his sister made their wills, in which they bequeathed their property to each other. After the death of $J o h n$, she was in possession of two considerable estates, one in Taunton, derived from her step-father, consisting of stores, and some land eligible for building in the outskirts of the town; and one in North Providence, consisting of the old homestead, a few tenements, a mill-privilege, and some 230 acres of unoccupied land, mostly suitable for building-lots. The former estate was taxed, when her will was made, at $\$ 30$,000 , and the latter at $\$ 75,000$.

On the 25th of April, 1854, this lady executed her will, the validity of which is now contested. In this will she gives an annuity of $\$ 100$ to one of her poor relations, who died before her; an annuity of $\$ 600$ to a cousin residing in South Carolina, and when she dies an 
annuity of $\$ 300$ to each of her daughters while they remain single; some gold watches which had belonged to her step-father, and a few other personal effects, such as pistols, rings, sleeve-buttons, to his grandchildren; and directs her executor to appropriate to each of her step-father's two sons as much as he may deem necessary to make them comfortable, the amount not to exceed $\$ 40$ per month. In no other particular does she recognize the existence of relations. She gives to the town of North Providence a lot for a town-house, with certain conditions, winch the town did not choose to accept. With these exceptions, all her property is given, in trust, to Rev. Dr. Wayland, late President of Brown University, Rev. Dr. Caswell, Professor in the same, and Rev. Dr. Granger, then minister of the First Baptist Church, and their successors, to be devoted by them to the erection of two Baptist Churches with parsonages attached, and to the support of a minister in each. One is to be on her estate in Taunton, the other on her estate in North Providence, both " to be built of stone of suitable dimensions," in "a plain and substantial manner." In order to build and support the former church, she devotes one of the Taunton estates, called the Barney farm, to be let, mortgaged, or sold, as the trustees may deem best. To build and support the latter, she derotes all the rest of her property, after all charges upon the estate are paid. If the "rents, profits, and proceeds" thereof "are not sufficient within a reasonable time to pay for the building of said last mentioned church and parsonage," then the trustees are directed to sell as much of her Taunton estate as may be necessary for this purpose. In no event, however, is any of the North Providence property to be sold. These objects being accomplished, the trustees are directed to divide the residue of the "rents, 
income, and profits" into three equal parts, one to be appropriated by them to "the support and education of the children, male and female, of orthodox Baptist ministers," one to "the support and education of the children, male and female, of orthodox Baptist missionaries," and the other to "the support and education of young men who are candidates for and intend to become ministers of the orthodox Baptist Church." The trustees are to appoint their successors, and to appropriate from the funds of the estate "a reasonable compensation for their services."

On the 9 th of July, 1855 , she executed a codicil in which she bequeaths to the American Colonization Society "all estates and property of every kind and nature whatsoever, which may come to me directly by descent or devise from my father, Joseph Angell, deceased, whether the same be situated in the State of Virginia or elsewhere."

This will was admitted to probate by the Probate Court, from which decision the heirs-at-law appealed to the Supreme Judicial Court. The case was tried in April, 1862, but the jury did not agree. The second trial in November next was followed by the same result; but on the third, in May of the next year, the jury returned a verdict setting aside the will on the ground of insanity. The trials were all of unprecedented length, the longest occupying five weeks. In the matter of evidence, the trials were but a repetition of each other, certainly, in every essential point; and therefore, in making up this account, there seemed to be no impropriety in using the evidence, without referring precisely to the trial in which it appeared.

The first trial was before Chief Justice Ames; the second, before Mr. Justice Brayton; the last, before Mr. 
Justice Bullock. Counsel for the appellants, Blake, Matthewson, B. N. Lapham, C. M. Smith; for the appellees, Curry, C. I. Reed, of Taunton, W. H. Potter.

The testimony of the appellants disclosed many indications of mental disorder, the most prominent of which was the belief, without proof and against proof, that her father, who died within a few years after he left Providence, having married a widow supposed to be wealthy, a few months before his death, had left her a large estate, but of which her uncles, then living in Baltimore, had somehow got possession, and transmitted to their children. This belief she entertained during at least the last twenty years of her life. Against the children of these uncles, - persons of the highest respectability, whom she was in the habit of meeting frequently, and some of them familiarly, - she made it a theme of bitter reproach that they were living in ease and luxury on property that had been stolen from her. Whenever one of them showed signs of prosperity, whether it was in building a block of stores, in putting children to school, or furnishing a house, she declared it was derived from her property. When one of them went South in the way of business, she declared it was for the purpose of visiting those plantations which rightfully belonged to her. All this she believed without a tittle of proof that her father left a single dollar behind him for her or anybody else. For a part of the time, at least, she had abundant proof that he died poor, and that the widow whom he married was almost as poor as he.

She also believed that her relations hated her, and had attempted, in various ways, to annoy and wrong her; and this belief she expressed to visitors, to servants, to chance acquaintances, and to her relations themselves, sometimes talking about it for hours together. No 
general expression can convey an adequate idea of the intensity of this feeling, and therefore we are obliged to refer particularly to statements made by witnesses, though these must be only a selection from a multitude like them. Several of her relations, who were in habits of familiar intercourse with her for many years, declared that she frequently spoke of the wrongs and insults she had received from her relations. One, whose acquaintance with her was very intimate, said she was never with her an hour without hearing something from her on this subject. The same kind of discourse was held to other relatives; her charges of wrong-doing often being made against the parents, brothers, or sisters of the person she was addressing. A witness who rented a mill belonging to her brother, and who, in consequence, was in the habit of going to the house, and thus seeing her frequently, for seventeen years, said that the treatment she received from her relations was, from the beginning to the end, her constant theme, not dropped even on the evening when her brother was drawing his last breath in an adjacent room. A neighbor, whose acquaint. ance with her was still longer, said she was always imputing bad designs to her relations, and he never knew her to speak otherwise. Another, an eminent lawyer, whose acquaintance with her was chiefly confined to several visits he made her, some for the purpose of inducing her to make an exchange of land, which would be for their mutual benefit, and some for the purpose of persuading her to join him in a gift of land (their estates being contiguous) to an orphan asylum, the friends of which were seeking a site, said she would constantly fly from the subject and talk against her relatives, so that he was unable to accomplish any thing. To the switchman at the station near her house, and a 
mechanic who rented one of her tenements, the shameful treatment she received from her relatives was the burlen of her story. The wrongs and wrongful designs which she imputed to them were cheating her out of her property, treating her or her brother discourteously, and making various attempts upon her own and her mother's life by poisoning or shooting.

That she was treated improperly by the sons of her step-father, is not impossible, though there was no evidence of it, and thus she may have had good reason for hating them very cordially. With this possible exception, she seems to have been treated by her relations respectfully, honorably, and courteously, and often with great forbearance. Her feelings towards the descendants of those uncles who defrauded her, as she believed, were attributable, of course, to this delusion, one part of which was that these descendants were enjoying what they knew to be the fruits of iniquity. Towards some others, her feelings must have sprung solely from morbid suspicion and distrust. Certainly, many of them had nothing to do with her father's property.

As might have been expected, these delusions, existing, as they did, for many years, were accompanied by various other mental manifestations such as are frequently observed in the insane, and are more or less characteristic of insanity. The most prominent were suspicions, if not fixed belief, of wrong-doing or wrongintending, on the part of those with whom she was conversant, or who had been connected with her affairs. So many instances of this feeling appeared in evidence, that our limits oblige us to make a selection, and that very limited. She declared that she had never received in full her share of her paternal grandfather's estate, charging the executor of his will, Moses Brown-a 
man distinguished in his day, as she well knew, for uprightness - with fraudulent practices in the settlement of the estate; and this not only without proof, but against proof. She also declared that she never received her share of her maternal grandfather's estate. She always believed that her step-father had been grossly defrauded by his clerks, - men who for many years afterwards enjoyed an unsullied reputation in the very community where all the parties were well known, who had made fortunes out of the estate. One of her neighbors, a gentleman of the highest respectability, she charged with unfairness in running the line between their respective lots. A Bleachery Company which had hired land of her she charged wrongfully with fencing in more land than they were entitled to, and with laying pipes to take water from her springs. So strongly had this last notion taken possession of her mind, that she directed her servants to dig down and cut off the pipes where there was no indication of the ground having been disturbed for many years. When she saw the railway people repairing the line fence, she would charge them with moving the fence in upon her land, and sometimes even when they were at work on the track, and not on the fence at all. She told one witness that everybody wanted to rob her, except her milkman. In talking with another about a suitable person to manage her affairs, after her brother's death, she said she could trust nobody. At one period she was in the habit of locking her servants in their rooms at night. Once, on going to bed, she found a window open which she had directed a servant to close, and declared it was left open purposely to let in her relatives. She said the same respecting an outside door she once found open in the morning. Coming home late one evening she found 
her gate locked, according to her own direction, and afterwards recorded in her diary her conviction that it was done purposely to annoy her. In her diary she writes, "My poor cat has been missing ever since last Tuesday, killed because my cut, I suppose. She is all I had left of former days." She thought it strange that a certain one of her relatives, a young woman who frequently stayed with her several days together, should express a desire to be rich, and said she felt afraid of her. During the latter years of her life she manifested great distrust of her servants. She said they always wanted to rob her. Three of them stated that it was her practice to lock them up in their rooms over night. Having disagreed with the man who had taken charge of her place, and dissolved the engagement, she sat up a part, if not the whole, of the night before he went away, apprehending harm. When it was suggested to her that she should have a man sleeping in the house, she replied that she would feel safer alone. A witness stated that during a visit of a few weeks which she made her, it was her practice to close the shutters before the lamps were lighted. She stopped her paper, the Christian Watchman, the organ of the Baptists in New England, because they charged her fifty cents more than any other subscriber; and she pronounced it a cheating concern. Within a year or two of her death, a couple of ladies, one of them a distant connection of the family, called on her and were courteously received. The conversation having turned on her lonely situation, they asked if she was not afraid of being molested. She replied that she had nothing to tempt burglars; when they asked if she had none of the Leonard plate in the house. Her whole manner changed instantly, and she told them, with some warmth, that if they had no better purpose in calling 
than to try to find out how much plate she had, they had better go along, as they•did immediately.

Intimately connected with this spirit of suspicion and distrust, was a disposition to charge the people around her with stealing and injuring her property. With others thus charged, was one extensively known, and regarded as preëminently honest and just, - a leading. member and preacher of the Society of Friends. He had hired her place, and had much occasion, of course, to handle her property. Him she charged with stealing her asparagus, currant-bushes, strawberry-plants, lilacs, loam, and some planks for firewood. Another, who had hired the place, she charged with stealing wood, tearing up the barn-floor, pushing down five or six rods of fence, and not feeding the cow. She also said he stole her key and filled the key-holes with sand. She charged the man who milked her cow with taking more than his share. Being unable to find some papers which had been in her possession, she declared they were stolen, though they were afterwards found in the hands of her lawyer, where she had placed them herself, or some one on her behalf. One of her poor relations, whom she was in the habit for years of sending for in all domestic straits, she charged with dishonesty. To one witness she declared she could keep no food in the house, because the servants stole it, and said that one of them stole her sheets and cut them up into night-clothes with an axe, on the barn-floor. Two of her servants testified that she charged them with stealing, and examined their clothes when they left. Her neighbors she charged with stealing her chickens, and taking boards and shingles from her barn.

The idea of being poisoned seems to have been very familiar to her mind. She often stated that, when they 
lived in Taunton, the children of her step-father by his first wife poisoned the well and the coffee, and placed on the window-sill and other parts of the house a white powder, which she believed to be poison. She also charged them with attempting to get rid of their young half-brothers (children of her mother), by offering them hot punch in which poison was put. John, she said, did not drink it; but Sam did, was very ill, and died in consequence some twenty-five years afterwards. Among the witnesses were many relatives, and they all concurred in the statement that she never ate or drank in the houses of her relatives, and that when she accompanied them on excursions she would never partake of the refreshments they carried with them. The reason she gare for it was, that she was afraid of being poisoned. The same apprehensions were manifested in regard to her house-servants, and the people whom she employed to manage her place. She refused to eat some sweet corn which one of the latter sent her, saying she would eat nothing he might send, adding that she once drank some cider he sent in, and was made sick by it. She suspected, if she did not really believe, that her well had been poisoned by the Quaker preacher then living on the place. She was in the habit, at one time, of locking up her coffee-pot over night, for fear of her servants poisoning it at the instigation of her relatives. The same relative who frightened her by expressing a desire to be rich, she suspected of poisoning the food. A roman, who had been employed by her as a servant for a little while, subsequently came to draw water from her well. She imbibed the notion that this woman came for the purpose of poisoning the water, and so strong was this belief, that within twenty hours of her death, when prostrated by a shock of paralysis and 
unable to articulate, she wrote on a slate, "woman came to draw water," alluding to a statement she had previously made to the witness, that Mrs. P. had come to draw water and had poisoned the well.

Several instances of that kind of fancied insult so characteristic of the insane appeared in evidence. She said that one day, when approaching the house of her cousins, the Misses G., with whom she had been for some years on friendly terms, some one came to the window and shut the blinds. This she considered a deliberate insult, and never entered the house again for the rest of her life, - nearly twenty-five years. Once the wife of another cousin grossly insulted her, she said, by a look, - "such a look as she should not forget to the last day of her life." In both cases the strongest disclaimers were made of any wish or thought to insult her, but without affecting her belief.

One instance, at least, was related of that disregard of moral propriety not unfrequently observed in the insane, even those who, to the casual observer, seem to retain their sense of moral obligation. Once, a year or two before her death, she engaged a man to watch her grounds by night, and when about proceeding to his duty put into his hands two pistols, and charged him to shoot down the first person or beast that came on the grounds, - she would hold him harmless. He of course declined the duty.

Several instances were related of that common trait of insanity, - the inability to appreciate the true relation between means and end. A witness, whose duties made him acquainted with the sick and destitute in her part of the town, was requested by her to bring such cases to her knowledge, that she might send them something. A suitable case occurring, - that of a poor woman 
in the last stage of consumption, with a couple of children who could not attend the Sunday school for want of clothes, - he told her of it, reminding her of the request she had made. On leaving, she handed him something wrapped in a bit of rag, which was found to be five little pickled cucumbers. At another time she sent by her servant four cold potatoes to a woman in consumption. Living in a district supposed to be rather lawless, she naturally thought of protecting herself by means of fire-arms; but instead of keeping a single reliable weapon within reach, as sane people would, she was in the habit, for several weeks at least towards the close of her life, of sleeping with a six-barrel revolver under her pillow, an old horse pistol on each side of the bed, and another at the foot of the bed, - an arrangement far more likely to harm herself than anybody else. And these pistols she insisted on having reloaded every four or five weeks, though assured by the gunsmith repeatedly that it was unnecessary to have it done so often.

The idea of shooting or being shot not unfrequently occupied her mind, from an early period. She once brought a pistol to a female friend and endeavored to persuade her to learn to use it, and once fired a pistol out of the window, as she said, at some fancied intruder. A story she often told was, that on a journey to South Carolina, in early life, she observed on board the steamer a man who watched her and kept near her for several days, until, his coat blowing open, she caught sight of a pistol sticking out of his pocket, when she got frightened and went below. This man she believed to be Commodore Barney, a relative, whose nepherws were claimants, with herself and many others, of an English estate then in Chancery, who designed to shoot 
her in order to better the claim of his nephews. During the last fifteen or twenty years of her life, she was fond of telling a story of a man coming to her door and snapping a pistol at her as she opened it. This story was told with many variations. Sometimes it was a man whom she had seen for several days loitering near the house, and sometimes it was a horseman. Sometimes it was a servant and sometimes herself that went to the door. Sometimes he only presented his pistol, when she said she also had a pistol, and turned to get it, when he was scared and went off. At first she did not pretend to know who it was, but latterly she always said it was the son of one of her cousins, instigated by other relatives to put her out of the way.

There was much evidence proving that fickleness of purpose so common with the insane. The people whom she employed in one way or another spoke much of this troublesome trait. Once she engaged a man to take the wood from a certain lot at a stated price per acre; but when he had nearly finished she forbade his cutting. more, or carrying away what remained on the ground. He agreed to this, on being paid for what he had cut. Afterward she got him to take away what he had cut, though at a quarter of a dollar less than by the terms of the original contract. Another was engaged to clear up a piece of swamp covered with a growth of brush and small trees, all of which he was to have for his labor. He went to work, but before he had got to that part which would afford any remuneration for his pains she stopped him and gave the job to another. Thinking a brood of newly hatched chickens would suffer from the rain, she had them taken from the hen and put into the kitchen sink. Soon, however, she imagined they would suffer from the heat indoors, and had them taken back 
to the hen. Again she changed her mind, and directed them to be brought back to the kitchen. Exactly how many times the change was made the witness could not say. The same trait was exhibited in regard to the work of her domestic servants, several of whom testified that she frequently changed their work without any reason.

Some of the reasons which she gave for her belief in the great Virginia estate are strikingly illustrative of the ways of the insane mind. She said that when a young girl she occasionally met in the street a servant woman who would exclaim when passing, "Poor child! what a pity she could not have her rights;" that a lawyer once said, alluding to her claims on the English property, that if she wanted property she could find it nearer home than England; that a relative of hers, one of the Angell family, once came to her greatly exercised about a question of conscience, - viz., whether, if she knew of property in the hands of persons that had no right to it, it would be her duty to disclose it, and thus bring disgrace on near relatives, such as a father or mother, or a friend; that once her uncle Thomas began to talk to her about property, saying that he knew of her having property in the hands of some persons from whom she could not obtain it, and when he had thus excited her suspicions she questioned him further, but his mouth was shut. Whether all or any of these incidents ever occurred as related, or were magnified out of some trivial expressions, of course we have no means of knowing. It is not improbable that they were all the mere coinage of a distempered mind.

Some facts in her domestic management might be paralleled in that of many an insane person. A cousin, accompanied by her husband, made her a visit and spent 
the night, Miss A. lighting them upstairs, putting them into different rooms, and locking the doors. Many years after, this same cousin called upon her about eleven o'clock, but found her just ready to go into town. Miss A. invited her to stay until she returned, directing another cousin then staying with her not to get dinner in the mean time. Late in the evening she made her appearance, seemed surprised to find her cousin there, and invited her very plainly to find a lodging somewhere else. She refused to leave the house at that late hour, and was sent off to bed in the dark, without dinner or supper. At breakfast next morning they had nothing to eat but rye-and-indian cake, and a very small bit of butter. Another, who resided in Maine, in the course of a visit to Providence was invited to dine with her, and she found the dinner scanty and the table-cloth ragged. A servant stated that, there being only three in the house, she bought at one time fifty scup, half a dozen of which would have been an ample dinner for them all. At another she bought a large turkey, and at another a large goose, both of which spoiled before they were half eaten. One witness spoke of her getting a quarter of veal, and at another time a side of pork, all of which, except a part of the pork which was salted, spoiled before they attempted to eat it. Two or three witnesses saw her getting breakfast by a fire of green wood.

Several witnesses testified to that disregard of little proprieties and observances which is so common with the insane. She would express her sentiments respecting her relatives, not only to those who would naturally be interested in them, but to her servants, and to people but little known to her, and often, during one winter at least, at the table of a public boarding-house. A witness once saw her near her mill-dam - about half a mile from 
her house - with a calash on her head and flour on her black dress, looking "dirty and miserable," with a troop of boys teasing her. The same witness once saw her, when chasing some cows, dash through a pool of water that lay between them. Another once found her in high altercation with her farmer, her hair down and dress open; and he led her away into the house. Another spoke of finding her in the road near her house, with her head bare, hair flying in all directions, and no shawl on.

There seems to have been occasionally a failure of the perceptive power, not so much indicative of mania as of impending trouble in the brain. One of her tenants said that, having paid his quarter's rent on one occasion, he recollected, a moment or two after leaving the house, that he had omitted speaking about some repairs, and returned for that purpose. Scarcely three minutes had elapsed; but she did not recognize him, and he found it difficult to make her understand who he was. Subsequently she mistook him for the carpenter who shingled her house, and complained that he had done the work badly. He explained, but she repeated the mistake several times afterwards. Once, having engaged a man to cut some hay, she came down in the course of the day to see how the work was going on. The switchman, whose station was near by, said he walked towards her, and that they met but a few steps from the workmen, she crying out, "What are they doing? Why, they are ploughing up my meadow. What shall I do?" He told her that they were only raking up the hay with a horserake, and it was all right. She kept on crying out, "What shall I do? They are ploughing up my meadow," and rushed into the field and ordered the people to stop. They gave no heed to her, and she started towards the city, saying she would tell Judge S. The witness 
said she was not more than twenty feet from the horserake.

Twice there seem to have been hallucinations, within the last year or two of her life. Once she said she had smelt chloroform three nights in succession, but it was proved that there was none in the house. Shortly before her death she awoke in the middle of the night, and, as she stated, found Mrs. P. - the woman who poisoned the well - standing over her.

She manifested much of that curious inconsistency which constitutes so common and so remarkable a feature of insanity. Among the friends and associates of her brother was her cousin, W.M. B. They were much together, and every day interchanging tokens of kindness and good will. On his death-bed the brother took his friend by the hand, the sister standing by, and asked him, as his last request, if he would continue to do for her as he had for him. For seven years he continued to visit her almost daily, and perform for her some little offices of kindness or care. He settled difficulties with her servants and tenants, renewed insurance on her tenements, and often paid the premium himself to save her the trouble, lent her money, advised her in the management of her affairs, and by countless services of this kind endeavored to redeem the promise made to her brother. And yet, a year or two before she died, she declared to one of her fellow-boarders that W.M.B. would as lief murder her as not, and had instigated a man to come to her house and shoot her. Once, at her own request, W. M. B. engaged a woman to go to the house and render such services as she could. This she did for several weeks, being treated by Miss A. courteously and confidentially. Yet to this very woman she said that W. M. B. visited her as a spy, and was at 
the head of the conspiracy against her. After urgently inviting Mrs. K., the mother of W. M. B., to visit her according to her usual custom, when she came to town, she said that Mrs. K. came as a spy for the Gs. Her rehement desire to see the churches built in her own lifetime, and the utter uselessness of her land, except to be sold, were sufficient reasons to induce her to advertise the land as she did, and to sell at a fair price, as she did not. She was never willing to set her price, and persons desirous of buying went away convinced that she did not wish to sell. Fair prices were offered, and those in whom she had most confidence advised her to accept the offers; but, with one or two trifling exceptions, she sold no land in North Providence. She gare as a reason for refusing to name her price that the assessors would hear of it, and the next year they would increase her taxes.

Of all the fancies which this woman adopted, it did not appear in evidence that she ever relinquished one to the weight of the most abundant proof. Many instances, on the contrary, appeared of her persisting to believe them as veritable truths, in spite of proofs sufficient to convince any sane mind. The dying request of her brother to W. II. B. has been already noticed. Shortly after that scene, she reported that this gentleman refused to assent to this request; and though he assured her she was mistaken, and offered in proof of it the attentions and services he had since rendered, yet she was unconvinced, and continued to circulate the report. She believed that this gentleman must have obtained some of her Virginia property, on the ground that he could not otherwise have built a block of stores and done some other things; and though he explained to her the origin of all his property, she was unconvinced. His mother, 
too, she believed to be indulging in a style of living which her husband's salary, as a college professor, could not support, and therefore she must be enjoying: her Virginia property. The amplest proof failed to disabuse her of a notion which was founded on mere rumor, for she had never been in this lady's house. The same sort of charges were made against his brother, then a professor at West Point, on the same sort of foundation, and with the same resistance to proof. She harped upon certain furniture which W. G. had sent from Baltimore to this gentleman's grandfather; and though he showed her the original account of his grandfather as trustee of W. G.'s wife, in which he had credited himself with this furniture, she was faithless, and continued to believe as firmly as ever that the old carpet and andirons were part of the spoil of her father's estate. And so with her belief that she had been wronged in the settlement of her grandfather A.'s estate. To her he bequeathed two hundred silver dollars; but the executors, for good and sufficient reasons, which were approved at the time by her uncles and aunts, set off to her a certain lot of land in lieu of the dollars. When the formal statement of the executors, which had been put on record, was shown to her, as well as an extract from their accounts explaining fully the transaction, she coolly replied that she knew all that before, and kept on saying to the last year of her life that she had been wronged in the settlement of her grandfather A.'s estate by Moses Brown, whose name, long after his death, was a synonyme for all manner of uprightness in this community. A year or two before she died she sent for a neighbor, J. W., to come and cut up an appletree which she said G. - the man who had hired her place for the year - had cut down with the intention of 
carrying away. He assured her that the tree had blown down, and that any one could see that it had rotted off nearly, and showed no marks of an axe. Another person, besides G. himself, said the same. But she insisted on having the tree cut up and put into the cellar, and when the door was shut and locked she exclaimed, "I guess G. can't get it now," and continued to tell the story of G.'s cutting down her apple-tree.

At last, on the 11th of October, 1860, this lady was struck down by that common sequel of chronic insanity - paralysis - which finished her life the next day.

The testimony disclosed many other indications of mental obliquity sufficient to swell this article to the dimensions of a volume. It was necessary to make a selection, and though the most prominent ones have been taken, yet many others, less striking to the casual observer, are not less significant to those conversant with mental disease. In stating the above facts, it has been my endeavor to adhere strictly to the evidence, its letter as well as its spirit, - avoiding every word or turn of expression which would tend to give it a higher coloring than the exact words of the witness would bear.

All the testimony was carefully heard on the first trial, by the writer, and on the second trial by him and by Dr. Tyler, of the McLean Asylum, while on the third it was heard only by the writer; and they unhesitatingly expressed the opinion that the testatrix was insane when she made the will and codicils. By them the belief that her relatives hated her and were ready to annoy and wrong her, and the belief that her father left her a large estate in Virginia of which her relations had defrauded her, were regarded as pure delusions, which, in connection with the suspicions, the notion of being poisoned, the indiscriminate charges of stealing, the 
breaches of propriety, the insensibility to argument, the fancied insults, the hallucinations, \&c., constituted an actual case of insanity, presenting nothing strange or extraordinary, as compared with the usual exhibitions of the disease.

To meet this clear and abundant proof of insanity, the other side produced many witnesses from various walks of life, who, on the strength of more or less intercourse with the testatrix, declared that they saw nothing strange or unusual in her conduct or conversation. They contended that the will was a rational act, rationally done; and endeavored to show that her notions respecting her relatives, her Virginia property, and some other fancies, had some foundation in fact, sufficient for a credulous, suspicious mind, and therefore could be justly regarded as mistakes, not delusions. The weakness of these several positions will be made apparent by a little examination of the evidence, and of the phenomena of insanity.

A lawyer wrote her will; another was her adviser and friend, from the death of her brother to her own; two or three physicians had casually met her, one at her house, on the occasion of the sickness of some member of the family, and another, as well as an ex-judge of the Supreme Court, in the parlor of a Saratoga hotel; several clergymen had conferred with her on the subject of missionary efforts, of plans for the religious teaching of the people in her neighborhood, and of contributions to a fund for educating young men; charitable and religious men sometimes found her zealous and liberal when appealed to for aid and coöperation; a dealer in real estate conversed with her about selling her land; a grocer sold her groceries, and a bookseller books, and she paid them promptly; and finally, passing by others whose acquaintance with her was very casual 
a gentleman whose long and honorable career as a leading minister in his denomination, as the president of a college, and a writer on education and mental science, have made his name familiar as household words, was intimately acquainted with her for many years, and conceived a high regard and respect for her, - these persons, one and all, declared that they never saw anything "strange or unusual in her conduct or conversation, dress or demeanor." To those practically conversant with the insane, it would be a waste of words to prove that such a fact is not incompatible with the existence of insanity. Having her delusions somewhat under her control, it is not strange that she refrained from introducing them when in the company of certain persons, especially those whose position would naturally forbid discourse of any kind on family difficulties. It was in the retirement of home, in the abandon of familiar intercourse with servants, relatives, and neighbors, that she would chiefly give vent to her belief and her feelings respecting her relatives and their unprincipled conduct. Occasionally, however, as the evidence shows, the proprieties of place and person were disregarded, and her complaints were poured into the ears of a very different class of people. In fact, the gentleman last referred to, and two or three others who came to the same conclusion, admitted that she spoke to them harshly about her relations, but that they, feeling no interest in the subject, paid but little attention to what she said. If they had encouraged her to go on, they might possibly have observed something strange or unusual in her conversation. That she had some self-control is obvious from the fact stated by many witnesses, that, when talking with them on her favorite theme, she would stop the moment her brother John made his appearance, because 
she knew such talk annoyed him exceedingly, he having. no faith in her fancies, as he called them. Neither was her interest in religious enterprises, nor the character of her own religious sentiments, incompatible with the existence of delusion; for if correct and clear on any subject, as she might be in the form of insanity alleged, it is not surprising that she was so in regard to them.

To meet directly the evidence which seemed to establish the existence of insanity beyond a doubt, the attempt was made to explain some of the facts so as to make them not incompatible with perfect sanity. Her feelings towards her step-father's family, it is said, were justified by their treatment of herself and mother. That she might have been treated coldly, even discourteously, by the older children, is not unlikely, though, as already said, there was no evidence of the fact. It would not have been a very strange or extraordinary event; nor would it have been surprising had she spoken unkindly of them and avoided all intercourse, for such would have been the course of an aggrieved but rational mind. In the true spirit of insanity, however, without the slightest color of proof, and against all reasonable supposition, she persists through her whole life in charging them with various attempts to kill her by poisoning the well, by poisoning the food, and by putting poison about the house; in charging them with actually poisoning one brother and intending to poison the other. Between the alleged fact that they treated her disrespectfully and her conclusion that they meant to take her life, there is all the interval that separates sanity from insanity. To other relations she attributed the same designs, though there was not a tittle of evidence to show unkind feelings or improper conduct towards her. Some were poor and dependent, coming and going at her call; others had a 
reputation in the community which should have placed them beyond suspicion, and all without exception treating her courteously and kindly. In regard to one family she offered a reason for her dislike, - a reason which had no other foundation than her own disordered im. agination.

The other main delusion - that of having inherited from her father a large property in Virginia, of which she had been defrauded by her uncles and their descendants - had a reasonable foundation, it was contended, in actual facts. In order to make this explanation intelligible, it will be necessary to state some facts connected with this delusion. In 1796, a letter was received in Providence from her uncle James, then living in Baltimore, in which he speaks, among other things, of his brother Joseph, father of the testatrix, "who died," he says, "(or rather, I am inclined to think from reports, was poisoned by his wife), near Moorfield, in Virginia, a few months since." In a postscript he returns to the matter: "Joseph," he says, "had married a widow in Virginia, possessed of an estate worth a considerable sum of money, which she held in her own possession at the death of her former husband, subject to her control. From what I can learn, there were marriage articles (or something like it) between them. He desired on his death-bed (so report says) that his body might be opened, as he suspected foul play. The corpse was in consequence arrested on its way to the place of burial; and no person appearing to push the business, supposing he had not a relative in America, it was interred without inspection, nor but for that circumstance should I have ever heard of it. I have, however, engaged a friend who lives in Moorfield to procure a copy of the agreement (will, if there is any), and from whom I soon ex- 
pect to hear. That there is property there that his heirs will inherit, I have no doubt; but whether it will fall to me as elder brother, I cannot say."

The contents of this letter became known, no doubt, to the testatrix and her mother. The latter, naturally enough, would not care to cherish the memory of her divorced husband; and the former, then but thirteen years old, would scarcely remember all the particulars of this letter. At a later period of life, she became desirous of knowing the exact circumstances of her father's death. Whether this letter was in existence, she knew not, nor where to seek for information about it.

In 1836 she ascertained that one of her relatives had in his possession many old family letters and other papers, and at her request they were given to her. Among them she found about a dozen letters written from Baltimore in 1792 , by her uncle W. G., to another uncle, J. W., then in Providence. The burden of these letters is, that he is trying to settle his business and go to the north; that he wants his brother-in-law to buy him a farm and provide stock, carriages, seeds, \&c. In almost every letter he speaks of having in his hands funds belonging to "Eliza," which he is desirous of investing in comnection with his own, or in a separate property. In one of them he says: "I have a small sum of money, the property of Eliza (which is accumulating, though it is lying idle), that I wish to make the foundation of a purchase for her, that will be productive now, secure the money, and facilitate my plans. If any advantageous small spec can be made for her, I should be glad." In a previous letter, he says: "If the Colonel will sell his contiguous land reasonable, I would endeavor to purchase it for Eliza. . . . You must know I can devote this money to no other use than purchasing property for 
Eliza, as her funds must pay for the land." This is a fair specimen of the references to Eliza in these letters. Had she seen no more, she might have had ground for a faint suspicion that she was the person referred to, and consequently that her father, who, she knew, did actually die about that time, had already deceased and left to her a trifle of property, which, by some means or other, had come into the possession of her uncle. But these very letters contained unequivocal evidence that the facts she suspected were, some of them false, and others impossible. In one of them her uncle speaks of making this investment "for a little daughter," and she might have known, had she inquired, that he had a daughter named Ann Eliza. Indeed, that fact appears in one of the letters. More than this, she found in them mention of her own father as then living. Mr. G. says: "I have just received intelligence from Berkely that $J_{\text {oseph }}$ [her father] keeps school, and behaves soberly and discreetly. He has twenty scholars, and appears and acts reputably. God grant it may last." Subsequently, his wife says, in a letter to Mrs. W.: "Brother Joseph has established a school of twenty scholars, and attends it with great sobriety and diligence." And thus it was that the casual mention of a family name in connection with money set that disordered chord in vibration; and under its influence, without proof and against proof, in the true spirit of insanity, she arrives at the monstrous conclusion that her father, while yet in the flesh, had died, leaving her a large property which he had acquired by his second marriage; that her uncles had fraudulently got possession of it; that their descendants, though above suspicion in their respective communities, were living upon it, and cognizant of the wrong; and, that they might enjoy undisturbed the fruits of the wrong, 
were instigating attempts upon her life. If this is not delusion, - gross, unequivocal, baseless delusion, - I know not what delusion is.

In 1855 she obtained possession of the original letter of her uncle James, in which he communicated the fact of her father's death, and from that she learned that he died some four or five years subsequent to the writing of those letters in which "Eliza's guineas" are mentioned. Yet not one jot did she relinquish of her faith in that strong belief that her uncles had cheated her out of her father's estate. She proclaimed it far and wide, and triumphantly appealed, for the truth of her story, to these old letters about "Eliza's guineas," written some three or four years before he died, or was even married.

In 1857 she employed the person named as executor of her will to pursue some inquiries into the circumstances of her father's marriage and death, and of the property he left. These inquiries were very satisfactorily answered, and among the papers obtained were copies of the inventories, both of the effects which he left, and of the property which his wife possessed when they were married. From these it appeared that the value of all their possessions, consisting of clothing, household furniture, and stock, amounted to just $£ 99$ $7 s .9 d$. Of a small parcel of land in that region, they had made a conveyance, for a few shillings the acre; but the deed was not perfected. She was now assured by her executor, whose professional and social position warranted the utmost confidence in his judgment, and in whom, in fact, she had placed more confidence than in anybody else, that she had not the shadow of a claim upon any property left by her father, and that she ought to abandon the notion for ever. She did no such thing. She treated these proofs precisely as all insane persons 
treat the proofs of their delusions, - precisely as she had treated the most conclusive proofs of other delusions. She continued to believe in this great Virginia property, and even more earnestly than ever. The testamentary disposition she had made of it two or three years before, she suffered to stand; and once at least, within a few months of her decease, she declared to a witness her conviction that she would finally obtain that property. Up to the very last, she declared to one and another that the children of those uncles were living on her property, and seeking her life. It was never a matter of suspicion or doubt, but always, from first to last, through a series of twenty years or more, a matter of intense, unwavering belief.

In reply to all this, the appellees say that she did not suppose the "Eliza's guineas" to have been a legacy from her father, but money intrusted by her father to her uncle, to be invested for her benefit, but which he appropriated to himself. Believing this, the next step very naturally taken was to believe that, after her father's death, this same uncle had got possession of the large estate which he had bequeathed to her. These two conclusions, they allege, were the result of a highly suspicious, distrustful temper, which, belonging to the natural constitution of her mind, cannot be regarded as an indication of insanity. This explanation scarcely helps them. Were the mental process precisely as they state, it shows a gross suspicion without the slightest foundation in fact, growing out of another suspicion about as baseless as the last. But in neither case was it a mere suspicion. It was a fixed, positive, unwavering belief, maintained to her dying day. After the conclusive evidence obtained by the executor, that her father left her nothing, then certainly her continued belief in 
the great property was undeniably a delusion. It may be justly asked when this notion ceased to be a suspicion, and began to be a delusion. Was it at the very moment when this evidence was placed before her? If so, then it appears that, while the facts in the case were somewhat doubtful and obscure, she merely suspected fraud; but when all doubt was removed, and the fact of her father's poverty conclusively established, she believed it! Of course, long before that time, probably from the very hour when she first read those old letters, she believed it as firmly as she ever did afterward. Unquestionably, a very suspicious person may suspect many very improbable things, with little or no proof; but the moment he believes them he is under a delusion. It is this confounding of two essentially different states of mind, - suspicion and belief, - which makes the explanation of the appellees utterly fallacious.

The attempt was made to explain away other things which were regarded as incidents of insanity. The executor alluded to her refusal to eat at the table of her relations, and remarked that "she was terribly afraid of other people's dirt." This statement, whether it originated with him or her, hardly helps the matter, considering what manner of persons those relations are, and the fact that she often dined at a hotel, and for several summers in succession spent a week or two at Saratoga. She kept pistols in her room, because, it was alleged, she lived in a lawless sort of district, and one or two of her neighbors were put upon the stand to testify that they also kept pistols in the house. This was an evasion of the true issue. It was not the fact of being armed which was regarded as indicative of insanity, but the manner in which this matter was managed. A sane person would have done just what her neighbors did, - put a loaded 
revolver under ber pillow or within reach, and been satisfied. She, on the contrary, makes a perfect arsenal of her room, - a six-barrelled revolver under her head, an old horse-pistol on each side, and another at the foot of the bed, as if this multiplicity of weapons were any better than one! as if they were not more likely to harm herself or her servants than any unwary burglar! And these implements of destruction must be taken to the gunsmith's every four or five weeks, to have the charges drawn and be reloaded. Perhaps there was no single incident of this woman's life more characteristic of insanity than this lack of all true relation between the means and the end of self-protection. Her charges of stealing, so often and so earnestly made against the honest old Quaker who lived a year or two on her place, the same witness accounted for by the fact that the testatrix was opposed to all agricultural improvements, and wanted everything to remain just as it was in her mother's time. He thought differently, and so he scraped the trees, trimmed the currant-bushes, reset the strawberry beds, \&c. She thus lost sight of many familiar objects which she thought must have been stolen. If she really came to her conclusions in this manner, the fact is not very creditable to her sagacity, and it is scarcely conceivable how any sane person could make such a mistake, - to attribute improvements like those to petty larceny. Such a process of thought, however, is very characteristic of insanity. In order to explain away ber belief that her step-father's clerks had defrauded him, it was alleged that such a village rumor prevailed at the time, nearly sixty years ago, and therefore that it was not strange she should entertain the same notion. But this is not sufficient. What was, with others, an idle rumor seriously believed by nobody, was, with her, a 
matter of earnest belief, and repeated to the discredit of persons who, for half a century, in many relations of life, social and business, had maintained an unsullied reputation.

The manner in which she undertakes to accomplish her designs shows no indication of insanity; but one would hardly appeal to it as a proof of a clear and vigorous mind. The greater part of her estate in North Providence consists of unoccupied land, valuable only for building purposes. Situated on the very border of a considerable and growing city, it would naturally be sought, while the abundance of other land similarly situated would prevent it being taken, except in the most satisfactory way. As long as equally eligible land can be obtained by purchase, - and that, to all human foresight, will be for many years to come, - this cannot be leased advantageously, except, perhaps, for a term so long as to practically defeat one of the conditions of the will. Eventually, perhaps, it may become valuable, even for leasing; but between the loss of interest on one side, and taxation upon its market value on the other, its whole worth may have been sunk, long before that time. And yet she refused to sell during her life, while land was up and her neighbors were selling; and in her will forbids the sale of a single acre, even for the accomplishment of her plans. Through all coming time, this estate must remain in the hands of the trustees, who, while invested with unlimited discretion in everything else, are allowed no discretion at all in a matter where they needed it most.

These trustees, too, are not required to give bonds: they are made responsible to nobody, and they are allowed to compensate themselves for their services. Not a single provision is made for preventing an abuse of 
the trust, or stopping it after it may occur. Instead of guarding, in every possible way, against the usual fate of such trusts, - a fate that was most distinctly pointed out to her by her most confidential advisers, - the dispositions of the testatrix would seem to have been made expressly for the purpose of inviting it.

So far, indeed, the will presents no conclusive proof of mental disorder; but the codicil, executed a few months subsequently, reveals a strong, striking delusion, calculated, beyond all others, to annul her testamentary capacity. There, deliberately and solemnly, she puts upon record her belief in that great Virginia property which, she was in the habit of declaring, was left by her father and purloined by her relations. True, at that time, she had probably found the letter of her uncle, giving an account of her father's decease, and expressing the suspicion that he had left property. This might have warranted her even in indulging the same suspicion that her uncle had, sixty years before, and in making it the basis of a testamentary bequest. But not long after, the inquiries of her executor removed every ground of suspicion, and furnished abundant proof that her father left her nothing, because he had nothing to leave. Did she thereupon revoke that codicil? Certainly not. Her declarations to witnesses show that she believed this notion of the Virginia property to the very last. The idea of property in the moon could not have been more indicative of folly.

True, the executor testified that this codicil was made at his suggestion, in order to preclude all claims from any heir-at-law who might possibly share her belief that she had property in Virginia, and thus to save himself from future annoyances. The executor's course in the matter implied no opinion necessarily, respecting the 
character of this bequest. For even if he had then believed as firmly as he did after his inquiries that her father left nothing whatever, he might still have advised the codicil, because he could not be sure that some one might not have got the impression that the testatrix had a good claim upon property in Virginia. However that may be, the essential fact is not affected. Her willingness to accept the codicil implies the existence of the belief on her part, and therefore it is immaterial whether it originated with herself or her executor. Whether any possible benefit from it could compensate for the legal consequences of this formal recognition of a palpable delusion, is a question which naturally arises, but which I need not discuss, because not exactly within my province.

The next point put forth by the appellees was much stronger apparently, but it lacked the essential element of strength, - a substantial foundation. The will, they alleged, is a rational act, rationally done, for a purpose worthy of the soundest reason, and under the most sacred of human obligations. Several of the witnesses men whose position and whose relations to her might be supposed to have procured for their opinions on such a subject some deference - stated that when they objected to this disposition of her property, and tried to convince her that it would ultimately fail of its purpose, as all other religious trust-funds had, her invariable reply was that it was in accordance with the expressed wishes of her brother ; that the object nearest and dearest to his heart was to establish and endow Baptist churches; that she felt bound by an imperative obligation to carry his wishes into effect, and consequently had no choice.

Unquestionably, if she had promised her brother so to dispose of the property obtained from him, such a 
will should be regarded as valid, in morals, if not in law. He had a right to exact such a condition, and she was bound to observe it. But as it regards her own property, - that which came from other sources than him, it was all very different. Her disposal of that must be bound by the usual conditions of a testamentary bequest. She could neither promise to dispose of it in a certain way, nor carry such a promise into effect, unless possessed of testamentary capacity.

As to the promise itself, on which so much stress was laid by herself and her counsel, it is to be considered that beyond her statement there was not the slightest proof in evidence that he wished his property might, after death, be devoted to religious or any other particular purposes. No one ever heard him express such a wish. On the contrary, four gentlemen, all friends and companions, with whom he was in the habit of expressing his views very freely, declared that in matters of religion he maintained a sort of philosophical indifference; that he did not confine his attendance on church to any particular denomination; and that, as one of them expressed it, he had no faith in creeds, nor the expounders of creeds. Indeed, it would seem, from the statement of one of them, that he had no active religious belief whatever. He had contemplated, no doubt, the erection of a church, in his lifetime, on his land in Taunton, and had obtained estimates of cost, \&c. This project he frequently spoke of; and when the land was offered for sale, one lot was reserved for a church, and it was so stated in public. Once, when passing by the land, before the sale, he pointed out this lot to the friend who was with him. The reply indicated very clearly the thought which was passing in both minds: "I advise you," said his friend, "to build at once, before you 
undertake to sell." It was to enhance the value of his land, and there was no proof that he regarded it in any other light. So, too, he would point out a lot on the North Providence estate, as that which Eliza intended for her church.

There is another fact of no insignificant bearing on this alleged vehement desire to execute her brother's wishes. Thirteen months were suffered to elapse between his death and the execution of her will. Had she died suddenly during this period, - an event not very unlikely at her age, - then the dearest wishes of her brother would have come to naught, and this property would have gone to those hated relatives, instead of being "given to the Lord." There was no reason for the delay, had her mind been made up; and it appeared that during this period she mentioned various other charitable objects to which she thought of bequeathing her property. The only possible conclusion is, that the disposition she finally adopted was her own deliberate choice, - not the execution of another's wishes.

The psychological history of this lady is easily read by the light of the evidence; and it may be worth our while to notice some of the prominent incidents of that mental movement which, beginning in the deepest emotions of childhood, fostered by the peculiar circumstances of her lot, and determined in a great degree, probably, by hereditary tendencies to disease, ended finally in delusion and disorder. It was the work of years, it is true, and not obvious to the casual observer; but it was none the less real or serious.

Though too young at the time to be much affected by the separation of her parents, yet, in the latter years of her childhood, it must have been a subject of curious and earnest speculation. At the age of ten, the second 
marriage of her mother introduced her to new domestic scenes, calculated to impart a peculiar tone to her thoughts and feelings. At the age of thirteen, news came of the death of her father in a remote State, coupled with intimations that he was poisoned; and it cannot be doubted that thereby a most suggestive and life-long impression was made upon her mind at this most susceptible period. When she first began to believe or suspect that attempts were made to poison her or any of her family does not appear. The evidence only showed that the belief existed, at least, some thirty or forty years before her death. It sprung, very probably, from the circumstances of her father's death, of which she always retained some recollection. In fact, the idea of poisoning and being poisoned thus suggested to her susceptible imagination, became so familiar to her mental experience as to defy the utmost efforts of reason to dislodge it.

This habit of mind was unquestionably strengthened by an event which happened towards the middle period of her life. An English gentleman bearing her name had died, leaving a considerable property, the heirs to which were supposed to live in this country. Various members of her family became interested in the matter, and one of them went to England for the purpose of making inquiries and prosecuting claims. It appeared, however, that they were not the heirs of this man; and the property went in another direction. But the idea thus suggested to her mind of being entitled to property in England was never abandoned by Miss A., though in her later years she said but little about it. It was accompanied by suspicions of foul play, and of attempts upon her life on the part of those who might better their own claims by getting her out of the way. 
Thus far the mental disorder had not a very wide or conspicuous operation. It was not obvious to the world, and interfered with none of the ordinary performances of life. A naturally active mind, a good education, an agreeable person, and social advantages, masked the morbid traits of her character, and enabled her to bear her allotted part in life with tolerable credit. Even those best acquainted with the workings of her mind would venture only to call her peculiar or fanciful. Nevertheless, the morbid element was steadily, though slowly, gaining strength, when it received an extraordinary stimulus from the reading of those old letters. The unusual circumstances attending her father's death, and the air of mystery in which that event as well as the whole history of his residence in the South was enveloped, had furnished food for much morbid reflection; but now, for the first time, her ideas assumed definite shape. In her suspicious and credulous temper, the mention there made of her own Christian name in connection with money and investments afforded confirmation strong as holy writ of the traditional belief that her father had married a rich planter's widow, and died leaving a large estate; while it also suggested the additional belief that that estate had belonged to her as her father's heir, but somehow had been wrested from her by dishonest uncles. The marvellous improbability of the whole tissue of events supposed in this belief caused neither hesitation nor doubt. Ever after, she did not suspect, but she believed with her whole heart and her whole soul, that she had been robbed by her own relatives of a valuable estate. Habitually dwelling on this idea, she was always seeing in every occurrence some fresh proof of the existence of this estate, and of the iniquity which defrauded her out of it. Did a relative build a block of 
stores, he certainly must have obtained the means from her property. Did another send his boys to a boarding school, his salary was too small to allow such an expense, and it could have been derived only from her property. When one of them went to Virginia, it was for the purpose of visiting her plantations. The style of housekeeping in which her relatives indulged was diligently scrutinized, in order to show that they were living beyond their ostensible means, and of course on the fruits of iniquity. A belief originating and entertained like this can be called by one name only, - delusion; and delusion is insanity.

Its first fruit was an excessive anxiety to ascertain where that property was, and for this purpose it was necessary to learn when and where her father died. While her mother and brother were living, she could do but little. They did not share in her belief; and seeing that the subject, when introduced, always excited her, they lent her no assistance in prosecuting her inquiries. After their death, however, she was free to pursue the desire of her heart, without let or hinderance from others. The very difficulty of getting information only strengthened her delusion, for to her distempered fancy the fact that they to whom she applied professed to be utterly ignorant was conclusive proof that they were participants in the crime. With her relatives, servants, and some others, it was the prevailing theme of her discourse; while in every descendant of those faithless uncles, whatever his position or character, she saw a foe fattening upon the spoils of her father's estate, and perhaps seeking her life in order to avoid exposure. At last the original letter containing the account of her father's death, burial, \&c., fell into her hands; and thus she was enabled to confirm her traditionary belief, so far 
as it went. At last she ascertained precisely what property her father had possessed, and what he left behind him. But the information came too late. For years her belief had been a delusion, and the most palpable proofs of his absolute destitution did not shake it in the slightest degree.

During the latter years of her life it is obvious that the mental infirmity had greatly extended its influence. The fear of being poisoned had steadily increased, until the circle of the suspected embraced many of her kinsfolk and most of her servants. To this was added the fear of foes from without as well as foes within. Doors and windows were kept fastened day and night, and she retired to rest in a bed surrounded by fire-arms. The suspicion and distrust of her earlier years were converted at last into utter disbelief of human honesty. All, from the kind old Baptist deacon who managed her charities, to the honest old Quaker who managed her farm; from the cherished friend of her brother, unceasing in his offices of kindness towards her, to the humble cousin who was ever her willing drudge, - all were, in her eyes, cheats, thieves, and liars. To the broadest moral distinctions she became insensible, charging with fraud and malice persons whose company and assistance she courted, and putting into the hands of the man who was to watch her premises the instruments of death, with directions to use them upon the first one who came along. The management of her property now betrays that lack of mental vigor, and the style of her housekeeping that insensibility to little conveniences and proprieties, which mark the progress of her malady no less clearly than other more demonstrative traits; and thus year after year, for the greater portion of her life, she was brought more and more under the influence of dis- 
ease, though seldom, if ever, deprived entirely of selfcontrol, or all sense of the fitness of things. To say that she was therefore not insane, is merely to say that she was not a raving maniac nor a stupid clod, devoid of all sense and reason.

It may be worth our while to observe that this case involves some questions touching the effect of mental disease on the testamentary capacity, that are not yet definitely settled. In cases where a will has been disputed on the ground of insanity, the kind of mental impairment alleged has generally been that which accompanies congenital imbecility, paralysis, acute disease of some bodily organ, the decay of old age, intoxication. It consists of enfeeblement rather than perversion, and affects the memory and judgment rather than the opinions and sentiments. These cases involved simply a question of capacity, and courts were always seeking some standard by which the testamentary capacity could be measured. In the case of imbeciles, the ability to count ten, to tell the day of the week, or measure a yard of cloth, was once considered eridence of a disposing mind; and though the standard was raised in later times, it was still an arbitrary one, having no necessary relation to the thing compared with it. In other cases of mental enfeeblement, courts have said that the testator should possess mind sufficient to transact the common business of life, or be capable of making a contract, or doing any other binding act. And this was the common doctrine, until it was discovered, almost within our own generation, that some wills require a stronger understanding and a wider comprehension than some contracts, and vice versa. 'This led to what may now be considered a settled principle, viz., that the testamentary capacity must be estimated in reference to the circum- 
stances of the particular act itself. Thus, a will disposing of a large amount of property to various persons, for various purposes, and under various conditions, requires a larger capacity than one devising a small property to the only two or three relatives the testator may have, or than a contract marked by few and simple conditions.

No sooner was this principle favored by courts, than it was found too narrow to cover all the ground which the subject presents. A class of cases began to make their appearance in which the testator, while possessing many of the highest powers and the ordinary traits of a sane mind, - transacting business correctly, mingling in society without exciting surprise, and discharging creditably the duties of a good citizen, - was bereft of reason in relation to certain subjects, believing notions utterly impossible in the nature of things or the circumstances of the case. Under the principle just mentioned, such a person could not be pronounced intestable; but if the delusion had reference to persons whose interests were thereby affected in the dispositions of the will, then, very clearly, the will might have been the offspring of insanity; and if it were, then, in spite of all the rules and definitions, it ought not to stand; and so it appeared to the court in one of the earliest cases reported, - that of Greenwood, who disinherited his brother under the delusion that he had been poisoned by him. On an appeal, however, this decision was reversed by Lord Kenyon, who, while he admitted the hardship of the case to the surviving brother, felt unwilling to quit the old landmarks. Some years afterwards a case of this description - Dew v. Clark - was decided in Doctors' Commons, under the benigner spirit of the civil law, by Sir John Phillimore, in whose long and elaborate judgment the true principle 
which should govern this class of cases was maintained with so much clearness and ability that it has been accepted, with scarcely a murmur of dissent, as the established law of the land. Finding that the testator was insane on the subject of his daughter, whom he had disinherited, he pronounced against the will; the question at issue being, not whether the insanity would vitiate any will (" a will generally") of the deceased, but this identical will.

One more class of cases remained to be disposed of, that where the insanity is not only partial and limited, but has had no influence, apparently, on the testamentary act. Is every insane person to be deemed intestable, however partial the disease, and however free from its influence the testamentary act may be, or only so when the act is shaped and colored by the disease? In the only reported case ${ }^{1}$ where this question has been clearly mooted, Lord Brougham came out strongly in favor of the former opinion, and, in the course of his discussion, even questioned whether the adrocates of the latter opinion would have the courage to say that the will of the man who declared that he was the Christ should be admitted to probate, though it bore no marks whatever of an unsound mind. ${ }^{2}$ This is an extreme case, and the courage which would be wanting here might be found amply sufficient in those far more numerous ones where the mental affection is less extravagant and absurd.

1 Waring $v$. Waring, 6 Moore, P. C. Cases, 349.

2 Lord Brougham's doctrine was approved by Lord Penzance in Smith v. Tibbetts, 36 L.J. R., x.s., Probate Court, 97 (1867), and subsequently disapproved by the Court of Queen's Bench, in Banks v. Goodfellow, 39 L. J. R., s.s., Q. B. 257 ; 5 L. R., Q. B. 54 ; Lord Chief Justice Cockburn delivering the opinion of the Court. 
In this country, the law would seem to be complicated by the legislative acts that have been passed in the different States on the subject of the will-making power. In Rhode Island, for instance, it has been enacted that, to make a valid will, a person must, among other qualifications, possess a "sane mind." If this language is to be taken literally, then certainly no distinctions as to the nature or extent of the disease can be compatible with a due observance of the law, which requires nothing less than the implicit adoption of Lord Brougham's rule. It will be contended, no doubt, that this language must be interpreted by the rules of the English law; in other words, that the meaning of one of our statutes must be determined, not by the ordinary signification of terms, but by the decisions of English courts, not in themselves harmonious. Such a course would be in curious contrast to that usual adherence to the language of a statute which allows the intentions of the legislator to be completely frustrated by a misplaced preposition, or an improper tense or mood. It adds another leaf to the chapter of contradictions and inconsistencies which form so large a part of the law of insanity. 


\section{MANAGEMENT OF HOSPITALS FOR THE INSANE.}

Hospitals for the insane, conceived in the modern spirit, came in with the present century. Establishments for the custody and treatment of the insane had existed, sometimes in connection with general hospitals of which they constituted a department, and sometimes separately, and independently of any other. In England, buildings were erected expressly for the purpose; but on the continent old monasteries were, at one time, almost exclusively used. In these rude, prison-like structures, patients were herded together without much attempt at classification; while every arrangement, every incident of management, was founded on the idea that, in mental disease, violence and insubordination are the rule, not the exception, to be met and overcome by opposing force. No attempt was made to act directly on the mind by means of work, books, or amusements. Drugs were thought to be the only thing that promised any good, and they certainly were allowed to have their perfect work. At the old Bethlehem, in London, it was customary, up to no very remote period, in addition to the special medication supposed to be required in each particular case, to bleed and physic most of the patients every spring. Instruments of re- 
straint were abundant. Day in and day out, patients were confined to their chairs or benches, for months, if not years together; and many who were free by day were chained to their beds by night, lest they might possibly do themselves some harm. At last, this dreary record of cruelty and contumely, of ignorance and unskilfulness, was finished. At last, the insane came to be recognized as possessing, in some degree, at least, the attributes of humanity, and therefore as fit subjects for the ameliorating arts of philanthropy and science. The point gained was not the mere disuse of chains, nor the reform of gross abuses, but the general recognition of the fact that the management of the insane is a matter of scientific inquiry and experiment, and, consequently, always and forever, susceptible of improvement. The result has been what might naturally be expected, when men begin to aim at something beyond an old routine. Every year witnessed some new advance; and, on looking back, it is easy to discern the broad interval between the uncouth, cold, dark, jail-like structure and the well-warmed, well-lighted, well-ventilated, commodious, and even elegant edifice, abounding in the conveniences and amenities of a domestic residence; between the harsh and peremptory keeper with command in his look and a bunch of keys at his girdle and the courteous attendant who gently leads his charge in the ways of propriety and decorum; between the discomfort of needless restraint and the enjoyment of the largest liberty compatible with the end in view; between the irksomeness of perpetual idleness and vacuity and the buoyant sensations that spring from mental and physical occupation.

In this retrospect, we may also discern an incident characteristic of most reformatory movements, - the 
tendency to run to opposite extremes; and perhaps I could not better use this occasion than to consider it with some degree of particularity. The reformer's creed frequently contains but a single article of belief; namely this, because a thing is bad therefore the directly opposite thing is necessarily good. The effect of this fallacy has been strikingly manifested, for instance, in the controversy, not jet settled, respecting mechanical restraint as applied to the insane. Everybody admits that it has been grossly abused, but an immense difference prevails as to the practical inference that should be drawn from the fact. While it leads one party to use it for proper purposes and in a judicious manner, so as to secure its benefits and avoid its evils, it leads another to disuse it altogether as an unmitigated wrong. Of course, abundant reasons are offered for the correctness of each of these conclusions, and they are not without their force; but - in accordance with a common phasis of belief - they have probably less to do with actual opinions, than a state of feeling antecedent to all reasons. This accounts for the difficulty of arriving at the truth in all questions of practical reform; but the number of those who learn from it a lesson of caution against hasty conclusions will always be small. In the present case there is a touch of the romantic in the idea of managing the insane entirely without mechanical restraint, and solely by moral suasion or the gentle laying on of hands; and when first announced, it is not strange that it was taken at once into public favor. It had all the éclat of a great discovery, worthy of being compared with that of anæsthetics or the vaccine virus; and in England, where it originated, it needed more than an average share of moral courage to regard it with the slightest distrust. 
One thing leads to another; and the idea of complete non-restraint was followed, in the fulness of time, by that of banishing all those distinctive architectural arrangements supposed to be indispensable to the proper care and custody of the insane. Open fires on the hearth, windows without guards, and doors without locks, have been adopted in one or two hospitals lately erected in England. It is not surprising that men of a sanguine, philanthropic temper, should hail such innovations with their warmest approval, and that under the pressure of public sentiment they should be sustained, temporarily at least, at all hazards. The careful observer, who studies insanity like any other object of scientific investigation, will hardly be satisfied with the reasons offered for such a radical reform; and though willing to accept results as the proper tests of their soundness, he will require that the experiment shall be tried on a large scale, by various parties, and its indirect and contingent as well as immediate results be fairly taken into the account. No experiment in the management of the insane can be considered successful, merely because no indications of failure are visible for a limited period, or under peculiar circumstances. For the very object may be, not to prevent an evil which otherwise would be sure to happen, but to meet a contingency that may never occur. The mere fact that it does not occur has no necessary connection with the means of prevention. No one at all conversant with hospitals for the insane can have failed to see that, in some degree, their results are apparently a matter of chance. To attribute them entirely and exclusively to management would be no mark of wisdom. The man who congratulates himself on the success of his measures for preventing suicide, on account 
of entire exemption for several years, will find his selfcomplacency somewhat ruffled when, without any change of practice, several cases occur in rapid succession. So, too, he may find that the large proportion of recoveries, and the small proportion of deaths and casualties, which, for a time, seemed to be indisputable proofs of his skill, are attributable to causes over which he had little or no control. Now, to ascertain how far this element of chance prevails, must always be a work of time; and we may fairly challenge the soundness of any conclusions where sufficient account has not been made of its influence.

Another error very incident to measures of reform in our specialty is to mistake individual traits for general conditions, and thus conclude, prematurely, that what is applicable to one case is no less applicable to all. Diversities of disease, of previous management, of natural character, may all be ignored, and some procrustean plan regarded as embodying all the wisdom worth retaining. A patient long subjected to mechanical restraint improves under its disuse; therefore no patient requires it, and complete non-restraint must be the unexceptionable rule. Another is annoyed by the sight of locks and guards, which, in fact, are unnecessary for him; therefore they are annoying to all and unnecessary for any. Another desires to go out unattended, and undoubtedly is all the better for the privilege; therefore unrestricted freedom in this particular should be the general rule. Deductions like these may seem somewhat puerile, but they are scarcely exaggerations of what have actually been made. Now, with all admiration for the spirit underlying these projected reforms, I am still obliged to doubt whether they do not exhibit some confusion of thought, both as to 
the ends which are proposed and the conditions of a successful experiment. These two questions it may be well to consider for a moment, beginning with the latter.

Morbid movements of the nervous system often require considerable time for their completion, and are marked by a certain periodicity not apparent in other affections. What we happen to see may be but a single phasis of the movement, to be followed by others equally prominent, before the morbid cycle is completed. What it may reveal precisely, we cannot predict before it is completed. Now, a kind of management that may be very proper in regard to one of these phases may not be so in regard to another, because the wishes and feelings of the patient, the force of his impulses and the gravity of his disease, may present the utmost possible difference. An inflexible rule of management, by ignoring these diversities, must necessarily occasion much mischief, directly or indirectly; and not more does the individual differ from himself at different periods, than does the general condition of the house. The expediency of non-restraint, for instance, might be very differently manifested, even in the same establishment, at different periods, insomuch that several months of complete disuse of restraint might, very properly, be followed by as long a period of its abundant use. We should not suppose we had cured a case of epilepsy or hysteria, merely because the period since the last fit has been much longer than any previous interval; or that a maniacal patient had recovered, because the high excitement had passed away and he replied to a ferw questions correctly; why, then, should we be required to accept any principle of management which has been tried, however successfully, on a limited scale and for a 
limited period? It is no satisfactory reply to the patent objections that lie against this or that arrangement, to say that no harm has arisen from it, so far. Great care, aided by great good luck, may unquestionably save us sometimes from the legitimate effects of a faulty arrangement. But in any provision relative to the management of the insane, it should be implicitly required that its operation shall depend as little as possible on the chances of fortune or the short-comings of men. Its merit should consist, in a great measure, in its independence of these contingencies. Success, in spite of manifest danger, would be a very feeble argument in favor of repeating the experiment. 'To say of it that we have got along under it without any untoward event, is to render but a vulgar estimate of success, though one most intelligible, perhaps, to the multitude. Let us bear in mind, too, that a broader field of trial, a wider scope of comparison, a more impartial judgment of results, is necessary, than any single individual can fairly claim.

Juch error has been committed on this subject, in consequence of misunderstanding the proper ends of any reformatory measure in the management of the insane. The philosophical test of social and political reform - the greatest happiness of the greatest number must not be exclusively adopted here. A provision is not to be hastily discarded merely because it has been attended by abuses, or because its evils, on the whole, seem to overbalance its benefits. The careful inquirer will first ascertain whether, by some administrative change, the former may not be prevented, and the latter retained. To give up a provision which is known to serve an excellent purpose, because in the hands of the careless and heartless it has been made an instru- 
ment of wrong, may be wise under some circumstances, but can hardly be considered a triumph of professional skill. True science, true skill, consist in meeting the exigencies of each particular case; and though these must sometimes be subordinate to the general good, this necessity must be regarded as a defect rather than a merit. The question we have to deal with is, how we can best reach the needs of each one of those individuals who make up the collective body under our charge; and so long as we keep this end before us, we may be sure we are on the right course. When, however, we strive after something above and beyond this, seeking, for instance, to establish some general rule or practice calculated to strike the fancy and to win the applause of the inconsiderate, there is great danger that the other and more important end will come to hold an inferior place in our regard. There may be no incompatibility between these ends, for many, I doubt not, are steadily keeping them both in view; but there is a natural tendency to seek that which is most easily appreciated by all who look only on the ontside, and which, by such, would be regarded as indicative of originality and vigor. We see it in the idea too often put forth, of claiming merit for encountering great risks with but little actual damage. So many epileptics have frequented a room having an open fire, so many uneasy, discontented patients have been allowed to go and come as they please, so many pugnacious ones have mingled freely with the rest, so many homicidal ones have been intrusted with edge-tools; and yet nobody has fallen into the fire, nobody has eloped, nobody has been struck, nobody has been killed or wounded. As if such a result might not possibly have been a remarkable instance of good fortune rather than the sign and seal of a 
blessed reform; and as if the welfare of the individual patient were a matter of little concern compared with the working of a general rule. I would not be understood as saying, that in the management of the insane we are to incur no risks whatever; in other words, that we are to withhold from them every privilege and the slightest measure of freedom, because they might possibly abuse them. The whole theory of modern management implies risk, to be avoided, however, as much as possible, by the exercise of discernment and tact. Sometimes, indeed, a desirable end can be obtained only through more or less risk, and on the general question there can be but one opinion. But such risks must be carefully distinguished from those which involve the welfare of others, or tend only to glorify individuals. If an attempt to benefit a particular patient by some exercise of risk, applicable solely to him, fail, he alone is affected; and if the circumstances fairly justified the attempt, he cannot complain. But if, while it is applied to one person, its consequences fall upon another, then the latter has good reason to be aggrieved. When a sanguine believer in non-restraint systematically exposes his patients to the assaults of those who are inclined to such mischief, in the rain expectation that any practical amount of vigilance can obviate actual harm, he will hardly be able to justify the occurrence of unpleasant casualties by pleading the common good. The sufferers would reply, and very properly too, that they were placed under his care for their own particular good, and not for the purpose of enabling him to work out some favorite theory. And they might also say that they were so placed, mainly for the purpose of being saved from themselves and others. 
I believe that the reasons urged in favor of some of these reformatory measures are founded in incorrect notions of insanity, and especially of the thoughts and feelings of the insane. It is contended that the safeguards which have been placed around the patient should be removed, because they are supposed to annoy him by constantly reminding him of his infirmity, and proclaiming from every door and window that he cannot be trusted. Unquestionably, in a small proportion of cases, restraint of any kind is disagreeable, and, perhaps, unnecessary; but it is equally certain that to many patients it is not even a source of discomfort. The latter class have an habitual sense of insecurity, fear to be left to themselves, and welcome the means of restraint. Many of those, even, whose form of disease is marked by high excitement, feel at times a consciousness that they are unfit to be at large, and recognize the necessity of those abridgments of their freedom which a hospital involves. Much of the repugnance which the insane are supposed to feel to the restrictive arrangements of a hospital may be fairly attributed rather to that captious, fault-finding spirit so common in the disease, than to any keen sensibilities in the matter.

When restraint of any kind is required, let it be applied, we are told, by the look and the touch of an attendant, not by barbarous implements of wood and iron. Mistakes have been made, no doubt, as to the amount of interference compatible with the best interests of the insane, but we ought not to err very widely as to the amount of care and vigilance that may be reasonably expected of attendants. Natural disposition and temperament, tact and culture, may affect the result somewhat; but we well know that beyond a certain point these qualities, in their best estate, are per- 
fectly impotent. For a short period and an imminent emergency, we may be warranted in relying upon them implicitly. But lengthen the period, or render the contingency more remote and uncertain, and to that extent personal vigilance becomes unreliable. An attendant placed in charge of a patient incessantly bent on selfdestruction may be safely relied on for several hours; but let it be his sole business to prevent a patient from striking when the impulse comes, which may be but once in two or three months, and who that knows anything of the subject supposes that the blow will not be struck at last? The continuity of attention required for this purpose may not be impossible, but in practice it would be idle to expect it. In fact there is really no relation between the end and the means. The question is not which of the two kinds of restraint, personal or mechanical, is preferable in this case, but whether the latter is not the only one capable, in the nature of things, of effecting the purpose. Considering the matter in reference to its immediate effects on the patient, and unconnected with theories or biases, it seems difficult to conceive how there could be two opinions about it. And in the class of cases where either would be admissible, I have been led by twenty years' experience to believe that a simple contrivance of leather or cloth placed on the limbs, performing its service quietly and steadily, is infinitely preferable to an array of attendants holding the hands and feet, and at every relaxation of their efforts provoking renewed struggles from the patient.

It has been of late years somewhat fashionable to ignore some prominent traits of insanity, or at least to suppose that they may be kept in abeyance by devices of management. The insane should be treated more 
like the sane, trusted with responsible duties, and thrown much upon their own power of self-control. No one would dissent from the general principle implied in this statement, because it is characteristic of all humane and intelligent management; but unquestionably some have been disposed to carry it to an almost unlimited extent. Among them was one whose name was intimately associated with the history of our specialty in this country. His practice was to treat his patients as if governed by the principles, motives, and impulses of sane men, until the contrary appeared. Very brilliant results sometimes followed this management, and some not so well calculated to recommend it for general adoption. He was fond of taking visitors to a window and showing them three or four patients mowing together in an adjacent field, all of whom had committed homicide. There was something very extraordinary, no doubt, in such an exhibition. To those who are governed by appearances merely, it indicated the triumph of the strong will and the commanding presence over the lower instincts of a diseased mind, and excited the usual admiration produced by the marvellous.

No good can come by shutting our eyes to an old truth, merely because it is old, and believing that the world has always been mistaken in the idea that a disposition to mischief is a frequent element of insanity. Tamed, diverted, modified it certainly may be; but there can be no graver error than to suppose that, by any system of treatment, it may be utterly extinguished. And even if it were possible to eradicate this element of the disease, there remains another which should prevent us from relying too much on the discretion of the insane. The guiding, determining power of the patient - the 
balance-wheel, if I may use the figure, which regulates the mental movement - is generally more or less impaired, and some foreign power must, to that extent, take its place. For this reason the patient is taken from home or his customary surroundings, where he is following the bent of his disordered fancies, and placed where his liberty of action is greatly curtailed, and his movements directed by others. To some, scarcely anything more is necessary than the unavoidable restrictions of the hospital. In others, the gravity of the disturbing element may call for the utmost amount of restriction at our disposal. In some shape or other, restriction is an essential element in all hospital management of insanity; but it would be preposterous to contend that just so much or so little is the exact measure best suited to all cases alike, or to any considerable proportion.

In the above remarks it has been my intention to indicate the only channels which the course of improvement can possibly take, and to state my reasons for dissenting from some current opinions on this subject. I am not disposed to anticipate only failure from the most skilfully managed experiments, nor to regard free and full inquiry in any direction as useless. What may be accomplished hereafter must be a matter of speculation, but probably the future will be much like the past. Men will continue to jump at conclusions, to imagine that they have found some royal road to the desired object, and that their own new ways are better than any old ones. One project after another will pass away, but not without leaving some pregnant suggestion behind. In the mean time, let us be less anxiọus to discover new truths than to turn the old ones to the best possible account, and then we need have no apprehension that the dark ages will return. The latter object is within 
the reach of all; the former is reserved for the gifted few.

We may bear in mind for our encouragement that in this country are circumstances peculiarly favorable to our progress. Establishments for the insane are everywhere provided, in addition to the usual executive officers, with a board of general direction, who watch over their interests and control more or less their management. This kind of organization is simple; it is in accordance with the customs of the land, and very well secures the object in view. In England, some twenty years ago, it occurred to a few amateur philanthropists that the efficiency of these establishments would be greatly promoted by placing them under the supervision of a large central board. Accordingly such a board was created by Act of Parliament, and its members, twenty in number, appointed by the Crown. They visit, once at least every year, by sub-committees, every house, whether public or private, in which the insane are kept for hire; make suggestions and recommendations on every point connected with the specialty; bestow censure or praise with a liberal hand; advise the removal of patients, even, from establishments in which they have been placed by friends; recommend, when the case seems to warrant it, the withdrawal of the license, without which no private individual can have charge of the insane; and make an annual report of their proceedings to the Lord Chancellor. Their office is advisory entirely; but, occupying their position, it will be readily seen that their suggestions can have scarcely less force than a positive order. Under the supervision of such a board, it is supposed that abuses will be seen and prevented; that defects will be pointed out and the proper remedy suggested; that new ideas will be disseminated; im- 
provements made in one place be rendered the common property of all, and a high standard of excellence established. These are very desirable objects no doubt; the only question is as to the qualifications of the commissioners for the appointed duty. The Lord Chancellor may send them forth under the sanction of the highest authority in the realm; but he can endow them with no knowledge of a specialty so peculiar as that of providing for and managing the insane. It can be obtained only by a long and familiar intercourse with them,- - by a practical acquaintance with their wants, ways, manners, tendencies, and impulses. It could hardly be supposed, considering the ways of persons in power, that many such men would receive the appointment merely on account of fitness for the office, without any claim on the score of political service or popular favor, or the dictation of a powerful friend or clique. Occasionally we observe in the English Lunacy Commission the name of some one creditably known for professional attainments; but, with these few exceptions, the members are barristers, clergymen, surgeons, military officers, members of Parliament, country squires, - all very respectable gentlemen, no doubt, and some of them eminent in their respective lines, but who, previous to their appointment, were probably never inside a hospital for the insane, except perhaps as casual visitors. On some points of general direction, their education and opportunities might enable them to offer sound and seasonable advice. But on all questions of a strictly special character their opinion can be worth nothing; and yet those are the questions with which their mission is chiefly concerned, and on which their views are promulgated with all the moral, if not legal, force of an Act of Parliament. To such views the officers of the hospitals are 
called upon to yield convictions which may be the result of much study and observation, or lose all their hold on the public confidence. Had a committee of just such gentlemen been appointed for the purpose of improving the condition of English surgery, and with this object in view had visited the hospitals once or twice a year, witnessed the operations, inspected the instruments, read every ticket of the diet and medicines prescribed for the day, and then submitted to the Lord Chancellor an elaborate report of their proceedings, full of criticism and counsel, the whole performance would have been regarded by everybody as highly ridiculous; and yet in all essential conditions the cases are precisely parallel. Their opinion on the subject of restraint and seclusion is actually worth as much as their opinion on the disputed questions of the circular and the flap amputation, or the high and the lateral operation for stone would be,neither more nor less. Even if better qualified than they actually are, their visits must necessarily be too few and far between to furnish that full and precise knowledge of the hospital which alone can warrant either praise or censure. Only a long succession of visits will enable one to become acquainted with its prevailing character and spirit, and to distinguish casual incidents and temporary arrangements from such as constitute an inseparable part of the habitual routine.

It may be thought that these objections to a central board of supervision would not lie against it were it composed entirely of experts, - of men who have had much practical experience in the management of hospitals. Such men would unquestionably do better. Their adivice would at least be worth listening to, and many of their suggestions might well be adopted; but I am not sure that the good thus done would more than bal- 
ance the unavoidable evil. Each one of these men would have opinions and practices of his own. He would believe them to be the best, and would naturally be desirous of seeing them generally adopted. He might disclaim all wish to force them upon others; but they would none the less influence his judgments respecting the opinions and practices of other men. They would, moreover, have the benefit of all the prestige attached to his official position, and thus obtain a currency to which their intrinsic merits would scarcely entitle them. All this would be prejudicial to true progress, which requires that scientific principles should make their own way in the world, to be finally accepted or rejected, according as they stand the decisive tests of all truth.

Happily for us, one of the principal reasons for a central supervisory board in England-viz., the large number of private, irresponsible houses - does not exist here; while the political relations of the States to one another would be incompatible with the plan of a national board. Thus our institutions are all perfectly exempt from extraneous interference, the superintendent and directors acting in their several spheres, under those inducements to fidelity found most effective among men, - the former, by his learning and skill, promoting directly the special object in view; the latter, by their personal influence, securing the public confidence on the strength of their own frequent and intelligent supervision. Nothing need prevent any board of directors from being composed of men as competent, in point of ability and intelligence, to promote the welfare of the insane and advance the general cause as those of any central, supervisory board. Independent of outside official influence, both they and the superintendent are at liberty to think for themselves and to act upon their own views. 
They are seldom if ever obliged to suppress their honest convictions, or conform to practices which they do not thoroughly approve. It would seem to be hardly necessary, in this age of the world, to contend that, in matters of science, the freest possible expression and exercise of opinion is essential to all true progress. Errors are incident, no doubt, to free inquiry; but they are insignificant when compared with those which result, more or less directly, when the range of inquiry is rigidly prescribed, and all conclusions must conform to an established pattern. If an honest inquirer gets upon the wrong track, it is better that he should find it out for himself, as he generally will, than be driven from it by superior force. The utmost diversity of practices and opinions would be a surer sign of progress than any uniformity which is obtained by restricting the freedom of inquiry. 


\section{THE EVIDENCE OF MEDICAL EXPERTS.}

IN all judicial investigations, the matters of fact which they involve are derived from the testimony of witnesses. The exact manner in which this testimony is elicited, and the limits within which it is confined, vary in different countries, and to such a degree as to be almost incredible to one who has always associated in his mind the administration of justice with a particular mode of procedure. In all Anglo-Saxon communities the tendency has been, for a considerable time, to confine testimony more and more strictly to matters of fact within the personal knowledge of the witness; and thus has been gradually formed a body of doctrine called the rules of evidence, marked by singular exactness and discrimination. One exception to the general principle has to be permitted. To promote the ends of justice, it sometimes becomes necessary to obtain the opinion of the witness rather than any facts he may possess, because what is wanted is, not merely the naked facts, but the inferences to be derived from them, - their significance with reference to the points in issue. To some persons certain facts would imply nothing beyond the impression made upon the senses, while to others they might signify the existence of another order of facts of vital importance. If a person has been particularly conversant with that department of knowledge to which 
such facts belong, he may thus be able to see in them a meaning utterly hidden from all who have not had that experience. The circumstances of a wound may be observed and described by any one; but whether that wound would be necessarily fatal is a matter of opinion, to be determined only by those whose studies and duties have made them acquainted with the ultimate effects of wounds. The conduct and conversation of a certain person may be correctly related by any one who has observed him ; but only those who have witnessed abnormal conditions of mind on a large scale may be competent to say whether the mental manifestations thus described are indicative of insanity. Any nurse can tell us how her patient died shortly after taking a certain pill or potion, but only a physician can enlighten us as to the actual connection between the two things. Now comes the peculiar difficulty. Considering that every man's experience differs, more or less, from every other man's; that education, taste, temperament, determine in some degree the significance even of the experience itself, it is no more than what might be expected that men should often differ in the conclusions to which they are led by the same state of facts. And yet, natural as it is, the fact is freely attributed to a very different cause. The cry arises for some change that shall place skilled testimony beyond the reach of improper influences, and thus render it perfectly reliable. That it is sometimes vitiated by the faults and infirmities incident to men, I would not deny. Whether the popular complaints against skilled testimony are well or ill founded; whether its imputed defects are a necessary consequence of modern scientific inquiry, to be tolerated in connection with the admitted merits of our judicial system; and whether they can be obviated by any practicable change of the system, are 
questions I propose to discuss on this occasion; and though I may be unable to propose a remedy for all the evils complained of, I may at least succeed in showing that the evil is not unmingled with much good.

The first objection to be noticed against skilled testimony, as taken at present, is that it is notoriously discrepant, if not contradictory, and therefore unreliable for judicial purposes. Nothing can better indicate the prevalent vagueness of thought on this subject than the idea that the lack of unanimity in skilled testimony completely destroys its value as evidence. Lawyers especially are fond of declaring, as if the fact were a conclusive proof of this position, that experts equally numerous and skilful may always be obtained on both sides of a case. As if a trial ever occurred in which the evidence was perfectly harmonious, - without the slightest discrepancy in regard to what the witnesses profess to have seen and heard. Absolute, unexceptional agreement is never expected, because it is a well-established fact in human experience that all men do not see and hear the same things precisely alike. Why then expect unanimity in matters of opinion any more than in matters of fact? Are the conclusions of reason more exact and uniform than impressions on the senses? If the former are to be distrusted and excluded from judicial proceedings, as some would wish, with what consistency can we admit the latter? If the one, with all its discrepancies, is to be received as, on the whole, the best means for learning the truth, may not the same argument be used in favor of the other?

Considering the proper function of the expert, we shall understand why skilled testimony should often be discrepant, and why, nevertheless, it should be indispensable to the purposes of justice. He is to tell us the 
significance of certain facts that have appeared in evidence. He has made that class of facts his particular study. He has enjoyed opportunities for seeing them displayed on a large scale, and under circumstances peculiarly favorable to observation. He is thus enabled to infer from the naked facts the existence of certain other facts, or bring them, it may be, within the range of some general truth. It does not follow, however, that every one thus qualified must arrive at precisely the same conclusions, for the simple reason that all cannot have had precisely the same experience. To expect from them invariable unanimity whenever they appear on the witness-stand would be as reasonable as to expect every judicial decision to express the united opinion of the full bench; that all historians should agree respecting certain characters or events; that literary critics should praise or condemn with one voice. Now do scientific pursuits insure any nearer approach to unanimity of opinion? We know that geologists are far from being agreed concerning the condition of the earth at any previous period, as indicated by facts apparent alike to all; that philosophers differ respecting the correlation of forces; that tillers of the soil, with all their reliance on practical experience, are agreed as to scarcely a single practice in husbandry. Why then be scandalized by the spectacle of chemists, physicians, or surgeons uttering conflicting opinions on any questions that may arise within the range of their respective pursuits? Indeed, agreement may imply less research, less attainment, than disagreement. Lord Thurlow once said that "the depcrees of the Scotch judges were least to be respected when they were unanimous, as in that case they probably, without thought, had followed the first of their number who had expressed an opinion; whereas, 
when they were divided, they might be expected to have paid some attention to the subject."

It may be remarked in passing, as one of the curious phases of the error in question, that it is more prevalent among the thinking and cultivated classes than among all others of a different description. Their idea is that the statements of the expert should be as unquestionable as Gospel trutb; that when once uttered, nothing can be added to it or taken from it. To them discrepancy implies incompetence, or something worse, and draws out expressions of contempt and disgust. Even when such discrepancy has led to an obviously righteous rerdict, they are far less disposed to hail the triumph of true science than to decry the testimony of experts and pronounce it unworthy of confidence. They expect of an expert nothing less than omniscience and infallibility, and this shows how little of intelligent thought has been given to this subject. As if there were no controverted points in physical science, and its followers were bound to present an invariable unanimity of opinion!

Besides the natural tendency of the mind to diversity of belief, there is another cause of it to be found in the nature and objects of scientific truth. This is not to be regarded, as it often is, as something fixed and invariable, like an object of sense, or the solution of a geometrical problem. In fact, all science is progressive, and its condition at any particular period represents the fruits of the observation and study of all who have engaged in its pursuit. Every one contributes to the common stock according to his ability and opportunity. These contributions may sometimes convey discrepant meanings, because the limits of science are beyond reach; and consequently the inquirer must ever 
fall short of a complete attainment. Valuable as each one's attainment may be, it covers but a small portion of the great domain of science, whatever the industry or genius by which it was accomplished. And though it may be correct, abstractly considered, yet it cannot be accepted as a final result. In other words, a matter of scientific research must be regarded from every possible point of view, and under every variety of circumstance, before we can be sure of understanding it very thoroughly. A person pursuing lis inquiries in the field that has fallen to his lot, with such talents and dispositions as he may have received or acquired, arrives at certain conclusions. Another, acting in like manner, arrives at conclusions apparently conflicting. And yet the several results of scientific investigation, differ as they may from one another, may have been fairly reached according to the rules and processes of philosophical inquiry. Some prove to be more valuable than others. Some will stand unaffected by the results of further investigation. Others will have to be modified, if not utterly swept away, by the subsequent progress of knowledge. All, however, in their several ways, indicate steps or stages towards the attainment of the final object, no one of which could have been dispensed with without detriment.

Without denying that the testimony of experts is often contradictory, as in the nature of things it sometimes must be, it must be borne in mind that such contradiction may be more apparent than real. What seems to be contradictory may be found on a closer inspection to be merely supplementary. It becomes a question, for instance, whether certain stains are made by blood. On the strength of some approved chemical tests they are pronounced to be blood, and the fact may be of the highest 
importance to the party concerned. But another expert, who has made extensive microscopical researches on the blood, is satisfied that the stains in question are made by the blood of some inferior animal. The practical effect of the latter conclusion is to destroy the force of the former; but there is really no contradiction between them. The one is merely the complement of the other, indicating, not error nor deception nor superficial attainment, but simply the progress of knowledge. Again, skilled testimony may seem contradictory only because it is partial, the subject matter being regarded from different points of view. A person's will is disputed on the ground of mental unsoundness. One expert declares that he frequently met the testator, conversed with him, and dealt with him; that, in his remarks on persons and things, he evinced uncommon shrewdness, and that he was interested in the events of the day. He therefore concludes that the testator was perfectly competent to make his will or transact any other business. On the other side, it is testified that the testator entertained delusions respecting some of his heirs, believing them to be hostile to him, and engaged in attempts to destroy his peace and comfort, if not his life. On the strength of this fact he is declared to be unsound and incompetent. Here, too, there is no real contradiction. On one side, the testimony is negative; on the other, it is positive. It only illustrates the old story of the knights who read the inscriptions on the shield from opposite sides.

It must be considered too, in this connection, as explanatory of some of the discrepancies of experts, that, in the practical application of science, much must depend on the person's particular experience, and that discernment of relations with which men are differently endowed. Persons who would be allowed to testify as 
experts in a given case, as engaged in pursuits having a common name, may have pursued their inquiries in paths somewhat remote from one another, and consequently be unequally fitted to meet the question before them. A person is found dead, for instance, with wounds and fractures of the head, and a kitchen poker lying near, with blood and hairs on it. One medical man, governed by appearances that would have conveyed the same impression to most men, testifies that the wounds were made by the poker. Another, who bas enjoyed peculiar opportunities for observing wounds made by the favorite weapons of burglars and assassins, thinks the blows were inflicted by one of these. If he were right in his conclusion, it was not discreditable to the other that he was not familiar with the effects of slung-shots and dipseys. In a case of alleged insanity, one expert, guided by the common light, comes to the conclusion that the person is not insane. Another, guided by a class of cases that happened to fall under his notice, though scarcely known to others, sees indications of insanity in certain acts or traits that, otherwise, lie would have regarded, with the rest of the world, as merely the singularities of a sane mind. Neither is there here any irreconcilable conflict of opinion. Both truly and faithfully declare the results of actual observation, one being the fitting supplement of the other. And thus it must ever be, for science is progressive and its domain without limits.

It has been seriously urged as an argument against skilled testimony, leaving out of view its moral and intellectual aspects, that it has the effect of confusing and distracting the minds of the jury at the very moment when they need to be self-confident and sure. If this is a sufficient reason for excluding such testimony, it may 
be urged with equal force against the admission of ordinary testimony, in which the discrepancies are a fruitful source of embarrassment to court and jury. And with a far stronger force it may be urged against the addresses of counsel, the very purpose of which, half the time, is to distract and puzzle the jury. Yet it was considered a great advance on the side of humanity, in England, when counsel were allowed to speak for the accused in criminal trials. It is not one of the privileges of a jury to have the formation of their verdict made easy for them; but it is very properly the privilege of the accused to have whatever may enure to his benefit brought to the knowledge of the jury. The argument we are considering is little heeded in the ordinary affairs of life. Men are seldom deterred from resorting to various counsellors by the fear of receiving conflicting advice. They take counsel one of another, in order to learn whatever belongs to the matter in hand, and thus obtain the materials of a correct decision.

This objection to the testimony of experts comes with an ill grace from lawyers, in view of the fact that it is regarded as sound law to admit, in questions of mental condition, the opinions of ordinary witnesses. Such, indeed, is the practice in nearly every State in the Union. When we express our surprise that so absurd a rule should ever have been admitted, the only reply we obtain is, that the jury will judge of the value of such opinions and allow to them their proper weight. That the jury will judge of their value is certainly true, but whether they will judge correctly may be very far from true. However this may be, we hear nothing of the tendency of such evidence to confuse and distract the minds of the jury. We cannot help being surprised when we see opinions confessedly worthless admitted 
with scarcely a murmur of dissent; while others, the fruits of reflection and experience, are viewed with distrust, and received under a tacit protest.

There remains to be noticed another complaint against skilled testimony, - the one most current among men of culture and worldly knowledge. Inasmuch as experts are engaged by one or the other of the litigant parties, it is contended that they testify under a bias, and consequently are not trustworthy. They are employed, it is said, much like counsel, with a distinct understanding as to what they shall utter, even before they have heard a syllable of the evidence on one side or the other, and paid for the service like counsel. Impartiality, under such circumstances, is ont of the question. The expert, though bound by his oath to tell the whole truth, tells only so much of it as will help his employers. His position, therefore, embarrasses the jury, who cannot safely accept or reject his testimony. In reply, let me say that this objection depends for much if not all its weight, on some misstatement of facts, a little false coloring, and a complete ignoring of the exact purpose of skilled testimony in a judicial proceeding. It is only a scandal, not a matter of fact, that experts are employed like counsel, for hire, without regard to the merits of the case. If such bargains have ever been made, I do not hesitate to pronounce them rare exceptions to the usual course, and regarded by the great body of scientific men as base and dishonorable. Because a man's opinions are worth money, it does not follow that they are corruptly bought. Nor is it very obvious how a fair compensation for this, more than for any other service, should obscure his perceptions of truth. That experts testify in the interest of a party is very true, but their testimiony may be none the less reliable on that account. That it is 
sure to favor the party that calls them rather than the other, could not well be otherwise. It is an incident of our judicial system, which leaves to the parties themselves the duty of maintaining their own cause, and it does not necessarily imply any unworthy bias. This will be manifest when we consider the manner in which the expert is engaged. The evidence to be produced is laid before him, so far as it can be ascertained, and he is requested to give his opinion respecting it. After due consideration, he may say, "If you can prove the facts as here stated, and if their force cannot be weakened by evidence not here anticipated, you have a good cause, and I am willing to testify to that effect." Or, as frequently happens, he is obliged to say that, "supposing these facts proved, they would not warrant the construction you wish to put upon them, and my evidence would not help you." Whatever conclusion he may reach on this preliminary examination, the party is duly warned that the evidence, as brought out on the trial, for it can seldom be exactly anticipated,-may oblige him to modify or abandon it altogether, and it is for them to decide whether they will take the chance. That this result actually happens occasionally, is a fact within the knowledge, I apprehend, of all who have been much consulted for this purpose. Thus it is that if the testimony of the expert is wholly and unconditionally in favor of one side only, it is simply because this result is warranted by the facts. Otherwise, he would not have been placed on the witness-stand at all. The idea that his receiving compensation from one of the parties is calculated to warp his judgment and make him see things differently from what he otherwise would, might have some foundation, were the circumstances under which he is engaged not precisely as I have represented. 
The opinion sought for happens to be favorable, honestly and conscientiously so; it is uttered on the witnessstand, and compensation follows. The objection has no weight except on the supposition that this order of things is reversed, - that the opinion follows the compensation. That this may possibly occur, is not denied. I am speaking of the general rule.

Under the fancied weight of the objections I have been considering, it has been proposed to place some restrictions on the admission of skilled testimony, whereby the freedom at present allowed would be considerably curtailed. Before examining the various methods proposed for this purpose, let us inquire into the practicability of any change under existing circumstances.

The accepted theory of our criminal law supposes that the accused is entitled to whatever, under the rules of evidence, can be truthfully alleged in his favor. He is not only entitled to any facts that bear upon his case, but also to any construction of those facts which a competent judgment can supply. Though twenty or a hundred experts pronounce him to be sane, he has the right to put in evidence the opinion of the one solitary expert who believes him to be insane. He could not be said to have had a fair trial if such opinion had been shut out. In allowing the parties to a suit to furnish the evidence, each for itself, with no restriction on the privilege, with some trifling exceptions, we have been accustomed to think that we have taken the highest attainable step towards perfection in our administration of justice. It is not easy to see how any exception to the general principle can be furnished by the evidence of experts. On the contrary, wherever there can be any ground for diversity of opinion, as there generally is in matters of science, it is simply a requirement of justice that such 
diversity should be fully and fairly expressed. Then the jury proceed to their deliberations, satisfied that everything has been said that could be said, for and against, and that nothing has been kept out which either party thought conducive to success.

Of course, I am aware that advantage is sometimes taken of this beneficent rule to foist opinions on the jury that are utterly unworthy of their confidence. It is an infirmity of many men to suppose that the possession of a little actual knowledge warrants them in claiming a great deal which they never did possess. Under the influence of this infirmity, they rush to the witness-stand to assume a duty for which they are entirely incompetent. In the character of experts, however, their opinions may have the same weight with the jury as those of better men. It cannot be disguised that this is one of the crying evils of our time, and is sufficient to account for much of the current prejudice against experts. Juries cannot decide between adverse opinions, even when sincerely desirous of relying on the best rather than that which confirms their own foregone conclusions. The most discouraging aspect of the evil is that, with juries constituted as they now are, reflecting as they do a public opinion satisfied with the feeblest excuses for human delinquency, and ever ready to favor the weak when opposed to the strong, it seems to be beyond the reach of correction. Still, while fully admit. ting this fact, we would regard it only as an unavoidable offset against the greater good of our present mode of procedure.

Believing, therefore, that the current objections to skilled testimony are of far less weight than is usually attributed to them, and that, greater or less, the evil complained of is incident to a system which, on the 
whole, is best calculated to promote the ends of justice, and is in harmony with our social and political institutions, I am unable to see any imperative reasons for much change. And this conclusion is only strengthened by an examination of the various methods that have been suggested for rendering skilled testimony more satisfactory.

In order to provide the community with a class of experts both competent and impartial, it has been proposed to have them appointed by the Executive of the State, no others being allowed to give opinions in evidence. It is understood, of course, that the duty would be assigned to men of distinguished attainments in their respective callings, and of a character that would raise them beyond the reach of improper influences. This, certainly, is a consummation devoutly to be wished; but, in view of the experience the country has had of Executive appointments, I doubt if it could be reasonably expected before some distant millennial period. But, even were it otherwise, there are practical difficulties in the way, I apprehend, sufficient to prevent the success of this method. Men whose standing and character would render them fit subjects for such an appointment would, for the most part, be debarred by the pressure of private duties from accepting it. On the supposition that the emoluments of the office would be worthy of its dignity and importance, we know very well that the appointment would be sought by men with small qualifications for the work; and we know, too, that by means of the customary appliances for obtaining office many of them would succeed. Besides, we have no guaranty that the Executive, even though not pestered by officeseekers, would make the wisest possible selections. How is he-a mechanic, or trader, or lawyer, or politician - to 
be able to distinguish between the claims of true science and empty pretension? In times like these, when the medical profession is invaded by people whose only claim to public confidence consists of some popular form of charlatanism, with or without the sanction of a college, and who are upheld by many of those who represent the fashion and culture of the social world, we might expect appointments to the office not remarkably calculated to flatter our professional pride, or increase our regard for medical experts. Thus, the only advantage which this method can pretend to claim, that of providing a better class of experts, would not be effectually secured.

There is another practical difficulty, which of itself would be fatal to the project. Such is now the division of labor in the various pursuits of art and science, that, in determining precisely the range of the expert's practice, it would be difficult to avoid making it either too broad or too narrow. A person appointed as an expert in surgery might be expected to testify in cases involving operations on the eye, or the ear, or the foot, and yet, even with a high surgical reputation, be less competent than many others who had made a specialty of diseases of those parts. Many an eminent physician, whom no Executive would hesitate to license as an expert in diseases generally, might know comparatively little of insanity. It is getting to be distinctly understood that one who gives his time and attention entirely to a particular pursuit is to be recognized as an expert in questions pertaining to that pursuit, to the exclusion of those who have attended to it incidentally, as a subordinate part of a more general department of inquiry. Nor is it easy to see how, under the most favorable conditions, the evils now complained of would be abated by 
this method. We should have as much diversity of opinion, for the simple reason that such diversity is as likely to spring from excess as from deficiency of knowledge. In every trial where expert testimony is given, we see men of distinguished name on one side as well as the other.

It has also been suggested, as an improvement on the present practice, that experts should be assigned by the court, in each particular suit, who, alone, should be allowed to express opinions in evidence. Beyond the chance of securing a higher degree of honesty and competence, I see nothing in favor of this course. Even if practicable, it is open to the objection that it limits the sources of information in a manner repugnant to the spirit of our judicial system. Nobody pretends that all knowledge, even in the narrowest specialty, is confined to one, two, or three individuals; and whatever ability they might exhibit, one or the other party would be likely to imagine that some important point could be established, if they had an unrestricted choice of experts.

It is not very obvious how this course could be followed under our present mode of procedure. Not being called by either party, their evidence could not be elicited like that of other witnesses, by examination in chief and cross examination. It would have to be given to the court or jury in the shape of a report, that might or might not be received with the binding force of evidence. Nor is it easy to see how the matter of compensation could be adjusted with a proper regard to the means of the different parties. The most obvious way of disposing of it would be to include it in the costs of court, but this would render the expense no less onerous to a party of narrow means. Whether large or small, it 
would imply a bargain between the court and the expert rather shocking to our ideas of judicial dignity. It might, perhaps, be fixed by law; but in all probability it would be placed too low to induce any persons of eminent skill to undertake the duty, which might occupy days and weeks together, with the abandonment of all other employment.

This method has probably been suggested by the practice of some foreign countries, France and Germany, where the law requires the judge to appoint the experts when needed, who inform themselves of the facts in the case previous to the trial, and report their opinion to the court in writing; this report being used like other documentary evidence. But it must be borne in mind that in Germany, for the most part, there is no trial by jury; and that in France a criminal case passes through its most decisive stages before it is submitted to a jury. The report of the experts is examined by the jury as a part of the documentary evidence, and their estimate of it is determined by that of the judge. When we shall have abolished the trial by jury, or made the jury the mere mouthpiece of the judge, we may be ready to have the experts appointed by the court, - and probably not till then.

On a comparison of the two systems, it must be admitted that, in one of its phases at least, that of France and Germany has a decided advantage over ours. There, in criminal cases, the government provides the experts for the sole purpose of obtaining the truth, whether for or against the accused. They are hampered by none of the incidents of personal feeling or a rigid technicality, and their investigation is made with all the deliberation and thoroughness of a scientific inquiry. If the accused fail to obtain exact justice, it is not for lack of skilled 
testimony. Here, it is left to the accused to employ such experts as he deems necessary to prove his innocence. If poor and friendless, he is quite unable to profit by this privilege; for in all the States, with a few exceptions, the aid furnished by the government scarcely remedies the defect, and thus he may be convicted, when, with the help of an ample fortune, he would have been acquitted.

Other methods of obtaining skilled testimony so as to obviate the defects of the present have been proposed; but, being manifestly impracticable under our modes of procedure, it would be hardly worth our while to consider them here. It is idle to expect our people to adopt any method which implies a change in the essential features of a jury trial.

Can nothing be done, then, to diminish the occasions of complaint, now so freely made against the testimony of experts? Not much certainly, because, as we have seen, much of the complaint is not well founded; but unquestionably the defects of the present practice might be corrected in some degree, at least, without changing a single essential feature of the existing system.

In some States, when the friends of a convicted felon apply to the Executive for his pardon, on the score of insanity, it is customary for this functionary to appoint experts to examine the person, and report their conclusions respecting his mental condition. Skilled testimony on any subject, thus obtained, is free from the objections made against it as it is usually obtained. It is not given in the interest of one party or the other; it is unbiassed by any pecuniary arrangements, and it escapes the damage of a cross-examination. It is the well matured conclusions of a calm, deliberate, thorough investigation. I propose, therefore, to make it obligatory 
on the Executive to appoint such a commission when applied for under the circumstances above mentioned. Of course, the provision would be applicable only to those cases in which the alleged mental disorder is still existing.

A similar purpose is still better served in the State of Maine. There it was enacted by the Legislature, a few years ago, that, whenever insanity was to be the defence in a criminal case, due notice thereof should be given to the court, by which the prisoner should be sent to the State hospital for the insane, that he might be observed by the superintendent, who, when satisfied thereon, should report to the court respecting his mental condition. During the twenty-one years that the law has been in operation, as I am informed by Dr. Harlow, the superintendent, thirty per'sons have been admitted under its provisions, of whom twenty-four were found to be insane, and the rest not insane. Of the former, fourteen were tried, acquitted on the ground of insanity, and some of them sent back to the hospital. Ten, having so far improved as to be considered safe to be at large, were discharged and taken care of by their friends; the Government, for some good reason, declining to bring them to trial.

Our present mode of examining experts is not by any means the best calculated to elicit a well considered opinion. Within a few years a change has been introduced, which is not a step in the right direction. The practice used to be for the expert to hear all the evidence given at the trial; and then he was asked for his opinion founded on that evidence, supposing it to be true. At last the idea was started that in this way the expert was assuming the functions of the jury, to which belongs the duty of passing on the credibility of the wit- 
nesses; and the practice now is, in most of the States, to put to the expert a hypothetical case, and ask his opinion on that. Of course, the counsel on each side, out of the facts that have appeared in evidence, construct a hypothetical case as fairly as will best serve their purpose, and no more so. By this means the expert may be obliged to assent to the propositions of both sides, and thus apparently nullify his own well matured convictions. And this may be accomplished, not by any addition to or even suppression of facts, but solely by such a twisting and coloring as is quite easy to the unfailing ingenuity of counsel. Besides, it is difficult to see how the objection in question is obviated by this course. Though you may not ask the expert's opinion on the evidence he has heard, supposing it true, you may recite every word of that evidence, not as something actually uttered, but as something that might have been uttered, and ask his opinion about that. 'The rule reminds one of those fictions of the law which were once supposed to promote the ends of justice better than the literal truth.

It should be considered that much of the unmerited distrust of experts' testimony springs from the manner in which it is elicited. Here the spirit and practice of the law are strikingly conflicting. While the former accords to the parties the benefit of the ripest and richest attainments of science and art, the latter provides a way for overwhelming them with utter discredit. If there is anything that should be carefully pondered, with every difficulty and objection anticipated, it is the testimony of an expert in court. And yet he takes the stand, ignorant, for the most part, of the particular points on which he will be cross-examined, and surprised by questions he did not anticipate. Cross-examination, though an ad- 
mirable means for detecting falsehood and helping the memory, is sometimes used to obscure and pervert the truth, and throw suspicion and distrust on the most bonest attempt to tell it. The object of counsel in examining witnesses is not to elicit the whole truth, but only so much of it as will best serve their purpose. Whatever does come out adverse to this end is to be discredited by every allowable means, and they are neither few nor small. Men who have spent a lifetime practising the arts of cross examination seldom fail to damage the testimony of an expert, however cautious and clear headed he may be. In this manner the gravest truth may be arrayed in the colors of error, and the profoundest wisdom invested with the garb of folly. It is hard for the expert to maintain his self-possession while ingenious counsel are endeavoring by every kind of professional art to destroy the legitimate effect of his testimony. The result is, that many an honest and truthful expression of opinion is deprived of its proper weight with the jury, and to that extent the ends of justice are defeated. To some degree, no doubt, this is unavoidable in the nature of the case; but it cannot be denied that counsel often assume a license that forms no necessary part of a jury trial. If the judge would use his rightful authority to keep the cross-examination within its proper limits; insisting upon that kind of courtesy which marks the intercourse of gentlemen on all other occasions, there would be far less reason for distrusting and sneering at the testimony of experts.

This evil would be entirely avoided if the testimony of experts could be given in writing and read to the jury without any oral examination. It would thus be deliberately prepared, its explanations well considered, and its full force and bearings clearly discerned. It 
would go to the jury on its own merits, no advantage being gained by either party by the superior adroitness of counsel in embarrassing the witness, and pushing his statements to a false or ridiculous conclusion. It is not for me to pronounce an opinion on the practicability of such a change; but there certainly does not seem, at first sight, to be any insuperable obstacle in the way. It would work no injustice to either party, and it could be managed without additional inconvenience. There certainly can be no difficulty in civil cases, where both parties consent to the arrangement. In a famous willcase heard a few year's ago in the Surrogate's Court of New York City, the judge preferred to have the opinions of the experts submitted to lim in writing, with the understanding that, although they could not be received as evidence, they would be carefully read, and allowed all the weight their intrinsic merits deserved. The arrangement was approved by both parties, and I am not aware that the result was unsatisfactory to either.

In another particular there might be a change for the better, involving no alteration in the letter or spirit of the law. Of late years, courts have often evinced a disposition to depreciate the testimony of experts, and the thoughtless cry against it has found an echo in their willing utterances. If, instead of sneering at such testimony, they would exert their rightful power to render it worthy of respect and confidence by gladly availing themselves of its help, and discriminating between the claims of true science and the pretensions of mere charlatanism, much less would be heard, I imagine, of the popular complaints on the subject.

But no possible change in our methods of eliciting expert testimony, nor even that improvement which is implied in more exact and comprehensive attainment, 
will ever place it beyond complaint, so long as the courts themselves, in utter disregard of their proper functions, assume the part of the expert. This is a spectacle that has become so common of late years as to excite little or no surprise. In cases of disputed sanity, have we not seen the judge calling the party to his side, and, after a few minutes' conversation, pronouncing him sane and safe to be at large, in spite of the declarations to the contrary of men long conversant with the discourse, conduct, ways, and manners of the insane? Have we not heard a judge declaring his willingness to discharge from our hospitals every patient not clearly dangerous, and then setting up his own peculiar tests of danger? In a recent case that came under my notice, of application to a judge to order the commitment of a woman to a hospital for the insane, supported by an abundance of testimony that she had been insane for several years, during which she had been constantly uttering the most revolting delusions respecting those who were nearest and once had been dearest to her, openly charging her husband and daughter with practices not fit even to be named, worrying them by the most painful forms of annoyance, and banishing all peace and comfort from their lives; roaming from one boarding-house to another as often as her presence became intolerable, breaking away from the most careful and considerate arrangements made for her support, and finally driving her family from their home by her unceasing persecutions, - in that case did we not hear the judge, while admitting that she was clearly insane, decide that she was not a suitable subject for a hospital ?

It is not a sufficient defence of such judicial performances to say that the judge, acting without a jury, as in 
the cases alluded to, must decide points of fact as well as of law; because neither judge nor jury can rightfully decide on a question of fact contrary to the evidence, even of experts. The judge who assumes the functions of an expert wanders from his own proper sphere, while he belittles and degrades the office of the true expert.

The conclusion of the whole matter is, that it is with this as with many other imperfect institutions. We must look for improvement, not so much to any devices of legislation, as to broader views and a firmer spirit on the part of those who administer the laws, to a higher sense of professional honor, both in the lawyer and the physician, and to a healthier public sentiment. 


\section{INSANITY OF KING GEORGE THE THIRD.}

[IF insanity in a private individual occupying a high social position, and engaged in important affairs, is always embarrassing and often disastrous, one may faintly conceive of the extent of such a result when it occurs in the sovereign of an empirc. The purpose of the following pages was not to minister to a vulgar curiosity by an exposure of mental infirmities that reduce the most favored mortal to the level of the lowest, but rather to present, as a matter of instruction, a manifestation of the disease under circumstances of extraordinary interest and importance. Every good citizen may well ponder upon such a complete and sudden dislocation of all the normal relations existing between the executive and the other branches of the government. No attempt to prevent it or provide for it by legislation can ever obviate entirely the difficulties necessarily connected with such a contingency. As a matter of history, however, of the cases of insanity in the sovereign that have occurred during the last hundred years, not one, with a single exception, perhaps, - that of Peter of Russia, - has given rise to a political crisis or blocked the wheels of government. Still, it is obvious that such an event has been avoided, rather in consequence of some happy concurrence of circumstances than by any prospective provisions of law. A daring departure from prescriptive forms and usages, a bold assumption of authority, may have been required, while the customary functions of the government were scarcely disturbed. Yet this experience furnishes no security for the future. It does not enable us to contemplate the possible occurrence of the calamity in question, with any more complacency. It is easy to conceive that, in a republican form of government like ours, the difficulties accompanying it would be 
far less manageable than in one where those immediately around the patient are bound to him by ties of loyalty and long association. When, exactly, to interfere, how the interference should be made, when it should cease, - these are questions which, we cannot doubt, would fearfully try the conservative powers of our system. If it be true that history is philosophy teaching by examples, we may reasonably believe that, in such an event, some salutary lessons might be derived from the case of George the Third.

Like everything connected with state affairs, the incidents of King George's attacks are involved in considerable obscurity. Some of them, as related, are obviously fabulous; and, together with others less improbable, had their origin, undoubtedly, in the gossip which would naturally spring from such an interesting event as the insanity of the Sovereign. In this paper, care lias been taken to inrlicate the source of its materials, and to make use of none that could not be well authenticated.]

To the mere pathologist, the insanity of a prince is inot more interesting than that of a peasant; but to the historian, to the medical jurist, to all who are engaged in the care of the insane, the attacks of George the Third are invested with peculiar interest. He was a prominent figure in a period that teemed with great men and great events, whose memorials are yet around us; and twice the recurrence of his disorder gave rise to a degree of political feeling that has seldom been equalled, and to political discussions that settled for ever a vital principle in the British constitution.

George the Third had a moderate intellectual capacity, but an obstinate will. Of abstract speculation he was totally incapable, and philosophical views of any kind were beyond his reach. His theory of government began and ended in a firm maintenance of the royal prerogative, and the whole duty and privilege of the subject were comprised in the single precept, "Fear God and honor the King." As a result, partly of defective training and partly of original inaptitude, 
he disrelished intellectual pursuits, but was fond of mixing himself up with the administration of affairs, even in the smallest particulars. Here he showed 110 lack of industry nor of energy. He was a stranger to sensual passion, and in the common observances of life was a model of propriety. He never forgot what he deemed an injury, and they who thwarted his wishes or opposed his measures were regarded as factious or dishonest. Always looking upon his eldest son as a rival near the throne, "he hated him," says Brougham, "with a hatred scarcely consistent with the supposition of a sound mind." He was fond of music, and occasionally went to the theatre; but, with these exceptions, he sought for recreation solely in riding and walking, in looking after his farm, and in an easy intercourse with his family and dependants. Few men would have seemed less likely to be visited by insanity. His general health had been always good; his powers were impaired by none of those indulgences almost inseparable from the kingly station; he was remarkably abstemious at the table; and took much exercise in the open air. Insanity had never appeared in his family, and he was quite free from those eccentricities and peculiarities which indicate an ill-balanced mind.

Five times was George the Third struck down by mental disease. The first was in the spring of 1765 , when he was twenty-seven years old $;^{1}$ the second in 1788 , the third in 1801, the fourth in 1804 , and the fifth in 1810. Excepting the last, from which he never recovered, the attacks were of comparatively short duration, none of them continuing very obviously beyond six months.

3 Adolphus, History of England, i. 175. 
The particulars of the first attack were studiously concealed by his family, and its true character was not generally known at the time. There seems to be no doubt, however, that its symptoms were similar to those of the subsequent attacks. Shortly before, an eruption on the face, which had troubled him for some years, had so entirely disappeared that it was supposed he had applied external remedies to repel it. This was followed by considerable cough and fever, and then by mental disturbance. In the course of a few weeks he completely recovered.

During the latter part of October, 1788, the King seemed to be not in his usual health. He had considerable pain in his limbs; felt weak; slept but little; was hurried and vehement in his manner. On the $22 \mathrm{~d}$ he "manifested an agitation of spirits bordering on delirium," said his physician. A few days afterwards, on returning from a long ride, he burst into tears and said, "he wished to God he might die, for he was going to be mad." He kept about until the 4th of November, when he had an outbreak at dimner, and was consigned to the charge of attendants. During the first few days there was considerable constitutional disturbance, and it was feared he might not survive. One of Sheridan's correspondents says: "The doctors say it is impossible to survive it long, if his situation does not take some extraordinary change in a few hours. . . . Since this letter was begun, all articulation even seems to be at an end with the poor King; but for the two hours preceding he was in a most determined frenzy." In the course of the succeeding night he had a profuse stool, then perspired freely and fell into a profound sleep. He awoke with but little fever, "but with all the gestures and ravings of the most confirmed maniac, and a new 
noise in imitation of the howling of a dog." He soon got calmer, and talked of religion and of being inspired. A day or two after, the same person writes: "This morning he made an attempt to jump out of the window, and is now very turbulent and incoherent." He also says that the King revealed some state secrets, much to the astonishment of Pitt. ${ }^{1}$

Miss Burney, afterwards Madame D'Arblay, was then in the personal service of the Queen; and in her "Diary," recently published, the progress of the attack may be traced with some degree of minuteness. The first night after the outbreak at dinner, she says, he was very restless, getting up and wandering into the Queen's room to see if she was there, and talking incessantly until he became hoarse, exclaiming, "I am not ill, I am only nervous." "He was never so despotic; no one dared oppose him. He would not listen to a word." Next night he got up and insisted on going into the neighboring room, where his equerries were. There he saw his physician, Sir George Baker, whom he called an old woman, and wondered that he ever took his advice, for he knew nothing of his complaint. From this time he rapidly grew worse. On the 12th and 13th of November he appeared considerably better, and continued so until the 20th, when he became as bad as ever. From this period his condition was variable, - always more or less excited; rather petulant, if not irascible; scolding his gentlemen for slighting him. On the 29th of November he was removed to Kew, where were better opportunities for exercise. Through the month of December there was little if any change in his condition. During the first two or three weeks in January he became less irritable, was quite calm at

1 Moore. Life of Sheridan, p. 360 . Amer. edition. 
times, and then would read and make sensible remarks on what he had read. From the latter part of the month he steadily improved. February $2 d$ Miss Burney accidentally saw him walking in the garden; and to avoid meeting him, in compliance with the rules, ran off at full speed, and he after her, the physicians and attendants in full chase after him. She finally stopped until he came up, when he put his arms around her neck and kissed her. He talked incessantly, blurting out whatever came uppermost. "He seemed to have just such remains of flightiness as heated his imagination without deranging his reason, and robbed him of all control of his speech, though nearly in his perfect state of mind as to his opinions.... He opened his whole heart to me, expounded all his sentiments, and acquainted me with all his intentions." He declared he 'was as well as he ever was in his life, talked of the official situation of her father, of music (when he undertook to sing), and then of her friends. He said he was dissatisfied with his ministers, and showed a list of new ones he had prepared. On the 17th he received the Chancellor, on the 18th drank tea with the Queen, and on the 7th of March received the address of the Lords and Commons in person. ${ }^{1}$

One of his first excursions after recovery was to a poor-house in the course of erection, of which he inspected every part, especially the rooms for lunatics, and expressed much satisfaction that such excellent accommodations were provided for persons laboring under the misfortune of insanity. During his convalescence, it is said, he passed much of his time in reading the debates on the Regency Bill. ${ }^{2}$

The King was attended at first by his own physicians,

1 Diary and Letters, chap. $x$.

2 Wraxall. Posthumous Memoirs of his own Time, p. 520. Phila. 
Sir George Baker and Dr. Warren; and they were shortly after joined by Sir Lucas Pepys, Drs. Reynolds, Gisborne, and Addington, of whom the latter alone had given any special attention to the treatment of insanity, and he discontinued his attendance after a few days. They had all achieved professional distinction, but Warren enjoyed an undisputed preëminence. He was not only at the head of his profession in London, and de servedly so, but such were his talents and manners that he associated intimately with the leading men of the day (Burke, Fox, Sheridan, \&c.), and was appointed physician to the Prince of Wales. The attack not readily yielding, it was thought proper by the Queen and the ministers, who had the direction of these matters, to have the constant attendance of some one particularly skilled in diseases of the mind. Their choice fell on the Rev. Dr. Francis Willis. This gentleman was educated for the Established Church, and took charge of a parish in Lincolnshire. Having some knowledge of medicine, in which he took the regular degree of M.D. at Oxford in 1759 , he was fond of prescribing for the medical as well as the spiritual wants of his people, and especially for mental diseases. He was soon regarded as very successful in this department of the healing art, and was so much resorted to that he provided an establishment designed expressly for the treatment of the insane. He was much patronized by the higher classes, and for fifty. eight years had never less than thirty patients under his care. He was at this time seventy years old, but "seemed to be exempt from all the infirmities of old age; and his countenance, which was very interesting, blended intelligence with an expression of placid selfpossession." Miss Burney describes him as "a man of.

1 Wraxall, Idem, p. 447. 
ten thousand, - open, honest, dauntless, light-hearted, innocent, and high-minded." The common opinion was that he was employed at the suggestion of Addington; but a lady of the court represents that the step was taken at the instance of the wife of one of the equerries, her mother having been cured by Willis. ${ }^{3}$ He joined the corps of physicians on the 6th of December, and took up his quarters in the palace. ${ }^{2}$ In the consultation which settled their respective functions, Willis was to have charge of the domestic and strictly moral management; in accordance, however, with such general views as had been agreed upon. The medical treatment was arranged in the morning consultation; and it was understood that Willis was to take no decisive measure, either medical or moral, not previously discussed and permitted. Pepys, Gisborne, and Reynolds attended, in rotation, from four o'clock in the afternoon until eleven the next morning. Warren or Baker visited in the morning, saw the King, consulted with Willis and the physician who had remained over night, and agreed with them upon the bulletin for the day. Willis was soon joined by his son $J_{0 h n}$, whose particular function seems not to have been very definitely settled. Willis professed to regard him as equal to himself in point of dignity and responsibility, but his colleagues considered him as merely an assistant to his father. Two surgeons and two apothecaries were also retained, each one in turn staying twenty-four hours in the palace. The personal

\section{Lady Harcourt's Diary. British Museum.}

2 Among the gossip of the court, it was related that the "King asked Willis, when he entered the room, if he, who was a clergyman, was not ashamed of himself for exercising such a profession. 'Sir,' said Willis, 'our Saviour himself went about healing the sick.' 'Yes,' answered the King, 'but he had not $£ 700$ a year for it." "- Lord Malmesbury's Diaries, \&c., iv. 317. 
service was rendered by three attendants, whom Willis had procured from his own establishment, and the King"s pages, - one attendant and one page being constantly in his room. ${ }^{1}$

The medical treatment seems to have consisted chiefly of "bark and saline medicines." An alterative pill, containing a little calomel, was given him once. Once, and once only, blisters were applied, - to the legs; but they occasioned considerable irritation and restlessness.

It was determined that the moral management of the King required strict seclusion from his family and minis-

1 And yet, notwithstanding all this attendance and supervision, the King told Lord Eldon he was knocked down by a man in the employ of one of his physicians. "When I got up again," he added, "I sairl my foot had slipped, and ascribed my fall to that; for it would not do for me to admit that the King liad been knocked down by any one." [Twiss, Public and Private Life of Lord Chancellor Eldon, chap. xviii.] From the same source, no doubt, Miss Burney and Lady Harcourt heard what they have reported respecting the brutal treatment suffered by the King from his attendants. They represent that he was beaten, starved, chained to a staple, and enclosed in a machine which left him no liberty of motion. In the interview with Miss Burney in the garden, already mentioned, the King complained that one of the attendants knocked him down, "seized him in his arms, carried him into a chamber, and throwing him violently on a sofa exclaimed in an insolent manner to the attendants, "There is your King for you." That two silly women should have thought these preposterous stories related to some actual occurrences is not strange, though Miss Burney herself doubted the truth of the last; but when Mr. Massey, in his History of England during the Reign of George the Third (iii. 381), relates them as if they were unquestionably true, we are almost ready to relinquish all faith in history. History, it is said, repeats itself. With equal truth we may say that the tales of the insane, and the way they are received, are but a repetition, generation after generation, of the same gross delusion and childish credulity. The stories of George the Third respecting the abuse he suffered, - how like those paragraphs of the newspaper reporter and the sensational novelist, which in our own day kindle the wrath of those worthy people who are always ready to accept a tale of outrage for gospel truth, without evidence and against reason. 
ters, and, as far as possible, from all other company. But nothing can more strikingly indicate the change that has occurred since that time, in respect to one means of managing the insane, than the fact that, for two or three months after. Willis took charge, the King was frequently subjected to mechanical restraint. There was nothing, however, in his condition which would now be considered in England a sufficient reason for its application. He was not disposed to injure his person or his clothing, his attendants or his furniture. In the King's case - and this, no doubt, was an example of the ordinary practice - it was evidently used by way of discipline, as a means of subduing turbulence and increasing self-control. Willis said, in his second examination by the committee of the House of Commons, that when he took charge of the King he was dissatisfied with the restraint which had been previously used, and for five days "endeavored to persuade and explain" that some more efficient method would be resorted to, unless there was a "ready compliance" with his wishes. The King seems to have been insensible to this kind of intimidation, and the new mode of restraint was applied, with the effect, as Willis states, of accomplishing the desired purpose more perfectly than before, being "more firm, but not so teasing to the patient." It does not appear what means of restraint were used by Willis, or by the other physicians in subsequent attacks, but an incident related by Wraxall renders it probable that one of them was that time-honored implement which is still associated with the popular idea of insanity. While walking through the palace, during his convalescence, accompanied by an equerry, they observed a strait-jacket lying in a chair. The equerry, averting his look, as if to conceal some embarrassment, the King said: "You need not be 
afraid to look at it. Perhaps it is the best friend I ever had in my life." I This incident does not strengthen a favorite position of the advocates of non-restraint, viz., that it leaves disagreeable impressions upon the patient's mind.

Of another fact respecting the King's treatment I cannot find a sufficient explanation. Between the 6 th of December and the 13th of January he went out of doors but twice, and for a month previous not at all. Considering the form of the disorder and the facilities for exercise which the grounds afforded, this is certainly surprising. On one occasion, when the King had been promised a walk, Dr. Warren revoked the promise, because, as the day was cold, and the King had perspired freely in the night, there would be some risk of his taking cold. It appears that on that night the restraint had not been removed at all.

The political consequences of the King's illness proved to be of the deepest interest, whether we regard the magnitude of the questions at issue, or the men by whom they were discussed. The array of talent which distinguished the Parliament of that period has never been equalled before or since. The interests of the administration were supported by Pitt, Thurlow, and Wilberforce, while the forces of the opposition were led by Fox, Burke, Sheridan, Windham, Grey, Loughborough, and North. During the two or three months that the struggle lasted, every weapon of argument, wit, ridicule, and invective was used by the contending parties with a dexterity and vigor which such men only could display.

When the King's incapacity was announced, Parlia- 
ment immediately set about to provide a regency. Both parties agreed that the Prince of Wales should be the Regent, but differed very widely as to the exact amount of authority and privilege he should receive. The Whigs contended that he should exercise all the functions of the Sovereign precisely as if there were a demise of the Crown. The ministers, on the other hand, were determined to hamper the Regent with limitations and restrictions which would have shorn the regal office of much of its dignity and power. The real question at issue, therefore, was, which of the two parties that divided the country should possess the administration, and hence the violent party spirit which characterized all the political proceedings of the time. The first step was to ascertain officially the exact condition of the King, and accordingly each House appointed a committee to examine his physicians. These committees proceeded immediately to the duty assigned them, and within a couple of days their reports were presented to their respective Houses, - that of the Lords on the 10th, that of the Commons on the 11th, of December.

To each physician was put the following questions: "Is his Majesty incapable, by reason of the present state of his health, of coming to Parliament, or of attending to public business? What hopes have you of his recovery? Is your answer to this question founded upon the particular symptoms of his Majesty's case, or your experience of the disorder in general? Can you form any judgment or probable conjecture of the time his Majesty's illness is to last? Can you assign any cause for his illness? Do you see any signs of convalescence?" The replies to these questions evince a knowledge of insanity quite creditable to men not expressly devoted to this branch of the science, - one that would 
hardly be expected by us who witness so frequently the remarkable discrepancies of opinion that characterize the reports of medical commissions, albeit they may include men whose names are not entirely unknown to fame. The replies also evince a certain discretion and reserve worthy of imitation on the part of those who are called upon for professional opinions. Few medical witnesses succeed, as most of these gentlemen did, in hitting that happy medium between saying too much and saying too little. They all expressed strong hopes of the King's recovery, because the majority of patients actually do recover, and they saw nothing particularly unfavorable in his case. None of them saw any signs of convalescence, and, with one exception, none of them pretended to assign causes or limits to his disorder. Willis said he would recover within a few months, and thought the attack was produced by "weighty business, severe exercise, too great abstemiousness, and little rest." The other physicians were as well aware as Willis, no doubt, of these facts in the history and habits of the King, and possessed better opportunities than he had of knowing how far they had affected his mind, but refrained from assigning them as causes of the disorder. Willis's opinion, though confidently uttered, was merely a speculation, resting on no very substantial grounds. The King's business had not been weightier than usual; and, though fond of exercise, there is no evidence that he carried it to a degree incompatible with its proper object, the promotion of health. His abstemiousness consisted merely in avoiding that excessive indulgence in the pleasures of the table which was common among the higher classes of that period, and was practised by him for the purpose of warding off disease. The want of sleep was probably one of the effects rather than a 
cause of his mental affection. Whether the committee were satisfied with Willis's theory does not appear ; but most of them probably were, like the rest of the world, curious to learn the cause of the attack, but readily satisfied with elaborate phrases and dogmatic assertions. ${ }^{1}$ Sheridan, however, saw in it a fair mark for his wit, and he was not the man to neglect an opportunity of that kind. Willis had stated, in proof of the correctness of his opinion, that the medicine which had been given to his Majesty ever since Sunday morning, in order to meet and counteract those causes, had had as much effect as he could wish, and "his Majesty had certainly been gradually better from the first six hours of his taking it." The orator said that, when he heard Dr. Willis assert that his physic could, in one day, "overcome the effects of seven and twenty years' hard exercise, seven and twenty years' study, and seven and twenty years' abstinence, it was impossible for him to keep the gravity fit for the subject. Such assertions put lim in mind of those nostrums that cure this and that, and also disappointments in love and long sea-voyages." 2

The policy of the cabinet was to make it appear that the King's illness would be of short duration, and let it be implied, as an obvious consequence, that the measure

1 Just previous to the attack, an eruption on the legs, of some duration, had suddenly disappeared. This incident, considered in connection with a similar one in the first attack, may be fairly regarded as a more efficient exciting cause than any one of those mentioned by Willis; and yet he overlooked it altogether.

2 The fact that the medicine referred to - which was simply Peruvian bark - was determined upon in the consultation of the whole corps of the King's physicians, and that no other observed any improvement in his condition, gives additional pungency to the ridicule, while the whole incident throws much light on Willis's character.

The Parliamentary Debates on the Regency are contained in the 27 th volume of Hansard. 
of appointing a regent should not be precipitated. On the other hand, the policy of the Whigs was to represent the disorder as incurable, or, at least, of very uncertain duration, and therefore that the sooner the regency was established the better for the country. In this view they received but feeble support, certainly, from the examination of the physicians; but Warren, who was high in the counsels of the Whig party, had privately encouraged the idea that the King would never recover. True, in his examination just referred to, and also in the examination on the 7th of January, he expressed as much confidence as the others in his ultimate recovery. The fact furnishes a striking illustration of the distorting influence of party spirit, eren upon the views of scientific men on scientific subjects. Willis, who always professed to be quite sure of the King's recovery, and was equally high in the estimation of the other party, inspired the administration with confidence in the policy they had adopted. Every occurrence at Kew was whispered about in political circles, before it was many hours old, colored and exaggerated, of course, by the prevalent hopes and fears. The names of Warren and Willis became as familiar as household words, and even served as rallying points for the two great parties into which the country was divided. In less than a month from the first examination, both parties were equally ready for another, and equally confident of deriving political capital from the result. For this purpose the Commons appointed a select committee, which commenced its sittings on the 7 th of January, and made their report, 400 folio pages long, on the 13th. ${ }^{1}$ The same questions as before were

1 The report of the first examination may be found in the parliamentary debates and annual registers of the time, but not so this, which long eluded my search, until found in a collection of pamphlets, entitled, 
put to the physicians, and were followed by the same replies, except that Willis, when asked if he had observed any signs of convalescence, replied affirmatively. The greater part of the examination was directed to matters having only an incidental connection with the King's condition, - the communications sent from Kew to the ministers and other leading characters, the domestic arrangements of the palace, the dissensions of the physicians, the merits and proceedings of the Willises, - to anything, indeed, calculated to strengthen one side or weaken the other. Upon the signs of recovery or convalescence the examination was particularly searching, because, more than anything else, they determined the political movements of the day. Willis, when asked if he saw any present signs of convalescence, replied: "About a fortnight ago, his Majesty would take up books and could not read a line of them; he will now read several pages together, and make, in my opinion, very good remarks upon the subject. I think, in the main, his Majesty does everything in a more rational way than he did, and some things extremely rational." This trait had been observed for the last five or six days, the books having been selected by the King, and read aloud. To the same purpose, he also stated that his patient was less frequently and less intensely excited, and less frequently required restraint. Beyond the simple acknowledgment that he was more quiet, the other physicians were not disposed to go, in regard to the signs of convalescence. They denied that he had appeared rational, even for a moment, but none of them

"History of the Regency," published by Stockdale, and brought to my notice by the librarian of Brown University, Mr. Guild. From this report chiefly I have obtained all that seemed worth preserving respecting the management of the King. 
had happened to see the King reading, and they were not disposed to take any fact of Willis's observing as a ground for their opinions. His constant attendance gave him an advantage over his colleagues, for it enabled him to see for himself much that they would never know at all, or only at second hand; and such observations, we are all very well aware, sometimes leave a stronger impression on the mind than the most definite and tangible facts communicated by others.

Willis's character, conduct, and practices were subjected to a very searching scrutiny, not more for the purpose of obtaining information than of torturing every inciclent into matter of censure against himself or his employers. It cannot be denied that he gave his adversaries abundant opportunities of this kind; for, with all his experience, and the frost of seventy years on his head, he had not a philosophical turn of mind, nor the art of concealing his deficiency by a prudent reserve. He had stated that nine out of ten of his patients recovered under his hands, but he was unable to tell how many he had received or how many he had cured. When further pressed, he said that the ground of his calculation was the fact that his first fifteen patients were cured, and that, subsequently, several instances occurred of ten going away together radically cured. The declaration of his colleagues respecting this alleged success - that it required other evidence than his bare assertion was not calculated to restore the harmony which had been so thoroughly disturbed. He was obviously very restive under the unusual restrictions imposed upon him. To be associated on equal terms with some half dozen other physicians, equal to himself in professional eminence, and more than his equals in general culture, he found a very different position from that of controlling 
an establishment where his simple word was law. He felt - very correctly, no doubt - that a great obstacle to the King's recovery consisted in his being obliged to see so many different persons, under circumstances calculated to excite strong emotion. He was actually dis. turbed, and sometimes even prevented from sleeping, by the visits of so many medical men, - never less than half a dozen every day; and, accordingly, Willis, "thinking it his duty," as he says, "to do for his Majesty what he should do for any private gentleman," put up a written notice that no person should be admitted into his Majesty's rooms without permission of himself or son. For this order, which was more easily given than enforced, for none of his colleagues seem to have regarded it, - he was severely handled by the committee, who endeavored to make it appear like an attempt on his part, and that of the Lord Chancellor, whose sanction he pleaded, to conceal, in some degree, the King's real condition.

Another obstacle to the King's recovery, apprehended by Willis, seems rather fanciful than real. "When his Majesty," he says, "reflects upon an illness of this kind, it may depress his spirits and retard his cure more than a common person;" but, subsequently, he states that "this apprehension is somewhat relieved by his knowledge of the King's sense of religion, which may lead him, with a proper resignation, to reflect on what it had pleased God to afflict him with."

The want of good faith was broadly charged upon Willis by his colleagues, and in the examination there came out one instance of it which has obtained a popular celebrity. Warren stated that, on the day Willis arrived, it was agreed, in general consultation, "that quiet of body and mind were to be endeavored to be obtained by every means possible; and that everything should be 
kept from his Majesty that was likely to excite any emotion; - that though his Majesty had not shown any signs of an intention to injure himself, yet that it was absolutely necessary, considering the sudden impulses to which his distemper subjects people, to put everything out of the way that could do any mischief." The very next day, however, he put into the King's hand a razor and a penknife. "I asked him," says Warren, "how he could venture to do such a thing. He sard he shuddered at what he had done." Willis said, in explanation, that the King "had not been shaved for a long while, perhaps a fortnight or three weeks; and the person that had been used to shave him could not complete the parts of his upper and under lips; and being confident, from the professions and humor of his Majesty at that moment, I suffered his Majesty to shave his lips himself; and then he desired he might have his whole face lathered, that he might just run over it with a razor; and he did so in a very calm manner. His nails also wanted cutting very much; and, upon his assurance, and upon my confidence in his looks, I suffered him to cut his own nails with a penknife, while I stood by him. It is necessary for a physician, especially in such cases, to be able to judge, at the moment, whether he can confide in the professions of his patient; and I never was disappointed in $\mathrm{my}$ opinion whether the professions of the patient were to be relied on or no." He denied that he said to Warren, he shuddered at what he had done, and also denied that, in regard to such matters, he ever agreed not to be governed solely by his own discretion. After professing such views, he found it a little inconvenient to answer the question, why he never afterwards repeated this indulgence. He replied, however, that it had a bad moral effect, his Majesty taking it ill that he was not 
allowed other privileges, such as going upstairs to see his family, and doing other imprudent things. "Do you think," asked the committee, "that the expectation of the liberties which the King might call for would be of more danger to him than the use of razors and penknives?" "To be sure," was the reply, "because the refusal would irritate him much and increase his disorder." "Whether," continues the committee, "you refuse to the King all indulgences which may be safely given, lest he should demand those that ought to be refused?" "I do a great many," said Willis. Those, certainly, were very embarrassing questions.

This incident furnished Burke with the materials of a violent diatribe against the ministers, who, he said, had committed his Majesty to the care of a man in whose hands he was not safe for a moment. ${ }^{1}$

It also came out that, within five days after he took charge of the King, Willis allowed him to have an inter-

1 There is a traditionary aneedote connected with this razor scene, strongly illustrative, if true, of Willis's character. Burke asked him, it is said, what he would have done, if the King had suddenly become violent while these instruments were in his hand. Having placed the candles between them, he replied, "There, sir, by the ErE! I should have looked at him thus, sir, - thus! "whereupon Burke instantaneously averted his head and made no reply. If such a scene as this occurred at all, it could not have been in the committee-room, as Burke was not on the committee. Why so prominent a member of the House was not placed on the committee with Fox, Shericlan, \&e., has always been a matter of surprise. The authority for this anecdote is Reynolds, the playwright, who says he had it from IVillis himself. (Life, \&c., ii. 15.) Among the gossip of the day was a similar story respecting the effect of Willis's tone on Sheridan when about to examine him. " "Pray, sir, before you begin,' said Willis, 'be so good as to snuff the candles, that we may see clear, for I always like to see the face of the man I am speaking to.' Sheridan was so confounded at this speech of the basilisk Doctor, that he could not get on in his examination, and for once in his life he was posed." (Swinburne's Courts of Europe, ii. 75.) 
view with his daughters, and another with the Queen, without the consent or knowledge of his colleagues, and contrary, as they alleged, to the terms of their agreement. In defence of his course, he said: "I am sure that such occurrences can scarce be too frequent, as it comforts the patient to think that he is with his family, and that they are affectionate to him ; and upon inquiries of patients who have been cured of the same indisposition, they have always mentioned those occurrences having given them the greatest comfort, and, as they thought, helped very much towards their recovery. .. The irritation occasioned by a patient's seeing his friends or relations is entirely overbalanced by the softening him into tears, which ever leads to amendment."

Another incident in Willis's management, which had greatly scandalized his colleagues, was deemed worthy of the notice of the committee. It was the allowing his Majesty to read the tragedy of Lear. It seems he refused the King's request to have it, though too crazy, he thought, to be affected by it, one way or the other; but allowed him to have a volume of plays, which happened, without his knowledge, to contain Lear. ${ }^{1}$

In the practical knowledge of insanity, and the management of the insane, Willis was unquestionably in advance of his associates; but, following the bent of his dictatorial habits, he often spoke without measuring his words, and often overstepped the limits of professional etiquette. Hence he suffered under the severe handling of the committee, to whom he presented a good

1 Willis's statement that he had never read this play is not calculated to raise our estimate of his general culture. 
many vulnerable points of attack. It is obvious, in fact, that Willis was a bit of a charlatan, and not always above the arts of that character. Sheridan remarked, in one of bis speeches, that Willis professed to have the gift of seeing the heart by looking at the countenance; and added, looking at Pitt, that the declaration seemed to alarm the Right Honorable gentleman. ${ }^{1}$

But, with all these imperfections, it cannot be denied that Willis evinced much practical sagacity in his views of the nature and management of mental disease, and a sturdy independence and self-reliance which, while they are always elements in a great character, were in him, under the circumstances, very remarkable. Let those who are emulous of his success strive to imitate him in these qualities, rather than in his dogmatism and disregard of professional observances.

The report of the committee was a fruitful topic in the subsequent debates in Parliament, furnishing fresh materials for declamation and intrigue. On no other occasion, probably, were the prominent qualities of the celebrated men who figured at that period more strikingly exhibited. Night after night, for weeks together, witnessed the unrivalled self-possession of Pitt, the clear, close, vehement argumentation of Fox, the irresistible wit of Sheridan, the multifarious knowledge and riotous fancy of Burke. But the prize, which seemed to be almost within the grasp of the Whigs, rapidly receded from their view. Towards the last of January the King had unquestionably improved, and on the 25th of February Warren signed a report declaring him "free from complaint."

1 There is nothing of this kind in the report of the committee, but it may have been suppressed. Sheridan would hardly have invented the fact, and then called on Pitt to witness its truth. 
The question of recovery was also embarrassing, for although it might be obvious enough to the family and friends, yet it was not so easy to establish it satisfactorily to the country. An apparent recovery is not always a real one. Often, after a person seems to have regained his natural feelings and views, and has recognized his mental disorder, and is preparing, perhaps, to resume his customary pursuits, he again passes under the cloud, and, to all appearance, is as far from sanity as ever. Burke was as ready for this as for any other occasion, and his remarks upon it exhibited his wonderful faculty of acquiring and appropriating every description of knowledge. "The disorder," said he, "with which his Majesty was afflicted, was like a vast sea which rolled in, and at low tide rolled back and left a bold and barren shore. He had taken pains," he continued, "to make himself master of the subject, he had turned over every book upon it, and had visited the dreadful mansions where those unfortunate beings were confined. ... An author of great authority, having mentioned the uncertainty of the symptoms of sanity, had declared that, after having been kept a month (and the rule was, at all the houses he had visited, though anxious to discharge the patients speedily, as they all were, to keep them a month after their recovery before they turned them out of the house), they would sometimes dread the day of their departure, and relapse on the very last day.... He drew a picture of the King's supposed return, which he described as most happy, if really cured; but as horrible in the extreme, in its consequences, if a sudden relapse took place."

The only effect of the King's alleged convalescence was to suspend all Parliamentary proceedings relative 
to a regency, while, quietly and without opposition, he resumed one after another his regal functions. ${ }^{1}$

His Majesty's third attack ${ }^{2}$ began about the 22d of February, 1801; and though supposed by the public to have recovered within three or four weeks, it is certain that he was not fully restored until the last of June. He was attended by Drs. Gisborne, Reynolds, Pepys, John Willis, Robert Darling Willis, and Thomas Willis, ${ }^{3}$

1 Willis was rewarded by Parliament with a pension of $£ 1,500$ for twenty-one years. He was shortly after employed to treat the Queen of Portugal, but she proved to be incurable. For this service he received $\mathfrak{f} 20,000$. These fees were without a parallel in the records of the medical profession. Dr. John Willis received for his services $£ 650$ per year during his life.

In Frederick Reynolds's " Life and Times," I find the following notice of Willis's establishment: "Gretford and its vicinity at that time exhibited one of the most peculiar and singular sights I ever witnessed. As the unprepared traveller approached the town, he was astonished to find almost all the surrounding ploughmen, gardeners, threshers, thatchers, and other laborers, attired in black coats, white waistcoats, black silk breeches and stockings, and the head of each 'birn poudré, frisé, et arrangé.' These were the Doctor's patients; and dress, neatness of person, and exercise being the principal features of his admirable system, health and cheerfulness conjoined to aid the recovery of every person attached to that most valuable asylum. The Doctor kept an excellent table, and the day I dined with him I found a numerous company. Amongst others of his patients, in a state of convalescence, present on this occasion, were a Mrs. B., a lady of large fortune, who had lately recovered under the Doctor's care, but declined returning into the world from the dread of a relapse ; and a young clergyman, who occasionally read service and preached for the Doctor. Nothing occurred out of the common way till soon after the cloth was removed, when $I$ saw the Doctor frown at a patient, who immediately hastened from the room, taking with him my tail, which he had slyly cut off."

2 “Mrs. Goodenough (sister to Mr. Addington) told Miss Jennings that the King had an attack somewhat similar to the present in 1795, from which he recovered in about a week." (Diary and Correspondence of Hon. George Rose, i. 322.)

3 Robert and John Willis were sons of Francis, and probably Thomas was, but of this I am not quite certain. Lord Sidmouth (Addington) 
who seems to have been a clergyman as well as a doctor. The early stage of the disease was much like that of 1788, except in being of shorter duration. On March $2 d$ there seems to have been a sudden exacerbation of his disorder; but about five P.x. he fell into sound sleep, which continued a couple of hours. Shortly after: he again went to sleep, and continued sleeping until four A.M., when he awoke quite tranquil, and asked how long. he had been ill. In the mean time his pulse fell from 134 to $84 .{ }^{1}$ After the first week or two he could control his morbid manifestations to such a degree that, to them who saw him only occasionally, he seemed to be less under the influence of disease than he really was. Indeed, as early as the 7th of March lie played at backgammon and piquet, and it was commonly reported and commonly believed that he had completely recovered, though on the 4th Reynolds lad stated that "much time would be necessary to complete the cure.". 2 The bulletins ceased on the 12th of March, when Reynolds ended his attendance. He received the resignation of Mr. Pitt on the 14 th, and transacted business on the 17 th. $^{3} \mathrm{He}$ continued under medical care until the end of June, appearing very well whenever circumstances required the exercise of self-control, but constantly exciting the

says (Diary, iii. 38) that "Dr. Willis and his two sons got $£ 10,000$." In the beginning of this attack it was proposed to send for the elder Willis; but the proposal met with opposition, the reason for which may be found, probably, in the remark made by Addington to Lord Colchester, that old Willis was "rude and violent." (Colchester, i. 24t.) He finally came, however, as early as the 27 th of February; but how long he stayed does not appear. It could not have been long, for his name is scarcely mentioned in the contemporary notices of the King's illness.

1 Rose, i. 325.

2 Diaries of Lord Malmesbury, iv. 28.

3 Rose, i. 335. 
apprehensions of his family and physicians by some manifestations of mental disturbance. It appears that some time in May, apparently, the royal family were all at Kew; but the King was kept in a house by himself, in the immediate charge of the Willises. ${ }^{1}$ John Willis, writing to Lord Eldon, May 16th, intimates that "artificial prudence" is still absolutely necessary, and informs him that his conversations with the King have not been of much service. "He seems," he continues, "rather to select and turn any part to his purpose than to his good." 2 Five days after, Addington writes to Lord Eldon that, "during a quiet conversation of an hour and a half, there was not a sentiment, a word, a look, or a gesture, that I could have wished different from what it was; and yet my apprehensions, I must own to you, predominate. The wheel is likely to turn with increasing velocity (as I cannot help fearing); and if so, it will very soon become ummanageable." 3 Four days after, one of the Willises writes that the King "is in a perfectly composed and quiet state. He told me, with great seeming satisfaction, that he had a most charming night, — 'but one sleep from eleven to halfpast four;' when, alas! he had but three hours' sleep in the night, which upon the whole was passed in restlessness, in getting out of bed, opening the shutters, in praying at times violently. . . He frequently called, 'I am now perfectly well, and my Queen, my Queen has saved me.' .. The King has sworn he will never forgive her if she relates anything that passes in the night." 4 June 9 th, one of the royal family writes to Thomas Willis, "He has been very quiet, very

1 Rose, i. 354.

2 Twiss, Public and Private Life of Lord Chancellor Eldon, i. 204.

3 Idem, i. 205.

4 Idem, i. 205. 
heavy, and very sleepy. ... God grant that his eyes may soon open, and that he may see his real and true friends in their true colors." Three days after, she again writes that "the sleepiness continues to a great degree. I am told the night has been tolerable, but he has got up in his usual way, which is very vexatious." I Four days after, one of the Willises writes: "His Majesty rode out this morning at ten o'clock, and did not return till four. He paid a visit in the course of the day to Mr. Dundas. His attendants thought him much hurried, and so did his pages. He has a great thirst upon him, and his family are in great fear. His Majesty still talks much of his prudence, but he shows none. His body, mind, and tongue are all upon the stretch every minute; and the manner in which he is now expending money in various ways, which is so unlike him when well, all evince that he is not so right as he should be." 2

A considerable change seems to have occurred within a few days of the date of this letter, since his physicians were discharged, and we hear no more of his disorder. He was strongly averse to having the Willises any longer about him ; though, as he says, "he respected the character and conduct of Robert Willis." "No one," he says, "who has had a nervous fever can bear to continue the physicians employed on the occasion." 3

During the first three weeks of the attack there was actually a suspension of the royal functions, and with it a suspension of some political arrangements of the high-

1 Twiss, i. 206.

2 Idem, i. 208.

3 The only thing respecting the medical treatment in this attack which has rewarded my inquiries is, that the Prime Minister, Mr. Addington, one day recommended a hop pillow for procuring sleep, which proved perfectly successful. "In this attack sleep always calmed and quieted the King, while in that of 1788 he would awake from a long sleep more turbulent than ever." (Malmesbury, Diaries, iv. 46.) 
est importance. Pitt had resigned, but there was no one to receive his resignation, or sign the commission of his successor; so that it would have been difficult to answer the question, Who is now Prime Minister? Of the other members of the administration some had resigned, and their successors had taken their places; while other's who had resigned still held on, because their successors had not been sworn in. Pitt and his friends continued to perform the necessary routine duties of their offices, and $\mathrm{Mr}$. Addington held constant communication with the palace. ${ }^{1}$ This change of ministry, which was exceedingly distasteful to the King, was regarded by some as the exciting cause of this attack; but it is probable that the differences between the Prince of Wales and his wife had also much to do with it. It was ushered in by a violent cold, which he contracted by remaining long in church on the $13 \mathrm{th},-\mathbf{a}$ chilly, snowy day.

Again, on the 12th of February, 1804, the King manifested unequivocal signs of mental disease, occasioned, it was thought, by the publication of certain correspondence between the Prince of Wales and the Duke of York, and immediately preceded by a cold and a consequent fit of the gout. This attack continued longer than the last; but, like that, was much less severe than the attack of 1788. He was attended by Sir Lucas Pepys, Dr. Reynolds, Dr. Heberden, and Dr. Simmons, physician of St. Luke's, ${ }^{2}$ and was in the particular charge of

1 Life, \&c., of Lord Sidmouth, by Pellew, i. 309.

2 Why none of the Willises were employed on this occasion does not appear. It was probably, however, for the same reason that was alleged for their not being employed at first in the next attack, - viz., the Queen's apprehension that their presence would excite umpleasant associations in the King's mind. In fact, the King conceived a strong dislike for the Willises; but it seems to have been a common impression at court 
the latter, who resided in the palace. The few scanty notices I have been able to find convey but little information respecting the character or progress of this attack. About the 25th of February it was generally understood that the King was improving; but in the bulletin of the 26 th it was stated that his speedy recovery could not be expected. ${ }^{1}$ We learn that on the 9th of March Lord Eldon walked with him around the garden, when he observed, as he says, "at first a mcmentary hurry and incoherence in his Majesty"s talk; but this did not endure two minutes. During the rest of the walk there was not the slightest aberration in his Majesty's conversation, and he gave me the history of every administration in his reign." 2 On the $23 \mathrm{~d}$ of April he presided at a council. On the $2 d$ of Nay Addington walked with him in the garden, and thought him perfectly well. ${ }^{3}$ Five days after, Pitt conversed with him three hours, and was "amazed at his cool and collected manner." 4 May 2.5th, the Duke of York writes that the King seems to dwell much upon the illegality of his confinement; and the next day Pitt, in a note to Eldon, expresses some alarm in reference to a conversation in one of the audiences two days before. "The topics treated of were such as did not at all arise out of any view (right or wrong) of the actual state of things,

(Malmesbury, ir. 316) that they managed him much better than Simmons.

1 Bulletins must necessarily be brief and rery general in their terms, and therefore not calculated to convey rery accurate information; but those which were issued by the physicians during this illness often indicate much confusion of ideas, and an uncertain, vacillating prognosis, which did not escape the notice nor the censure of Parliament. For instance, the very next day after the bulletin above mentioned, the bulletin said, "He is still better than he was yesterday, and gradually approaching recovery." (Rose, ii. 121.)

${ }^{2}$ Twiss, i. 228. ${ }^{3}$ Life of Sidmouth, i. 313. ${ }^{ \pm}$Malmesbury, iv. 306. 
but referred to plans of foreign politics, that could only be creatures of an imagination heated and disordered." 1

About the same time, his family and physicians remarked an unduly familiar tone of conversation, and other little improprieties of manner. When conversing on serious matters and business, he was cool, rational, and dignified; but on lighter subjects he would indulge in unseemly levities. Pitt advised him in a letter to put himself under medical direction, and Eldon did the same. The King, after reading them, said he had received two very foolish letters. ${ }^{2}$ Since 1801 he had conceived and often expressed a great dislike of medical men.

His conduct at this period, as described by one of his court, indicates a phasis of insanity which, though common enough, is apt to be greatly misunderstood by people not professionally acquainted with the subject. "Mrs. Harcourt confirms all that Lady Uxbridge had told me, - that the King was apparently quite well when speaking to his ministers, or to those who kept him in a little awe; but that towards his family and dependants his language was incoherent and harsh, quite unlike his usual character. She said Symonds did not possess in any degree the talents required to lead the mind from wandering to steadiness; that in the King's two former illnesses this had been most ably managed by the Willises, who had this faculty in a wonderful degree, and were men of the world, who saw ministers, and knew what the King ought to do ; that the not suffering them to be called in was an unpardonable proof of folly (not to say worse) in Addington, and now it was impossible, since the King's aversion for them was rooted; that Pitt judged ill in leaving the sole disposal of the household to the King; that this sort of

1 Twiss, i. 244.

2 Rose, ii. 149. 
power, in his present weak and of course suspicious state of mind, had been exercised by him most improperly. He had dismissed and turned away, and made capricious changes everywhere, from the Lord Chamberlain to the grooms and footmen. $\mathrm{He}$ had turned away the Queen's favorite coachman, made footmen grooms, and vice versa; and what was still worse, because more notorious, had removed lords of the bedchamber without a shadow of reason; that all this afflicted the royal family beyond measure; the Queen was ill and cross, the Princesses low, depressed, and quite sinking under it; and that unless means could be found to place some very strong-minded and temperate person about the King, he would either commit some extravagance, or would by violent exercise and carelessness injure his health and bring on a deadly illness. ... She said that Smart, when alive, had some authority over him; that John Willis also had acquired it, but in a different way. The first obtained it from regard and high opinion, the other from fear' that, as was always the case, cunning and art kept pace, in the King's character, with his suspicion and misgivings, and that he was become so very acute that nothing escaped him." 1

Even so late as September 11th, Lord Auckland says, he was much dissatisfied with the Queen, and that in the large house to which he is to return, he is to have a range of apartments wholly separate from hers. ${ }^{2}$

The general impression at the time was, that in both these attacks the King was deprived of his reason for a short period only; and Parliament was readily satisfied by the declarations of ministers that there was no necessary suspension of the royal functions. Before the ques-

1 Malmesbury, iv. 326.

2 Journal and Correspondence, ii. 213. 
tion of a regency could be fairly started, the bulletins ceased, and he was supposed to have recovered. Of course there was no examination of the physicians, and the public had no means of learning the subsequent progress of the disorder, because they alone to whom the facts were known were most interested in saying nothing about them. That the ministry were playing a very bold game seems to have been more than suspected by one of themselves. In 1804, Mr. Rose says, "How Mr. Pitt can carry on the government if the King is to be in the hands of his physicians, I cannot discover." 1 It was not until the examination of the physicians relative to the next attack (1810), some of whom had also attended him in 1801 and 1804, that the true state of the case was revealed. ${ }^{2}$ It then came out for the first time that both these attacks were of much longer duration and greater severity than the public had been led to suppose; that about the middle of March, 1801, and after the bulletins ceased, a relapse took place; that in $1804 \mathrm{Dr}$. Simmons continued in the palace as late as June; and that either Heberden or Sir Francis Millman attended the King up to October. ${ }^{3}$ And yet it had become a matter of history that, during those very periods when his Majesty was in charge of medical men on ac count of mental disorder, he was exercising the highest

1 Diaries, \&c., ii. 149.

2 It must be borne in mind that the memoranda showing the progress of the disease, which we have given, were mostly published only a few years ago, so that, in fact, the whole state of the case was not generally known until long after the examination of the physicians in 1811.

3 Indeed, as late as December the King had not entirely regained the confidence of his family. Lord Malmesbury says (iv. 344), on the anthority of one of the court, "The Queen will never receive the King without one of the Princesses being present; never says in reply a word; piques herself on this disereet silence; and, when in London, locks the door of her white room (her boudoir) against him." 
functions of sovereignty. On the 14th and 17th of Narch, 1801, - which, as we have just seen, was only fifteen days subsequent to the date of a "severe paroxysm," - measures of vital interest and importance to the country received his assent and concurrence. On the 14th Pitt's resignation was accepted, and the new ministers received their commission. On the 17th the King presided at a council. On the 9th of March, 1804, a commission under the King's sign-manual was passed, by virtue of which fifteen bills received the royal assent, and on the 23d his assent was given to many other bills.

It is not surprising that the discovery of his real mental condition, half a dozen years afterwards, excited both astonishment and indignation. In Parliament, the conduct of Lord Eldon, who, in consequence of his office as Lord Chancellor and of his intimate personal relations to the King, was held responsible for these transactions, was condemned in the strongest terms. Earl Grey charged him with having done what was equivalent to treason. "What," said he, "would be the character, what the appropriate punishment of his offence, who, knowing his Sovereign to be actually at the time incompetent, - who, in the full conviction of his notorious and avowed incapacity, and whilst he was under medical care and personal restraint, should come here, and in the name and under the pretext of his Majesty's commands, put the royal seal to acts which could not be legal without his Majesty's full and complete acquiescence?" ... "I will ask the noble lord," he continued, in another part of his speech, "what he would have done had a case of a similar nature come before him in Chancery? I will suppose such a case; and that in the interval, when it appeared from the testimony of physicians that 
the unfortunate individual was incapable of exercising his mental faculties, a person had prevailed on an attorney to make a will for him, would the noble lord have given his sanction to such a proceeding? Would he have taken the opinion of the interested individuals in preference to that of the physician? Let the noble lord apply this case to himself. I say that his Majesty's name has been abused. The noble lord has said, on his own authority, that his Majesty was not then incapacitated from acting; but will your lordships allow yourselves to beliere that his Majesty's health was then such as to admit him to act in his royal capacity, upon an authority which contradicts that of his physicians?"

In his defence Lord Eldon declared that, on the 27th of February, and again on the 9th of March, 1804, the King's physicians had pronounced him competent to perform a certain act; or, as the matter was described more particularly in his Memoirs, he inquired of the physicians if, in their opinion, the King was competent to sign an instrument, provided he (Lord Eldon) had satisfied himself that the King understood its effect. To this query Sir Lucas Pepys and Dr. Simmons replied affirmatively, the other physicians being supposed to concur. Chiefly, however, he grounded his defence on the right to judge for himself respecting the King's mental condition, irrespective of medical opinions. "I have been significantly asked," said he, " if I would supersede a commission of lunacy against the opinion of physicians. I have often done so. The opinions of physicians, though entitled to great attention, were not to bind him absolutely. ... It was most important to the Sovereign that the Chancellor should not depend wholly on the evidence of the physicians, if he himself thought the King perfectly competent to discharge the functions of the royal 
authority." 1 In a letter to Perceval, he declares that if the King had been found to understand the nature of the act he was asked to perform, he should have been bound by his sense of right and duty to have sanctioned such act, though he might have believed, with his physicians, that some delusions might occur an hour afterwards. ${ }^{2}$

Eldon declared in the debate that, on the 9th of March, 180 , the King understood the duty he had to perform better than he did himself, and among his papers was found what he regarded as a conclusive proof of his opinion. "On applying to the King," he says, "to obtain his sign-manual to several bills, he (Eldon) began to read an abstract of the bills with more of detail than usual, when the King said, ' My lord, you are cautious.' He (Eldion) begged it might be so, under existing circumstances. 'Oh,' said the King, 'you are certainly right in that; but you should be correct as well as cautious.' Eldon replied he was not conscious that he was incorrect. 'No,' said he, 'you are not; for if you will look into the commission you have brought me to sign, you will see that I there state that I have fully considered the bills proposed to receive my sign-manual. To be correct, therefore, I should have the bills to peruse and consider.' I stated to him that he had never had the bills whilst I had been Chancellor, and that I did not know that he had ever had the bills. He said during a part of his reign he had always had them, until Lord Thurlow had ceased to bring them; and the expression his Majesty used was, Lord Thurlow said it was nonsense his giving himself the trouble to read them." 3

Lord Eldon, as well as the physicians, made the com.

1 Stockdale's Parliamentary Register, 1811, i.

2 Twiss, i. $356 . \quad 3$ Idem, i. 226. 
mon mistake of confounding the power to understand the exact terms of a transaction with that of perceiving all its relations and consequences. Such a mistake, natural enongh as it might have been to him, could hardly have been expected from the physicians, especially under circumstances so peculiar and important. It would be considered a bold assertion, that a person, regarded by his family and physicians as insane, was perfectly competent to make a contract or execute a will; but to declare that the King, who by their own admission was more or less insane, was nevertheless competent to exercise the most important functions of his office, was, to say the least of it, to assume a tremendous responsibility. But they knew very well the wishes of the court on the subject; and it could hardly have been expected of court physicians that they would be over scrupulous on such an occasion, especially as they were aware, no doubt, that the measures in question were proper enough in themselves, and the royal assent was merely a matter of form. This unquestionably was the real ground on which Eldon acted, thongh it did not furnish the kind of defence exactly which he was disposed to set up. The nation was at war; a change of ministry was in progress, both in 1801 and 1804 ; a project of a regency would have distracted the national councils and impaired the national vigor; and the disease, scarcely severe at any time, seemed likely to be of very short duration. A man much less devoted to political ends than Eldon might, under such circumstances, have considered it perfectly justifiable to avoid the real evils of a regency question by allowing one more theoretical than practical, and followed by salutary consequences. In fact, the same thing was done by Lord Loughborough, who went to his Majesty on the 24th of February, 1801, - 
Addington having declined the service, - and obtained his signature to a commission for giving the royal assent to the Brown Bread Bill, ${ }^{1}$ the bill being actually taken to the King by Dr. Willis, and signed in his presence only. ${ }^{2}$

There was another charge against Lord Eldon, which cannot be so easily parried. It was insinuated by Earl Grey, in the debate already alluded to, that he used the facilities of his position to prevent a junction between Fox and Pitt in 1804; and it appears, from his own papers, that he used similar means to accomplish the removal of Addington, his own colleague, and bring in Pitt. These might have been precisely the arrangements which the King would have favored, had his mind been perfectly sound; but no man could have promoted them as Eldon did, without forfeiting every claim to upright and honorable conduct. ${ }^{3}$

About the 25th of October, 1810, the King was again, and for the last time, smitten by mental disease, consequent, it was generally supposed, upon the fatal illness of a favorite daughter, the Princess Amelia. It was first indicated by unusual hurry and restlessness of manner, by indiscreet talking, addressing unseemly language to the Princesses, giving away valuable articles, such as gems, and turning away his servants capriciously.4

1 Life of Lord Sidmouth, i. 302.

2 Rose, i. 341.

3 True, Eldon pronounced the charge that he had taken advantage of the King's weakness to prejudice him against Mr. Fox to be a direct falsehood. His biographer candidly remarks, that "this denial must not be extended beyond the charge it was meant to meet, of laving taken advantage of the King's weak state to excite a prejudice against Fox in the royal mind," - meaning, probably, that, as he did not believe the King to be incompetent, he might safely deny that he took any advantage of his weakness. ('Twiss, i. 356.)

${ }^{4}$ Rose, ii. 248. 
Within a few days he was in a state of extreme excitement, attended by high fever and great loss of sleep. During the first six or eight months, the disorder was characterized by paroxysms of this kind, alternating with intervals when he was free from fever, calm, and quite rational in his conversation. At times he was extremely violent; and on one occasion, 7 th of November, 1810 , they were obliged to close the doors and windows, and finally the apothecary of St. Luke's came over with some of his attendants and applied restraint. ${ }^{1}$ Four days after, he came to himself, asked how long he had been confined, and when told, he said he had no recollection of the time, and that this was the fourth blank in his life. ${ }^{2}$ Up to the 17 th of this month, he continued to improve; but on that day he undertook the task of dismissing and remunerating all the persons employed in the Princess Amelia's establishment, - a task in which he puzzled himself at last, and which he was obliged to leave unfinished. ${ }^{3}$ This was followed by a paroxysin of excitement, which, however, soon subsided, for on the 4th and 5th of December he is said to be "surprisingly well." On the 6 th he became excited, 4 but towards the middle of the month he began again to improve, and on the 17th of January he walked out on the terrace, for the first time. ${ }^{5}$ On the 26th, Eldon and Perceval spent an hour and twenty minutes with him, conversing on private and domestic affairs. Referring to this interview, the former said: " $\mathrm{He}$ is not well, and I fear he requires time. In the midst of this state, it is impossible to conceive how right, how pious, how religious, how everything that he should be, he is, with the

1 Colchester, ii. 288.

2 Rose, ii. 445.

3 Colchester, ii. 291.

4 Idem, ii. 288.

5 Idem, ii. 308. 
distressing aberrations I allude to." 1 Perceval met him again three days afterwards, and it was said that "for the first half hour of their conversation nobody would have supposed from the King's manner that he had been indisposed at all." 2 When in a passion, it appears that he spoke in Latin, as was the case in a former attack.

From this time forth till July, there occurred no marked change for better or worse in his Majesty's disorder. He was more or less excited, and entertained various delusions; but he was fond of conversing on public and domestic affairs, and it was supposed that what he heard did not tend to hasten convalescence. He became impatient of restraint and importunate to be restored to his royal state. He had fixed on May as the period for resuming the royal functions, but before that time came he insisted on immediate resumption. ${ }^{3}$ The Queen, in a note to Lord Eldon, soliciting the attendance of one of the council at Windsor, at least once a week, says: "The King is constantly asking if not one of the council is coming to receive the report of the physicians, and seems to feel that putting it off procrastinates his recovery, as his Majesty (she is sorry to say) thinks himself too near that period." + Lord Ellenborough, under date of April 3d, speaks of the King's "delusions and irregularities and extravagances of plans and projects of which we hear daily." 5 On the 25 th of May, the Duke of York had an interriew with him, in which his mental condition was pretty fairly exhibited. "He appeared at first very much affected at seeing me, and expressed himself in the kindest and most affectionate manner upon my reäppointment to the chief command of the army, but soon

1 Twiss, i. 359.

2 Colchester, ii. 314.

3 Buckingham, Memoirs of the Court of England, i. 57.

4 Twiss, i. 363.

5 Idem, i. 363. 
flew off from that subject, and then ran on, in perfect good humor, but with the greatest rapidity, and with little or no connection, upon the most trifling topics, at times hinting at some of the subjects of his delusion, in spite of all our endeavors to change the conversation." 1 Dr. Robert Willis, one of the King's physicians, expressed to the Duke his alarm at this "frivolity, or rather imbecility of mind."

Occasionally during this spring, he was quite conscious of his condition, and once, at least, manifested this consciousness in a curious manner. Francis Horner, in a letter to his father, mentions that at a concert of ancient music the King himself made the selection. "This," he says, "consisted of all the finest passages to be found in Handel, descriptive of madness and blindness; particularly those in the opera of Samson; there was one also upon madness from love, and the lamentation of Jephtha upon the loss of his daughter, and it closed with 'God save the King,' to make sure the application of all that went before." 2

About the middle of July, 1811, the disease took an unfavorable turn, and from that time forth only the worst event was expected. In October, his bodily health had considerably declined, and at times he became more violent than ever. In November his reasoning faculties "were quite gone," writes Lord Colchester in his diary.

From those who, in one way or another, were connected with the court, we learn something respecting the King's delusions. Once, in January, he refused food, apprehending that they wanted to poison him. ${ }^{3}$ One very persistent notion was, that he was married to Lady

1 Twiss, i. 363.

2 Memoirs and Correspondence, ii. 70.

3 Colchester, ii. 356. 
Pembroke, with whom he was enamoured before his actual marriage. "They refuse to let me go to Lady Pembroke," he complained to one of his sons, "though everybody knows I am married to her ; but what is worst of all is, that infamous scoundrel, Halford (Sir Henry), was by at the marriage and now has the effrontery to deny it to my face." 1 Another of his notions was that all marriages were dissolved by act of Parliament. He thought he was Elector of Hanover, and was much exercised as to what was to be done about Hanover. ${ }^{2}$ In July he sometimes talked as if he were conversing with persons long since dead, such as Perceral's father, or some old Hanoverian minister; and sometimes also, concerning himself, as an antediluvian to be shut up in Noah's ark. The last notion was expressed during one of his former attacks. ${ }^{3}$ Another strange fancy is mentioned by Lord Eldon. "It was agreed," he says, "that if any strong feature of the King's malady appeared during the presence of the council, Sir Henry Halford should, on receiving a signal from me, endeavor to recall him from his aberrations; and accordingly, when his Majesty appeared to be addressing himself to two of the persons whom he most favored in bis early life, long dead, Sir Henry observed, 'Your Majesty has, I believe, forgotten that that _- and - - both died many years ago.' 'True,' was the reply, 'died to you and to the world in general, but not to me. You, Sir Henry, are forgetting. that I have the power of holding intercourse with those whom you call dead. Yes, Sir Henry,' continued he, assuming a lighter manner, 'it is in vain, so far as I am concerned, that you kill your patients. Yes, Dr. Baillie, - but, Baillie, Baillie,' pursued he with resumed grav-

1 Buckingham, i. 50.

2 Colchester, ii. 303.

3 Idem, ii. 343. 
ity, ' I don't know. He is an anatomist: he dissects his patients ; and then it would not be a resuscitation merely, but a re-creation, and that, I think, is beyond my power." I The Princess Amelia he imagined to be still alive and residing in Germany, where she would never grow old; and he urged one of his physicians who had lost his wife to believe that she had met a similar fate. ${ }^{2}$ At a later period (1813), he believed he was surrounded by angels, with whom he conversed. ${ }^{3}$

In this attack, the physicians first employed were Heberden, Baillie, and Halford: Reynolds and Robert Darling Willis were added to the medical staff in the early part of November. In the course of a fortnight, Simmons was called in; but as the family were unwilling to comply with his wishes in regard to the management, he did not attend. ${ }^{4}$ These physicians were all examined by a committee of the Commons on the 14th of December, and by a committee of the Lords about the same time. The questions propounded were precisely the same as those of 1788 , and the replies were of a very similar character. They all concurred in the opinion that the disease would ultimately yield, but no one undertook to set limits to its duration. The same reasons, too, were also given for this favorable prognosis, - the patient's previous good habits and firm health, the suddemness of the attack, and the general curability of the disease. To the question, whether his Najesty's age, then seventy-two years, was not an unfavorable circumstance, the unanimous answer was, that, as a general rule, extreme age was an unfavorable circumstance, in

1 Camploell's Lives of the Lord Chancellors, Art. Eldon.

2 Autobiography of Cornelia Knight, i. 179.

3 Madame D’Arblay's Memoirs (Letter in 1811).

4 Rose, ii. 453. 
mental as well as other disease; but, in the present case, it would probably have little influence upon the result, because the King had borne his ago remarkably well, and the attack had originated in circumstances independent of any bodily indisposition. To the question, whether the King's very defective sight - for he had become almost, and soon after, entirely blind might not operate unfavorably, the reply was, substantially, that, in the early stages of the disorder, it would be more likely to have a beneficial effect than otherwise, by keeping from him many sources of irritation; while, in the later stages, it might, by diminishing his means and opportunities of occupation, retard his recovery. To the question, whether the fact of his having had so many previous attacks was not an unfavorable circumstance, Reynolds and Baillie replied - to them only was the question put - that his having recovered from so many previous attacks furnished strong grounds for expecting recovery again. Baillie, however, qualified his opinion by the suggestion that the susceptibility to disease might be increased by its frequent recurrence, and thus prove an obstacle to recovery.

In regard to the form of disease, Willis and Heberden set up some distinctions between delirium and insanity that seem more fanciful than real under the light of our better knowledge of the disease. The former said the King's disorder. was more allied to delirium than insanity. "Taking these two points as extreme points," he said, "derangement will lie somewhere betwixt them. The derangement which is the object of this inquiry I consider as partaking of delirium, but never of insanity." Heberden said: "It is not merely the delirium of fever, nor is it any common case of insanity. It is derangement attended with more or less fever, and liable 
to accessions and remissions." They sought no doubt to give the impression that it was simply a case of delirious wandering produced by bodily disturbance, which would readily pass away with the condition on which it depended. It is impossible to see any ground for this opinion. This attack closely resembled the others. It was manifested by hurry, restlessness, caprices, indiscretions, violence, and delusions. In one word, it presented all the characters of ordinary acute mania. It should be remarked, however, in this connection, that some of the writers on insanity of that period divided what we call mania into two classes, - viz., derangement of mind and insanity. The first would now be called acute mania, or acute delirious mania, and the other chronic mania. 'This no doubt led to Heberden's distinction, though it certainly was not well made in the case of the King. ${ }^{1}$

Dr. Simmons and Dr. John Willis, who had both attended the King in former attacks, had not been employed in this, the Queen fearing it might awaken disagreeable emotions. In fact, she had promised him that neither of them should have charge of him again. ${ }^{2}$ A year having passed and brought no improvement, Simmons and Munroe, physician of Bethlehem, were joined to the medical corps on the 9 th of October.

Towards the middle of January, 1812, the physicians were again examined by committees of the Lords and of the Commons. From this examination we gather that during the months of April, May, and June, the King was apparently improving. About the middle of July he became much worse, the disease being attended by

1 The Report may be found in Stockdale's Parliamentary Register, 1810, and Hansard's Parliamentary Debates, first series, v., xix.

2 such gham, i. 133. 
increased excitement and stronger delusions. His sight and hearing were quite gone, but the other senses were as acute as ever. He retained a consciousness of his regal state; and during the latter part of the year, when there seemed to be a little improvement, he bore his part in conversation very correctly for a few minutes, and related anecdotes of the past. The physicians were all as confirlent in the opinion that his recovery, though not hopeless, was highly improbable, as they were the year before in the opinion that he would recover. This change in their prognosis they attributed chiefly to the change in the phasis of the disorder, which occurred in July. ${ }^{1}$

The very confident expectation of recovery expressed by the physicians during the first few months was hardly warranted either by the circumstances of the case or the nature of insanity. He must be a bold man who would predict recovery in any case as strongly as it was predicted here of this old man, whose nervous system had been already tried by repeated attacks of mental disease. Physicians who have but a casual acquaintance with insanity are apt to be more sanguine in their prognosis than those who have been specially conversant with the disease. The latter are so accustomed to see the most favorable indications during the early stage followed by renewed excitement and unalterable derangement, that they learn to distrust the permanence of any improvement at that period.

There are many points in regard to the delusions, management, and medical treatment, of great interest to the professional reader, not touched upon at all in the examinations of the physicians. From other sources we learn that restraint was applied to the person, and this probably is what is meant by some obscure allusions in

1 Hansard, xxi. 73. 
the examination to a change of management. The fact is not calculated to strengthen the doctrine of absolute non-restraint, which is now put forth as the sign and seal of a signal advance in the treatment of the insane. Plenty of attendants and careful supervision are all that is needed, we are told, to enable us to dispense entirely with restraint. It cannot be supposed that any such means were lacking in the case of a monarch on whose realms the sun never set. Starting, as the family and the physicians did, with the determination not to employ restraint if it could be possibly avoided, ${ }^{1}$ the event showed that leather and canvas were found at last to be preferable to the hands and arms of attendants.

The examination of the physicians discloses nothing respecting the medical treatment. From other sources we learn that, objecting to be bled, he was leeched, which led Sir Everard Home to say, in the spirit of a pathology rather prevalent at that time, that he would have bled him till he fainted. ${ }^{2}$

The annoyance produced by the visit of so many physicians together, and which was so much complained of by Willis in the illness of 1788 , was so obviuus, that it was concluded to be best for the plyysicians to see him singly. ${ }^{3}$

Bulletins, necessarily general and vague, were issued twice a day in the earliest stage of the attack, as well as private advice for the eyes of the court and cabinet. These two sources of information were not always calculated to convey the same impression, and occasionally there was a remarkable discrepancy between their respective statements. How untrustworthy the bulletins were, the public learned from the examination of the

1 Culchester, ii. 282.

${ }^{2}$ Rose, ii. 458.

${ }^{3}$ Colchester, ii. 292. 
physicians, by which it appeared that for a day or two at one time, in the attack of 1801 , the King was supposed to be so very dangerously ill, "that the physicians were in great despondency and alarm," while the bulletins represented his condition as very favorable. ${ }^{1}$ The fact was noticed in Parliament and drew out some severe rebukes.

The examination was chiefly directed, not so much to the present condition of the King as to the attacks of 1801 and 1804, several of the physicians having attended him at one or both those periods, and to some interviews between the King and his ministers. It showed the usual amount of intrigue and cabal on the part of the King's friends, with subserviency to the predominant party and disregard of each other on the part of the physicians. As in the illness of 1788 , the policy of the Tories was to stave off the regency by representing the attack as speedily curable, while the Whigs were equally strenuous in precipitating this measure. But the result appeared so doubtful, and the exigencies of the country were so pressing, that it could not long be evaded; and accordingly the Prince of Wales was made Regent in February, 1811, - an event which enabled the Whig party, as is well known to all who are acquainted with the history of that period, to verify the scriptural declarations respecting the faithlessness of princes.

The following account of the King's condition subsequent to 1812 is given by an anonymous writer, but no authority is mentioned for the statements it contains, and $I$ have been unable to verify them.

"At interrals he still took a lively interest in politics. His perception was good, though mixed up with a number of erroneous ideas; his memory was tenacious, but

1 Rose, i. 325. 
his judgment unsettled; and the loss of royal authority seemed constantly to prey upon his mind. His malady seemed rather to increase than abate up to the year 1814, when at the time the allied sovereigns arrived in England he evinced indications of returning reason, and was made acquainted with the astonishing events which had recently occurred. The Queen one day found the afflicted monarch engaged in singing a hymn and accompanying himself on the harpsichord. After he had concluded the hymn, he knelt down, prayed for his family and the nation, and earnestly supplicated for the complete restoration of his mental powers. He then burst into tears, and his reason suddenly left him. But he afterwards had occasionally lucid moments. One morning, hearing a bell toll, he asked who was dead. 'Please your Majesty,' said an attendant, 'Mrs. S.' 'Mrs. S.,' rejoined the King, ' she was a linen-draper at the corner of _ street, and brought up her family in the fear of God. She has gone to heaven : I hope I shall soon follow her.' He now became deaf, imbibed the idea that he was dead, and said, 'I must have a suit of black, in memory of George the Third, for whom I know there is a general mourning.' In 1817 he appeared to have a faint glimmering of reason again. His sense of hearing returned more acute than ever, and he could distinguish persons by their footsteps. He likewise recollected that he had made a memorandum many years before, and it was found exactly where he indicated. After 1818 he occupied a long suite of rooms, in which were placed several pianos and harpsichords. At these he would frequently stop during his walk, play a few notes from Handel, and then stroll on. He seemed cheerful, and would sometimes talk aloud, as if addressing some nobleman; but his discourse bore reference only to past 
events; for he had no knowledge of recent circumstances, either political or domestic. Towards the end of 1819 his appetite began to fail. In January, 1820, it was found impossible to keep him warm; his remaining teeth dropped out, and he was almost reduced to a skeleton. On the 27 th he was confined wholly to his bed, and on the 29 th of January, 1820, he died, aged eightytwo years." 1

\section{Georgian Era, i.}

It is a curious coincidence that this monarch, who suffered so much from mental disease, should have been pursued, as if by a kind of fatality, by insane people. In 1786, an old woman (Margaret Nicholson) attempted to stab him as he was alighting from his carriage; in 1790 , a lieutenant of the army (John Frith) threw a stone at him through the window of the carriage in which he was riding; and in 1800, a soldier (James Hadfield) shot at him with a pistol in the theatre. Miss Burney says that, during his illness in 1788, they were often annoyed by insane persons, who contrived to elude the restrictions of the palace and to roam over the grounds. The persons who committed the first two assaults were so obviously insane that, without any further action, the Privy Council sent them to Bethlehem Hospital. Hadfield was brought to trial, and, it being on an action of treason, his counsel was allowed to speak in his defence; for until quite recently this privilege was never permitted in criminal cases, except those of treason. It was on this occasion that Erskine made his great forensic effort, and obtained the acquittal of his client. 


\section{SHAKESPEARE'S DELINEATIONS OF INSANITY.}

[IT has been the welcome privilege of a comparatively recent period to recognize the extraordinary merit of Shakespeare's representations of insanity. To the critics and literary men of an earlier time, the phenomena of this disease were as little known as the modern theories of heat or electricity. Dr. Johnson could see in the madness of Hamlet only a provocative of mirth; and even Coleridge, profoundly as he discoursed on the various springs and forms of human thought, regarded it as a clever sham, used for the purpose of concealing a real design. And so, for many years, one of the most remarkable manifestations of Shakespeare's genius was but slightly appreciated by his most intelligent admirers.

The revolution in the management of the insane, that occurred towards the end of the last century, produced among its legitimate effects a better knowledge of insanity, that became visible in works of literature as well as in the current opinions of society. Previously to the publication of the following paper, the "mad folk" of Shakespeare had been but little regarded from a pathological point of view. In a series of papers in the "London Magazine," in 182t, by Mr. William Farren, then an actor on the English stage, they were, for the first time, severally discussed in a manner that evinced, for an unprofessional man, a very accurate perception of the workings of the disordered mind. The insanity of Hamlet he regarded as real, not feigned, and though treating it like a critical observer of men, rather than as a student of disease, it cannot be denied that his view was strongly sustained. In 1859 , Dr. Bucknill, now one of the English Chancery Visitors in Lunacy, published a volume, entitled "The Psychology of Shakespeare," consisting of an elaborate criti- 
cism on the insane characters. He brought to his task a practical knowledge of insanity obtained while in charge of a large hospital for the insane, and much of that philosophical sagacity that detects the springs of human conduct. It is a valuable contribution to Shakesperian literature, and every true admirer of the great poet will be grateful for the light it throws on the characters in which mental disease was a controlling element. A similar attempt in the same direction, and not unworthy to be named in connection with it, was subsequently made by our countryman, Dr. Kellogg, Assistant Physician in the State Hospital for the Insane at Poughkeepsie, and the intelligent reader of Shakespeare will be well rewarded by a careful study of its contents. Preëminent above all other works of this description is a little volume from the pen of the late Dr. Conolly, of England, entitled "Hamlet," in which he proves that the insanity of the Prince is not feigned, but genuine, by tracing its manifestations from one period to another, and showing that every step in the progress of the affection represents the ordinary course of the disease, and is so true to nature as to banish the idea of simulation. Hamlet's insanity, he thinks, does not consist of a few freaks ingeniously assumed for purposes of deception, but is a regular case of mental disease whose manifestations are all in accordance with the laws of mental pathology and the normal constitution of the patient's mind. And so clearly and foreibly is this idea developed, that the author's conclusion seems to be as irresistible as that of a mathematical demonstration. But, whether convinced or not, the reader willingly yields to the charm of a work clothed in the graces of a finished style seldom surpassed in purity and elegance.]

IT is a curious fact that metaphysicians, whose special province it is to observe and analyze the mental phenomena, have shown much less knowledge of mind as affected by disease, than writers of poetry and romance whose ideas are supposed to be the offspring of imagination, rather than a sober observation of facts. No one would look into Locke, Kant, or Sterwart, to find any light on insanity; but in the pages of Shakespeare and Scott are delineations of this disorder that may be ranked with the highest triumphs of their masterly 
genius. The cause of this difference is obvious. The one looks at mind in the abstract; the other, in the concrete. The former seeks for its laws and modes of operation exclusively in the inmost recesses of his own being. The latter is more curious to observe the workings of minds around him, and none of them are deemed to be unworthy of attention, even though controlled by the influence of disease.

To represent a character whose mind has been blasted by the touch of disease, but still retains the semblance of its former integrity as well as its power to awaken our interest and sympathy, has not unfrequently been attempted, but seldom so successfully as to satisfy those who are professionally acquainted with the subject. That knowledge of insanity which is obtained by special study of its phenomena in the wards of a hospital is confined to medical men, and is used for scientific rather than literary purposes. The opportunities afforded to the poet and novelist for studying this disease are confined to the few patients that meet their observation in the ordinary walks of life, and most of whom possess an order of intellect not particularly interesting in its best estate. With the aid only of materials thus furnished, to construct a character which, with all its aberrations, shall still manifest, in a certain degree, its natural consistency and congruity, the insane bearing the impress of the sane, and each in harmony with the other, - like the needle retaining its polarity amid all its variations, - this is the work of the master mind.

Such a mind was Shakespeare's ; and it is because he clearly perceived at a glance those numberless shades of distinction which entirely escape the notice of ordinary observers, that his characters, whether sane or insane, are neither personified abstractions of specific qualities, 
marked by a name and assigned a part in the play, nor servile copies from life which have lost their interest under the process of transference, but real, mortal men who live and act before us, and lose their senses it may be, and whose names live after them in the memory of men. His success in this difficult line is to be attributed to that distinguishing faculty of his mind, of deducing with wonderful correctness general principles of character from the narrowest possible range of observation. And yet he had peculiar difficulties to overcome. He had not only to divest himself of the popular misconceptions of insanity, which regard it as a jumble of intellectual manifestations acknowledging no principle of cohesion or concatenation, but his opportunities for observing the insane were scanty and imperfect. No friendly asylum furnished subjects for study whose mental endowments were worthy of his study; and such as he occasionally met by the roadside, or beheld through the bars of their prison-house, were for the most part, it is probable, too far degraded by neglect and unkindness, to be available for any poetical purpose. It is not to be supposed, however, that he, was guided solely by intuition. He unquestionably did observe the insane, but he observed them as the great comparative anatomist of our age observed the remains of extinct species of animals, - from one of the smallest bones reconstructing the whole skeleton of the creature, reinvesting it with flesh and blood, and divining its manners and habits. By a similar kind of sagacity, Shakespeare, from a single trait of mental disease that he did observe, was enabled to infer the existence of many others that he did not observe, and from this profound insight into the law of psychological relations he derived the light that special observation had failed to supply. Thus, in spite of all 
the obstacles in his way, he succeeded, to a degree that has seldom been equalled, in representing insanity, both in the form of maniacal wildness and disorder, and in that of extreme depression and gloom. Its progress through its various stages, from the first scarcely perceptible deviation from the soundness of health to its termination in recovery or death, is traced with that thorough fidelity to nature so characteristic of all his conceptions.

In the tragedy of King Lear, Shakespeare has represented the principal character as driven to madness by the unexpected ingratitude of his daughters; or, more scientifically speaking, he has represented a strong predisposition to the disease as being rapidly developed under the application of an adequate exciting cause. It is no part of his object to excite curiosity by a liberal display of wildness and fury, nor awaken our pity by the spectacle of a mind in ruins, and unconscious of its wretchedness. He aimed at dramatic effect by opening the fountains of sympathy for a being of noble nature and generous impulses cruelly despoiled of the highest endowment of man, but not so far as to lose all trace of his original qualities, or cease for a moment to command our deepest respect. In Lear, we have a man of a hot and hasty temper, of strong and generous passions, of a credulous and confiding disposition, governed by impulses rather than deliberate judgment, rendered impatient of restraint or contradiction by the habit of command, with a nervous temperament strongly susceptible to the vexations of life, and, moreover, with all these moral infirmities aggravated by old age. With these simple elements of character is mingled and assimilated more or less of mental derangement, with equal regard to pathological propriety and dramatic effect. And so nicely 
adjusted are the various elements of sanity and insanity, and so admirably do they support and illustrate one another, that we are not surprised in the progress of the action by violent contrasts; and we feel at last as if it were the most natural thing in the world that Lear should go mad, and precisely in the way represented by the poet. Mad as he becomes, the prominent attributes of his character are always to be seen. Through the whole play, he is the same generous, confiding, noblehearted Lear. In short, assuming Lear to be an historical portrait instead of a poetical creation, we should say there existed in his case a strong predisposition to insanity, and that if it had not been developed by the approach of old age, or the conduct of his daughters, it probably would have been by something else. His inconsiderate rashness in distributing his kingdom among his children, his disinheriting the youngest for the fearless expression of her feelings, and his banishment of Kent for endeavoring to recall him to a sense of his folly, all indicate an ill-balanced mind, if not the actual invasion of disease. This view of the case is confirmed by the conversation between the sisters, immediately after the division of the kingdom. Goneril says: "You see how full of changes his age is; the observation we have made of it hath not been little. He always loved our sister most; and with what poor judgment he hath now cast her off, appears too grossly." "'Tis the infirmity of his age," replies Regan, "yet he hath ever but slenderly known himself." "The best and soundest of his time," continues Goneril, "hath been but rash; then must we look to receive from his age, not alone the imperfections of long engrafted condition, but, therewithal, the unruly waywardness that infirm and choleric years bring with them." Regan then adds: "Such in- 
constant starts are we like to have from him, as this of Kent's banishment." With a knowledge of insanity that could hardly have been expected from any but a professional observer, Shakespeare has here and elsewhere recognized the fact that very many of those who become insane are previously distinguished by some of those mental irregularities that pass under the name of oddity or eccentricity.

The next thing we hear of Lear is his beating one of Goneril's gentlemen. Her remarks on learning the fact show that his mental condition has not been improving since his abdication, and prepare us for the mournful sequel.

"By day and night he wrongs me; every hour

He flashes into one gross crime or other,

That sets us all at odds. I'll not endure it ;

His knights grow riotous, and himself upbraids us

On every trifle."

The development of the early stage of Lear's insanity, or its incubation as it is technically called, is managed with masterly skill, the more surprising as it is that stage of the disease which attracts the least attention. And the reason is that the derangement is evinced not so much by delusions or gross improprieties of conduct, as by a mere exaggeration of natural peculiarities, by inconsistencies of behavior, by certain acts for which very plausible reasons are assigned though they would never have been performed in a perfectly sound state of mind, by gusts of passion at every trifling provocation, or by doing very proper things at unseasonable times and occasions. With his own free will and accord he gives away his kingdom, but finds it difficult to sink the monarch in the private citizen. He attaches to his person a band of riotous retainers, whose loose and lawless 
behavior proves destructive to the peace and good order of his daughter's household. Goneril describes them as

"A hundred knights and squires;

Men so disordered, so debauched and bold,

That this our court, infected with their manners, Shows like a riotous inn."

Under such an infliction it is not strange that she should remonstrate, and had not the divine light already begun to flicker, he would have acknowledged the justice of the reproof. As it is, however, instead of admit. ting some share of the fault, he attributes the whole of it to her, flies into a passion, pours upon her head the bitterest curses, upbraids her with the vilest ingratitude, and forthwith proclaims his wrongs to the public ear. Like most cases of this kind in real life, it would have, to a stranger, the appearance of a family quarrel springing from the ordinary motives of interest or passion, but where, really, the ill regulated conduct resulting from the first influences of disease provokes restrictions more or less necessary and appropriate, that become exciting causes of farther disorder. Another life-like touch is given to the picture, in Lear's attributing all his troubles to filial ingratitude, not being aware, of course, that he was on the high road to insanity long before he had any reason to doubt their kindness. In fact, nothing is more common than for the patient, when telling his story, to fix upon some event, and especially some act of his friends, as the cause of his troubles, which occurred long subsequently to the real origin of his disorder, and might have had but an accidental connection with it.

The conduct of the daughters faithfully exhibits the strong tendencies of human nature. No doubt their 
patience was severely tried, - such a trial as only the mildest temper joined with the firmest principle could enable them to stand successfully. Wanting these, however, his irregularities are met with reproaches and restrictions, instead of kind and conciliating measures; an explosion follows, and in mutual hate and anger they separate. To their heartless natures such conduct may not have appeared like unmitigated ingratitude towards a father who had loved and cherished them as the very idols of his heart, but to be founded on provocation that seemed to justify their behavior. Such is the ingratitude of the world, ever coupled with some shallow pretence of wrong or indignity sustained, and often presenting the fair, outside show of a worthier feeling. In the daughters' treatment of their father, Shakespeare strips off the thin disguises of conventional morality, and lays bare that heartless selfishness which is ever ready to sacrifice to momentary ease and gratification the tenderest sympathies of our nature. It is fearful to think how often the case of Lear and his daughters is paralleled in actual life, and it is this very commonness of the fact that prevents us from regarding it as a curious monstrosity fitted to excite but a momentary horror, and which imparts a deep moral interest to the representation of the poet.

When the astounding fact of Goneril's baseness is finally made so plain to Lear that he can no longer doubt it, his senses appear to reel under the shock, and for a moment he questions his own identity. "Does any here know me? - Why, this is not Lear; does Lear walk thus? speak thus? Where are his eyes? Either his notion weakens or his discernings are lethargied. - Sleeping or waking? - Ha! sure 'tis not so. - Who is it that can tell me who I am ?" 
The continued objurgations of Goneril, and her barefaced impudence in proposing a diminution of his train, soon produce a reaction in his mind, and Lear gives vent to his feelings in that blasting curse whose bitterest ingredient was the wish that she might feel

\section{"How sharper than a serpent's tooth it is \\ To have a thankless child!"}

Then bursting into tears of which his noble nature is ashamed, he quits the presence of a child upon whose affection he had reckoned for the support of his declining years, and resolves to go to his other daughter who had shared in his bounties, certain that he would receive from her the hearty welcome and tender regard that had been scornfully refused by her sister. While pondering upon past scenes, he is conscious that his mind has sustained a fearful shock; and, as is often the case in such circumstances, he has a vague presentiment of the sad, fatal result.

"O, let me not be mad, not mad, sweet Hearen!

Keep me in temper; I would not be mad!"

On arriving at Regan's residence, he finds that she refuses to see him, and that his faithful follower has been placed in the stocks. These things excite his suspicion that all is not right, and renew the agitation that had been momentarily quieted. Still he is slow to believe what is evident enough to everybody else, and fondly hugs the delusion in which his only hope of happiness rests. But when the conviction is forced upon him that Regan even goes beyond her sister in ingratitude, he utters a wail of heartfelt wretchedness and lofty indignation, ending with another foreboding of the impending calamity. "O, fool, I shall go mad." Driven with contumely and scorn from that shelter in the affec- 
tions of his child which he had fondly expected to find, he goes forth at night and braves the pelting of the pitiless storm. The howling of the wind, the roar of thunder, and the flash of lightning are welcome, for at least they lack the sting of filial ingratitude, and are in mournful accordance with the tumult in his own crushed and bleeding bosom. One dark, overshadowing, all-engrossing idea - the cruelty of his daughters - is suggested by every object, gives a tone to all his reflections, and, like the worm that never dies, is gnawing perpetually at his heart. Well might he invoke the fury of the elements upon his head, for the worst they could do would be mercy compared with the torments his own flesh and blood had inflicted.

\section{" The tempest in my mind}

Doth from my senses take all feeling else, Save what beats there."

There is now obviously a degree of incoherence and absurdity in the thoughts that race through his mind, though they are never destitute of that grandeur and boldness of expression indicative of his lofty and noble nature. But the idea of the thunder cracking nature's moulds and destroying the germs of the race, contained in his invocation to the elements, is a little too fanciful for even a figure of poetry. In a similar strain he charges the elements with conspiring with his daughters against his old white head, and soon after imagines that the Gods have raised the storm for the purpose of finding out their enemies. This is crazy enough, no doubt; but his apostrophe to sinners of various kinds, that immediately follows, is both correctly and beautifully expressed. He seems to be fully aware that his thoughts are deviating from the right track, and exclaims that his "wits begin to turn." The predominant idea follows 
him into the next scene, and ever and anon intrudes upon his reflections, though he always recoils from it with a kind of horror, as if conscious it had the power to deprive him of his reason. "O, that way madness lies." Unable as the insane are to perceive their own insanity, yet this apprehension of its approach so frequently repeated by Lear usually occurs during its incubation. While still able to control his mental manifestations, the patient is tortured with anticipations of insanity; but when he actually becomes so insane that the most careless observer perceives the fact, then he entertains the most complacent opinion of his intellectual vigor and soundness. And yet this is one of the nicer traits of insanity which the ordinary observer would hardly be supposed to notice. But Shakespeare was no ordinary observer; and this, I imagine, explains the cause of his preëminence in certain parts of his art.

The appearance of Edgar, who is feigning madness in order to avoid his enemies, again excites Lear's predominant idea, and fixes it permanently in his mind. The former's ragged, wretched, degraded condition, he can attribute to nothing but filial ingratitude, and he pours out curses on Edgar's unnatural daughters. He is no longer able to correct the errors of his own judgment; reason exercises but a feeble control over his conclusions, and scarcely a gleam of light struggles through the darkness which envelops his soul. The predominant idea, however, has not yet relinquished its hold, and it still gives direction to his thoughts. The very images of his daughters appear before him in visible forms, glowering upon him with looks of scorn and hate. The idea of placing them on trial enters his mind, and he proceeds to the business with all due forms and solemni- 
ties. Edgar, the fool, and Kent are appointed to the bench; his daughters, in the shape of jointstools, are arraigned before the court; and Lear appears as witness against them. Then, after a brief interval during which it would seem as if he imagined them to have been convicted and sentenced, he exclaims with touching pathos, "Let them anatomize Regan, see what breeds about her heart. Is there any cause in nature that makes these hard hearts?"

The scene on the heath between Lear, Edgar, and the fool, has not its like, we may safely say, in the whole range of English dramatic literature. No less a genius than Shakespeare's would have ventured to bring together, face to face, three such difficult characters, one actually mad, one falsely pretending to be so, and the third a fool; and yet in the successful management of such discordant and intractable materials, he has given a fresh instance of his wonderful skill. Nothing could have seemed more likely to disappoint and displease, than to bring the noble-hearted Lear, staggering under the shock of his daughters' ingratitude, with blasted heart and bewildered reason, into such strange companionship; and yet who can finish this scene, without feeling that he has read a new chapter in the history of mental disease, of most solemn and startling import? The sight of another in rags and wretchedness reveals to Lear a deeper depth of agony in his own soul. $\mathrm{He}$ sees in the stranger only another victim of filial ingratitude, - the counterpart of his own case, - and Edgar's weak and blighted condition forewarns him of his own approaching fate. Its first effect, as we have already observed, is to produce a shower of curses on Edgar's unnatural daughters, and the next to draw him towards his fellow sufferer by that kind of sympathy which, irre- 
spective of social condition, is awakened by mutual affliction. In this play of wild and discordant fancies the fool mingles his humors, which fall on the ear like sounds of jollity and mirth ascending from a house of mourning. The successful management of such deep masses of light and shade, whether in poetry or painting, requires the master hand of a Shakespeare or a Rembrandt.

Thus far the progress of Lear's insanity is represented with the closest fidelity to nature. It is not more different from the disease as daily observed, than Lear's moral and intellectual constitution, when in health, is different from ordinary men's. At every interview reason seems to have lost somewhat more of its control. The mental excitement has been steadily increasing, until now, having reached its height, he goes about singing, dancing, and capering through the fields, fantastically decorated with weeds and flowers, looking, acting, and talking like a madman. His perceptive organs are deceived by hallucinations; and his discourse, though tinctured with his natural shrewdness and vigor of thought, is full of incolserence and incongruity. In short he is now what is called raving. In the representation of this condition we have another instance of Shakespeare's unrivalled powers of observation. To ordinary apprehension, the raving of a maniac is but an arbitrary jumble of words and phrases between which no connecting threads can be discerned. But in fact, discordant and heterogeneous as they may appear, they are nevertheless subjected to a certain law of association, difficult as it may be frequently to discover it. The phenomenon may thus be physiologically explained. In consequence of the cerebral excitement, impressions long since made - so long perhaps as to have been forgotten previous to the at- 
tack - are so vividly and distinctly recalled, that they appear to be outward realities. So long as the intellect retains its integrity, it is able to recognize the true nature of this phenomenon; but, when touched by disease, it ceases to correct the error of perception. The impressions are actually considered to be what they appear, and the patient thinks and discourses about them as such. In his mind's eye he sees sights, and in his mind's ear he hears sounds, imperceptible to others; and this is the source of much of our difficulty in discovering the object and relevancy of his remarks. Persons and things appear before him in the greatest variety and confusion; and past scenes and associations are recalled in all their original freshness, suggesting thoughts to which he alone possesses the clew. The images raised in the mind by this morbid excitement are also rapidly changing, thus giving to the thoughts that phantasmagoric character by which they are so distinguished in mania. They seem to be suggested and associated very much as they are in ordinary dreaming, in which the mind is occupied with impressions previously made, and uncontrolled by that regulating principle necessary to give them logical sequence and cohesion. In sleep the person we are addressing, for instance, unaccountably changes into some other; the scene in which we are engaged suddenly vanishes away, and another appears in its place; the powers of memory are endowed with an energy seldom witnessed in the waking state; the relations of space, of time, of place, of form, of color, are sadly embroiled; the living and the dead, the near and remote, wisdom and folly, stand side by side, and no sense of the strange combination is perceived. We may strive perhaps to believe it a dream; but, with some exceptions, we strive in vain. Precisely so it is in mania 
which may, with some propriety, be designated as dreaming with the senses all open, the morbid excitement rendering the images unnaturally vivid.

Another source of our difficulty in discovering the filiation of the maniac's thoughts has been generally overlooked, and the fact strongly shows with how little sagacity the operations of the insane mind have been studied. The maniac, being restrained by no sense of the propriety or fitness of things, expresses every thought that enters his mind, or at any rate is governed by no principle of selection. In the sound mind, on the contrary, a considerable portion of the thoughts never find utterance in words, being suppressed from their want of connection with one another, or their irrelevancy to the subject in hand. Every one must be aware how often, in the course of ordinary conversation, thoughts start up having the remotest possible connection with anything already said, - so remote, indeed, as to defy any one but himself to discover it. Any person who should utter every thought that arose in his mind, in the freest possible conversation, would most certainly be taken for a fool or a maniac. This mental defect is far from being confined to the state of raving. In a greater or less degree it occurs in almost every form of insanity. Even those whose delusions are very circumscribed; who conduct for the most part with great propriety, and to common observers betray no indication of unsoundness in their conversation, will usually evince it, when very talkative and encouraged to talk without interruption. Their remarks may be correct and even shrewd; not a single word may be uttered "sounding to folly," while there is a certain peculiarity in the association of their ideas never witnessed in the sound mind. Though not easily described, it is readily recognized by those who 
are conversant with the insane, and to them it is a conclusive proof of mental disease, though they may be incapable of making the grounds of their conclusions intelligible to others. Courts and juries are not always disposed to make sufficient allowance for this fact, and regard with suspicion the embarrassment of the medical jurist, who sees that what is to him the strongest proof of insanity is to others no proof at all. Bearing in mind these facts, we readily see how there may always be some method in madness, however wild and furious it may be, - some traces of that delicate thread which, though broken in numerous points, still forms the connecting link between many groups and patches of thought. It is in consequence of Shakespeare's knowledge of this psychological law, that in all his representations of madness, even though characterized by wildness and irregularity, we are never at a loss to perceive that the disease is real and not assumed. Not so, however, with most writers, even of distinguished name, who have undertaken to represent the workings of a diseased mind. Unaware of the law in question, and governed by the popular notions on the subject, they seem to have aimed only at unlimited extravagance and incoherence. Otway, for instance, in "Venice Preserved," represents Belvidera in that state of mental disturbance which results from wounds of the softer affections of the heart. A speech full of those strong and vehement expressions characteristic of deep-felt emotion, but presenting no trace of delusion, finishes with the following jargon, which, we venture to say, no insane person would have uttered in such a connection, though it might, very likely, proceed from one simulating the disease,-

"Murmuring streams, soft shades, and springing flowers,

Lutes, laurels, seas of milk, and ships of amber." 
In the first scene in which Lear makes his appearance after becoming stark mad, his mind is solely occupied with images formed under the influence of the intense excitement of the internal perceptive organs. He at first fancies himself in a battle, and then as engaged in the sports of archery and falconry. Something reminds him of Goneril, and then succeed to one another, by a natural association, the ideas of a white beard, of the flattery of his courtiers, and of the detection of their deceptions. When Gloster hears his voice and asks if it be not the King's, Lear replies, "Aye, every inch a king." Tisions of his royal state then pass before his eyes, and he is reminded of the criminals he pardoned and the crimes they committed, and thence, by a natural transition, he is led to some caustic reflections on the frailties of woman. Another remark of Gloster turns his mind to the examples of self-righteousness and selfdeception, servility and time-serving, with which the world abounds, and in a strain of bold, indignant sarcasm he lashes the vices to which poor human nature is especially prone. All this is exceedingly natural. It is not uncommon to meet with madmen of the most wild and turbulent description mixing up their utterances with the shrewdest remarks upon men and things, and the keenest and coolest invective against those who have incurred their displeasure. The poet, perhaps, has used the utmost license of his art in the present instance; but if few madmen have exhibited"so much matter mingled with their impertinency as Lear, it may be replied, in justification, that fer men are endowed like Lear with such a union of strong passions and natural shrewdness of understanding.

Here endeth the madness of Lear. By his youngest daughter he is placed in the charge of a physician whose 
medicines throw him into a deep sleep, from which and his madness together he awakes as from a dream. The manner of his recovery displays the poet's consummate skill, that could delineate the most touching and beautiful traits while observing the strictest regard to facts. Lear at first knows not where he is, nor where he has been. He scarcely recognizes his own friends, and almost doubts his own identity.

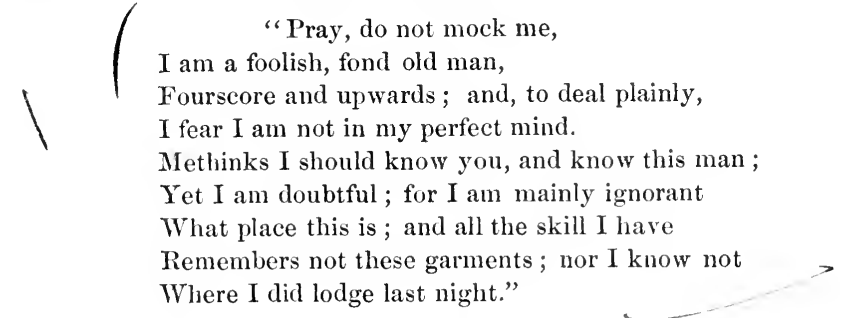

A faint idea of recent events now occurs to him, and he says to Cordelia, $\curlyvee$ $\left(\begin{array}{c}\text { "Your sisters } \\ \text { Have, as I do remember, done me wrong." }\end{array}\right)$

A more faithful picture of the mind, at the moment when it is emerging from the darkness of disease into the clear atmosphere of health restored, was never executed than this of Lear's recovery. Generally, recovery from acute mania is gradual, one delusion after another giving way, until, after a series of struggles, which may occupy weeks or months, between the convictions of reason and the suggestions of disease, the patient comes out a sound, rational man. In a small proportion of cases, however, this change takes place very rapidly. Within the space of a ferv hours or a day he recognizes his true condition, abandons his delusions, and contemplates all his relations in an entirely different light. The management of Edgar's simulation strikingly 
evinces the accuracy and extent of Shakespeare's knowledge of mental pathology. In placing the real and the simulated affection side by side, he has shown a confidence in his own skill which the result has perfectly justified. In no other way could the fidelity of his delineations have been subjected to so severe an ordeal. We are left in no doubt as to his views of what is and what is not genuine insanity; and by holding before us an elaborate picture of each, he enables us to compare them together, and to judge of his success for ourselves. In these pictures he has availed himself of no equivocal traits; the touches of his pencil are of that strong and decided character that admits but a single meaning. Not more true to nature is the representation of Lear writhing under the stroke of real insanity, than is that of Edgar playing upon the popular curiosity with such shams and artifices as would most effectually answer the simulator's purpose. The one is an exhibition of character as genuine, and marked by as distinctive traits, as the other; and Shakespeare would have been as unlikely to confound them, and mistake the one for the other, as to fail to recognize the commonest forms of nature around him.

Edgar's first design is to personate a Tom o' Bedlam beggar, - one of a class of lunatics who were discharged from Bethlehem Hospital when restored in some measure, that they might subsist upon the charities of the community. Accordingly, he provides himself with their usual dress and appurtenances, repeats their phrases, and imitates their practices for exciting the compassion of the charitable. In his anxiety to produce an impression, he falls into the common mistake of simulators, who overact their part, and thus betray their true character to the practised observer. We could not commit a greater 
error, however, than to regard this fact as a fault of the poet, who displays in it a power of philosophical discrimination which, when strongly marked, is indicative of the highest order of genius. The object of the part is to deceive the multitude, not the professional student; and for this purpose nothing could be better calculated than the gibberish which he utters in his double character of a lunatic beggar and a victim of demoniac possession. Had it been Shakespeare's design to represent a case of real demonomania, or of chronic mania, we should unquestionably have had something very different from the part of Edgar. If the former, we should not have found the patient talking so clearly about his own case, while indulging in unlimited incoherence and rambling about everything else; and if the latter, we should not have seen a strain of acute moralizing succeeded, more than once, by a trait of mental imbecility. Poetically considered, the feigned madness of Edgar is well calculated, by force of contrast, to deepen the impression made by the real madness of Lear. The abject condition of the former excites our pity, as an object of physical distress which we would endeavor to relieve. In the case of Lear, however, all the finer emotions of the soul are aroused by the sight of a noble nature crushed to the earth by sufferings which touch the inmost springs of lumanity.

We cannot dismiss this play without a passing notice of the Fool, in whose character Shakespeare has shown that his observation of mental impairment was not confined to one or a few of its forms. He is used like the same character in other plays, his quips and cranks serving as a foil to the humors of his stronger-minded companions. They who find fault with the poet for infusing too much wisdom into the folly of his fools may 
well take a lesson from him in certain branches of psychological study. In the present instance, he knew, what is not generally known even now, as we often have painful reason to remark, that a very obvious degree of intellectual deficiency is sometimes accompanied by a little shrewdness of observation and practical sagacity. They who are much conversant with this form of mental impairment have no difficulty in believing that the very person who is unable to rise to the simplest abstract truth may occasionally utter a shrewd remark, and succeed as well as wiser men in "shooting folly as it flies." It was this class of subjects that furnished the domestic fools and court-jesters of the olden time. With not sufficient understanding or character to awaken the jeal. ousy of their patrons, or exercise any restraint upon their manners, they had the sense to discern the foibles and follies of their superiors, and ready wit enough to extract from them food for amusement and mirth. The biting jest and timely reproof were good-naturedly received, for their acknowledged imbecility rendered them, for the most part, quite irresponsible for their sayings and doings. With such characters royalty could unbend without loss of dignity, and enjoy a jest even at its own expense.

In Hamlet, that noble play in which beyond all others, perhaps, Shakespeare has displayed the wonderful diversity of his powers, we have another and a very different picture of disordered intellect, but one no less remarkable for its fidelity to nature, nor less calculated to awaken the interest and sympathy of the reader. Before considering the origin and progress of Hamlet's insanity, it may be thought incumbent upon us to dispose of a preliminary question now discussed by every commentator on Shakespeare. 
It is somewhat curious that, until within a few years, Hamlet's derangement was universally regarded as feigned. Aside from his own intimation after meeting the ghost, that he might "put an antic disposition on," it is difficult to conceive of any foundation for this opinion. And yet it would seem as if the strongest and clearest reasons alone could warrant the idea that the most faithful delineation of a disordered mind ever marle by man represents a deceptive counterfeit, not a truth and a reality. Without a single adequate reason, this notion has been handed down, like an heirloom, from one critic to another, unquestioned and apparently unquestionable, in the very face of the fact that Hamlet's insanity, which is supposed to be assumed for the purpose of concealing his plans, immediately excites the apprehensions of the king, and leads to his own banishment from the State. True, it is supposed to answer another purpose, - that of enabling him to break off his attachment with Ophelia, which the dread mission he had to perform forbade him any longer to entertain. But the necessity of this step is unsupported by a single proof. No intimation of it is given in the course of the play, and it has no foundation in the nature of things. Of course, no possible difficulty would be allowed to prevail against a theory deliberately founded on such premises as these. A most perverse ingenuity has been exercised in endeavoring to reconcile some passages in Hamlet's conduct with the ardmitted qualities of his character and the ordinary springs of human action. It would be hardly worth our while here to expose any particular instances of this kind. Enough of them will appear in the course of this inquiry to justify our opinion, while the attentive reader will not fail to see that Hamlet's disorder is often manifested under circumstances that forbid the idea of simulation. 
It may be well to remark, in passing, that the reluctance of critics to abandon the old view of Hamlet's mental condition, springs, in great measure, from their inability to discern the essential distinction between real and feigned insanity. If, say they, the latter is made to resemble very closely the real thing, it is only a proof of the poet's power of imitation, not of his intention to represent a case of genuine disease. They forget that the purpose of feigned insanity is to deceive, - to trick the spectator into the belief of something that has no real existence. Therefore, no traits of the disease are exhibited but such as are calculated to make this impression in the strongest manner, those being carefully avoided which are not generally obtruded upon the observer, as well as those which pass in the world for something else, such as eccentricity, bad humor, low spirits. The purposes of the simulator require that the traits he assumes should be obvious immediately, and so he forces them on the attention with no regard to pathological proprieties, or to any principle of subordination. That Shakespeare bore this distinction in mind in the present instance, is obvious in every scene of the play. All can recognize insanity in one who raves or ntters gross delusions; but how few can see it in Hamlet's scorching rebuke of his mother, in his harsh treatment of Ophelia, in his murder of Polonius, in his famous soliloquy on death, or in his welcoming address to his old school fellows. In much of this conduct and discourse most persons would see nothing more than an extreme acerbity of temper, an early experience of the hollow. ness of life, and at the worst, perhaps, a fit of depression.

It is to be considered also that there are many traits of the real disease that defy the utmost efforts of mim- 
icry to simulate. The perversion of the moral affections, the sincere and solemn earnestness with which the patient announces and maintains his delusions, that peculiar concatenation of the thoughts, so difficult to describe, but so characteristic of insanity, - all these are traits as far beyond the power of the simulator to imitate, as the quick pulse, furred tongue, and dry skin of its more recent and acute forms.

It has been occasionally suggested that Hamlet's insanity is real, but the idea has never been supported by proof drawn from the pathological aspects of the case. Some - and they belong to the class that have illuminated the pages of Shakespeare with the torch of a profound and philosophical criticism - have come to the conclusion that the truth lies in an eclectic view of the case, less burdened with difficulties. They admit that a cloud unquestionably hangs over Hamlet's understanding, but they are reluctant to attribute so sad and humbling an incident as madness to such a noble and elevated character. His profound speculations on the purposes of life and his solemn questioning of its meaning, the pertinency of his replies, the exquisite wit and wisdom of his discourse, the sagacity and forecast displayed in his plans, the true nobility of his nature, - all forbid the idea of madness. These persons embrace the popular error of regarding madness as but another name for confusion and violence, overlooking the daily fact that it is compatible with some of the ripest and richest manifestations of the intellect. They flout at the idea of real madness, as if it were connected with images of straw and straight-waistcoats, while in the simulation of the disease they see no breach of pathological, moral, nor dramatic propriety. In regard to this point, it is enough to state it as a scientific fact, that Hamlet's mental con- 
dition furnishes, in abundance, the characteristic symptoms of insanity, in wonderful harmony and consistency.

The insanity of Hamlet, supposing it to be real, furnishes us with a satisfactory clew to some of his conduct, and especially to the leading principle of the play. Although no other of Shakespeare's plays has excited so much speculation, there still prevails a remarkable discrepancy of opinion on the most interesting questions connected with it. No one denies that the character and conduct of Hamlet are in the strictest accordance with the principles of human nature, but no two are agreed upon what particular principles they are to be explained. In plain terms, Shakespeare's science of human nature is more profound than that of his critics. Had his characters been constructed as the heroes of the novel and drama often are, to illustrate the workings of some particular passion or rule of action, made, so to speak, like those automata that execute a series of motions by an ingenious combination of springs and levers, it would have been comparatively easy to discover the principle of their construction. It is for the very reason that Hamlet is no machine, but a living, human soul, that, as in the case of most distinguished men, his character is not so easily read.

The principal canse of the failure of critics to discover the central principle of this admirable creation of Shakespeare's genius is that they have overlooked one of its most important elements. The pathological element working in the midst of his motives and impulses, and throwing its shadow over his affections, they have failed to discern; while others of very questionable existence have been found in abundance. Goethe says, "It is clear to me that Shakespeare's intention was to 
exhibit the effects of a great action imposed as a duty upon a mind too feeble for its accomplishment. In this sense I find the character consistent throughout. Here is an oak planted in a china vase, proper only to receive the most delicate flowers: the roots strike out, and the vessel flies to pieces. A pure, noble, highly moral disposition, but without that energy of soul that constitutes the hero, sinks under a load which it can neither support, nor resolve to abandon altogether. All his obligations are sacred to him; but this alone is above his powers." Certainly, Hamlet is not one of that class of persons to whom such a commission as he received is peculiarly congenial; but on other occasions, when the utmost energy of purpose and of performance is required, we witness nothing of this feebleness of will. His spirit fully awakens to the call, his nerves are braced, and his execution is prompt and decided. He instantly decides on following the ghost, feels "each petty artery in his body hard as the Nemæan lion's nerve," and fiercely throws off his friends who would prevent him. In killing Polonius, when his hand as rapidly executes as his mind conceives, he shows no lack of energy, no halting between two opinions. True, he evinces great infirmity of purpose in regard to the great mission assigned him, but this must be accepted as one of those inconsistencies so characteristic of the insane mind.

Mr. Hudson, the very able lecturer on Shakespeare, attributes Hamlet's irresolution, not to any original defect in his mental constitution, but to the peculiar circumstances in which he, is placed. A refined, amiable, and conscientious man, with high notions of honor and a strong sense of reverence, is suddenly required to become the minister of vengeance, - to destroy his uncle, the husband of his mother, and his king. Is it 
strange that he should hesitate, that he should shrink from the terrible duty imposed upon him, and dally with excuses for delay? Had he not been affected thus, he would not have been Hamlet, and would have failed to excite that feeling of personal regard produced by his noble nature, his gentle and gentlemanly demeanor. There is much truth in this view of Hamlet. The circumstances in question undoubtedly had great influence upon him; but not to an extent, as here supposed, unbecoming his reputation as a scholar, a gentleman, and a prince. In his interview with Ophelia, where he studiously lacerates her feelings with harsh and bitter sarcasm, we see none of this extraordinary refinement of feeling; and in consigning his old friends Rosencrantz and Guildenstern to the fate that was intended for himself, we can perceive no signs of a troublesome tenderness of conscience. ${ }^{1}$

On the supposition of his real insanity, we have a satisfactory explanation of the difficulties which have received such various solutions. The integrity of every train of reasoning is marred by some intrusion of disease; the smooth, deep current of his feelings is turned into eddies and whirlpools under its influence, and his most solemn undertakings conducted to an abortive issue. His clearest perceptions, his holiest purposes, his strongest determinations, are followed by the doubts, apprehensions, and scruples that torment and distract the disordered mind. While his whole soul is occupied with the idea of revenge, he is ever finding excuses for postponing the moment of execution, - constantly

I In a work lately published by this gentleman, entitled "Shakespeare's Life, Art, and Characters," he declares that subsequent reading and reflection have convinced him that Hamlet's madness is real, and not feigned. 
turned from his purpose by the merest whim, and justifying his conduct by reasons too flimsy to satisfy any but a disordered intellect. Such is the nature of insanity, - to talk, but not to act; to resolve, but never to execute; to support the soundest projects for action by the most imperfect performance.

In Lear we are presented with the origin, progress, and termination of a case of acute mania, - that form of mental disorder in which the mind becomes at last completely unsettled, and all its operations pervaded by discord and confusion. Hamlet's insanity differs from. Lear's, in not having the successive steps of its progress so well marked and regular; in presenting less incoherence of thought and less nervous excitement. In his case, acute general mania like Lear's would have been incompatible with that degree of forecast and self-control which the character required; and simple monomania, where the sphere of the mental aberration is a very limited one, - the individual for the most part observing the ordinary proprieties and courtesies of life,would have been equally out of the question, because it would not have exerted the requisite influence over the action of the play. With great skill therefore, - a skill founded on what would seem to be a professional knowledge of the subject, - Shakespeare has selected for his purpose that form of the disease in which the individual is mad enough to satisfy the most superficial observer, while he still retains sufficient power of reflection and self-control to form and pursue, if not to execute, a well-defined, well-settled purpose of revenge. In order the better to understand the conduct of Hamlet, we should bear in mind that he was a man of warm affections, refined tastes, and a quick sense of honor, and possessing a high order of intellectual endowments. With 
these simple elements of character, the manifestations of disease are made to harmonize and blend so intimately together, that it is not always easy to distinguish between them.

It is obvious that the death of his father and the precipitate marriage of his mother have already depressed his spirits, and thrown an air of sadness and gloom over his conversation and general bearing. The iron had entered his soul, and on his first introduction to us we perceive some indication of the torture it produces. When his mother reproves him for unduly yielding to his grief, he touchingly replies,-

" 'Tis not alone my inky cloak, good mother,

Nor customary suits of solemm black,

Nor windy suspiration of forced breath,

"No, nor the fruitful river in the eye,

Nor the dejected havior of the visage,

Together with all forms, modes, shows of grief,

That can denote me truly. These, indeed, seem,

For they are actions that a man might play :

But I have that within which passeth show ;

These but the trappings and the suits of woe."

A moment after, we find him bewailing, in the heaviness of his spirit, the cheerless aspect of all outward things, and harboring thoughts of self-destruction. Subsequently, in the famous soliloquy, we find him dwelling earnestly and anxiously on the subject of suicide, and sounding the depths of the untried world, but without the aid of philosophy or religion. Shakespeare has here evinced his usual fidelity to nature, in attributing to Hamlet sentiments that are entertained by almost erery person whose insanity is accompanied by much depression, although such frequency of the trait is far from being generally known. In this state of mind, full of grief, mistrust, and weariness of life, he has an inter- 
view with the ghost of his father, whose communications are followed by effects that might have been readily anticipated. In view of the villany by which he is surrounded, thus solemnly and fearfully made known to him, his mind grows giddy, and for a moment he loses all control over his thoughts. This is evident from his replies to his friends, when asked what news the ghost had brought him, and which were aptly designated by them as " wild and whirling words." This fact explains the light and disrespectful manner in which he speaks, of and to, the ghost, while administering the oath of secrecy to his friends, - a manner entirely at variance with the respect and reverence he unquestionably entertains for his father. "Ha, ha, boy! sayest thou so? Art thou there, true-penny?" "Hic et ubique! then we'll shift our ground." "Well said, old mole! canst work i' the earth so fast?" This is something more than the natural reaction of the mind after experiencing some powerful and extraordinary emotions. It betrays the excitement of delirium, - the wandering of a mind reeling under the first stroke of disease. Impossible though it is to explain this on any other theory, it has given but little trouble to commentators, who have been content to see in it, as Dr. Johnson did, in "the pretended madness" of Hamlet, as he calls it, a "cause of much mirth."

In this scene he adjures his friends, if they see him bearing himself however strange or odd, "as he might perchance think meet to put an antic disposition on," never to let drop the slightest intimation of his design. This remark, on which the theory of Hamlet's insanity being feigned is mainly founded, indicates at most an indefinite, half-formed resolve to accomplish a purpose 
by simulating a disease that was already overshadowing his spirit in all its fearful reality.

His visit to Ophelia, as described by herself, is generally regarded as the first act of the part he had determined to assume. Perhaps there is no single in. cident of the scene incompatible with the theory of simulation; but it is to be borne in mind that the indications of derangement are here confined to looks, gestures, and demeanor. Not a word escapes his lips; but a language more expressive than that of the voice betrays the violence of his emotions. From a mere description of looks and behavior, it is impossible to judge whether they are the cunning device of the simulator or the involuntary manifestations of disease. She alone who witnessed the scene could decide that question; and can we believe that Ophelia could be deceived by any possible play of those features in which she had been wont to read the language of his inmost soul? Although we have admitted that no single incident in this interview is incompatible with simulation, yet when we regard the whole picture which his appearance presented, - his pallid face, his piteous look, his knees knocking each other, his hatless head and down-gyved stockings, his deliberate perusal of Ophelia's face, and the sigh, "so piteous: and profound as it did seem to shatter all his bulk," - we feel as little disposed to believe all this to be a well-acted sham as we should the wail of a new-born infant, or the flush that glows on the cheek in the fever of consumption. The skilful physiognomist, the practised observer of men, might mistake the meaning of such an exhibition; but not she whose senses are quickened by the vigilant sympathies of woman's love. Considered then as a picture of a remarkable phasis of insanity, we discern in it some of 
those exquisite touches that always distinguish the genuine from the false; and to attribute these to a mere counterfeit of the disease is to show how little we are able to appreciate the wonderful fidelity of Shakespeare's conceptions, or his sense of poetical propriety, that saved him from the solecism of confounding the features of the true and the real with those of the spurious and false. Poetically, dramatically, and pathologically true, is this exhibition of Hamlet in his interview with Ophelia. We see him in a sudden paroxysm of his disorder that renders him heedless of his personal appearance, obeying the instinct of his affections, and making his accustomed way to her whose love had shed a radiance over his opening prospects. Dark and fearful images of disease throng into his mind, degrading to an uncertain and secondary place that which had been enshrined in its inmost sanctuary. He is dimly conscious of the spell by which he has been transformed, and clearly so of his utter impotency to dissolve it. In this tumult of strange and contending emotions he has lost the power of speech, for he had already lost the power to think and feel like himself. He can only gaze into her face as if to penetrate into the mystery that surrounds him, and then heaves a convulsive sigh that threatens to end his being. Such is madness; and such scenes as this, and others that subsequently occurred between Hamlet and Ophelia, have happened a thousand times in real life, where the insane lover thrusts himself into the presence of his mistress, only to frighten and distress her by the painful exhibition of clouded intellect and disordered affections.

In all Hamlet's interviews with Polonius, the style of his discourse is indicative of the utmost contempt for the old courtier; and he exhibits it in a manner quite 
characteristic of the insane. To the common observer, such hearty and undisguised contempt, such pungent sarcasm, and such relentless sporting with the old man's servility, savor more of malice than of madness, and afford strong ground for the theory that he was acting a part. But nothing is more characteristic of the insane than a fondness of annoying those whom they dislike by ridicule, raillery, satire, vulgarity, and every other species of abuse; and in finding the sore spot of their victim, and adding venom to their sting, they display an aptitude in which they are seldom surpassed by the sane. In this spirit Hamlet, who looks upon Polonius as an intriguing, meddlesome old man in the interest of the court, calls him a fishmonger, doubts his honesty, rails at old men, makes him eat his own words, and finally thanks him for leaving his presence. Had Hamlet been feigning insanity, it still would have been hardly consistent with his character to have treated in such a style the father of one so dear to him as Ophelia, for whose sake alone he was entitled to receive from Hamlet forbearance, if not respect.

Towards his old friends, Rosencrantz and Guildenstern, his discourse and manner are suitable to his own character and to their ancient friendship. He treats them respectfully, if not cordially; discourses sensibly enough about the players, and other indifferent subjects, occasionally losing his self-control and uttering a remark strongly savoring of mental unsoundness. "O God, I could be bounded in a nutshell, and count myself a king of infinite space, were it not that I have bad dreams." It is a well observed fact, though not generally known, that in a large majority of cases the invasion of insanity is accompanied by more or less sleeplessness, and disagreeable dreams. I have not yet met with the case, 
however sudden the outbreak of the disease, in which the first symptom did not exist for some time before any suspicion of impending derangement was excited in the minds of the friends. Althongh strongly suspecting, if not knowing, that they are in the interest of the king, sent expressly for the purpose of observing his movements, he makes no attempt to impress them with a conviction of his madness, as might have been expected had he been acting a part. For certainly if he had been anxious to spread the belief that he was really mad, he would not have neglected so favorable an opportunity as this interview with the courtiers. On the contrary, he calmly and freely describes the state of his feelings, as he previously did to his mother. "I have of late (but wherefore I know not) lost all my mirth, forgone all custom of exercises, and, indeed, it goes so heavily with my disposition, that this goodly frame, the earth, seems to me a sterile promontory; this most excellent canopy, the air, look you, this brave o'erhanging firmament, this majestical roof fretted with golden fire, why, it appears no other thing to me than a foul and pestilent congregation of vapors." A most faithful and vivid picture is this of a mental condition that is the precursor of decided insanity, - the deepening shadow of that steadily advancing eclipse by which the understanding is to be darkened. In Hamlet the disease has not yet proceeded so far as to prevent him, in his calmer moments, from recognizing and deploring its existence, though he mistakes its character. Like every other person in his condition, he is very far from considering himself insane, and indeed there is no reason why he should. He entertains no delusions; persons and things appear to him in their customary relations; and for the most. part he well sustains his character as a man and a prince. 
His unwonted excitability of temper, his occasional disregard of some minor propriety of life, the cloud which envelops all outward things, depriving them of their worth and beauty, - in the eyes of the world, these do not constitute insanity, and are not incompatible with the most perfect integrity of intellect. Why then should he suppose himself insane, or beginning to be so?

Hamlet now, in the true spirit of insanity, upbraids his own indecision and want of energy, doubts whether the ghost were an honest ghost, and contrives a plan, by means of the players, to test the truth of his declarations. So much ingenuity and forecast as this contrivance evinces are not often witnessed among those who are popularly regarded as insane; but it must be recollected that Hamlet is yet in the initiatory stage of the disease, before the intellect has shared in that obliquity which marks the manifestations of the moral sentiments.

We next meet with Hamlet in his remarkable interview with Ophelia, - remarkable not more for his language and conduct than for the difficulties which it has presented to commentators, to whom it has proved a perfect pons asinorum. Some regard his treatment of Ophelia as unnecessarily harsh and unfeeling, even for the purposes of simulation, and in this instance, at least, can see no cause of mirth in his pretended madness. If Homer sometimes nods, so may Shakespeare. Others think that Hamlet's love for Ophelia was but lukerarm, after all, and therefore he was justified in treating her in such a way as to lacerate her feelings and outrage her dignity. The most natural view of the subject that which is most readily and obviously suggested relieves us of all these difficulties, and reveals to us the same strong and earnest significance which appears in 
every other scene of this play. If Hamlet is really insane, as he presumptively is, and as we have much reason to believe that he is, then his conduct is what might have been naturally expected. It discloses an interesting feature in mental pathology, - the change which insanity brings over the warmest affections of the heart, whereby the golden chains wrought by love and kindness are utterly dissolved, and the forsaken and desolate spirit, though it continues among men, is no longer of them. Such aberrations from the normal course of the affections were closely observed and studied by Shakespeare, who saw in them that kind of poetical interest which master-spirits like his are apt to discern in the highest truths of philosophy. The frequency with which he introduces insanity into his plays shows that it was with him a favorite subject of contemplation; and from the manner in which he deals with it, it is equally obvious that he regarded it. as not only worth the attention of the philanthropist and physician, but as full of instruction to the philosopher and the poet. $\mathrm{He}$ perceived that many of its phenomena were calculated to touch the warmest sympathies of our nature, and therefore peculiarly suitable for producing dramatic effect. If in this feature he differs from every other poet, it is not from that fondness for dwelling on the morbid anatomy of the mind, which is the offspring of a corrupt and jaded taste, but from a hearty appreciation of all the works and ways of nature, and a ready sympathy with every movement of the human soul.

In no instance are these views so strongly confirmed as in this remarkable scene. The gradually increasing excitement, the frequent, sudden starting from the subject, his denial of his former affection, and the general air of extravagance and perversity that pervades the 
whole scene, - all indicate a most thorough mastery of the phenomena of insanity, and the most consummate skill in combining and displaying them in action. Especially is this obvious in the rapid transition from the calmness and courtesy with which Hamlet first addresses Ophelia, to the storm of contending feelings which immediately after ensues. He has just been speculating on themes of the deepest moment, endeavoring to penetrate through the gloom that reils the future from the present, when she passes before him. The sight of her awakens a healthy and tender emotion.

\section{"Soft you, now!}

The fair Ophelia. - Nympl, in thy orisons

Be all my sins remembered.'

She immediately takes the opportunity to return him the gifts she had received from him, with an intimation that he had ceased to love her. Quick as thought, the current of his feelings is changed, and the demons of mistrust, jealousy, and anger run riot in his bosom. The courtesy of the gentleman and the tenderness of the lover are forgotten, and words of gall and bitterness are poured out upon the gentle being whom he loved with more than the love of forty thousand brothers. I need not remind those who are at all conversant with the insane, how very natural this is; and how unnatural it would have been in Hamlet, had he been acting a part, is sufficiently obvious from the disposition of critics to regard it as a fault in the author. The fury and extravagance of mania, the moodiness of melancholy, he might successfully mimic; but to do violence to his affections, to desecrate and trample upon the idol that had been enshrined in his heart of bearts, - this was beyond the power of mimicry.

In Hamlet's remarkable interview with his mother, 
his discourse is rational and coherent enough; but it is pervaded by that wild energy, that scorching sarcasm, that overwhelming outpouring of bitter truths, which, though not incompatible with perfect soundness of mind, are exceedingly characteristic of madness. Well might she say, -

"These words like daggers enter in mine ears."

That his mind is in a state of fearful commotion, is also shown by the reäppearance of the ghost, which, in this instance, is present only to the mental eye. His air and manner as noticed by his mother are strongly expressive of the inward emotion, and such as the most consummate actor could scarcely imitate.

\section{"Alas, how is't with you?}

That you do bend your eyes on vacancy, And with the incorporal air do hold discourse?

Forth at your eyes your spirits wildly peep,

And as the sleeping soldiers in the alarm,

Your bedded hair, like life in excrements, Starts up, and stands on end."

When she tells him that the image he beholds is the very coinage of his brain, resulting from ecstasy, like most insane men he repels the idea of being mad, and offers a test of his soundness, which, if not always conclusive, indicates, at least, on the poet's part, a close observation of the operations of the insane mind.

\section{"It is not madness}

That I have uttered : bring me to the test, And I the matter will reword; which madness Would gambol from."

This test was once successfully applied by Sir Henry Halford to a patient laboring under some degree of mental disorder, who insisted on making his will which had been already prepared according to his instructions, and to the several items of which, when read to him, he dis- 
tinctly assented. In order to determine the real condition of his mind on the subject, Sir Henry proposed to apply Shakespeare's test; but instead of rewording the matter precisely as he had just heard it, he made a very different disposition of most of his property. In most cases of acute mania attended with much excitement, as well as in that form of mental impairment called dementia, the patient would be unable, no doubt, to repeat what he had just before deliberately uttered; but in such cases as Hamlet's, where some of the mental operations are perfectly well conducted, the power of repeating correctly one's own statements is not necessarily lost, and consequently is no proof of sanity in doubtful cases.

Hamlet's conduct at the grave of Ophelia was madness in its purest state. The unexpected news of her death, the sight of her funeral solemnities, the passionate language of her brother, are too much for his self-control, and he gives vent to his feelings in the most extravagant expressions of grief and defiance. He is truly in a towering passion, but it is the passion of a madman, without end or aim, and justified by no sufficient provocation. The apology which he afterwards offers to Laertes, beg. ging him to attribute the impropriety of his conduct to madness, deserves a moment's attention. It is one of the rarest things in the world for a madman to admit the existence of his own insanity. It has been already remarked, however, that Hamlet's disease is yet in its initiatory stage where paroxysms of wildness and fury are intercalated with intervals of calmness and self-control when, through the cloud that envelops his spirit, he is able to discern his true relations to others, and the occasional influence of disease over his thoughts and actions. Bearing this fact in mind, we shall hesitate to attribute the above apology to a misapprehension, on Shake- 
speare's part, of the true characters of insanity. On the contrary, it evinces a most delicate perception of its various forms, which leads him to introduce a feature that the simulator would have scarcely ventured to assume.

The final event, the crowning catastrophe of the piece, most aptly finishes the story of Hamlet's irresolution, his vacillation, his forereaching plans, his inadequate performance. The nearest object of his heart - the revenge of his father's wrongs - is at last accomplished, but by means of a contrivance he had no part in effecting.

It may be thought, perhaps, that in deciding the question whether Hamlet's madness be real or feigned, some weight should be allowed to the original history in which he is represented as having actually simulated the disease. This fact is certainly entitled to some consideration, but my own reflections upon it have rather confirmed than weakened the view I have taken of the subject. Shakespeare was so much in the habit of varying from the tale or history that formed the groundwork of his plays, that this fact alone would deter us, in a doubtful case, from expecting that any particular trait or event in the former would be faithfully represented in the latter. In tracing the history of his plays, however, we find him acting upon a general principle that should not be overlooked in settling a difficulty like the present. This was, that he never hesitated to vary from the original whenever the higher objects of the drama required it. It could have been scarcely otherwise, indeed, if his own work were to be distinguished from its prototype by marks of a nobler lineage. The puerilities of the old story-tellers were to be exchanged for incidents of commanding interest, the common natures that figured 
in their narratives were to be transformed into more ethereal spirits, and their lame and impotent conclusions were to give place to lessons of ever enduring truths. Thus, in the present case, the wronged prince who is undistinguished by any mark of superiority from the common herd of kings' sons, and who resorts to an artifice in order to revenge his wrongs, is to be transformed into

"The expectancy and rose of the fair State,

The glass of fashion, and the mould of form."

The shining worth and dignity of such a character would have been essentially compromised by an imposture, however justified by the end; while the example of a refined and noble spirit staggering under the weight of a great responsibility, with powers crippled by the intrusion of disease, - at one time, a dangerous maniac rushing recklessly into crime; at another, discharging offices of friendship and uttering words of profoundest wisdom, - is a spectacle worthy of men and gods. Indeed, the principle in question is so common in Shakespeare, and its application in the present case so obvious, that it appears to me scarcely necessary to strengthen the position by additional arguments.

In this play, for the first and only time, Shakespeare has ventured on representing the two principal characters as insane. His wonderful success in managing such intractable materials, the world has long acknowledged and admired. They are never in the way, and their insanity is never brought forward in order to enliven the interest by a display of that kind of energy and extravagance that flows from morbid mental excitement. On the contrary, it assists in the development of events, and bears its part in the great movement in which the actors are hurried along as if by an inevitable decree of 
fate. Herein lies the distinguishing merit of Shakespeare's delineations of insanity. While other poets have made use of it chiefly to diversify the action of the play, and to excite the vulgar curiosity by its strange and striking phenomena, he has made it the occasion of unfolding many a deep truth in mental science, of displaying those motley combinations of thought that are the offspring of disease, and of tracing those mysterious associations by which the ideas of the insane mind are connected. Few men, I apprehend, are so familiar with those diversities of mental character that are, in any degree, the result of disease, as not to find the sphere of their ideas on this subject somerwat enlarged by the careful study of Shakespeare.

Ophelia is one of those exquisite creations of the poet's fancy, whose earthly types occasionally cross our path in the course of our sublunary pilgrimage. Like them she wins all hearts, but, too delicate to encounter the world's rude shocks, she is unable to survive the wreck of her affections; and, like them, her brief history consists in being seen, and loved, and mourned. The morning of her days which had been illumined by the light of love and parental affection had been early clouded by the death of her father and the misfortunes of her lover; life had no longer any joys in store, and in mercy she is spared all further afflictions, by the loss of reason and a premature death. Wisely has the poet abbreviated the duration of her madness. The prolonged exhibition of this afflictive disease in one so gentle and lovely would have distressed the mind of the beholder, in a manner unfavorable to dramatic effect. We see enough to understand that she is no longer conscious of her sufferings; and after listening to the snatches of songs that flit through her memory, with the same kind 
of melancholy interest with which we hear the sighing. of the autumnal breeze through the limbs and leaves of the trees, we are willing that the finisher of all earthly sorrows should come. There is no method in her madness; no quips and cranks of a morbidly active ingenuity surprise and gratify the curious beholder, and no bursts of passion such as madness alone can excite fall on his astonished ear. Like one who walks in his sleep, her mind is still busy, but the sources of its activity are within. Heedless of everything else, her mind wanders among the confused and broken recollections of the past, deserted by the glorious light of the Divinity that stirs within us, but which is soon to be rekindled with unquenchable brightness.

In the character of Macbeth, Shakespeare has exhibited a mental phenomenon of a pathological kind which he seems to have correctly understood, and in that respect was greatly in advance of the current notions of his own and perhaps the present times. It has been already observed, that, when the brain is morbidly excited, previous impressions, even some that may long: since have been forgotten, are often so distinctly and vividly recalled as to appear to have an objective existence. This activity of the perceptive organs is not confined to madness, but may also occur whenever the nervous system is unusually excited by protracted watching, by errors of diet, by long and anxious meditation, by powerful emotions, or by the presence of other diseases. In this condition, the ordinary relations between the mind within and the world without are quite reversed. The imaginary takes the place of the real ; the inward is no longer reflected from the outward, but the latter becomes the mere shadow of the former. Thus in Macbeth 


\section{SHAKESPEARE'S DELINEATIONS OF INSANITY.}

the suggestions of his own unprincipled ambition, the predictions of the weird sisters, and the goading of his wife, kept the prize of royalty constantly before his eyes, only to be won, however, by the foulest treachery and violence. This one thought takes possession of his mind, absorbs his whole being, and so often and intently does he revolve the only means for accomplishing his purpose, that finally the very instrument thereof appears before him in a visible shape. He sees a bloody dagger with its handle towards him; and so clear is the image, that nothing less than the sense of touch convinces him that it is merely a dagger of the mind, " proceeding from a heat-oppressed brain." The deed was done and the prize was gained; but, tortured almost to distraction by the most painful apprehensions, he sought in vain for security and repose, in the commission of fresh crimes. In this state of agitation induced by his bloody career, the murder of Banquo was more than sufficient to reproduce that morbid activity of the perceptive organs, which invested the images of the mind with visible forms, and gave them an outward existence. The image of his slaughtered brother-in-arms, so foully taken off, glides into the banqueting-room and seats itself at the table. But the suggestions of reason are no longer able to correct the error of sense. Not more real to Macbeth are the forms of his invited guests, than is the dreaded image in his own seat; for it shakes at him its gory locks and glares upon him with its vacant eyes. His mind is driven from its propriety, he forgets his situation and relations, and, carried away by the force of the hallucination, he reveals to the company the tremendous secret which they should have been the last to learn.

The reader scarcely needs to be told how the true 
meaning of this phenomenon is perverted and its terrible power worse than lost, - even made ridiculous, - in its representation on the stage, by the introduction of a real ghost as visible to everybody else as to Macbeth. The absurdity of the whole matter is heightened by the guests pretending not to see what is plainly before their eyes, and wondering what should so startle their royal host. This puerile contrivance is but a sorry compliment to the intelligence of the audience, who, if they could once forget the prescriptive usages of the stage, would be infinitely more impressed by a proper representation of the scene. The sight of a king springing from the banquet-table, in the midst of his lords and nobles, gazing on vacancy, with horror and alarm depicted in his countenance, addressing to the imaginary object before him words of reproach and defiance, is calculated to make a far deeper impression on the beholder than the trumpery contrivance of an actual ghost. With the first appearance of the ghost in Hamlet, however, the case is very different. In Macbeth it is the poet's object to exhibit, by means of the ghost, the power of conscious guilt upon an over-active brain; while in Hamlet he merely makes use of a vulgar superstition for bringing out a fact necessary to the action of the play. How clearly Shakespeare appreciated this difference, is also evident from the manner in which the ghost is afterwards introduced during the interview between Hamlet and his mother. This is meant to be regarded merely as a mental apparition, - a previous impression reproduced in consequence of the inordinate nervous excitement under which he is suffering at the moment, - because, though as distinctly visible to Hamlet as the actual ghost in the first act, it is, unlike that, visible to no one else. True, he speaks to it, and the apparition answers, but its words 
are obviously intended to be audible only to him, for his mother hears no voice, and sees no form.

The pathological correctness of Macbeth's character is made still more manifest by attributing to him a hallucination of another sense, - that of hearing. In that matchless interview between him and his wife immediately after Duncan's murder, he declares that, among other circumstances attending that fearful deed, he heard a voice cry,

\section{"Sleep no more!}

Glamis hath murdered sleep ; and therefore Cawdor Shall sleep no more, - Macbeth shall sleep no more!"

The cerebral excitement produced by the circumstances of the murder has so sharpened the sensibility of the auditory organs, that the slightest sound, or, it may be, even the very thoughts of his soul, ring through his ears in words of unmistakable meaning.

We may admire, while it would not be very easy to explain, the wonderful sagacity of Shakespeare in conceiving that true theory of apparitions, which now, after more than two centuries, is just beginning to be adopted by scientific men.

In the character of Lady Macbeth, the poet has exhibited a mental condition of a most curious and interesting kind, which, though not strictly insanity, is unquestionably of a pathological nature. The successive crimes into which her husband's ambition has plunged him produce in her a state of mental disquietude that undermines her weaker constitution and eventually occasions her death. The circumstances connected with the murder of Duncan are stamped upon her brain, as if with a hot iron, and there they remain in characters of fire, not even to be temporarily effaced by sleep. To such a pitch does the nervous excitement increase, that in sleep 
she rises from her bed, and acts over her own part in the bloody scene. Again she reproaches her husband with his irresolution, wonders that the old man should have so much blood in him, endeavors in vain to wash the spots from her hands, and is startled by a knocking at the gate. The wound is too deep to be healed; no medicine can be found to cleanse the bosom of such perilous stuff, and nature finally succumbs under the weight of bodily exhaustion and mental anguish. Within the whole round of human wretchedness, there is not a case more deplorable than that of the man or woman who, with the moral depravity adequate to the commission of great crimes, wants the nerrous hardihood capable of sustaining the shock they give to the mental constitution. Such a case has Shakespeare presented in Lady Macbeth, and with so much power and truth that no lapse of time, no change of human condition, will ever weaken its effect.

To be convinced of the unapproachable preëminence of Shakespeare in the delineation of insanity, we have only to compare him with the poetical luminaries of his own generation. Fletcher, who is generally regarded as inferior to none of them, has represented one of his female characters - the jailer's daughter in "The Two Noble Kinsmen" - as going mad from love. Some scenes are a feeble imitation of Ophelia, and the whole effort probably originated in a feeling of emulation excited by that part. But how inferior to that exquisite creation, as a specimen of mental pathology, or an expression of poetical taste! Both her conduct and conversation are crazy enough, no doubt. Not a single word nor act, separately considered, is inconsistent with real insanity; but there is a visible straining for effect, a certain extravagance of thought, a perpetual recurrence to the cause of her disorder, an abruptness in changing the 
train of reflection, far more characteristic of simulated than real insanity. The author has committed the popular error of supposing that the lunatic is ever dwelling on the cause of his calamity, and hence the love-cracked damsel utters the name and expatiates upon the perfections of her lover at every breath. It has already been remarked that in acute mania, if we except the initiatory stage when reason is not quite driven from her throne, the patient seldom even alludes to the events connected with the origin of his disease. Lear, for instance, talks much of the ingratitude of his daughters, but not after he becomes raving mad. The manner in which Fletcher has executed his task, shows how little he was inspired by those lofty conceptions of the true object of dramatic representations of insanity, which impart to Shakespeare's insane characters inexhaustible interest and instruction. To put crazy speeches into the mouth of a person, and send him capering through the fields, is an easy matter, - any tolerably shrewd attendant in a lunatic hospital might do as much. But to observe through a succession of scenes the method that is in madness, to make its various phases consistent one with another and preserve the individuality of the character through them all, and, more than all else, to present a picture calculated not only to excite emotions of sympathy with physical distress, but to strike the imagination and gratify the poetical sentiment, - this is the work of the highest order of genius alone. In the hands of inferior writers, insanity is too much regarded as an absolute condition in which all personal distinctions are annulled and all traces of the individual's former self effaced. But not so with Shakespeare. Lear, while forming the prominent figure in the motley group that wandered in the forest, was no less Lear than when 
seated on a throne and dispensing favors to his dependants. The tempest of fury exhibited by Hamlet at the grave of Ophelia is not inconsistent with the character of the speculating, irresolute prince who mournfully soliloquizes on his infirmity of purpose, and quails before the solemn commission he has taken upon himself to perform. Considered in a still higher aspect, — as a creation of poetical art, - we see in the jailer's daughter none of those shadowy reminiscences of youthful joys, none of those delicate allusions to the subject of love, none of those flitting images of purity and peace, none of those bursting throbs of filial affection, - not one, in short, of those exquisite touches that throw a melancholy charm over the madness of Ophelia. She is gross, carnal, of the earth, earthy, and her imagination wanders into forbidden paths. She is but a poor mad woman whom idle boys would gather around in the streets, and humane people would wish to place in a hospital. Whatever truth there may be in the opinion some critics have entertained, that Shakespeare had any part in the writing of this play, it is very certain that this character, at least, received not a single finishing stroke from his pen.

In this review of Shakespeare's delineations of insanity, I trust I have made it appear in some measure how their wonderful fidelity to nature renders them not only valuable as pathological illustrations, but exceedingly effective in producing a dramatic impression. Great as he is in every other attribute of the poetical character, yet in this department of the art he seems to be without a rival. No other writer, unless it may be Sir Walter Scott, has made the slightest approach to his success. In several of this writer's novels, the workings of a disordered mind are displayed with the hand of a master, 
and that too with a degree of pathological accuracy which ordinary men would hardly acquire by years of observation within the precincts of a hospital. But the novelist possesses an advantage over the poet in the broader limits within which he may exercise his art, untrammelled by the restrictions imposed upon the other by severer rules of composition and the comparative brevity of his efforts.

I have already intimated that in his knowledge of insanity Shakespeare was greatly in advance of his own and succeeding generations, and that this was owing, not to any superior advantages he possessed for the study of the disease, but to an extraordinary power of observation which, more than any other mental attribute, perhaps, deserves to be considered as the true inspiration of genius. It needs but a glance at the common views of insanity that prevailed in his own, and even later times, not merely among the rude and uneducated, but among: men of distinguished names, to show how little they evince of his profound science of mind. By a profession which has always numbered in its ranks a large proportion of the luminaries of the age, the insane generally, with the exception of such as were actually raving or reduced to a state of idiocy, were regarded as having reason enough to enable them to conduct with tolerable propriety, and made responsible for their actions to a degree that would startle the criminalists of our own time, ready as most of them are to look upon the plea of insanity as the last resort of ingenious counsel. Sir Matthew Hale declared, many years after Lear was written, that insanity affects only the strength and capacity of the mind, and upon this idea he has actually founded a test of responsibility. "Such a person as laboring under melancholy distempers hath yet ordinarily as great understanding as ordinarily 
a child of fourteen years, is such a person as may be guilty of felony or treason." These views, it is true, belong to a province of insanity somewhat remote from that which engaged Shakespeare's attention; but there can be no difficulty in inferring, from his delineations of the disease, in what light he would have regarded them. Can we suppose, for instance, that if the question of the responsibility of Hamlet for the killing of Polonius had been referred to him, he would have pronounced him guilty of murder in the first degree, because he possessed more understanding than a child fourteen years old? Had the great jurist, in forming his opinions on this subject, meditated upon the pictures of Shakespeare as well as the statements of Lyttleton and Coke, it would have been better for his own reputation and better for the cause of humanity. Would that we were able to say that the courts of our own times have entirely avoided his error, and studied the influence of insanity upon human conduct more by the light of Shakespeare and of nature than of metaphysical dogmas and legal maxims. 


\section{ILLUSTRATIONS OF INSANITY BY DISTIN- GUISHED ENGLISH WRITERS.}

Next to Shakespeare, no English writer has been so successful in making insanity conducive to the exhibition of character under strong and impressive aspects, as Sir Walter Scott. This, indeed, might have been expected, from the fact that no other has partaken so largely of some of the distinguishing attributes of Shakespeare's genius, - his faithful and profound observation, his skilful appropriation of its results, and, above all, his hearty appreciation of every striking or extraordinary form of mental manifestations. The same breathing, speaking lineaments, the same life-like touches that impart an inexpressible charm to his characters, are no less obvious in those whom he has represented as victims of mental disorder. We scarcely need to criticise their fidelity: we are assured of it by intuitive evidence. Any one who doubts it would be ready to pass his hands over the face of a living man to satisfy himself that it was real flesh, and not an imitation in wax.

Scott's best representation of madness is unquestionably Madge Wildfire, in the "Heart of Mid Lothian." She is an admirable illustration of a form of chronic insanity in which the mental manifestations are distinguished less 
by delusions and gross incoherence, than by a certain irregularity and unsteadiness not easily described. The general condition is aptly characterized by the remark applied to Nadge, that her "mind, like a raft upon a lake, was agitated and driven about at random by each fresh impulse." For a moment or two she pursues a train of reflections with tolerable coherence, when some fanciful or grotesque idea, some incident in her experience, seizes her attention, and diverts her thoughts into some new channel. With a single exception, she exhibits no delusions; but that which she does entertain seems scarcely necessary to confirm our convictions of her insanity. And yet the mental disorder so obrious, even without the addition of delusion, we should find it not easy, in an actual case, to establish or prove satisfactorily by the most careful description. Were we asked on the witness-stand, in a court of justice, our reason for believing Madge Wildfire insane, we should have to rely solely on her fancy that she was once dead, and danced on the green sward by moonlight with other dead folks. Proof drawn from the general style of her conduct and conversation would fall on unwilling ears as something too fanciful or theoretical to deserve serious consideration. It certainly would have gone hard with Madge, had she been on trial for some capital crime, and this delusion of hers been overlooked; for it could have been easily shown, that she could distinguish between right and wrong; that she knew the wicked would be punished hereafter for their deeds; that she could lay plans, and select proper means for accomplishing her ends, - all which would have been considered as clearly incompatible with the kind of insanity which annuls criminal responsibility. True, a whole century and more has elapsed since that time, and left us the 
benefit of its liglit; but I am not quite sure that her case would be more favorably regarded, even in our own times.

The distinction between the form of disease represented in this character and other forms is admirably preserved. Its drifting thoughts are never exchanged for the sudden and violent transitions of acute mania, nor the solemn and persistent absurdities of pure monomania. For a moment or two, she pursues a train of thought with tolerable correctness, and then her mind is diverted from the track by some incongruous image or fantastic association. The fault is not so much in the thoughts themselves, independently considered, as in their vicious succession, the bond of union being broken at frequent intervals. In Madge, these unnatural transitions are made more abrupt than they would otherwise have been, by a considerable degree of excitement which imparts to the mental movements a constant hurry, if not confusion, not easily described. Her memory is strong, her conceptions are vivid, her sense of the true and the beautiful is still keen, and many of her relations to others are correctly discerned. But her mind is intensely introspective, absorbed in an outspoken reverie from which it is drawn only by suggestions from without. Her emotional nature also shares in the disorder that pervades her intellectual operations; for the least opposition or a fancied slight raises a gust of passion that spares neither friend nor foe. This trait is admirably displayed by Madge, who, while quietly making her way to church, suddenly turns and spies Jeanie about to sit down on her father's grave. "She followed her with long strides, and, with every feature inflamed with passion, overtook and seized her by the arm. 'Do ye think, ye ungratefu' wretch, that 
I am gaun to let you sit down upon my father's grave? The deil settle ye down, if ye dinna rise and come into the Interpreter's house, that's the house of God, wi' me, but I'll rive every dud aff your back!' She adapted the action to the phrase; for with one clutch she stripped Jeanie of her straw bonnet and a handful of her hair to boot, and threw it up into an old yew tree."

That Sir Walter well understood the form of disease he had to deal with, is made very evident by many of those exquisite touches which, like that just mentioned, would seem to have been beyond the reach of any but the strictly professional observer.

What can be better than Madge's reply to Jeanie Deans when she said she was never in Bedlam. "Weel, I think thae daft carles the magistrates send naebody to Bedlam but me, - they maun hae an unce respect for me, for whenever I am brought to them, they aye hae me back to Bedlam. But troth, Jeanie, (she said this in a very confidential tone,) to tell ye my private mind about it, I think ye are at nae great loss; for the keeper's a cross patch, and he maun hae it a' his ain gate, to be sure, or he makes the place waur than hell. I often tell him he's the daftest in a' the house."

Something suggests a comparison between her own condition and circumstances and those of Bunyan's Pilgrims; and the fondness with which she recurs to this idea, and her ingenuity in managing the comparison, constitute a very life-like trait in this portrait of insanity. Her exhibition in the parish cliurch illustrates the ways and manners of the class of insane to which she belonged, better than a volume of description. We cannot forbear to extract a passage from this exquisite scene.

"She swam rather than walked up the centre aisle, dragging Jeanie after her, whom she held fast by the 
hand. She would, indeed, have fain slipped aside into the pew nearest the door, and left Madge to ascend in her own manner, and alone, to the high places of the synagogue; but this was impossible without a degree of violent resistance, which seemed to her inconsistent with the time and place, and she was accordingly led in captivity up the whole length of the church, by her grotesque conductress, who, with half shut eyes, a prim smile upon her lips, and a mincing motion with her hands, which corresponded with the delicate and affected pace at which she was pleased to move, seemed to take the general stare of the congregation, which such an exhibition necessarily excited, as a high compliment, and which she returned by nods and half courtesies to individuals amongst the audience, whom she seemed to distinguish as acquaintances. Her absurdity was enhanced in the eyes of the spectators, by the strange contrast which she formed to her companion, who, with dishevelled hair, downcast eyes, and a face glowing with shame, was dragged, as it were, in triumph after her.

"Madge's airs were at length fortunately cut short by her encountering in her progress the looks of the clergyman, who fixed upon her a glance at once steady, compassionate, and admonitory. She hastily opened an empty pew which happened to be near her, and entered, dragging in Jeanie after her. Kicking Jeanie on the shins, by way of hint that she should follow her example, she sunk her head upon her hand for the space of a minute. Jeanie, to whom this posture of mental devotion was entirely new, did not attempt to do the like, but looked around her with a bewildered stare, which her neighbors, judging from the company in which they saw her, very naturally ascribed to insanity. Every person in their immediate vicinity drew back from this extra- 
ordinary couple as far as the limits of their pew permitted, but one old man could not get beyond Madge's reach, ere she had snatched the prayer-book from his hand, and ascertained the lesson of the day. She then turned up the ritual, and, with the most overstrained enthusiasm of gesture and manner, showed Jeanie the passages as they were read in the service, making at the same time her own responses so loud as to be heard above those of every other person."

In the last scene of all, in the agony of spirit produced by the execution of her mother, she recurs to this passage between herself and Jeanie, and with a pathos heightened by her distracted emotions she exclaims, "Oh, Jeanie Deans, - Jeanie Deans! save my mother, and I will take ye to the Interpreter's house again, and I will teach ye a' my bonny sangs, - and I will tell ye what came o' the - "

Few of Scott's young ladies inspire a deeper interest than Clara Mowbray in "St. Ronan's Well," and for no other reason, that I can see, but that the blight of insanity has fallen upon her joyous spirit, and insulated it in the very midst of the allurements and promises of life. She does not, however, so much illustrate any particular form of insanity, as that peculiar condition of the mind which is generally the precursor, and sometimes the follower, of a decided attack of the disease. 'To its former relation with insanity, I have already adverted, p. 4t3, and the latter is also full of interest to the poet and the psychologist. It may be well to premise, however, that I do not suppose that, in the mental impairment of Clara Mowbray, Scott expressly designed to represent that particular condition that precedes or follows an attack of insanity. It was enough for him to represent what had come within the range of his observation. Its exact 
relation to decided, unquestionable insanity, he probably regarded as a subject belonging to the scientific inquirer.

It is a well confirmed fact that in a certain proportion of those who recover from an attack of insanity, the mind never exactly regains its normal condition. Although the person's thoughts may be apparently, and perhaps really, correct, and his duties performed with the utmost propriety, yet there is an oddity in his ways, a singularity in lis dress and demeanor, a brusqueness of manner, and a general want of harmony between the manifestations of his character and conduct, that attract the attention of the bystander and give rise to special remark. The morbid influence is witnessed only occasionally, and is confined to points of secondary consequence, - the "minor morals" and the minor manners of the individual. The shadows of disease flit across his mental horizon, like clouds in a summer sky, before the face of the sun, merely subduing, while they pass, the brightness of its light. We are no sooner aware of their presence than they have vanished, and the glorious luminary shines out again in its undimmed splendor. Such persons are more or less aware of their infirmity, and are able, to a certain extent, especially in the presence of others, to exercise their self-control, and restrain the manifestations of disease. It is when alone and unobserved, when forming or executing their plans, or even when quietly following their ordinary routine of duty, that they betray, unconsciously to themselves, the infirmity by which they are mastered. To those who have frequent intercourse with them, their mental impairment is perfectly obvious; but they would find it difficult, merely by a description of their conduct and conversation, to convince others of the fact who have 
not had the same means of acquaintance. It is one of those things that cannot be described, - it must be seen . in order to be adequately conceived and understood.

This condition of mind is admirably represented in Clara Mowbray. From others we learn that she has "a bee in her bonnet," and we find indeed that her insanity is a matter of common remark, but we hear nothing of it from her own lips. To the casual observer she appears merely to be a free-spoken young lady, rather regardless of those conventional forms by which the intercourse of society is maintained, but whose discourse sparkles with wit, and lacks neither vigor nor point. At the most he observes only an unfeminine independence, or a dash of eccentricity quite compatible with the soundest condition of mind. If then she says nothing "sounding to folly," and behaves, in our presence at least, like many young ladies whose manners have been somewhat neglected, we may be asked where we find the evidence that she is otherwise than perfectly sane. We find it in her distaste of society and impatience of its forms, and especially in those occasional freaks which are at variance with every principle of prudence and common sense. We find it in her appearance before a brilliant company in her riding-dress; in thoughtlessly giving away the costly present of her brother; in the variety of feminine labors begun but never finished, that lie scattered about her boudoir. Some of the traits which she exhibits also are not natural to her character, but proceed from a physical condition that is intimately connected with insanity. The inward grief that consumes her heart produces a kind of nervous erethism, which occasionally breaks out into extravagant spirits and an unnatural buoyancy of the feelings, which, though sometimes assumed for one purpose or another, are the involuntary 
reaction of the prevalent and habitual condition. In such a state of mind it scarcely needed so severe a blow as the disclosure of her brother's designs to dissolve the feeble bond that holds her shattered intellect together.

Norna of the Fitful Head, in the "Pirate," "is meant," says the author, "to be an instance of that singular kind of insanity, during which the patient, while he or she retains much subtlety and address for the power of imposing upon others, is still more ingenious in endeavoring to impose upon themselves." It is a less common form of the disease than general mania, but its pathological characters are equally constant and well defined. Although apparently a simpler disorder than the latter, because fewer of the mental powers are involved in the morbid action, yet I am not sure that it has been more successfully represented by literary writers. The phenomena that first meet the attention are so strange and extraordinary, that others less striking are apt to be overlooked altogether. The mind is so steady to its favorite fancies, and so consistent and coherent in maintaining them, that less opportunity is afforded for the display of the writer's skill than in those forms of derangement where the bonds of association are more delicate and obscure, and the thoughts have a more motley and impulsive character. The task of the simulator, however, who chooses it for the purpose of deception, is far from being lighter. He may easily profess the extraordinary notions of the monomaniac, and even avoid, with some ingenuity, the absurdities to which they lead, but there are numberless other traits which all his skill would utterly fail to represent. What sane mind can fully imitate the monomaniac's style of reasoning which, while it has some show of logic, would never have been 
offered, even in jest, by a rational understanding? What power of mimicry can represent his transparent sincerity, his unfaltering confidence, the prevailing tendency of his unsuggested and spontaneous reflections to the morbid point, his abstracted air, his constrained and fitful movements? The most accomplished actor, after years of observation, would fail, I think, to imitate these traits well enough to deceive the practised observer of the insane. The writer has an easier task, and consequently has been more successful. He deals only with mental manifestations. The air, the manner, the gesture, the look, the act, though equally bearing the impress of insanity, do not come within his province. Considered in this light, Norna must ever be regarded as a most impressive and life-like delineation of monomania. The lofty bearing, the magnificent pretensions, the grandiloquent announcement of her supernatural powers, and the constant yet unconscious endeavor to deceive others, as she had already deceived herself, are represented with unimprovable fidelity. Norna's insanity, however, is evidently but a secondary feature in her character, and subordinate to the higher part she plays in the course of events in which she is destined to mingle. The idea is, not so much to represent this part as the result of insanity, as to make the latter a sufficient reason for what would have been inexplicable and impossible without it. The force and pertinency of her discourse are not indeed incompatible with very serious lesion of the understanding, but other traits and qualities are attributed to her character, only at the expense of its pathological correctness. She keeps a vigilant eye on what is passing around her, displays a mother's affection for her son, and a very natural interest in the honor and happiness of her kindred. This was necessary to the development 
of the plot, but not very strictly in accordance with the nature of the disease. The monomaniac retains but little interest in anything but his own delusions, and family and frieuds are generally regarded with indifference, if not positive dislike. I will not say that no exception can be found to this rule, but Scott would scarcely be helped by the admission that the type of one of his prominent characters is to be found in an extreme case, a solitary instance, rather than a large class of mankind. It is understood to be the peculiar merit of Scott as well as Shakespeare, that the men and women in whom he enlists our interests are no questionable existences, whose mortal affinities are hard to be discerned, but bear upon their front the unmistakable features of humanity. And, with the single exception before us, neither has deviated from the general principle upon which he labored in his conceptions of character.

By no English writer have the delusions of pure monomania been more truthfully represented than by Dr. Johnson in "Rasselas," - an achievement we should hardly have expected from one whose own mental movements were of the most regular and measured character. An old astronomer had been so long and deeply engrossed in the observation of the heavens, that he finally imbibed the idea that he could control their motions and regulate the distribution of their blessings. In homely phrase, he imagined that he was "clerk of the weather." Who that has mingled much with the insane has not witnessed tho counterpart of the childlike naïvete and unquestion. ing self-confidence with which he relates his wonderful powers, and which is admirably set off by the grandiloquent language of Johnson?

"I have possessed for five years the regulation of the weather, and the distribution of the seasons: the sun has 
listened to my dictates, and passed from tropic to tropic by my direction; the clouds at my call have poured their waters, and the Nile has overflowed at my command; I have restrained the rage of the dog-star, and mitigated the fervors of the crab. The winds alone, of all the elemental powers, have hitherto refused my authority, and multitudes have perished by equinoctial tempests which I found myself unable to prohibit or restrain. I have administered this great office with exact justice, and made to the different nations of the earth an impartial dividend of rain and sunshine. What must have been the misery of half the globe if I had limited the clouds to particular regions or confined the sun to either side of the equator?"

His account of the manner in which he obtained and became conscious of his powers presents an excellent illustration of the characteristic mistake which the insane very often commit on this point. "About ten years ago, my daily observations of the changes of the sky led me to consider, whether, if I had the power of the seasons, I could confer greater plenty upon the inhabitants of the earth. This contemplation fastened on my mind, and I sat days and nights in imaginary dominion, pouring upon this country and that the showers of fertility, and seconding every fall of rain with a due proportion of sunshine. I had yet only the will to do good, and did not imagine that I should ever have the porrer. One day as I was looking on the fields withering with heat, I felt in $m y$ mind a sudden wish that I could send rain on the southern mountains and raise the Nile to an inundation. In the hurry of my imagination I commanded rain to fall; and, by comparing the time of my command with that of the inundation, I found that the clouds had listened to my lips." 
The immediate execution of his command he represents to be the sole ground of his faith, and is quite unconscious that the thought in question was but a result of the morbid action that had long been established in his mind. Judging merely from his own account one might be led to suppose that his mind was as firm and steady as ever, and that the fact of the necessary connection of the two events was forced upon him by irresistible evidence. His friends would probably have told us a different story, and made us acquainted with strange deviations from his natural demeanor or style of thinking, long before his delusion had taken a definite shape. An insane person can seldom trace very clearly the initiatory steps by which he has been brought into trouble, or led to some extraordinary conclusion; and the ability is not always gained after the recovery. In seeking for the causes of the remarkable change that has come over him, he is apt to fix upon some person or incident which had but a trivial or accidental connection with it, or appeared at a subsequent date. As in the present case, the execution of the command is regarded as the first noticeable fact in the history of his case, while the idea of uttering such a strange command scarcely arrests his attention. It may be well to add that this coincidence between the thought and subsequent event frequently appears in the narratives of persons relating to the origin of their disorder, and probably arises from that misplacement in the succession of their ideas, which is not an uncommon phenomenon of insanity.

The accuracy of Johnson's picture of monomania is farther displayed by the astronomer's account of the mental conflicts he endured, and of the final triumph of his delusion. When asked if some other cause might 
not have produced the concurrence, he replied that such objections did not escape him. "I reasoned long against my own conviction, and labored against truth with the utmost obstinacy. I sometimes suspected myself of madness, and should not have dared to impart this secret but to a man like you, capable of distinguishing the wonderful from the impossible, and the incredible from the false." A more faithful and graphic description than this, of what is called the incubation of insanity, could not be' had. The strange fancies that ever and anon intrude themselves into the mind, the gradually weakened struggle by which they are resisted, the suspicion of one's own madness, the ultimate conviction of the reality of the marrellous belief, the unfaltering self-complacency with which the patient proclaims his own mental integrity and vigor, - how common, how life-like, are these traits! In the latter part of the passage, however, the old astronomer is altogether too cool, too sensible, too considerate on the subject of his belief. True, the convictions of the monomaniac are always too strong: to be shaken by any possible force of evidence or reason: but he never troubles himself about the impression they make upon others, because they seem to him self-evident, as it were, beyond question or cavil. I do not deny the possibility of his thinking that others ought to differ from him, according to "the laws of demonstration," but I have never met with an instance of the kind.

Richardson, in "Sir Charles Grandison," has tried his hand upon a case of acute mania characterized by depression. The lady Clementina, whom he has endowed with every possible feminine virtue, rather suddenly falls into fits of absence and revery, in which the subject of her thoughts seems to assume an objective existence. 
With unnatural precipitation the mental malady increases in severity, - the depression frequently alternating with a state of restlessness and excitement, though never rising to the pitch of fury or raving. The canse of the trouble, as we subsequently ascertain, is an affair of the heart, though, after making every allowance, this seems to be rather a forced conclusion. Before the course of her affections had been thwarted, before a single objection could have been reasonably anticipated, before, probably, such a woman could be supposed to be conscious of the existence of the tender passion, she ingenionsly reasons herself into the belief of insuperable difficulties, and the peace and joy of her pure and innocent soul give place to sorrow and bewildering reveries. To such a soul, no sentiment can be more congenial, and consequently none more healthy, than love. To represent it, therefore, under such circumstances, as nearly allied to madness, betrays an inability to appreciate one of the most beautiful harmonies between our moral and physical nature, or at least the willingness to sacrifice it to the paramount object of drawing forth the tears of sentimental young ladies and gentlemen. Indeed, Richardson's task was hardly within his vein. The lighter movements of the hart, especially as they are revealed through the conventional guises of society, have never been more faithfully portrayed than by him; but the deep currents of passion, the central springs of character in which are the issues of moral life, seem to have been entirely beyond his reach.

As a picture of mental disorder considered without reference to its origin, the rerit of Clementina is somewhat various. Occasionally, the hand of the master is plainly visible, especially in representing the drifting character of the thoughts, and in managing the tran- 
sitions from depression to excitement. In these respects, I am inclined to regard some scenes as perfect. How genuine and life-like are her whole appearance and manner when found by her maid about to risit the Chevalier, in order, as she said, to deliver him a message from God! They impress us like some of those marvellous pictures whose figures seem to stand out from the canvas, and imbibe the Promethean fire, while we gaze upon their expanding features. Richardson seems, however, to have exhausted his resources before he had finished his task, which, considering the interminable length to which everything he handles is spun out, is not surprising. Through some whole scenes her discourse is unexceptionably sensible and appropriate, and we lose sight altogether of her insanity. Of course, in the conver. sation of the insane, we expect to find "matter and impertinency mixed;" but in the present case the mixture is often almost entirely composed of the former element. In shunning the common error of representing the discourse of the insane as a jargon of words unconnected by a single tie of congruity or coherence, he has committed the opposite one of freeing it from every trace of insanity, and filling it with pertinent and judicious reflections. To avoid these two extremes of error has always been found, I imagine, the most difficult part of the task of writers who undertake to delineate insanity. We have previously remarked that in a large proportion of cases the mental disorder is indicated in the patient's discourse, not so much by wild and extravagant expressions as by the peculiar and not easily described succession and grouping of the ideas. Richardson seems not to hare been aware of this fact. The lady talks altogether too much and too sensibly of her lover, for one in her distracted condition. If there is any subject in 
the world on which the insane manifest their insanity, provided they talk about it at all, which they very seldom do, it is usually that which is intimately connected with the origin of their disorder. However sober and correct their conversation may be on indifferent matters, on that they are sure to wander.

The prominent fault, however, of this attempt of Richardson to delineate insanity, is that the disease contributes no additional interest to the character. It brings out no new trait, and magnifies none with which we were previously acquainted. The patience, resignation, and sweetness of temper which it leads her to exhibit, are not the exclusive offspring of insanity, and might as well have been exemplified in any other disease. We are grieved for her distressed family, and especially for the gentle sufferer herself; but we are not sure that our feelings are anywise different from what they would be were she laboring under an attack of pneumonia or gastritis. We see only affliction, disappointment, and sorrow, and we feel accordingly. We are made acquainted with no new phases of character, and our deepest interest and warmest sympathies are not enlisted by the sight of moral or intellectual treasures which only the storms of mental disease can upheave from the depths of their concealment. In short, she is the same Signora Clementina that we knew when sane, and in the enjoyment of every blessing; and we cannot disguise the fact that we are heartily rejoiced when she fairly gets through the disorder with which the author, in his wisdom, has seen fit to visit her.

Richardson has one merit, however, in his delineation of insanity, that ought to atone for a multitude of defects. At a time when the insane were treated with harshness and even barbarity, for the purpose of subduing their 
wills, he set himself decidedly against the popular practice, and contended for the opposite kind of treatment. He fairly exhibited the results of the two different methods; and in a manner more convincing than the most formidable array of statistics could have made it demonstrated the superiority of that mild and indulgent management which is now firmly established among all civilized nations. Indeed, with some propriety, he may be regarded as the pioneer of that blessed reform which, shortly after, was quietly introduced and almost perfected by the Quakers at the York Retreat. Merit of this kind is seldom duly appreciated by the world, for it does not strike the imagination like that of brilliant discoveries in the physical sciences; and the very reason that reforms like that in question are so obriously sanctioned and confirmed by common sense and the feelings of common humanity is apt to detract from the merit of those who conceive them. 



\section{N D E X.}

Ardington, recommends a hop pillow for the King, 459; supposed to have recommended Willis, 440 .

Allison, Julge, decision respecting confinement of the insale, 174 .

Aphasia, lntely much investigated, 315.

Approximation to truth, what it means, 95.

Belief:, false, how distinguished from delusions, 152.

Bentham, his disposal of hi= body, 155.

Books, not allowed to be read in trials, 226.

Brewster, Judge, h's lecision re-pecting confinement, $173,1 \leq 1,184$.

Bucknill, writes about Shakespeare's mad folk. 483 .

Bulletins, 461.

Burke, crimplained th th the King wis not sufe in Willis's hands, 452; had visited hospitals for the insane and read many book - on insanity, 455.

Burney, Miss, describes the first attack, 437; describes her meeting with the King, 438; repeats his story of haring been abuset. 441 .

Burnside, Judge, his decision respecting confinement. $\mathbf{1 7 6}$.
Capacity, testamentary, compared with capacity for making contracts. 343 . $3 \& 7$.

Causes rf insanity, imperfectly understrod, 25 ; often confounded with the incirlents, 29: not necessarily the most prominent event. 31 ; often confoundel with its effects, 36,90: cannot be ascertainerl witinut a thorough knowledge of patient's antecedents, 34; most efficient is inherent cerebral defect, 38 ; obviated by infusinn of better blood. 41 ; their ragueness of meaning, 88.

Census of 1840 , misrepresents the amount of insanity among crilorerl free people, 69 .

Clara Howbray, character of her insanity, 539.

Classification of mental diseases, 94 .

Clementina, character of her insinity. 547 .

Colby $r$. Jackson, 170.

Coleridge, Justice, his decision respecting confinement, 173.

Combe, his refinition of im-anity. 10 s.

Confinement of the insane, a n'tural duty of friends, 169; authorized by constitution of Pennsylra ia, 176; laws respecting it still conflicting, 188: commissions of lunacy to be 
aroided as long as possible, 191; seldom if ever: abused, 198.

Conolly, his essay on Hamlet, 483.

Conspiracy, action of, a source of flagitious suits, 294.

Contracts with God, cases of, 156, 164; implied in the ancient covenants of God with man, 166.

Crime, elements of, 205.

Cross-examination often frustrates the purposes of skilled testimony, 428 .

Danger, its relation to confinement, 177.

Deatlis from insanity, not accurately represented in hospital statistics, $8 \mathbf{2}$; how their proportion is obtained by Tuke, .83; causes of, vaguely expressed, 84 .

Delinquency, often the result of cerebral imperfection, 16, 47, 48 .

Delusion, a legal test of insanity, 142, 207 ; not always recognized after recovery, 129, 130 ; definition of, 143; not to be confounded with singularities of belief, 144 ; not regarded as a valid defence, 262.

Demented persons, can play at whist and other games, 323 ; observe little proprieties and usages, 334 .

Denman, Lord, decision respecting confinement, 173.

Depression, in relation to recovery, 136 .

Development of disease, true doctrine of, 40 ; sometimes rapid, 57 .

Devil, personality of, 146 ; once supposed to cause insanity, 208.

Disease, manifested by disturbance of function, 53 ; time of its beginning uncertain, 76 ; Dr. Thurnam on this point, 78; how transmitted, see Transmission.

Dix, Miss, notice of, 11.

Drunkenness, a symptom, as well as cause of mental disease, 35 .

Eccentricity, 42, 154 .
Eldon, defends his transactions with the King, 466; charged with preventing the junction of Fox and Pitt, 469.

Epilepsy, sometimes manifested by unconsciousness without convulsion, 274 ; its effect on the mind in its early stages, not much studied, 279; always annuls legal responsibility, 281.

Erskine, Lord, relates a case of excusable homicide prompted by revenge, 288.

Excitement in relation to recovery, 136.

Executive, proper occasion for his interposition, 276 ; not likely to appoint most suitable men as commissioners, 422 .

Experts, their testimony influenced by training, habits of study, experience, 410; not infallible, 413 ; not biassed by pecuniary motives, 418; how they are engaged, 419 ; should not be appointed by the Executive, 422; nor by the courts, 424; not now examined in the best way, 427; every one not an expert who professes to be one, 421 ; their function not to be assumed by judges, 430 .

Farren, writes about Shakespeare's mad folk, 483 .

Flavel, extract from, 162.

Fletcher's representation of insanity, 529.

Fools of Shakespeare, 502.

Friends, establish hospitals in York and Frankford, 8 .

Fyler, case of, 278 .

Gall and Spurzheim, contributed much to our knowledge of insanity, 27.

Gardiner, Colonel, his vision, 149.

George III., his natural traits, 434; first became insane in 1765,435 ; next attack in 1788,436 ; incidents of his convalescence, 438,448 ; his 
gibe at Willis, 440; abused, he said, by his attendants, 441; was restrained by strait-jacket, 442 ; gave sign of convalescence by reading. 448: bent on reading Lear, 453; allowed to shave, 451 ; and see his family, 45.3: attacked in 1801, 456: recovers in a few months, 457 ; attacked again in 1804.460 ; continued capricious and headstrong after apparent recovery, 463: the last two attacks longer than they were supposed to be, 463: continued in both to exercise powers of sovereignty, 464; dislikes the Willises, 460 ; wants to read bills before signing them, 467 ; is attacked again in 1810,469 ; near dying, 436: has various delusions, 472; had become blind, 477; impatient to resume his regal functions, 471 ; selects the music of a concert, 472; condition during his last years, 479 ; approves of straitjackets, 443 .

Ghosts of Shakespeare not meant to be visible, 527 .

Goethe, his theory of Hamlet, 508.

Gilchrist, C. J., his decision respecting confinement, 171.

Goss, case of, 209.

Greenwood, case of, 129 .

Grey. Earl, attacks Eldon for allowing the King to exercise regal powers, 465.

Hale, Lord, on partial insanity, 228.

Hallucinations, how distinguished from delusions, 145; how they are sometimes excited, 148, 150: their frequency, 225 ; their true nature known to Shakespeare, 528 .

Hamlet, really insane, 5n4; how regarded by Goethe, 50s: by Hudson, 509 ; theory of insanity explains his conduct, 507,519 .

Hardness of feeling exhibited by the insane towards friends, 138.
Harris, case of, $2 \& 2$.

Heberden, Dr., describes the King's insanity, 475.

Herbert, Lord, his vision, 149.

Hereditary taint, its various forms and stages, 51; how recognized, 52; may remnin latent, $j 2$

Heredity, its tendency to abolish deviations from the normal type, 44 .

Hinchman $x$. Richie, $\mathbf{1 7} 6$.

Hospitals for the iussne, established in Pennsvlvania, 6, 8, 17; have improved oul knowledge of healthy mind, 13; danger of crowding them, 18; duty of the community to, 23; have become pleasant abodes, 179; intender for incurables as well as curables, 180 ; prejudices against them, 198 .

Hudson, his theory of Hamlet, jog.

Hunter. Dr. William, on infanticide, $2 \varsigma$.

Hypothetical cases, 428.

Impatience in relation to recovery, 134. Insane, the, their condition before the era of hospitals, 4 : in Catholic countries. kept in old monasteries, 7; circumstances leading to reform, 10 ; the State obliged to assume their care, 11: hospitals solicited by Miss I)ix, 11: State bound to provide for all, not a part. 18; number of, in Massachusetts and in Pennsylvania, 19; the common law on their confinement, 170 ; their propensity to mischief, 178,402 ; too proud to acknowledge their delusions, 128; in most States committed by magistrates, 193; in some by jury, 194: most of them regarded by somebody as sane, 196; not deterred from crime by fear of punishment. 206; can distinguish between right and wrong, 227; sometimes deny their acts, 248: sometimes provide against their consequences, 249 ; unable to 
defend themselves in criminal suits, 262; some apparently recovered, deny they have ever been insane, and are bitter towards all who treated them as insane, 309; may understand the terms and not the merits of a question, 333 ; may possess all the mental faculties, memory, judgment, \&c., 336; fond of charging others with wrong-doing, 356 ; will talk with strangers about their private affairs, 362 ; given to practical inconsistencies, 364; their mental processes resemble dreaming, 496; they give utterance to all thoughts alike, 497 .

Insanity, what it means, 3 ; its connection with organic qualities of the brain overlooked, 26 ; a matter of blood, 35; generally the product of more than one generation, 41 ; distinguished from depravity, 56 ; divided into old and recent, 75 ; mistake respecting the range of its morbid influence on the mind, 182; appears under two general forms, 98 ; supposed by some to be always attended by intellectual derangement, 104, 106; how proved, 115; once mistaken for some other disease or the work of Satan, 203, 208; its range of operation on the mental faculties, 227 ; better understood by novelists and poets than by metaphysicians, 434 ; plea of, 262 ; remission in the early stage, 131.

Interdiction, to be avoided if possible, 190 ; opinion of English Commissioners in Lunacy respecting it, 191.

Irresponsibility, no single test of, 213; Judge Shaw's tests, 226.

Irreverence, somewhat conventional, 162.

Jarvis, Dr., on transitory mania, 253; his census of the insane, 19.
Johnson, Dr. Samuel, his hallucination, 150 ; represents a case of monomania in Rasselas, 544.

Jurges should not assume the functions of experts, 430 .

Kellogg, writes about Shakespeare's mad folk, 483 .

Language, should be used with precision, 88 .

Lear, character of his insanity, 486 .

Lecky, Mr., remark respecting mental pathology, 15.

Legislation on confinement of the insane, in Pennsylvania, Massachusetts, Lhode Island, \&c., 200; act of, recommended by superintendents of nospitals, 200; what is really needed, 201.

Lunacy, English Commissioners of, nature of their dnty, 405 .

Nacbeth and wife, their cases described, $525,528$.

Madge Wildfire, character of her insanity, 534.

Iaine, disposal of persons in, charged with crime, 427.

Mania transitory, Dr. Walker's case, 286 ; its existence denied, 252.

Mann, Horace, declares the pauper insane to be wards of the State, 9 .

McNaughton, his case referred to, 110 .

Mendacity of the insane, 296.

Menstrual periods, accompanied by increased excitement, 141.

Mischief, propensity of the insane to, 178,402 .

Mistake as distinguished from delusion, 346.

Noral insanity, not dependent on phrenology, 97; described by Pinel, 99 ; admitted by most of the best observers, 99; not depravity, 106, 107 ; its name disliked, '112; tendency thought to be bad, 114, 117. 
Moore, case of, 174, 188.

Nichols, Dr., opinion in the Harris case, 283.

Non-restraint, not supported by George III.'s case, 478 .

Norna, her case described, 542.

Nottidge $v$. Ripley, 171.

Nyce $v$. Kirkbride, 173.

Oakes, case of, 174 .

Ophelia, her case described, $5 \mathbf{2 4 .}$

Opinions, medical, given in writing, 316 ; unanimity in, not to be expected, 411 ; of ordinary 'witnesses sometimes admitted, 417 .

Otway, fails in his illustrations of insanity, 498 .

Paralysis, its effects discussed in the Parish case, 315 ; its manifestations, 318 ; loss of voice in, supplemented by gestures, writing, \&c., 328 ; indicated by irritability, 331; leads to petulance, freaks of passion, 339 ; a common termination of insanity, $36 \%$.

Partnership with God, 156, 165.

Pathology, mental, throws light on healthy mental operations, 14 ; also on moral anā social questions, 16 .

Pellico, his hallucinations, 150 .

Pennsylvania, the first State to provide for the insane, 5; its constitution authorizes confinement of the insane, 176.

Perley, C. J., decision in State $v$. Pike, 213.

Pollock, Sir Frederick, decision respecting confinement, 172.

Psychology, its study assisted by mental pathology, 123.

Recovery, often confounded with improvement, 73 ; affected by various accidental circumstances, 72 ; not exactly defined, 74; proportion of: 81; not always fullowed by recognition of delusions, 129, 130; frequently imperfect in bodily diseases, 297.

Redfield, C. J., on strange wills, 154.

Reformers, run to extremes, 393 .

Remission, its occurrence in the early. stage of insanity, 131.

Restraint, true doctrine of, $393,400$.

Reynolds, Sir Joshua, his hallucination, 150.

Richardson. his success in representit is insanity, 547 .

Sane persons, supposed to be confined, 296; scarcely one authentic case, 198.

Science, conclusions of, change with increase of knowledge, 414.

Scott, happy in his illustrations of insinity, 534 .

Seduction, its connection with insanity, 286.

Sexual influences, in connection with insanity and crime, 285.

Shakespeare, well acquainted with morbid psychology, 124; how he studied it, 485 ; fond of delineating it, 518 .

Shaw, C. J., decision in the Oakes case, 174, 310; in the Rogers case, 210, 226.

Sheridan, ridicules Willis, $4 \pm 6$.

Simulation of insanity, can be detected, 218; how distinguished from real insanity, 301, 304, 501, 505.

Spiritualism, worth investigating, 272. Spurzheim on insanity, 186.

Statistics, applicable to facts, not to opinions, 66 ; imply more than a process in arithmetic, 68; applied to recoveries, 72 ; applied to deaths, 81 ; wrongly regarded as approximations to truth, 95 .

Stephen, on the plea of insanity, 205. 
Stewart, thinks insanity contagious, 182.

Story, Judge, decision in a case of infanticide, 286.

Suicide, committed impulsively, 102; contemplated by a large proportion of the insane, 511 .

Suspicion, a common trait of insanity, 353.

Tables of causes, umreliable, 33, 37, 84 et seq. ; often reflect the special views of their makers, 92.

Temperament, insane, 150.

Tendency to disease is transmitted, 49 ; what becomes of it, 49 ; how distinguished from natural qualities, 54 ; practical consequences, 58.

Testimony, skilled, charged with being contradictory, 411, 414; and venal, 418 ; must sometimes be discrepant, 413; decried by men of culture, 413 ; said to distract the minds of the jury, 416; how obtained in foreign countries, 425 ; its purposes frustrated by cross examination, 428 ; sometimes given in writing, 430 .

Townley, case of, 60, 261.

Transmission, hereditary in animals and plants, 39; how it modifies diseases, 39, 41; and tendency to disease, 43; cannot perpetuate all the traits of both parents, 43 ; abnormal deviations die out, 44 .

Unanimity of opinion in skilled evidence, 411.
Unconsciousness, used with uncertain meaning, 259.

Virginia, the first State to provide a hospital specially fur the insane, 7 .

Walker, Dr. C. A., his case of transitory mania, 286 .

Walker, Dr. W. J., testifies in the Rogers case, 221.

Wharton and Stille, on confinement, 177.

Willis, Dr. Francis, called to attend George III., 439; applies restraint, 442 ; described by Wraxall and Miss Burney, 439 ; his physic ridiculed by Sheridan, 446; allows the King to shave, 451 ; his character and disposition, 454; his traditionary replies to Burke and Sheridan, 452; his establishment described, 456; his compensation, 456,457 ; called in in 1801 , but soon ceased his attendance, 457 .

Willis, John, employed in the attacks of 1788 and $1801,440,456$.

Willis, Robert, employed in the attacks of 1801 and $1810,456,474$.

Willis, Thomas, employed in the attack of $1801,456$.

Wills, how affected by hostility to relations, 345 .

Vinslow, on delusions, 153.

Winthrop, Goremor, on a case of insanity, 208.

Witcheraft explained, 151.

Woodward, Dr., his account of Rogers, 220.

Writing with left hand, soon acquired, 328. 





\section{UNIVERSITY OF CALIFORNIA LIBRARY}

\section{Los Angeles}

This book is DUE on the last date stamped below.

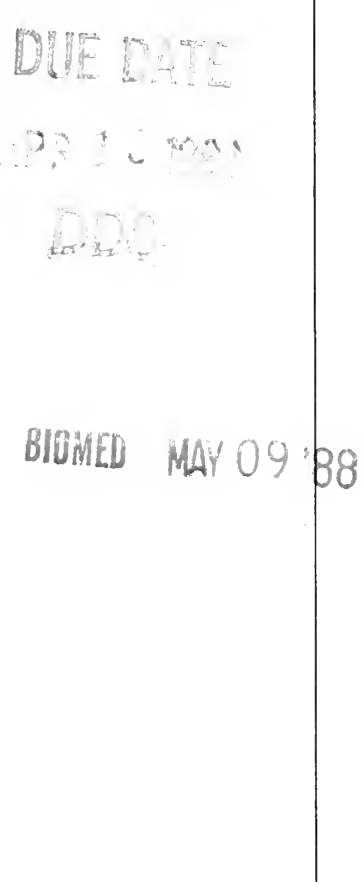

24131 


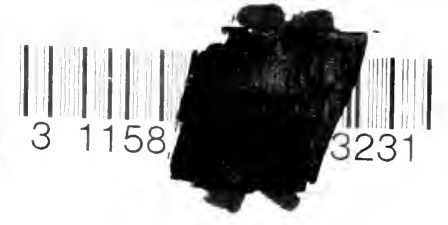

$R C$
601
$R 21$

UNIVERSIT \& CALIFORNIA

LUS A.GLLtes 
wow

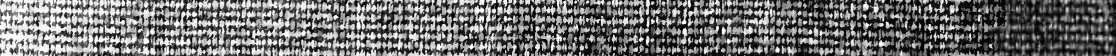

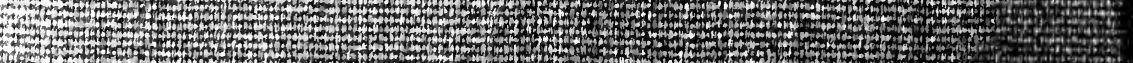
Thtom

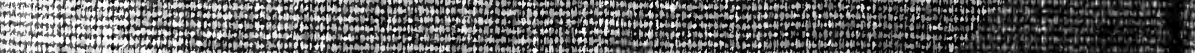
6.

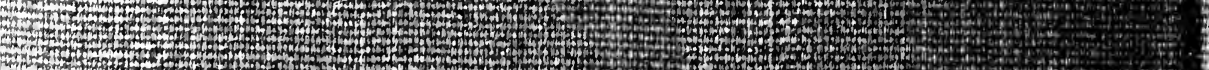

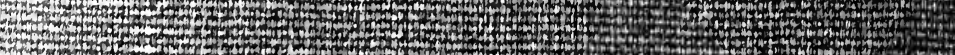

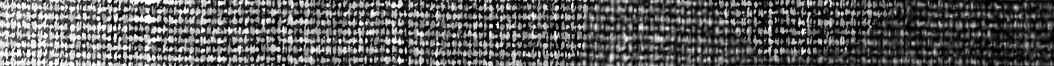
rvat

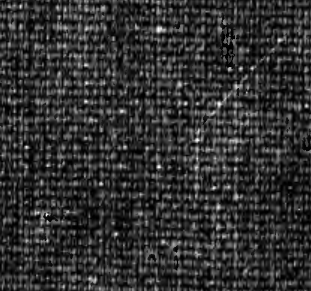

